\title{
PROPRIEDADES QUÍMICAS E DISPONIBILIDADE DE NUTRIENTES E DE METAIS EM DIFERENTES SOLOS ADUBADOS COM COMPOSTO DE RESÍDUO URBANO
}

\section{CASSIO HAMILTON ABREU JUNIOR}

Engenheiro Agrônomo

Orientador: Prof. Dr. TAKASHI MURAOKA

Tese apresentada à Escola Superior de Agricultura "Luiz de Queiroz", Universidade de São Paulo, para obtenção do título de Doutor em Agronomia. Área de Concentração: Solos e Nutrição de Plantas.

PIRACICABA

Estado de São Paulo - Brasil

Janeiro - 1999 


\title{
Dados Internacionais de Catalogação na Publicação (CIP) DIVISÃO DE BIBLIOTECA E DOCUMENTAÇÃO - Campus "Luiz de Queiroz"/USP
}

\author{
Abreu Junior, Cassio Hamilton \\ Propriedades químicas e disponibilidade de nutrientes e de metals em \\ diferentes solos adubados com composto de resíduo urbano / Cassio Hamilton \\ Abreu Junior. .. Piracicaba, 1999. \\ 159p. : il.
}

Tese (doutorado) - E Escola Superior de Agricultura Luiz de Queiroz, 1999. Bibliografia.

1. Arroz 2. Espectrometria de emissão de plasma 3. Extrator químico 4. Fertilidade do solo 5 . Metal 6 . Nutrição vegetal 7. Propriedade físico-quimíca-dosolo 8. Resíduo urbano 1. Título 
Aos meus pais, Cassio (in memoriam) e Célia,

e a minha mãe de coração Maria (in memoriam)

Minhas homenagens

À fascinante experiência da vida...à Terra...ao aprendizado, Agradeço essa dádiva a DEUS.

À minha Valéria, pelo companheirismo, paciência, apoio e cumplicidade. À familia Amadio pelo carinho,

Ofereço

Às crianças, Felipe, Raissa, Paola, Vitória, Veridiana, André e Lucas, pelo futuro que lhes aguarda,

Dedico 


\section{Agradecimentos}

Ao Prof. Dr. Takashi Muraoka, não só pela orientaçāo segura, mas confiança e apoio nas decisões que foram tomadas durante o curso e pelo estimulo nas dificuldades surgidas, que foram muitas;

À Fundação de Amparo à Pesquisa do Estado de São Paulo (FAPESP) pela bolsa de doutoramento e pela reserva técnica, sem o qual muito deste trabalho não teria sido realizado;

Ao Conselho Nacional de Desenvolvimento Científico e Tecnológico ( $\mathrm{CNPq}$ ) pela concessão da bolsa nos dois primeiros anos do Curso de Pós-Graduação;

À Escola Superior de Agricultura "Luiz de Queiroz" (ESALQ/USP) e seu corpo docente, em especial aos Departamentos de Solos e de Nutrição de Plantas, aos Professores Dr. Luiz Ignácio Prochnow, Dr. Arquimedes Lavorenti e Dr. Luiz Reynaldo F. Aleoni, pelas sugestões dadas no desenvolvimento deste trabalho;

Ao Prof. Dr. Francisco Antônio Monteiro, como coordenador da Comissão de Pós-Graduação de Solos e Nutrição de Plantas e demais membros, por ter possibilitado minha participação neste Curso de Doutorado e pelo apoio e amizade durante o Curso;

Ao Centro de Energia Nuclear na Agricultura (CENA/USP), pela amizade com seus Pesquisadores e Funcionários, e a possibilidade da utilização de seus laboratórios e dependências;

Aos Laboratórios de Fertilidade do Solo e Nutrição de Plantas do CENA, ao Prof. Dr. Antônio Enedi Boaretto, às laboratoristas Marileuza Aparecida Bassi Elias, Sandra Teresa Pereira dos Santos e Enriqueta M. Gimenes Fernandes, cujos os infinitos auxilios prestados foram imprescindiveis para a realização deste trabalho. Ao João Odemir 
Salvador e à Maria Aparecida Calegaro Soares pelos auxilios prestados sempre que necessário:

Ao Laboratório de Química Analítica do CENA, em especial à Prof. Dra. Maria Fernanda Giné-Rosias, por ter possibilitado a utilização do ICP-AES, aos seus pós-graduandos que cederam espaço para que eu utilizasse o equipamento e o Laboratório de preparo de soluções, e à Técnica de Laboratório Aparecida de Fátima pela assessoria no ICP-AES;

Ao Pesquisador Dr. Manoel da Silva Cravo, EMBRAPA de Manaus, com quem tive as primeiras conversas que deram origem à este trabalho e pelo fornecimento de solos da Amazônia;

Ao Laboratório de Biogeoquímica de Solos do CENA, a seus Pesquisadores e Laboratoristas pelas análises de carbono total e, somando-se aos pós-graduandos, pela vivência agradável;

À Professora Maria Izalina Ferreira Alves e ao colega Marcelo Alves Corrêa, pelas elucidações em como proceder as análises estatisticas;

Ao estagiário do Laboratório de Fertilidade do Solo André F. Lavorante e estagiários do Laboratório de Nutrição de Plantas Felipe R. B. Granja e Rodrigo M. Boaretto pelo auxilio na condução do experimento e nas análises quimicas;

Ao amigo Marciano de Medeiros Pereira Brito, pelo indispensável auxilio na confecção desta Tese;

Aos colegas de Pós-Graduação, Robson Rui C. Duete, Felipe C. A. Villanueva, Sânia Lucia Camargo, Fernando Grossi e Adônis Moreira pelas trocas de experiências e bons momentos vividos juntos;

Enfim, à todos aqueles que de uma forma ou outra colaboraram com o desenvolvimento deste trabalho, o meu sincero agradecimento. 


\section{SUMÁRIO}

Página

RESUMO.

viii

SUMMARY

xi

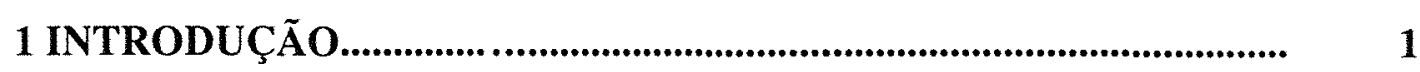

2 REVISÃO DE LITERA TURA........................................................ 3

2.1 Considerações gerais........................................................................ 3

2.2 Resíduos urbanos result antes da atividade do homem........................ 3

2.3 Aplicação agrícola do composto de resíduo urbano e suas conseqüências........................................................................................................ 5

2.3.1 Generalidades e caracter ização do composto....................................... 5

2.3.2 Efeitos sobre as propried ades do solo....................................................... 7

2.3.3 Efeito sobre as plantas.................................................................. 8

2.4 Avaliação da disponibilidade de nutrientes e metais no solo.

2.5 Espectrometria de emissão atômica com plasma acoplado indutivamente.

3 MATERIAL E MÉTOD OS............................................................

3.1 Solos utilizados................................................................................................. 24

3.2 Composto de Resíduo U rbano........................................................... 26

3.2.1 Informações adicionais sobre o processo de obtenção do composto na usina...................................................................................... 26

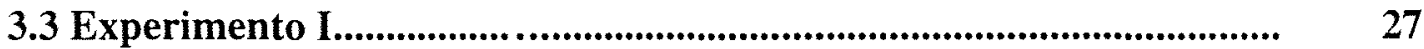

3.3.1 Arranjo dos tratamentos e delineamento experimental..................... 27

3.3.2 Condução do experiment o I........................................................................... 29

3.4 Experimento II................................................................................. 31

3.4.1 Arranjo dos tratamentos e delineamento experimental ................... 31

3.4.2 Condução do experimen to II.................................................................... 32 
3.5 Caracterização química do composto de resíduo urbano

3.6 Caracterização física e química dos solos utilizados no experimento.

3.7 Caracterização química dos fertilizantes e calcário e gesso natural usados no experimento.

3.8 Análise química dos solos. 34

3.9 Análise química do mate rial vegetal............................................................ 36

3.10 Parâmetros de operação do ICP-AES.......................................................... 36

3.11 Análise estatística dos da dos.................................................................... 37

4 RESULTADOS E DISCUSSÃO............................................................ 39

4.1 Caracterização do composto de resíduo urbano, solos, adubos, calcário e gesso natural

4.1.1 Análise química e física do composto de resíduo urbano.................... 39

4.1.2 Análise química e física dos solos....................................................

4.1.3 Análise química dos adubos, calcário e gesso natural......................... 46

4.2 Propriedades químicas do solo devido à aplicação do composto de resíduo urbano.................................................................................. 52

4.2.1 Condutividade elétrica................................................................ 52

4.2.2 Reação do solo e acidez potencial.................................................. 55

4.2.3 Carbono orgânico, nitrogênio total e relação $\mathrm{C} / \mathrm{N}$............................... 63

4.2.4. Disponibilidade de fósforo e enxofre................................................ 67

4.2.5. Bases trocáveis, Soma de bases, capacidade de troca de cátions e saturação por bases........................................................................ 72

4.2.6 Disponibilidade de micronutrientes................................................. 82

4.2.7 Disponibilidade de metais............................................................... 91

4.3. Efeito da adubação com composto de resíduo urbano sobre as plantas de arroz................................................................................ 102

4.3.1 Produção de matéria seca..................................................................... 102

4.3.2 Absorção de macronutrientes e de sódio.......................................... 107 
4.3.3 Absorção de micronutrientes........................................................

4.3.4 Absorção de metais..................................................................... 121

4.4 Efeito do enriquecimento do composto de resíduo urbano com $\mathrm{Cd}$, $\mathrm{Cu}, \mathrm{Mn}, \mathrm{Pb}$ e $\mathrm{Zn}$ sobre a extração de metais no solo............................... 131

4.5 Efeito do enriquecimento do composto de resíduo urbano com $\mathrm{Cu}$, $\mathrm{Cd}, \mathrm{Mn}, \mathrm{Pb}$ e $\mathrm{Zn}$ sobre a Produção de matéria seca de plantas de

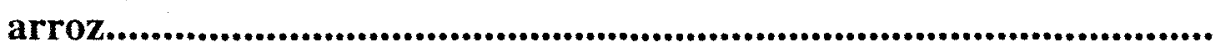

4.6 Efeito do enriquecimento do composto de resíduo urbano com $\mathrm{Cu}$, $\mathrm{Cd}, \mathrm{Mn}, \mathrm{Pb}$ e $\mathrm{Zn}$ sobre a absorção de metais em plantas de arroz.... 132

4.7 Avaliação da eficiência agronômica dos extratores................................... 135

5 CONCLUSÕES................................................................................ 146

REFERÊNCIAS BIBLIOGRÁFICAS.................................................... 147 


\title{
PROPRIEDADES QUÍMICAS E DISPONIBILIDADE DE NUTRIENTES E DE METAIS EM DIFERENTES SOLOS ADUBADOS COM COMPOSTO DE RESÍDUO URBANO
}

\author{
Autor: CASSIO HAMILTON ABREU JUNIOR \\ Orientador: Prof. Dr. TAKASHI MURAOKA
}

\section{RESUMO}

Foram instalados dois experimentos em casa de vegetação. No experimento I, foram estudados os efeitos da aplicação de composto de resíduo urbano, da cidade de São Paulo, na presença ou ausência de calagem e adubação, sobre as propriedades químicas de 21 solos ácidos e 5 solos alcalinos, nos quais a calagem foi substituída pela aplicação de gesso natural, e sobre a nutrição e produção de matéria seca da cultura de arroz. O calcário foi aplicado para elevar a saturação por bases a $70 \%$, e o gesso natural na dose de $3 \mathrm{~g} \mathrm{dm}^{-3}$. Após incubação por 30 dias, foi aplicado o composto $\left(30 \mathrm{~g} \mathrm{dm}^{-3}\right)$ e o adubo N-P-K + micronutrientes. Após nova incubação por mais 30 dias, fez-se a amostragem de terra e cultivou-se arroz (IAC 165), 7 plantas por vaso, por 60 dias. O delineamento experimental foi em blocos ao acaso, com parcelas em faixas, com três repetições. Foi realizado um segundo cultivo de arroz, para se avaliar o efeito residual do composto sobre a produção de matéria seca. No experimento II, foram avaliados os efeitos do enriquecimento do composto com $\mathrm{Cd}, \mathrm{Cu}, \mathrm{Mn}, \mathrm{Pb}$ e $\mathrm{Zn}(0,15$, $30,60,120$ e $240 \mathrm{mg} \mathrm{dm}^{-3}$ ) sobre a disponibilidade desses metais no solo, nutrição e 
produção de matéria seca de plantas de arroz. Foram utilizados 7 solos. A condução e o delineamento experimental foram semelhantes a do experimento I.

Em ambos os experimentos, foi avaliado a eficácia dos métodos de extração com Resina de troca iônica, DTPA, Mehlich-1, Mehlich-3, AB-DTPA, WolfMorgan, AA-EDTA. $\mathrm{Na}_{2}$ e $\mathrm{CaCl}_{2}$ na predição da disponibilidade e toxicidade de nutrientes e metais pesados, para o arroz. Foram determinados, tanto no solos como nas plantas, os teores de $\mathrm{P}, \mathrm{Ca}, \mathrm{Mg}, \mathrm{B}, \mathrm{Co}, \mathrm{Cu}, \mathrm{Fe}, \mathrm{Mn}, \mathrm{Mo}, \mathrm{Ni}, \mathrm{Zn}, \mathrm{Ba}, \mathrm{Cd}, \mathrm{Cr}, \mathrm{Pb}, \mathrm{Sr}$, Ti e $\mathrm{V}$ por espectrometria de emissão atômica por plasma acoplado indutivamente (ICP-AES) e de $\mathrm{K}$ e $\mathrm{Na}$ por fotometria de chama de emissão. Os teores de $\mathrm{P}, \mathrm{K}, \mathrm{Ca}$ e $\mathrm{Mg}$ obtidos pela Resina e de micronutrientes e de metais obtidos pelo DTPA foram considerados como de referência para a avaliação das propriedades químicas dos solos no experimento I.

A aplicação do composto com calagem promoveu a maior elevação no pH. do solo. A condutividade elétrica aumentou em cerca de 10 vezes nos tratamentos com o composto e foi maior onde se aplicou composto com adubo. A aplicação do composto aumentou os teores de nitrogênio total e de carbono orgânico, notadamente nos solos de textura arenosa a média. Os teores de $\mathrm{Ca}$ e $\mathrm{Mg}$ foram superiores e a acidez potencial foi menor nos tratamentos com composto + calagem, enquanto que o $\mathrm{K}$ foi maior no tratamento com composto + adubação. O teor de $\mathrm{Na}$ aumentou devido à aplicação do composto, independentemente do modo de aplicação. O aumento no teor de $\mathrm{Na}$ foi proporcional ao das demais bases trocáveis. A disponibilidade dos micronutrientes e dos metais foi aumentou com a aplicação do composto. tendo todavia sido diferenciada em função da textura, teor de matéria orgânica nativa e reação do solo, exceto o $\mathrm{V}$ e Tí. O aumento da disponibilidade dos demais metais devido ao composto, geralmente, não diferiu da aplicação de calcário com adubo, nos solos ácidos e com gesso + adubo nos solos alcalinos.

A aplicação do composto com adubo, na presença ou ausência de calagem, aumentou a produção de matéria seca da parte aérea, no primeiro e segundo cultivo, e raízes de plantas de arroz. Todavia, estes efeitos não foram superiores ao da calagem com adubo. A aplicação do composto sem adubação, com ou sem calagem, promoveu um efeito intermediário, dependendo do tipo de solo, mas geralmente superior à testemunha. 
Em alguns solos ácidos de textura arenosa, hidromórfico ou de pH inicial relativamente alto, o aumento no pH, C.E. e bases trocáveis, associado à uma provável atividade microbiana mais intensa, transformações bioquímicas e liberação de compostos orgânicos/inorgânicos estranhos ao solo devido à aplicação do composto, foi observado produção de matéria seca igual ou superior à testemunha. Constatou-se esse tipo de comportamento, também nos solos alcalinos, destacando-se o solo Salino-Sódico, no qual foi observado ausência de desenvolvimento completo das plantas de arroz em todos os tratamentos. No segundo cultivo, foi observado um padrão bem mais uniforme entre os tratamentos com composto, sendo que o composto + adubação, independentemente da calagem, promoveu maior produção de matéria seca.

Não houve diferenças significativas entre as propriedades químicas dos solos devido à aplicação do composto enriquecido com diferentes doses de metais. No primeiro cultivo de arroz, não houve redução no peso de matéria seca da parte aérea (PMSPA) até a dose de $30 \mathrm{mg} \mathrm{dm}^{-3}$, exceto nos solos PV e LV, onde a redução ocorreu a partir de $60 \mathrm{mg} \mathrm{dm}^{-3}$. O peso de matéria seca da raiz (PMSR) praticamente não foi afetada com o enriquecimento do composto até a dose de $60 \mathrm{mg} \mathrm{dm}^{-3}$ e foi menos afetada, também, nos solos PV e LV. A capacidade dos solos PV e LV em promoverem maior PMSPA e PMSR, sob condições de dose alta de metais (acima de $30 \mathrm{mg} \mathrm{dm}^{-3}$ de metais), deve estar relacionada ao alto teor de M.O. nativa (41 e $36 \mathrm{~g} \mathrm{dm}^{-3}$, respectivamente) presente nesses solos. No segundo cultivo, foi observado redução de cerca de 25 a $40 \%$ na PMSPA da dose de 0 para $15 \mathrm{mg} \mathrm{dm}^{-3}$ de enriquecimento do composto. Essa diferença entre os cultivos deve ter sido causada, possivelmente pela redução do $\mathrm{pH}$ do solo devido às subsequientes adubações, principalmente com nitrogênio (uréia), e o próprio cultivo, aumentando a solubilidade dos metais ligados à matéria orgânica, CTC e óxidos de $\mathrm{Fe}$ e Al, que passaram a ter concentrações tóxicas. 
CHEMICAL PROPERTIES AND NUTRIENT AND METAL AVAILABILITY AS CONSEQUENCE OF URBAN WASTE COMPOST APPLICATION IN SOIL

\author{
Author: CASSIO HAMILTON ABREU JUNIOR \\ Adviser: Prof. Dr. TAKASHI MURAOKA
}

\title{
SUMMARY
}

Two experiments were carried out in green house. In the experiment I, the effects of applying urban waste compost, from S. Paulo city, with or without lime (to reach $70 \%$ of base saturation) and fertilizer, on the chemical properties of 21 acid and 5 alkaline soils, and on nutrition and dry matter weight of rice crop were studied. Natural gypsum $\left(3 \mathrm{~g} \mathrm{dm}^{-3}\right)$ was applied in the alkaline soil, instead of lime. After incubation for 30 days, the compost $\left(30 \mathrm{~g} \mathrm{dm}^{-3}\right)$ and N-P-K fertilizers + micronutrients were applied. The soils were further incubated for 30 days. Then, soil samples were taken for analysis and rice (IAC 1657 plants per pot), were grown for 60 days. The experimental design was spit-plot completely randomized block with 3 replicates. Rice as then grown again for evaluate the residual effect of compost on the dry matter yield. In the experiment II, the effects of $\mathrm{Cd}, \mathrm{Cu}, \mathrm{Mn}, \mathrm{Pb}$ and $\mathrm{Zn}\left(0,15,30,60,120\right.$ and $\left.240 \mathrm{mg} \mathrm{dm}^{-3}\right)$ enrichment of compost, on the availability of these metals in the soils, rice plant nutrition and dry matter weight were studied. Seven soils were utilized. The experiment was carried out, as in the experiment $I$ and the experimental design was also similar. The efficiency of extraction methods: Ionic exchange resin, DTPA, Mehlich 1, Mehlich 3, AB-DTPA, 
Wolf-Morgan, AA-EDTANa 2 and $\mathrm{CaCl}_{2}$, in predicting the availability and toxicity of nutrients and heavy metals to rice plants was evaluated. The following elements were determined in both soil and plant samples: $\mathrm{P}, \mathrm{Ca}, \mathrm{Mg}, \mathrm{B}, \mathrm{Co}, \mathrm{Cu}, \mathrm{Fe}, \mathrm{Mn}, \mathrm{Mo}, \mathrm{Ni}, \mathrm{Zn}$, $\mathrm{Ba}, \mathrm{Cd}, \mathrm{Cr}, \mathrm{Pb}, \mathrm{Sr}$, Ti e $\mathrm{V}$ by ICP-AES and $\mathrm{K}$ and $\mathrm{Na}$ by flame emission photometry. The $\mathrm{P}, \mathrm{K}, \mathrm{Ca}$ and $\mathrm{Mg}$ content obtained by resin method and micronutrients and metals obtained by DTPA were considered as the reference for evaluating the chemical properties of soils in the experiment I.

The compost application with liming promoted the greater increase on soil $\mathrm{pH}$. The electric conductivity increased around 10 times in the treatments with composts and the effect was the greatest when the compost was applied with fertilizers. The application of compost increased the total $\mathrm{N}$ and organic carbon O.M. content, mainly in the sandy and medium texture soil. The $\mathrm{Ca}$ and $\mathrm{Mg}$ contents were higher and the potential acidity was lower in the treatment compost + liming, while the $\mathrm{K}$ content was higher in the treatment compost + fertilizer. The Na content increased due to the compost application, irrespective to lime or fertilizer addition. This increase was proportional to the other exchangeable bases increase. The availability of micronutrients and of heavy metals increased with compost application, being however differentiated as a function of soil texture, native O.M. content and $\mathrm{pH}$, except for $\mathrm{V}$ and $\mathrm{Ti}$. The increase on the availability of other metals due to compost, did not differ, generally, with the lime and fertilizer application in the acid soils and with gypsum + fertilizer in the alkaline soils.

The application of compost + fertilizer, with or without liming, increased the above ground part dry matter weight (AGDMW), in the first and second rice growing, and also of rice roots dry weight (RDW). However, the effects was not better than lime + fertilizer. The application of compost without fertilizers, with or without liming, promoted an intermediate effect, depending on the soil type, but generally superior to the control. In some sandy texture acid soils, hidromorfic or relatively high initial $\mathrm{pH}$ soil, the increase on pH, E.C. and exchangeable bases, associated with a probable microbial activity, biochemical transformations and organics/inorganics composts, unusual to the soil caused by the compost application. The dry matter 
weights were equal or superior to the control treatment. This type of behavior was also observed in alkaline soils, the saline-sodic soil beingoutstanding, in which occurred the absence of complete plant development in all treatments. In the second crop, a more uniform pattern was observed among the treatments with compost, and the treatment compost + fertilizer, irrespective to the liming, promoted higher yield of dry matter.

These were not significative differences, among the soil chemical properties due to the application of compost enriched with different metals levels. In the first growing, there were no reduction on AGDMWs up to $30 \mathrm{mg} \mathrm{dm}^{-3}$, except in the PV and LV soils, where the reduction occurred from $60 \mathrm{mg} \mathrm{dm}^{-3}$. The root RDWs, were almost not affected with the metals enrichment up to $60 \mathrm{mg} \mathrm{dm}^{-3}$ and were less affected, also, in the PV and LV soils. The capability of PV and LV soils on promoting greater AGDMW and RDW, under high metals doses (over $30 \mathrm{mg} \mathrm{dm}^{-3}$ metals), may be related to high native O.M. content ( 41 and $31 \mathrm{~g} \mathrm{dm}^{-3}$, respectively) present in these soils. In the second growing, there was decrease of approximately 25 to $40 \%$ in AGDMW in the 0 to $15 \mathrm{mg} \mathrm{dm}^{-3}$ compost metal enrichment. This difference between the crops might be caused, probably, by the soil $\mathrm{pH}$ reduction, due to subsequent fertilizer applications, mainly with nitrogen (urea), and to the crop itself, increasing the solubility of O.M. bound metals, $\mathrm{CEC}$ and $\mathrm{Fe}$ and $\mathrm{Al}$ oxides, which passed to toxic levels. 


\section{INTRODUÇÃO}

Tem sido observado um aumento crescente na quantidade de resíduo urbano, ou seja de lixo, produzido devido à atividade humana e ao crescimento populacional. A falta de controle sobre a produção e destino final do resíduo urbano, principalmente nos grandes centros, tem levado à constante ameaça de poluição dos rios, do ar e do solo. Uma considerável parcela destes recursos próximos aos grandes centros urbanos, encontram-se, atualmente, com um nível de poluição elevado, causando prejuízos à saúde da população, e de um modo praticamente irreversível a curto ou médio prazo, havendo a necessidade de se estabelecer uma política agrícola e/ou ambiental que reverta tal quadro.

A estruturação de uma política ambiental, tendo como sustentáculo a pesquisa e educação sobre o controle no modo de produção e sobre as possibilidades de utilização racional dos resíduos provenientes da atividade humana, é um dos primeiros passos para se evitar à poluição indiscriminada do ambiente e dos seus recursos, conseqüentemente, a sobrevivência da própria espécie humana. Atualmente, com o intuito de reduzir o volume de resíduos nos grandes centros urbanos, tem-se realizado algumas práticas, tais como a incineração, a deposição em aterros sanitários, a reciclagem dos diversos materiais via coleta seletiva, a descarga em rios ou bombeamento para os oceanos e a compostagem.

A aplicação de composto de resíduo urbano na agricultura, observada em experimentos instalados a partir da década de 80 , tem-se mostrado como uma importante fonte de nutrientes para às plantas e um excelente corretivo das propriedades químicas e físicas do solo. Todavia, permanecem dúvidas quanto à possibilidade de contaminação do solo e das plantas por metais pesados. 
Concomitantemente à necessidade de se avaliar a disponibilidade e o acúmulo de nutrientes e de metais pesados no solo, devido à aplicação de composto de lixo, existe a problemática dos diferentes procedimentos para a extração dos elementos no solo. Não é recente, na Ciência do Solo, a busca por um extrator que possibilite a determinação simultânea do maior número possível de nutrientes do solo, proporcionando uma economia em tempo e de recursos financeiros. A utilização de soluções extratoras multielementares associada a espectrometria de emissão atômica com plasma acoplado indutivamente (ICP-AES) têm permitido avanços nos estudos envolvendo nutrientes, metais pesados e a qualidade dos solos.

Baseados nos problemas acima, este trabalho propôs o estudo dos efeitos da adubação com composto de resíduo urbano, proveniente da cidade de São Paulo, na presença e ausência de calagem e adubação, sobre as propriedades químicas, disponibilidade de nutrientes e metais de diferentes solos do Brasil, nutrição e produção de matéria seca de plantas de arroz (Oryza sativa L.) em condições de casa de vegetação, e a avaliação de extratores multielementares na predição da disponibilidade e toxicidade de nutrientes e de metais nos solos por ICP-AES. 


\section{REVISÃO DE LITERATURA}

\subsection{Considerações gerais}

O termo metal pesado tem sido usado na literatura científica de uma forma bastante abrangente (Alloway, 1990; Malavolta, 1994; Melo et al.. 1997). De acordo com Alloway (1990), metais pesados são os elementos, e respectivas formas iônicas, que pertencem ao grupo de transição e não transição da tabela periódica com densidade maior que $6 \mathrm{~g} \mathrm{dm}^{-3}$. Outros autores consideram os metais pesados como sendo os elementos com densidade maior que 4,5 ou $5 \mathrm{~g} \mathrm{dm}^{-3}$ (Malavolta, 1994; Melo et al., 1997). Observa-se que o termo tem sido utilizado para designar qualquer elemento, metal, semi-metal e não metal, associados à problemas de poluição, contaminação e toxicidade no solo, plantas e animais. Alguns desses elementos são nutrientes essenciais às planta (B, $\mathrm{Cu}, \mathrm{Fe}, \mathrm{Mn}, \mathrm{Mo}$ e $\mathrm{Zn}$ ) e são denominados aqui por micronutrientes. Baseando-se em Malavolta (1994) e Malavolta et al. (1997), os elementos Co e Ni também foram considerados como micronutrientes. Assim, utilizou-se o termo metais para designar todos os outros elementos, metais cu não, excluindo-se os micronutrientes.

\subsection{Resíduos urbanos result antes da atividade do homem}

Toda e qualquer atividade do homem tem como conseqüência a produção de um resíduo e a alteração do meio que o cerca. O desenvolvimento dos grandes centros urbanos tem conduzido a um aumento crescente na quantidade de resíduo urbano, ou seja de lixo, produzido devido à atividade humana. A intensidade de produção de resíduo está diretamente relacionado com o aumento da densidade 
demográfica nesses grandes centros (Melo et al., 1997). Assim, a produção de lixo de modo desordenado tem levado à constante ameaça de poluição dos rios, do ar e do solo do ambiente em que vivemos, quando não a ocorrência de contaminação in situ, de modo praticamente irreversível a curto ou médio prazo (Matiazzo-Prezotto, 1992). Os principais resíduos sólidos urbanos, derivados da atividade humana. são o lixo domiciliar e o lodo de esgoto (Kiehl \& Kiehl, 1996; Melo et al., 1997).

Embora o homem sempre tenha utilizado o solo, o ar e os recursos de água como forma natural de descarte dos resíduos gerados de sua atividade, nas últimas duas décadas, iniciou-se uma série de discussões sobre o que se fazer com a grande quantidade de resíduo urbano e o qual o destino final deste lixo. Tal preocupação é decorrente de uma maior conscientização sobre a importância de se preservar a natureza, fonte de recursos naturais para o hornem, do descarte indiscriminado de resíduos, visto que esses recursos apresentam uma capacidade de depuração limitada (MatiazzoPrezotto, 1992).

A estruturação de uma política ambiental, tendo como sustentáculo a pesquisa e educação sobre o controle no modo de produção e sobre as possibilidades de utilização racional dos resíduos provenientes da atividade humana, é um dos primeiros passos para se evitar à poluição indiscriminada do ambiente e dos seus recursos, conseqüentemente, a sobrevivência do própria espécie humana. Atuaimente tem-se realizado algumas práticas, com o intuito de reduzir o volume de resíduos nos grandes centros urbanos, tais como a incineração (seja para geração de energia ou simples eliminação), a deposição em aterros sanitários e ou industriais, a reciclagem dos diversos materiais reaproveitáveis via coleta seletiva, a descarga em rios, o bombeamento para os oceanos e a compostagem para a aplicação na agricultura. Todavia. de acordo com Matiazzo-Prezotto (1992), o bombeamento para os oceanos, a incineração e os aterros. são práticas consideradas insuficientes para receber a quantidade cada vez maior de resíduos. A consorciação destas práticas com técnicas de compostagem, contribuiria, sem dúvida, para reduzir o volume de resíduos descartados (Ferro Neto, 1994) e reciclagem dos elementos neles contidos (Melo et al., 1997). 
De um modo geral, pode se estimar que a produção de resíduo urbano no Brasil esteja na faixa de 0,5 a $0,7 \mathrm{~kg}$ por habitante por dia (Kiehl \& Kiehl, 1996). Sabendo-se que na Grande São Paulo a produção de resíduo per capita está no limite superior desta faixa e que do total produzido apenas $5 \%$ é reciclado (Costa, 1983), podemos estimar um acúmulo anual de resíduo urbano da ordem de $3,6 \times 10^{9} \mathrm{~kg}$.

De acordo com Ferro Neto (1994), o Estado de São Paulo apresenta 282 municípios com população de até 12.500 habitantes e que produzem no máximo $5 \mathrm{t} \mathrm{dia}^{-1}$ de resíduo urbano, cada um; 123 municípios com até 25.000 habitantes e que produzem no máximo $10 \mathrm{t} \mathrm{dia}^{-1} ; 73$ municípios com até 50.000 habitantes e que produzem de $10 \mathrm{a}$ $20 \mathrm{t} \mathrm{dia}^{-1}$; e acima disto temos 41 municípios que produzem de 20 a $30 \mathrm{t} \mathrm{dia}^{-1} ; 14$ que produzem de 30 a $50 \mathrm{t} \mathrm{dia}^{-1}$ e 15 que produzem de 50 a $75 \mathrm{t} \mathrm{dia}^{-1}$. Quanto à disposição final dos resíduos, o autor relata que em $87 \%$ do Estado de São Paulo é feita em lixões a céu aberto, em $5 \%$ na forma de aterro sanitário e usina (apenas $1 \%$ utiliza aterro sanitário), e em $8 \%$ na forma de aterro controlado.

\subsection{Aplicação agrícola do co mposto de resíduo urbano e suas conseqüências}

\subsubsection{Generalidades e caracterização do composto}

A utilização agrícola de resíduos urbanos parece ser una opção bastante razoável para, pelo menos em parte, reduzir o volume e reciclar os minerais neles contidos. Todavia, é totalmente inviável a utilização agrícola do resíduo bruto, este deve ser tratado pelo processo de compostagem para se tornar adequado a este fim (Kiehl, 1985).

O composto de resíduo urbano é o lixo domiciliar que, após a remoção prévia dos componentes não orgânicos na usina de reciclagem e compostagem, passou por decomposição microbiológica da parte orgânica, transformando-se, então em fertilizante orgânico (Kiehl, 1985; Kiehl \& Kiehl, 1996). De acordo com Kiehl \& Kiehl (1996), as características exigidas pela lei brasileira para a comercialização sob registro desse tipo de fertilizante orgânico, dentro de certos limites, sào: mínimo de $40 \%$ de 
matéria orgânica total, umidade máxima de $40 \%$, pH mínimo de 6 , mínimo de $1,0 \mathrm{~g} \mathrm{~kg}^{-1}$ de $\mathrm{N}$ total, relação $\mathrm{C} / \mathrm{N}$ mínima de 18:1 e, a ausência de agentes fitotóxicos, agentes patogênicos ao homem, animais e plantas, metais pesados, agentes poluentes. pragas e ervas daninhas.

O êxito na aplicação agrícola do composto de resíduo urbano sólido é em grande parte determinada pela maturidade do composto, ou seja, pelo grau de estabilidade nas suas propriedades físicas, químicas e biológicas (Xin et al., 1992). O composto devidamente curado deve apresentar reação alcalina ou próxima da neutralidade e relação $\mathrm{C} / \mathrm{N}$ baixa (Kiehl, 1985; Berton \& Valadares, 1991). Assim, enquanto que a aplicação de composto imaturo (elevada relação $\mathrm{C} / \mathrm{N}$ ) ao solo pode causar a deficiência de $\mathrm{N}$ nas plantas, devido à imobilização desse nutriente pela microbiota do solo, a aplicação de composto com relação $\mathrm{C} / \mathrm{N}$ estreita pode ter efeito tóxico às plantas, devido ao excesso de $\mathrm{N}$ mineralizado (Cardoso et al., 1995).

A composição química dos compostos de resíduos urbanos é extremamente váriável, dependendo da região, da época do ano e da usina de compostagem (Xin et al., 1992; Cravo, 1995; Cravo et al., 1998). Xin et al. (1992) compararam as análises químicas de vários compostos de resíduo dos Estados Unidos e de vários países da Europa, e observaram que os teores e $\mathrm{C}, \mathrm{N}, \mathrm{P}, \mathrm{K}, \mathrm{Ca}, \mathrm{Mg}, \mathrm{S}, \mathrm{Cl}$ e $\mathrm{Na}$ variaram, em g kg-1 de 270 a 400; 9,0 a 17,8; 1,5 a 6,0;0,7 a 9,7;12,0 a 75,7;0,8 a 6,0; 2,0 a 6,$0 ; 3,2$ a 5,0 e de 2,0 a 6,7 ; respectivamente. Berton \& Valadares (1991) determinaram, em composto de resíduo urbano proveniente da cidade de São Paulo, valores de $\mathrm{pH}$ entre 6,8 a 8,3 , teor de umidade de $40 \%$, teores de matéria orgânica de 190 a $530 \mathrm{~g} \mathrm{~kg}^{-1}$, C orgânico de 120 a $220 \mathrm{~g} \mathrm{~kg}^{-1}$, P de 2 a $5,3 \mathrm{~g} \mathrm{~kg}^{-1}, \mathrm{~K}_{\text {de }} 3$ a $6 \mathrm{~g} \mathrm{~kg}^{-1}$, $\mathrm{Mg}$ de 3 a $5 \mathrm{~g} \mathrm{~kg}^{-1}$ e $\mathrm{S}$ de 2 a $3 \mathrm{~g} \mathrm{~kg}^{-1}$. A análise química de compostos de lixo urbano proveniente de Belo Horizonte, Brasília, Rio de Janeiro, Florianópolis, São Paulo e de Manaus, de um modo geral, apresentou teores dentro destas faixas (Cravo et al., 1998).

De acordo com Petruzzelli (1989), Petruzzelli et al. (1989) e Xin et al. (1992), a principal preocupação com relação ao uso de compostos de resíduos urbanos na agricultura é devido aos elevados teores de metais pesados, principalmente $\mathrm{Cd}, \mathrm{Cr}$, $\mathrm{Cu}, \mathrm{Mn}, \mathrm{Ni}, \mathrm{Pb}$ e $\mathrm{Zn}$, que estes produtos podem conter e que, portanto, podem levar à 
contaminação do ambiente. Xin et al. (1992), comparando compostos de diversos países da Europa e Estados Unidos, observaram as seguintes variações nos teores de metais, em $\mathrm{mg} \mathrm{kg}{ }^{-1}$ com base no peso seco: 0,04 a 100 de $\mathrm{Cd} ; 2$ a $270 \mathrm{de} \mathrm{Cr} ; 100$ a 630 de $\mathrm{Cu} ; 4$ a 5 de $\mathrm{Hg} ; 0,76$ a 190 de Ni; 300 a 600 de Mn; 5 a 900 de Pb e 500 a 1.650 de Zn. Deve-se salientar que os valores inferiores de $\mathrm{Cd}, \mathrm{Cr}, \mathrm{Ni}$ e $\mathrm{Pb}$ foram observados exclusivamente para o composto proveniente da Espanha. A análise de composto de residuo da Itália apresentou teores de $\mathrm{Cd}, \mathrm{Cr}, \mathrm{Cu}, \mathrm{Pb}$ e $\mathrm{Zn}$ próximos aos limites superiores das faixas mostradas acima (Petruzzelli et al., 1985).

As análises químicas de compostos de lixo urbano proveniente de Belo Horizonte, Brasília, Rio de Janeiro, Florianópolis, São Paulo e de Manaus, realizadas por Cravo (1995) e Cravo et al. (1998), apresentaram as seguintes faixas de teores de micronutrientes e de metais pesados, em mg kg-1: 11.300 a 35.800 de $\mathrm{Al} ; 0$ a 7 de $\mathrm{B} ; 85$ a 437 de $\mathrm{Ba} ; 1$ a 5 de $\mathrm{Cd} ; 7$ a 21 de $\mathrm{Co} ; 29$ a 168 de $\mathrm{Cr} ; 45$ a 815 de $\mathrm{Cu} ; 13,5$ a 52,1 de Fe; 154 a 536 de Mn; 16 a 38 de Mo; 11 a 91 de Ni; 92 a 599 de Pb; 60 a 169 de Sr; 912 a 5.376 de Ti; 41 a 317 de V; e 111 a 1.007 de Zn. Destacam-se os elevados teores de Al, Fe e Ti. De acordo com Petruzzelli et al. (1985), embora sejam observados teores totais elevados de nutrientes e de metais em compostos de lixo, nota-se que apenas uma pequena fração desses totais se apresenta em formas disponivel às plantas, quando da aplicação destes compostos ao solo.

\subsubsection{Efeitos sobre as propried ades do solo}

A aplicação de composto, quando obtido de modo adequado, tem propiciado a melhoria dos atributos físicos, químicos e biológicos do solo. Embora, em muitos casos, tenha havido a necessidade de complementação com adubação mineral. Também, tem sido relatado um efeito sinérgico da aplicação combinada de composto e adubo mineral sobre o solo e a planta.

Conforme mostrado por Hortenstine \& Rothwell (1972), Giordano et al. (1975), Mazur et al. (1983), Kiehl (1985) e Ferro Neto (1994), entre outros, os principais efeitos do composto sobre as propriedades químicas do solo são: elevação do $\mathrm{pH}$, 
redução da acidez potencial e aumento da disponibilidade de $\mathrm{P}, \mathrm{Ca}, \mathrm{Mg}$ e K. De acordo com Igue \& Pavan (1984), a elevação do pH do solo diminui a disponibilidade de metais, devido à formação de complexos estáveis.

Trabalho conjunto realizado pela CETESB de Novo Horizonte e a UNESP de Jaboticabal, mostrou que a aplicação de $30 \mathrm{t} \mathrm{ha}^{-1}$, de um vermicomposto, aumentou os teores de matéria orgânica em $15 \%$, de $\mathrm{K} \mathrm{em} 40 \%$, de $\mathrm{Mg}$ em $50 \%$ e de $\mathrm{Mn}$ e de $\mathrm{Zn}$ em $30 \%$, e aumentou o pH do solo, com conseqüente diminuição da acidez potencial (Ferro Neto, 1994).

Foi, também observado por Trindade et al. (1996) que a aplicação de composto, nas doses de $0,10,20,40$ e $60 \mathrm{t} \mathrm{ha}^{-1}$, promoveu aumento linear do $\mathrm{pH}$ (de 4,74 para 5,03) do solo e nos teores disponíveis de $\mathrm{P}\left(2,8\right.$ para $\left.13,2 \mathrm{mg} \mathrm{kg}^{-1}\right), \mathrm{Cu}(1,28$ para 2,60 $\left.\mathrm{mg} \mathrm{kg}^{-1}\right), \mathrm{Zn}\left(1,16\right.$ para $\left.9,75 \mathrm{mg} \mathrm{kg}^{-1}\right), \mathrm{Mn}\left(23\right.$ para $\left.39 \mathrm{mg} \mathrm{kg}^{-1}\right)$ e de $\mathrm{Cd}(0,09$ para $\left.0,14 \mathrm{mg} \mathrm{kg}^{-1}\right)$, e efeito quadrático no caso do $\mathrm{Pb}\left(0,31\right.$ para $\left.1,49 \mathrm{mg} \mathrm{kg}^{-1}\right)$, extraídos com Mehlich-1. Embora tenha sido verificado o aumento da disponibilidade de metais, estes não atingiram niveis considerados tóxicos.

Em um outro experimento com 6 anos de aplicação de composto em um solo calcário, foi observado um aumento significativo e gradativo dos teores totais de $\mathrm{Cu}, \mathrm{Zn}$ e $\mathrm{Pb}$ do solo já no primeiro ano, aumento de $\mathrm{Cu}$ a partir do segundo ano e aumento de Cr no quinto ano (Gigliotti et al., 1996). Contudo, não houve transferência significativa de metais do solo para plantas de milho.

\subsubsection{Efeito sobre as plantas}

Embora haja respaldo científico para a aplicação do composto de resíduo urbano na agricultura, observa-se algumas dúvidas quanto aos efeitos sobre o desenvolvimento e produção das plantas, quando da sua aplicação isolada. Todavia, também tem sido relatado um efeito sinérgico da aplicação combinada de composto e adubo mineral sobre os vegetal.

De acordo com Cravo (1995), parece que para algumas culturas. dependendo do tipo de solo, a aplicação de compostos de resíduo urbano não é suficiente 
para garantir o adequado suprimento de nutrientes e da produção, havendo necessidade de adubação mineral complementar. Isto pode estar associado ao fato de que, embora sejam observados teores totais elevados de nutrientes em compostos de resíduo urbano. apenas uma pequena fração desses totais se apresenta disponível às plantas (Petruzzelli et al., 1985). Foi observado por Cravo (1995), em estudo sobre o efeito da aplicação de doses de $0,10,20,40,80$ e $120 \mathrm{t} \mathrm{ha}^{-1}$ de composto proveniente da cidade de São Paulo sobre a produção de alface fresca, que a aplicação do composto em um solo argiloso promoveu a diminuição da produção nos dois primeiros cultivos. Todavia, a aplicação do mesmo composto em um solo arenoso promoveu aumento significativo na produção dos dois primeiros cultivos, mas com decréscimo no terceiro cultivo.

Em povoamentos de eucalipto, também foi relatado o aumento da produção de madeira devido à aplicação de composto (Zen et al., 1994). Os autores verificaram que a aplicação de composto, na fase de plantio, com doses variando de 4 a $56 \mathrm{t} \mathrm{ha}^{-1}$, promoveu aumento crescente nas produções volumétricas de madeira, que variaram de 58,85 a $90,59 \mathrm{~m}^{3} \mathrm{ha}^{-1}$ (contra $66,72 \mathrm{~m}^{3} \mathrm{ha}^{-1}$ obtido pela adubação convencional: $210 \mathrm{~kg} \mathrm{ha}^{-1}$ da fórmula $10-20-10+100 \mathrm{~kg}$ de fosfato parcialmente solúvel) aos dois anos de idade; de 137,37 a 226,58 $\mathrm{m}^{3} \mathrm{ha}^{-1}$ (contra $154,67 \mathrm{~m}^{3} \mathrm{ha}^{-1}$ obtido pela adubação convencional) aos três anos e de 184,99 a $308,78 \mathrm{~m}^{3} \mathrm{ha}^{-1}$ (contra $233,13 \mathrm{~m}^{3} \mathrm{ha}^{-1}$ obtido pela adubação convencional) aos quatro anos. Na fase de manutenção. a aplicação de doses de $7,14,21,28$ e $56 \mathrm{t} \mathrm{ha}^{-1}$ levou a incrementos volumétricos crescentes até a dose de $28 \mathrm{tha}^{-1}$ (de 296,09 a 428,55 $\mathrm{m}^{3} \mathrm{ha}^{-1}$ ).

De acordo com Lopes et al. (1996), a adição de composto proporcionou maior nodulação e maior absorção de $\mathrm{N}$, produção de matéria seca da parte aérea de caupi quando aplicado uma pequena dose de adubo nitrogenado $\left(25 \mathrm{mg} \mathrm{kg}^{-1}\right)$, do que quando aplicado doses mais elevadas (50 e $100 \mathrm{mg} \mathrm{kg}^{-1}$ ) que inibiam o processo simbiótico, proporcionando baixo desenvolvimento do caupi. Foi observado, também por Trindade et al. (1996) que houve um efeito sinérgico entre a aplicação de composto e a inoculação com fungos micorrízicos (Glomus clarum), sobre o crescimento de plantas de milho, promovendo maior absorção de $\mathrm{P}$ e $\mathrm{Cu}$ e menor de $\mathrm{Mn}$ e $\mathrm{Cd}$. 
Não obstante os altos teores de metais nos compostos de resíduo urbano e o aumento do teor destes metais no solo devido à aplicação deste material, para algumas culturas tem sido relatado a ausência de efeitos negativos sobres a nutrição e produção. Mortvedt \& Giordano (1975) observaram que a aplicação de doses elevadas de composto de lixo urbano e de lodo de esgoto contaminados com $\mathrm{Zn}$ e $\mathrm{Cr}$ não causaram efeitos fitotóxicos em plantas de milho e nem redução na produção de forragem, mesmo após um periodo relativamente longo da aplicação e sob altas doses de $\mathrm{Zn}(0 \mathrm{a} 1.400 \mathrm{mg}$ $\left.\mathrm{kg}^{-1}\right)$ e $\mathrm{Cr}\left(0\right.$ a $\left.1.360 \mathrm{mg} \mathrm{kg}^{-1}\right)$ aplicados ao solo.

Plantas de milho crescidas em solos tratados com composto de residuo urbano durante seis anos, apresentaram uma maior absorção de $\mathrm{Cu}, \mathrm{Zn}, \mathrm{Pb}, \mathrm{Cr}$ e de $\mathrm{Ni}$. do que as testemunhas (Gigliotti et al., 1996). Todavia, devido ao maior desenvolvimento das plantas tratadas com o composto, as concentrações destes elementos nas plantas tratadas e não tratadas praticamente não diferiram entre si. As concentrações de $\mathrm{Cu}, \mathrm{Zn}, \mathrm{Pb}, \mathrm{Cr}$ e $\mathrm{Ni}$ na planta toda, do primeiro ao sexto ano de tratamento, variam em $\mathrm{mg} \mathrm{kg}^{-1}$ de 4,4 a 22,6;34,8 a 79,3;0,80 a 2,07; 0,34 a 1,00 e de 1,85 a 6,76; respectivamente. Também, foi observado que o $\mathrm{Cr}$ e o $\mathrm{Pb}$ apresentaram baixa mobilidade e se acumularam nas raizes.

A dimensão dos efeitos que os metais podem exercer sobre as plantas depende muito da espécie, do cultivar, variedade e do melhoramento genético. Dentre quatorze espécies vegetais estudadas por Bingham et al. (1975), o arroz foi a única que apresentou tolerância à doses elevadas de $\mathrm{Cd}$. Eles observaram que a aplicação ao solo de 0 a $640 \mathrm{mg} \mathrm{kg}^{-1}$ de $\mathrm{Cd}$, na forma de lodo de esgoto enriquecido com $\mathrm{CdSO}_{4}$, causou o aumento da produção relativa de arroz. Espécies susceptíveis, como o espinafre, alface, milho, cenoura e soja, tiveram redução de $25 \%$ na produção relativa com a aplicação de 4 a $20 \mathrm{mg} \mathrm{kg}^{-1}$ de $\mathrm{Cd}$. Espécies com tolerância média, tais como tomate, repolho e abobrinha, tiveram redução de $25 \%$ na produção relativa com a aplicação de 160 a 170 $\mathrm{mg} \mathrm{kg}{ }^{-1}$ de Cd.

Existem, também, outras fontes com potencial de introduzir metais pesados no solo. As rochas fosfatadas utilizadas na produção de fertilizantes, podem conter quantidades significativas de $\mathrm{Cd}$, sendo observado concentraçces desde 10 até 
$200 \mathrm{mg} \mathrm{kg}^{-1}$ (Adriano, 1986). A presença deste elemento no fertilizante poderá acarretar um acúmulo de $\mathrm{Cd}$ nos solos. Outro metal pesado que também pode ser encontrado em alta concentração nos adubos fosfatados, é o Cr. A análise química de adubos fosfatados revelou teores de 23, 232, 41, 60, 39 e $557 \mathrm{mg} \mathrm{kg}^{-1}$ de $\mathrm{Cd}, \mathrm{Cr}, \mathrm{Cu}, \mathrm{Ni}, \mathrm{Pb}$ e $\mathrm{Zn}$, respectivamente (Pezzaroza et al., 1990).

Os resultados da análise química de esterco de vaca, calcário dolomítico, cloreto de potássio, superfosfato simples e uréia, obtidos por Cravo (1995), são apresentados na Tabela 1. O autor chama a atenção para os teores de Cd no calcário e de $\mathrm{Cd}, \mathrm{Cr}, \mathrm{Sr}, \mathrm{Ti}$ e $\mathrm{V}$ no super simples. O teor de Ti no esterco, também deve ser destacado. Todavia, considerando-se as quantidades desses insumos que normalmente são aplicadas ao solo, em comparação as de composto, pode-se supor que o acúmulo desses elementos no solo seja praticamente desprezível.

\subsection{Avaliação da disponibilidade de nutrientes e metais no solo}

Concomitantemente à necessidade de se avaliar a disponibilidade e acúmulo de nutrientes e de metais pesados no solo e nas plantas, devido à aplicação de compostos de lixo, existe a problemática dos diferentes procedimentos para a extração dos elementos do solo (Jones Junior, 1990; Raij, 1994). Não é recente, na Ciência do Solo, a busca por extratores que possibilitem à determinação simultânea do maior número possível de nutrientes do solo, proporcionando uma economia de tempo e recursos financeiros (Raij, 1994).

Dependendo do enfoque, tais extratores são chamados de extratores multinutrientes ou multielementares ou ainda de universais. Tais termos têm sido utilizados para designar extratores que possibilitam a determinação simultânea da concentração de vários elementos ou íons no solo e, permitindo o estabelecimento dos níveis de fertilidade e de toxicidade (Jones Junior, 1990; Raij, 1994), sendo cada extrator composto por um ou mais reagentes. Tem sido sugerido que tais extratores são de grande aplicabilidade em estudos envolvendo à aplicação de compostos de resíduos urbanos e a qualidade do ambiente, pois possibilitam uma avaliação eficaz das alterações 
químicas no solo e, conseqüente disponibilidade de nutrientes e de metais pesados para às plantas (Wolf, 1982; Soltanpour, 1985; Houba et al., 1990, 1992; Sippola, 1994; Hanlon et al., 1996).

Tabela 1. Teores de micronutrientes e de metais pesados em esterco de vaca, calcário dolomítico, cloreto de potássio, superfosfato simples e uréia (Cravo, 1995).

\begin{tabular}{lrrrrr}
\hline Elemento & Esterco & Calcário & $\mathrm{KCl}$ & $\begin{array}{c}\text { Super } \\
\text { Simples }\end{array}$ & Uréia \\
\hline $\mathrm{Al}$ & 14.732 & 4.066 & 411 & 1.598 & 77 \\
$\mathrm{Ba}$ & 160 & 45 & 3 & 96 & 3 \\
$\mathrm{Cd}$ & 1 & 4 & 1 & 3,5 & 0 \\
$\mathrm{Co}$ & 9 & 8 & 20 & 11 & 0 \\
$\mathrm{Cr}$ & 11 & 0 & 0 & 133 & 0 \\
$\mathrm{Cu}$ & 314 & 5 & 4 & 25 & 25 \\
$\mathrm{Fe}$ & 12.520 & 3.014 & 1.147 & 5.635 & 47 \\
$\mathrm{Mn}$ & 958 & 213 & 18 & 251 & 0 \\
$\mathrm{Mo}$ & 16 & 9 & 0 & 8 & 0 \\
$\mathrm{Ni}$ & 14 & 24 & 5 & 33 & 0 \\
$\mathrm{~Pb}$ & 26 & 61 & 19 & 38 & 0 \\
$\mathrm{Sr}$ & 99 & 452 & 14 & 2.636 & 0 \\
$\mathrm{Ti}$ & 1.225 & 220 & 33 & 176 & 19 \\
$\mathrm{~V}$ & 0 & 0 & 0 & 62 & 0 \\
$\mathrm{Zn}$ & 251 & 13 & 18 & 84 & 7 \\
\hline
\end{tabular}


Atualmente, os laboratórios de análise de solo do Estado de São Paulo têm utilizado a resina trocadora de íons e o DTPA como os métodos oficiais para a análise de $\mathrm{P}, \mathrm{K}, \mathrm{Ca}$ e $\mathrm{Mg}$ e de $\mathrm{Cu}, \mathrm{Fe}, \mathrm{Mn}$ e $\mathrm{Zn}$, respectivamente (Cantarella et al., 1995). O DTPA, também, tem sido utilizado para a extração de metais pesados do solo (Abreu et al., 1995). Para a extração de B tem sido utilizado a extração com água quente. Todavia, até o ano de 1995 o extrator para micronutrientes $(\mathrm{B}, \mathrm{Co}, \mathrm{Cu}, \mathrm{Fe}, \mathrm{Mn}$, Mo e $\mathrm{Zn}$ ) mais empregado nos laboratórios de análise de solo no Brasil era o Mehlich-1 (Cantarella et al., 1995).

A solução de Morgan (acetato de sódio $0,73 \mathrm{~mol} \mathrm{~L}^{-1}$, tamponado em $\mathrm{pH}$ 4,8 com ácido acético) foi muito usada para determinação de $\mathrm{Al}, \mathrm{As}, \mathrm{Ca}, \mathrm{Cu}, \mathrm{Fe}, \mathrm{Hg}, \mathrm{K}$, $\mathrm{Mg}, \mathrm{Mn}, \mathrm{N}-\mathrm{NO}_{3}, \mathrm{~N}-\mathrm{NH}_{4}, \mathrm{P}, \mathrm{S}-\mathrm{SO}_{4}, \mathrm{~Pb}$ e $\mathrm{Zn}$ em solos, na década de 50 e início de 60 nos Estados Unidos, sendo atualmente muito pouco empregada (Jones Junior, 1990). Wolf (1982) modificou este extrator através da combinação com ácido dietilenotriaminopentacético (DTPA), para melhorar a extração de $\mathrm{Cu}, \mathrm{Fe}, \mathrm{Mn}$ e $\mathrm{Zn}$, que passou a ser conhecido como extrator Wolf-Morgan.

$\mathrm{O}$ pH 4,8 foi escolhido devido à similaridade com a solução do solo saturada em $\mathrm{CO}_{2}$ próximo as raízes secundárias, que poderia atuar como um solvente moderado de nutrientes e, o uso do acetato de sódio e ácido acético pode permitir a extração de quase todos os nutrientes, exceto do Na (Wolf, 1982). Também, segundo Wolf (1982) a introdução de DTPA à solução de Morgan, somente foi possível após avaliação de vários agentes quelantes (DTPA, Na $a_{2}$-EDTA e NTA) em diversas concentrações. A adição de DTPA promoveu um aumento significativo nas correlações entre as concentrações de $\mathrm{Cu}, \mathrm{Fe}, \mathrm{Mn}$ e $\mathrm{Zn}$ nas folhas de várias culturas e no solo. $\mathrm{O}$ extrator Wolf-Morgan tem sido utilizado com êxito para a avaliação de $\mathrm{Al}, \mathrm{B}, \mathrm{Ca}, \mathrm{Cu}, \mathrm{F}$, $\mathrm{Fe}, \mathrm{K}, \mathrm{Mg}, \mathrm{Mn}, \mathrm{N}-\mathrm{NO}_{3}, \mathrm{~N}-\mathrm{NH}_{4}, \mathrm{P}, \mathrm{S}_{-} \mathrm{SO}_{4}$ e $\mathrm{Zn}$ em solos ácidos e neutros (Wolf, 1982; Jones Junior, 1990) e pelas suas características parece ser promissor para à avaliação de metais pesados em amostras de solos.

A utilização de uma mistura de bicarbonato de amônio $1 \mathrm{~mol} \mathrm{~L}^{-1}$ e ácido dietilenotriaminopentacético $0,005 \mathrm{~mol} \mathrm{~L}^{-1}$, em solução $\mathrm{pH} \mathrm{7,6}$ (AB-DTPA) foi proposta por Soltanpour \& Schwab (1977) para a extração de $\mathrm{NO}_{3}, \mathrm{P}, \mathrm{K}, \mathrm{Cu}, \mathrm{Fe}, \mathrm{Mn}$ e $\mathrm{Zn}$ em 
solos alcalinos. Posteriormente, este procedimento foi modificado por Soltanpour \& Workman (1979), através da remoção do carvão ativado, o qual adsorvia complexos metais-DTPA, o método passou a ser mais abrangente possibilitando a avaliação eficaz de $\mathrm{P}, \mathrm{K}, \mathrm{Cd}, \mathrm{Fe}, \mathrm{Mn}, \mathrm{Mo}, \mathrm{Ni}, \mathrm{Pb}$, Se e $\mathrm{Zn}$ (Soltanpour, 1985). Teoricamente este extrator, também, poderia avaliar o $\mathrm{S}, \mathrm{As}$ e $\mathrm{Cu}$ em condições normais e, o $\mathrm{B}$ em níveis tóxicos.

Soltanpour \& Schwab (1977) observaram boas correlações com valores obtidos com o extrator AB-DTPA e o padrão (Olsen para $\mathrm{P}$, acetato de amônio para $\mathrm{K}$ e DTPA para $\mathrm{Cu}, \mathrm{Fe}, \mathrm{Mn}$ e $\mathrm{Zn}$ ), embora os teores em si tenham sido diferentes, exceto o $\mathrm{K}$ e Fe que apresentaram valores semelhantes. O AB-DTPA não é adequado para a determinação de $\mathrm{Ca}$ e $\mathrm{Mg}$, uma vez que durante o processo de extração há liberação de $\mathrm{CO}_{2}$, o $\mathrm{pH}$ se eleva de 7,6 para aproximadamente 8,5, e conseqüentemente ocorre precipitação de carbonato de Ca e Mg (Soltanpour, 1985). Todavia, segundo Hanlon et al. (1996), o método não compromete a avaliação do $\mathrm{Mg}$, quando a sua determinação é realizada logo após a extração.

Hanlon et al. (1996) observaram que o extrator AB-DTPA apresentou resultados promissores quanto ao monitoramento de nutrientes e de metais pesados, em um solo calcário do sul da França, devido à aplicação de composto de resíduo urbano e de lodo de esgoto processados. Boon ${ }^{1}$ (1984) e Boon \& Soltanpour ${ }^{2}$ (1983), ambos citados por Soltanpour (1985) observaram correlação significativa entre os teores de $\mathrm{Cd}$, $\mathrm{Mo}, \mathrm{Ni}$ e $\mathrm{Pb}$ nas plantas com teores destes elementos extraídos do solo com AB-DTPA.

O extrator Mehlich-1 tem sido utilizado para a determinação de $\mathrm{P}, \mathrm{Ca}$, Mg, K, Cu, Mn, Na e Zn (Sims, 1989; Jones Junior, 1990). E como observado por Cantarella et al. (1995), este era o extrator mais empregado nos laboratórios de análise de solo no Brasil para a determinação de $\mathrm{B}, \mathrm{Co}, \mathrm{Cu}, \mathrm{Fe}, \mathrm{Mn}, \mathrm{Mo}$ e $\mathrm{Zn}$ em amostras de

${ }^{1}$ BOON, D.Y. The $\mathrm{NH}_{4} \mathrm{HCO}_{4}$-DTPA soil test for determination of plant available $\mathrm{Pb}, \mathrm{Cd}, \mathrm{Ni}$, and $\mathrm{Mo}$ in mine tailings and contaminated soils. Proc. of 6 th High Altitude Vegetation Conference. Colorado State Univ. Water Resources Res. Inst. Ft. Collins, CO, 1984.

${ }^{2}$ BOON, D.Y. \& Soltanpour, P.N. The $\mathrm{NH}_{4} \mathrm{HCO}_{4}$-DTPA soil test for determination of plant available lead, cadmium, and molybdenum in mine tailings and contaminated soils. Agronomy Abstracts, p.29, 1983. 
terra. Posteriormente, a utilização do extrator Mehlich-3 ampliou a possibilidade para determinação de P, Ca, Mg, K, B, Cu, Fe, Mn, Na e Zn (Mehlich, 1984; Jones Junior, 1990). Embora, este extrator tem sido utilizado sem grandes problemas para a avaliação do Ca (Mehlich, 1984), uma vez que a presença de $\mathrm{F}$ na sua composição dificulta a determinação de Ca nos extratos de solo (Hanlon \& Johnson, 1984).

Amaral Sobrinho et al. (1993) estudaram a eficiência de extração de $\mathrm{Cu}$, $\mathrm{Fe}, \mathrm{Mn}$, Ni e Zn pelos extratores Mehlich-1 e $\mathrm{Na}_{2}$-EDTA, em um latossolo vermelhoamarelo tratado com resíduo siderúrgico. $\mathrm{O}$ extrator Mehlich-1 apresentou maior capacidade extratora, exceto para o $\mathrm{Cu}$, que foi mais extraído pelo EDTA. Os teores de $\mathrm{Cu}$ e $\mathrm{Ni}$ extraídos com a solução Mehlich-1 foram altamente correlacionados com a concentração desses elementos na parte aérea de plantas de sorgo $(0,90$ e 0,81; respectivamente). Todavia, tal extrator se mostrou ineficiente para a avaliação da disponibilidade de Fe, Mn e Zn.

Com relação a determinação de macronutrientes, Hanlon \& Johnson (1984) obtiveram valores de $\mathrm{K}$ e Mg, extraídos por Mehlich-3 e AB-DTPA, comparáveis com o padrão acetato de amônio. Todavia, comparando os dois primeiros extratores, o Mehlich-3 proporcionou uma melhor eficiência analítica em termos da rapidez de análise. Os teores de $\mathrm{P}, \mathrm{Ca}, \mathrm{Mg}, \mathrm{K}, \mathrm{Cu}$ e $\mathrm{Zn}$ obtídos pelo extrator Mehlich-3 e Mehlich-1, em amostras de 400 solos da Planície litorânea do Atlântico dos EUA, foram altamente correlacionados entre si $(r=0,92$ a 0,97$)$, quando todos os dados foram considerados. Todavia, quando se excluíam teores altos, os coeficientes de correlação variaram de 0,67 a 0,90 (Sims, 1989). O extrator Mehlich-3 apresentou teores superiores de $\mathrm{P}, \mathrm{K}, \mathrm{Mn}, \mathrm{Cu}$ e $\mathrm{Zn}$.

Mamo et al. (1996), comparando a eficiência de vários extratores na avaliação da disponibilidade de $\mathrm{P}, \mathrm{Ca}, \mathrm{Mg}, \mathrm{K}$ e $\mathrm{Na}$ de solos da Etiópia e da Alemanha, tendo como referência o método de Olsen para $\mathrm{P}$ e o $\mathrm{NH}_{4} \mathrm{OAc} 1 \mathrm{~mol} \mathrm{~L}^{-1}$ para os cátions trocáveis, observaram que o Mehlich-3 proporcionou teores semelhantes de $\mathrm{K} \mathrm{e} \mathrm{Mg}$, e de $\mathrm{Ca}$ um pouco inferior, em ambos os grupos de solos. Os extratores de $\mathrm{P}$ apresentaram comportamento diferenciado em cada grupo de solo. Em solos alemães, o extrator Olsen parece não ser eficiente na avaliação de $\mathrm{P}$, sendo utilizado como referência o $\mathrm{P}$ extraído 
com uma solução lactato e acetato de cálcio. O extrator Mehlich-3 apresentou as melhores correlações, exceto para o Na. O extrator Mehlich-1 apresentou os menores teores para todo os elementos avaliados.

Outro extrator que vem sendo utilizado nos países europeus, é uma solução $\mathrm{CaCl}_{2}$ 0,01 mol L'-1 (Houba et al., 1986; Houba et al., 1990; Houba et al., 1992). Houba et al. (1990) propuseram a utilização de $\mathrm{CaCl}_{2}$, originalmente indicada para a determinação do pH do solo, como extrator multielemento do solo (P, Mg, K, Na, Zn, N$\mathrm{NO}_{3}, \mathrm{~N}_{-} \mathrm{NH}_{4}$ e $\mathrm{N}$ orgânico solúvel), objetivando em parte, conciliar a análise multielementar com a avaliação de frações do $\mathrm{N}$ do solo.

Houba et al. (1990) apresentaram as seguintes vantagens aa utilização do extrator $\mathrm{CaCl}_{2}$ : a) a concentração da solução é próxima a da solução do solo; b) sendo o $\mathrm{Ca}$ o cátion predominante do complexo de troca, uma solução relativamente diluída em Ca facilitaria a troca dos demais cátions; c) é possivel determinar diferentes frações do $\mathrm{N}$, incluindo o $\mathrm{N}$ orgânico solúvel, além dos principais cátions; d) facilidade na automação da determinação de diferentes parâmetros com um único extrator; e) a extração é adequada para a determinação de micronutrientes e de metais pesados, especialmente em estudo de poluição ambiental; f) é possível medir relevantes relações entre nutrientes; g) a análise química é acurada e reproduzível; e h) alta economia na quantidade de reagentes químicos usados nas análises em comparação com os métodos convencionais, o que também contribui para reduzir a poluição ambiental. A capacidade de medir o fator intensidade de disponibilidade elementos, faz da solução extratora $\mathrm{CaCl}_{2}, 0,01 \mathrm{~mol} \mathrm{~L}^{-1}$ ter grandes perspectivas para a diagnose de fitotoxicidade de um número significativo de metais pesados (Houba et al., 1990).

O potencial da solução $\mathrm{CaCl}_{2} 0,01 \mathrm{~mol} \mathrm{~L}^{-1}$ ser utilizada como extrator de elementos do solo para fins de avaliação da fertilidade do solo e da poluição ambiental, foi avaliado por Houba et al. (1990) em diversos solos do Quênia, Indonésia e Países Baixos. Os teores de $\mathrm{N}-\mathrm{NO}_{3}{ }^{-}$e de $\mathrm{N}-\mathrm{NH}_{4}{ }^{+}$, obtidos nos extratos de $\mathrm{CaCl}_{2}$, apresentaram boa correlação com o procedimento padrão (Eletro Ultra Filtração), além de permitiu a extração do $\mathrm{N}$ orgânico solúvel. $\mathrm{O}$ teor de $\mathrm{P}$, que apresentou boa correlação com a extração em água, obtido por este extrator avalia apenas o fator intensidade de P no solo, 
portanto, em solos tropicais (cujas intensidades de $\mathrm{P}$ é muito baixa), este procedimento não deve ser muito adequado. Os teores dos cátions $\mathrm{Mg}, \mathrm{K}$ e Na, também apresentaram muito boa correlação com o padrão acetato de amônio $1 \mathrm{~mol} \mathrm{~L}^{-1}$, todavia a quantidade extraída depende do tipo de solo, pois o extrator desloca apenas uma parte dos cátions trocáveis. Por exemplo, cerca de $90 \%$ do $\mathrm{K}$ é extraído em solos arenosos, enquanto solos argilosos apenas $40 \%$ é extraído.

Em 1994, foi apresentado por Sippola (1994) um novo extrator multielemento, uma solução de acetato de amônio-EDTA dissódico com pH 4,65 (AAEDTA. $\mathrm{Na}_{2}$ ), desenvolvida pelo Centro de Pesquisa Agrícola da Finlândia. Esta solução foi inicialmente proposta por Lakanen \& Erviö ${ }^{3}$ (1971), citados por Sippola (1994), e tem mostrado bons resultados para a avaliação de $\mathrm{P}, \mathrm{Ca}, \mathrm{Mg}, \mathrm{K}, \mathrm{Cd}, \mathrm{Co}, \mathrm{Cr}, \mathrm{Cu}, \mathrm{Fe}, \mathrm{Mn}$, $\mathrm{Mo}, \mathrm{Ni}, \mathrm{Pb}$ e $\mathrm{Zn}$ em solos não ácidos. Conforme o autor, este extrator parece ser adequado tanto para a recomendação de adubação, quanto para o monitoramento da qualidade do solo. Sippola (1994) relata que não foram observadas diferenças significativas entre os teores de macronutrientes obtidos pelo AC-EDTA e pelo padrão acetato de amônio, exceto para o $\mathrm{P}$, que foi de quatro a sete vezes maior no primeiro extrator, devido a sua maior eficiência em extrair o P ligado à fração orgânica.

O extrator DTPA tem sido satisfatoriamente empregado em solos tropicais para a extração de $\mathrm{Cu}, \mathrm{Fe}, \mathrm{Mn}$ e $\mathrm{Zn}$ do solo, notadamente em solos ácidos do Estado de São Paulo (Muraoka et al., 1983a, 1983b; Bataglia, \& Raij, 1989; Abreu \& Raij, 1996; Abreu et al., 1996), onde é método oficial, embora o método tenha sido originalmente estabelecido para solos alcalinos (Lindsay \& Norvell, 1978). O único inconveniente de sua utilização isolada, é a de não permitir a determinação simultânea dos macronutrientes.

O extrator DTPA, também, tem sido utilizado para a extração da metais pesados, tais como $\mathrm{Cd}, \mathrm{Cr}, \mathrm{Ni}$ e $\mathrm{Pb}$ (Street et al., 1977; Abreu et al., 1995). Foi constatado por Sommers \& Lindsay (1979) que o DTPA apresenta relações de equilíbrio

\footnotetext{
${ }^{3}$ LAKANEN, E. \& ERVIÖ, R. A comparison of eight extractants for the determination of plant available micronutrients in soils. Acta Agr. Fenn., v.123, p.223-232, 1971.
} 
que dão suporte teórico à sua potencialidade em extrair $\mathrm{Cd}, \mathrm{Ni}$ e $\mathrm{Pb}$ do solo, embora outros quelantes, tais como EDTA, EGTA e HEDTA, também o tenham apresentado.

Muraoka et al. (1983a, b) estudaram a eficiência de vários extratores ácidos $\left(\mathrm{H}_{2} \mathrm{SO}_{4} 0,05 \mathrm{~mol} \mathrm{~L}^{-1} ; \mathrm{HCl} 0,1 \mathrm{~mol} \mathrm{~L}^{-1}\right.$; ácido cítrico $0,05 \mathrm{~mol} \mathrm{~L}^{-1}$ e $0,5 \mathrm{~mol} \mathrm{~L}^{-1}$; com diferentes tempos de agitação) e salinos $\left(\mathrm{MgCl}_{2} 0,05 \mathrm{~mol} \mathrm{~L}{ }^{-1} ; \mathrm{CaCl}_{2} 0,05 \mathrm{~mol} \mathrm{~L}^{-1}\right.$; $\mathrm{CoSO}_{4}$ 0,5 mol L ; acetato de amônio $0,5 \mathrm{~mol} \mathrm{~L}^{-1}$; acetato de cálcio $0,5 \mathrm{~mol} \mathrm{~L}^{-1} \mathrm{e} \mathrm{KNO}_{3}$

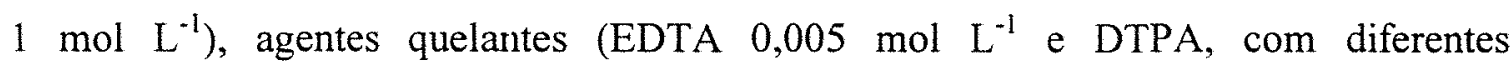
concentrações de $\mathrm{CaCl}_{2}$, tempos de agitação e modificações no $\mathrm{pH}$ das soluções) e água na avaliação da disponibilidade de $\mathrm{Mn}$ e $\mathrm{Zn}$ para a cultura do feijão, em diferentes solos do Estado de São Paulo. Para a avaliação da disponibilidade de $\mathrm{Mn}$, a solução de $\mathrm{CaCl}_{2}$ $0,5 \mathrm{~mol} \mathrm{~L}^{-1}$ foi a que mais se destacou e, o DTPA não apresentou resultados satisfatórios em alguns solos. O DTPA modificado com o pH ajustado de acordo com o do solo e o EDTA com $\mathrm{CaCl}_{2}$ e, também, com pH ajustado e, ambos com 60 minutos de agitação, foram os melhores para a avaliação da disponibilidade de $\mathrm{Zn}$. Os demais extratores, na sua maioria, praticamente não discriminaram o comportamento do $\mathrm{Mn}$ e $\mathrm{Zn}$ em função da reação do solo.

Bataglia, \& Raij (1989) comparam a eficiência de extração de $\mathrm{Cu}, \mathrm{Fe}, \mathrm{Mn}$

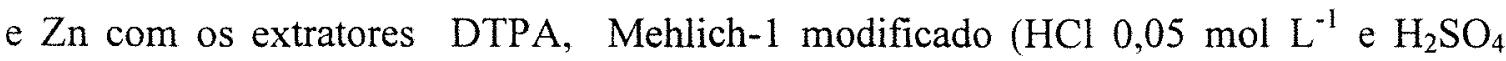
$\left.0,0125 \mathrm{~mol} \mathrm{~L}^{-1}\right), \mathrm{HCl} 0,1 \mathrm{~mol} \mathrm{~L}^{-1}$ e EDTA $0,1 \mathrm{~mol} \mathrm{~L}^{-1}$, em 26 solos de SP, e observaram que os extratores ácidos extraíram mais $\mathrm{Zn}$ e menos $\mathrm{Cu}, \mathrm{Fe}$ e $\mathrm{Mn}$ do que os complexantes. O EDTA teve um comportamento diferenciado dos demais extratores, extraindo maior quantidade de $\mathrm{Cu}, \mathrm{Fe}$ e $\mathrm{Mn}$. Embora os extratores DTPA, Mehlich e $\mathrm{HCl}$ tenham proporcionado teores médios próximos e todos os extratores foram igualmente eficientes, notadamente na avaliação do $\mathrm{Zn}$, os autores indicaram o $\mathrm{HCl}$ e o DTPA como os mais adequados, o primeiro pela simplicidade e o segundo pela capacidade de discriminação dos elementos em relação à acidez do solo.

Abreu \& Raij (1996) constataram, também, a capacidade do DTPA em discriminar a disponibilidade do $\mathrm{Zn}$ conforme a com a reação do solo. Todavia, o teor de Zn obtido pelo DTPA foi menor do que aquele proporcionado pelo Mehlich-1. Com relação ao $\mathrm{Cu}$, foi reportado por Abreu et al. (1996) que o extrator Mehlich-3 apresentou 
maior extração deste micronutriente (de 0,9 a $36,8 \mathrm{mg} \mathrm{dm}^{-3}$ antes da calagem e de 0,7 a $44,2 \mathrm{mg} \mathrm{dm}^{-3}$ depois da calagem), o DTPA apresentou teores medianos (0,4 a 29,9 mg $\mathrm{dm}^{-3}$ antes da calagem e de 0,3 a $29,5 \mathrm{mg} \mathrm{dm}^{-3}$ depois da calagem) e o Mehlich-1 teores bem inferiores $\left(0,3\right.$ a $10,1 \mathrm{mg} \mathrm{dm}^{-3}$ antes da calagem e de 0,2 a $5,5 \mathrm{mg} \mathrm{dm}^{-3}$ depois da calagem). Deve-se salientar, porém, que a capacidade de extração não significa a eficácia em predizer a disponibilidade de um nutriente.

Bingham et al. (1975), aplicando lodo de esgoto enriquecido com doses de 0 a $640 \mathrm{mg} \mathrm{kg}^{-1}$ de $\mathrm{CdSO}_{4}$ ao solo, observaram correlação altamente significativa entre o teor de Cd no solo extraído com DTPA e as doses aplicadas. Silveira \& Sommers (1977) observaram que enquanto a proporção de $\mathrm{Cu}, \mathrm{Zn}$ e Cd extraído com DTPA aumentava com o tempo de incubação, o teor de $\mathrm{Pb}$ permanecia constante. Também, foi observado que as proporções relativas destes metais no solo extraídos com $\mathrm{HNO}_{3}$ e DTPA variavam inversamente entre si.

De acordo com Maclean \& Dekker (1976), o DTPA não apresentou boa extração de $\mathrm{Pb}$ em amostra de solo contendo resíduo ácido de descarte de mineração (pH entre 2,5 a 3,3), possivelmente devido à imobilização na forma de $\mathrm{PbFe}_{6}\left(\mathrm{SO}_{4}\right)_{4}(\mathrm{OH})_{12}$.

Em um experimento de casa de vegetação com lodo de esgoto marcado com $\mathrm{CdSO}_{4}$, Street et al. (1977) encontraram correlação significativa entre o teor de $\mathrm{Cd}$ no solo, extraído com DTPA e, a concentração deste elemento em plântulas de milho ( $\mathrm{r}$ $=0,96)$. O DTPA, também, se mostrou como o mais eficiente para a predição de $\mathrm{Cu}$ para a cultura de cevada (Singh et al., 1986).

Lee \& Zheng (1994), compararam a eficiência dos extratores $\mathrm{HCl} 0,1$ mol L ${ }^{-1} ; \mathrm{CaCl}_{2}$ 0,01 mol L-1; DTPA-pH 7,3 e DTPA-pH 5,3 com uma membrana de resina quelante de metais na avaliação da disponibilidade de $\mathrm{Cd}, \mathrm{Cu}$ e $\mathrm{Pb}$, de solos contaminados, para plântulas de trigo, observaram que as correlações entre absorção e extração de $\mathrm{Cd}, \mathrm{Cu}$ e $\mathrm{Pb}$ foram significativas ao nível de $1 \%$ para todos os extratores, exceto para o $\mathrm{Pb}$ extraído com $\mathrm{CaCl}_{2}$. O melhor extrator para a avaliação de $\mathrm{Cd}$ foi $\mathrm{o}$ $\mathrm{CaCl}_{2}(\mathrm{r}=0,93)$, de $\mathrm{Cu}$ foi a resina quelante $(0,82)$ e para o $\mathrm{Pb}$ foi o DTPA-pH 5,3 $(\mathrm{r}=0,99)$ e DTPA-pH 7,3 $(\mathrm{r}=0,98)$. 
Em um estudo sobre a eficiência dos extratores Mehlich-1, Mehlich-3 e DTPA na avaliação da disponibilidade de metais em solos representativos do Estado de São Paulo, foi observado por Abreu et al. (1995) que o extrator Mehlich-3 extraiu quantidades bem superiores de $\mathrm{Cd}, \mathrm{Cr}$, Ni e $\mathrm{Zn}$. O DTPA não foi capaz de discriminar a disponibilidade destes metais em relação à reação do solo, diferindo, nesse caso, do comportamento que normalmente tem sido observado com os micronutrientes. Os extratores foram ineficientes para avaliar a disponibilidade de $\mathrm{Cd}, \mathrm{Cr}, \mathrm{Ni}$ e $\mathrm{Pb}$ para plantas de trigo e de $\mathrm{Pb}$ e $\mathrm{Cd}$ para plantas de feijão. Tal fato, foi atribuído como sendo conseqüência dos baixos teores destes metais no solo.

De acordo com Raij (1994) há uma certa limitação na maioria dos estudos de extratores multielementos do solo. Grande parte dos trabalhos com Mehlich-3 e ABDTPA são feitas regressões dos dados obtidos em amostras de diferentes solos, considerando geralmente uma faixa de valores muito além das de interesse nas análises de solo, o que resultaria em coeficientes de correlação altos. Tem-se dado muita ênfase no aspecto analítico dos métodos, contudo sem se considerar os aspectos agronômicos, sendo poucos os estudos onde se correlacionam os teores dos elementos no solo, obtidos pelos extratores, com a extração destes elementos pelas plantas.

\subsection{Espectrometria de emiss ão atômica com plasma acoplado indutivamente}

A técnica de espectrometria de emissão atômica com plasma acoplado indutivamente, ou ICP-AES (do inglês "inductively coupled plasma atomic emission spectrometry) vem sendo utilizada com sucesso na análise multielementar nas mais diversas áreas, e tem se mostrado de grande aplicabilidade em análises de interesse agronômico. Conforme apresentado por Malavolta et al. (1997), é possível se determinar os teores de $\mathrm{P}, \mathrm{Ca}, \mathrm{Mg}, \mathrm{B}, \mathrm{Cu}, \mathrm{Fe}, \mathrm{Mn}, \mathrm{Zn}$ e $\mathrm{Al}$ com boa precisão e exatidão em apenas um minuto e em $1 \mathrm{~mL}$ de amostra de planta.

Conforme descrito por Conte (1995) e Giné (1998), o plasma pode ser definido como gases que possuem uma fração significativa de seus átomos ou moléculas no estado ionizado em movimento. Para a formação do plasma, o gás argônio é 
direcionado através de uma tocha de quartzo conforme indicado na Figura 1. Há uma bobina de cobre refrigerada a água (chamada de bobina de carga) que circunda a extremidade superior da tocha e é conectada a um gerador de rádio-freqüência. Quando a potência de rádio-freqüência (tipicamente 700 a $1.500 \mathrm{~W}$ ) é aplicada à bobina de carga, uma corrente oscila com uma freqüência correspondente à freqüência do gerador (em geral 27 ou $40 \mathrm{MHz}$ ). Estas correntes de rádio-freqüência oscilantes geram campos eletromagnéticos cujas linhas de força são orientadas axialmente dentro da bobina de carga. Com o gás argônio sendo suprido continuamente através da tocha uma faísca é aplicada ao gás fazendo com que alguns elétrons sejam ejetados dos átomos de argônio (ionização do argônio). Estes elétrons são capturados pelo campo magnético e acelerados por ele. O fornecimento de energia aos elétrons através de uma bobina, da forma descrita acima, é conhecida como acoplamento indutivo. Os elétrons com alta energia por sua vez colidem com outros átomos de argônio, ejetando mais elétrons. Os campos magnéticos axiais induzidos forçam as partículas (elétrons e íons) a fluírem em órbitas anulares fechadas. Os elétrons e íons encontram resistência ao seu fluxo, a geração de calor ôhmico ou por efeito Joule é uma conseqüência natural e a ionização do gás argônio continua numa reação em cadeia, quebrando o gás em um plasma constituído em átomos de argônio, elétrons e ions de argônio, formando o que é conhecido como uma descarga de plasma acoplado indutivamente, ou do inglês "inductively compled plasma" (ICP).

A descarga de um ICP aparece como uma descarga em forma de lágrima. brilhante e intensa. Um plasma formado desta maneira atinge temperaturas entre $500 \mathrm{e}$ $10.000 \mathrm{~K}$, portanto é necessária alguma isolação térmica para o tubo de quartzo. Esta isolação térmica é feita através da técnica de estabilização de vórtices de Reed, que usa um fluxo de argônio introduzido tangencialmente (Figura 2). O fluxo de argônio tangencial, que é superior a $12 \mathrm{~L} \mathrm{~min}^{-1}$, flui de baixo para cima, resfriando o tubo de quartzo na seção anular externa e centrando o plasma radialmente no tubo, e também atuando como fluxo de sustentação primário. O plasma propriamente dito é ancorado perto da extremidade de saída do arranjo de tubos concêntricos. $\mathrm{Na}$ seção anular intermediária entra o gás auxiliar $\left(1\right.$ a $\left.2 \mathrm{~L} \mathrm{~min}^{-1}\right)$ necessário para a estabilização do 
plasma. Outro fluxo de argônio, na seção interna ou tubo injetor, menor que $1 \mathrm{~L} \mathrm{~min}{ }^{-1}$, transporta a amostra como um aerossol por arraste até o plasma (Conte, 1995; Giné, 1998).

Após a introdução da amostra no plasma, seus átomos são excitados e emitem espectros de radiações característicos de cada átomo, que são detectados por um espectrômetro ótico. O espectrômetro é formado por um conjunto de lentes, espelhos, rede de difração e detectores (válvulas fotomultiplicadoras), que pode ser do tipo monocromador ou policromador e, cuja função é selecionar a linha espectral do elemento de interesse com o mínimo de interferência. Os detectores são os responsáveis pela quantificação dos elementos através da conversão dos sinais óticos em sinais elétricos proporcionais aos teores dos elementos na amostra (Malavolta et al., 1997; Giné, 1998).

A principal precaução de se deve ter com esta técnica, é a de se evitar possíveis interferências espectrais e de matriz, que podem ocorrer e causar graves erros se não forem tomadas as devidas medidas de correção. Soltanpour et al. (1982) e Malavolta et al. (1997) comentaram que as determinações de P, Ca, Mg, Al, B, Cu, Fe, $\mathrm{Mn}$ e $\mathrm{Zn}$ em extratos de solos e de plantas são relativamente simples. A determinação de Mo pode ser problemática devido às interferências espectrais e limite de detecção. Todavia, a análise total por ICP-AES de extratos de solo, consequentemente de outros materiais complexos, é complicada devido às elevadas concentrações de $\mathrm{Fe}, \mathrm{Al}, \mathrm{Ti}$, entre outros elementos que interferem de sobremaneira na determinação dos outros elementos de interesse em menor concentração (Soltanpour et al., 1982).

Soltanpour et al. (1979), utilizando o extrator AB-DTPA, observou que os teores de $\mathrm{K}, \mathrm{Cu}, \mathrm{Fe}, \mathrm{Mn}$ e $\mathrm{Zn}$ determinados por ICP-AES eram comparáveis a dos obtidos por espectrometria de absorção atômica, enquanto que o teor de $\mathrm{P}$ determinado por ICP-AES foi maior que o método colorimétrico, provavelmente devido à presença de $\mathrm{P}$ orgânico nos extratos e, cujas as formas não são determinadas pelos métodos colorimétricos. 


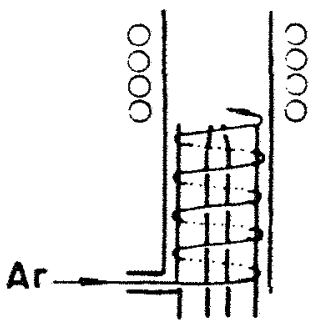

A

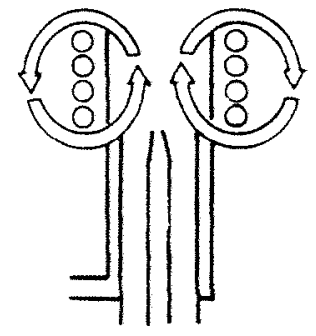

B

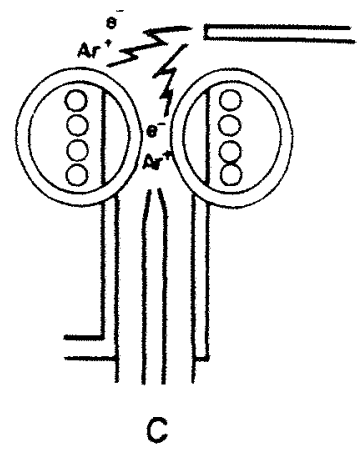

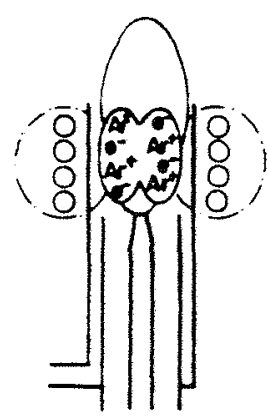

D

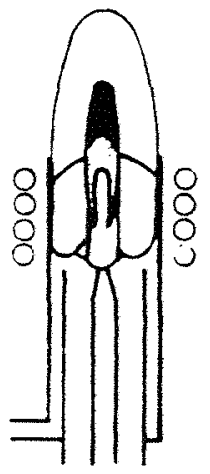

E

Figura 1. Secção transversal de uma tocha ICP de quartzo e da bobina de carga mostrando uma sequiência de ignição: (A) o argônio é circulado através da tocha; (b) potência RF é aplicada à bobina de carga; (C) uma faísca produz alguns elétrons livre no argônio: (D) os elétrons livres são acelerados por campos magnéticos, ocasionando ionização e a posterior formação do plasma; e em (E) o fluxo do nebulizador conduzindo o aerossol da amostra faz um buraco no plasma.

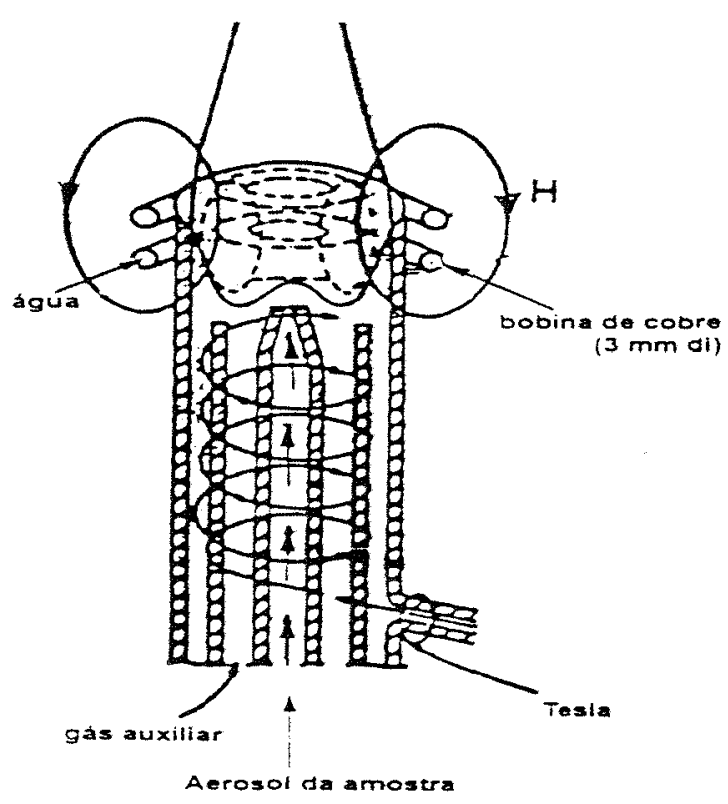

Figura 2. Esquema de montagem da tocha de quartzo e espiral de indução do plasma. 


\section{MATERIAL E MÉTOD OS}

Foram conduzidos dois experimentos em condições de casa de vegetação, no Centro de Energia Nuclear na Agricultura, (CENA/USP), em Piracicaba, Estado de São Paulo. O experimento I teve por objetivo o estudo dos efeitos da aplicação de composto de resíduo urbano (que será denominado apenas de composto), na presença e ausência de calagem e adubação sobre as propriedades químicas, nutrição e produção de matéria seca pela cultura de arroz. O experimento II teve por objetivo se avaliar o efeito do enriquecimento do composto com $\mathrm{Cd}, \mathrm{Cu}, \mathrm{Mn}, \mathrm{Pb}$ e $\mathrm{Zn}$ sobre a disponibilidade desses metais no solo, nutrição e produção de matéria seca de plantas de arroz. E, em ambos os experimentos, foi avaliado o potencial de análise multielementar de vários extratores empregados na análise química de solos por espectrometria de emissão atômica com plasma acoplado indutivamente (ICP-AES).

\subsection{Solos utilizados}

Experimento I: foram utilizados 26 solos, sendo 21 solos ácidos e 5 solos alcalinos, englobando 4 solos calcários e 1 solo salino-sódico, de diferentes Estados do Brasil.

Experimento II: foram selecionados sete solos (PE, LRa, PV-3, LV-1, LA-5, LA-6 e SS) cujas as características químicas se revelaram mais distintas.

A sigla, classificação e localização dos diferentes solos utilizados nos experimentos I e II são apresentadas na Tabela 2. A amostra do solo TR-2 foi coletada na ESALQ/USP, a do PE na estação experimental do IAC, em Piracicaba, SP, a da AQa em São Pedro e o LRa em Guatapará, próximo à cidade de Ribeirão Preto, os demais 
Tabela 2. Sigla, classificação e localização dos solos utilizados nos experimentos I e II.

\begin{tabular}{|c|c|c|c|}
\hline Sigla & Solo & Município & Estado \\
\hline \multicolumn{4}{|c|}{ Solos ácidos } \\
\hline GPH & Glei Pouco Húmico & Iranduba & AM \\
\hline AQd & Areia Quartzosa, distrófica & Paraipabas & $\mathrm{CE}$ \\
\hline LUa & Latossolo Variação Una, ácrico, A moderado, textura muito argilosa & Viçosa & MG \\
\hline LE-1 & Latossolo Vermelho-Escuro textura argilosa & Três Lagoas & MS \\
\hline LE-2 & Latossolo Vermelho-Escuro textura muito argilosa & Cuiabá & MT \\
\hline LA-1 & Latossolo Amarelo álico, caulinítico, A moderado, textura argilosa & Capitão Poço & PA \\
\hline PV-1 & $\begin{array}{l}\text { Podzólico Vermelho-Amarelo álico, caulinítico, A moderado, } \\
\text { textura média/argilosa }\end{array}$ & Capitão Poço & PA \\
\hline LA-2 & Latossolo Amarelo álico, A moderado, textura muito argilosa & Ipixuna & PA \\
\hline LA-3 & Latossolo Amarelo, álico, A moderado, textura média & Ipixuna & PA \\
\hline TR-1 & Terra Roxa Estruturada, textura muito argilosa & Maringá & PR \\
\hline LA -4 & Latossolo Amarelo textura média & Ariquemes & RO \\
\hline PV-2 & Podzólico Vermelho-Amarelo, textura média/argilosa & Ariquemes & RO \\
\hline LA-5 & Latossolo Amarelo, textura argilosa & não identificado & $\mathrm{SC}$ \\
\hline PV -3 & Podzólico Vermelho-Amarelo, álico, textura média/argilosa & Capão Bonito & $\mathrm{SP}$ \\
\hline LRa & Latossolo Roxo, ácrico, textura muito argilosa & Guatapará & $\mathrm{SP}$ \\
\hline LE-3 & Latossolo Vermelho-Escuro, textura argilosa & Piracicaba & SP \\
\hline PE & Podzólico Vermelho-Escuro, textura argilosa & Piracicaba & $\mathrm{SP}$ \\
\hline PV-4 & Podzólico Vermelho-Amarelo, distrófico, textura média/argilosa & Piracicaba & $\mathrm{SP}$ \\
\hline TR-2 & Terra Roxa Estruturada, textura argilosa & Piracicaba & SP \\
\hline AQa & Areia Quartzosa, álica & São Pedro & SP \\
\hline LV-1 & Latossolo Vermelho-Amarelo, álico A proeminente, textura média & Três Barras & SP \\
\hline \multicolumn{4}{|c|}{ Solos calcários } \\
\hline $\mathrm{CL}$ & Cambissolo Latossólico, textura muito argilosa & Irecê & BA \\
\hline $\mathrm{CV}$ & Cambissolo Vértico, textura muito argilosa & Irecê & $\mathrm{BA}$ \\
\hline LA-6 & Latossolo Amarelo, textura argilosa & Irecê & $\mathrm{BA}$ \\
\hline LV -2 & Latossolo Vermelho-Amarelo, textura argilosa & Irecê & $\mathrm{BA}$ \\
\hline \multicolumn{4}{|c|}{ Solos salinos-sódicos } \\
\hline SS & Salino-Sódico & Souza & PB \\
\hline
\end{tabular}


solos pertenciam à coleção de solos do Laboratório de Fertilidade do Solo, CENA/USP. As respectivas amostras foram coletadas na camada superficial de 0 a $20 \mathrm{~cm}$ de profundidade, secas ao ar, passadas em peneiras de $2 \mathrm{~mm}$ de malha, homogeneizadas e armazenadas em sacos plástico. Subseqüentemente foram retiradas três subamostras representativas de cada solo para a caracterização química.

\subsection{Composto de Resíduo U rbano}

O composto de resíduo urbano foi coletado na usina de compostagem São Matheus, da cidade de São Paulo (Figura 3). Por ocasião da coleta do composto, foram tomadas três amostras da parte mais externa para a parte mais interna da pilha de compostagem, de aproximadamente 60 litros cada uma, as quais foram designadas por amostra 1, amostra 2 e amostra 3, respectivamente. As amostras foram secas ao ar e passadas em peneira de $4 \mathrm{~mm}$ (fração $<4 \mathrm{~mm}$ ), sendo estimado a umidade e a relação entre a fração $<4 \mathrm{~mm}$ e o composto bruto.

Após a retirada de três subamostras, de cada uma das amostras do composto, para a caracterização química, todo o material $<4 \mathrm{~mm}$ foi homogeneizado e armazenado para ser utilizado nos experimentos.

\subsubsection{Informações adicionais s obre o processo de obtenção do composto na usina}

Em visita realizada à usina de compostagem, por ocasião da coleta do composto, observou-se que o lixo urbano é recebido em uma esteira rolante horizontal, passando por um processo de catação manual do material mais grosseiro (madeira, metal, plástico, vidro, etc.), seguido de passagem por um eletroímã, moagem, peneiragem e compostagem. De acordo com Kiehl (1985), a usina São Matheus emprega o processo DANO de compostagem, tendo como equipamento principal um bioestabilizador. Para a obtenção de um composto de boa qualidade o material deveria ser compostado por um período de 60 a 120 dias (Kiehl, 1985). Porém, pôde-se observar que, devido à grande demanda, o material distribuido ao consumidor era um 
composto cru. Fato semelhante, também foi relatado por Cravo (1995). O composto, utilizado nesse trabalho, foi obtido a partir de uma leira com cerca de quatro meses de compostagem e que se destinava à Prefeitura de São Paulo.

\subsection{Experimento I}

\subsubsection{Arranjo dos tratamentos e delineamento experimental}

Os tratamentos primários (denominados apenas de solos) foram constituídos pelos diferentes solos e os tratamentos secundários (denominados apenas de tratamentos), para os solos ácidos, foram baseados na aplicação do composto de resíduo urbano com e sem calagem e adubação mineral, somente calagem com adubação e uma testemunha (Tabela 3), enquanto que para os solos alcalinos, a calagem foi substituída pela aplicação de gesso natural (Tabela 4). O experimento foi instalado em um delineamento em blocos, com os solos em faixas e os tratamentos nas subparcelas com 3 repetições, de modo independente para solos ácidos e calcários.

Tabela 3. Tratamentos secundários aplicados nos solos ácidos do experimento I.

\begin{tabular}{lccc}
\hline Subtratamentos & Composto de resíduo urbano & Adubação química & Calcário dolomítico \\
\hline T1 (C) & $60 \mathrm{t} \mathrm{ha}^{-1}$ (peso seco) & Ausente & Ausente \\
T2 $(\mathrm{C}+\mathrm{A})$ & $60 \mathrm{t} \mathrm{ha}^{-1}$ & N-P-K-S-B-Cu-Fe-Mn-Mo-Zn & Ausente \\
$\mathrm{T} 3(\mathrm{C}+\mathrm{C})$ & $60 \mathrm{t} \mathrm{ha}^{-1}$ & Ausente & saturação por bases a 70\% \\
$\mathrm{T} 4(\mathrm{C}+\mathrm{C}+\mathrm{A})$ & $60 \mathrm{t} \mathrm{ha}^{-1}$ & N-P-K-S-B-Cu-Fe-Mn-Mo-Zn & saturação por bases a 70\% \\
$\mathrm{T} 5(\mathrm{~A}+\mathrm{C})$ & Ausente & N-P-K-S-B-Cu-Fe-Mn-Mo-Zn & saturação por bases a 70\% \\
$\mathrm{T} 6(\mathrm{~T})$ & Ausente & Ausente & Ausente \\
\hline
\end{tabular}



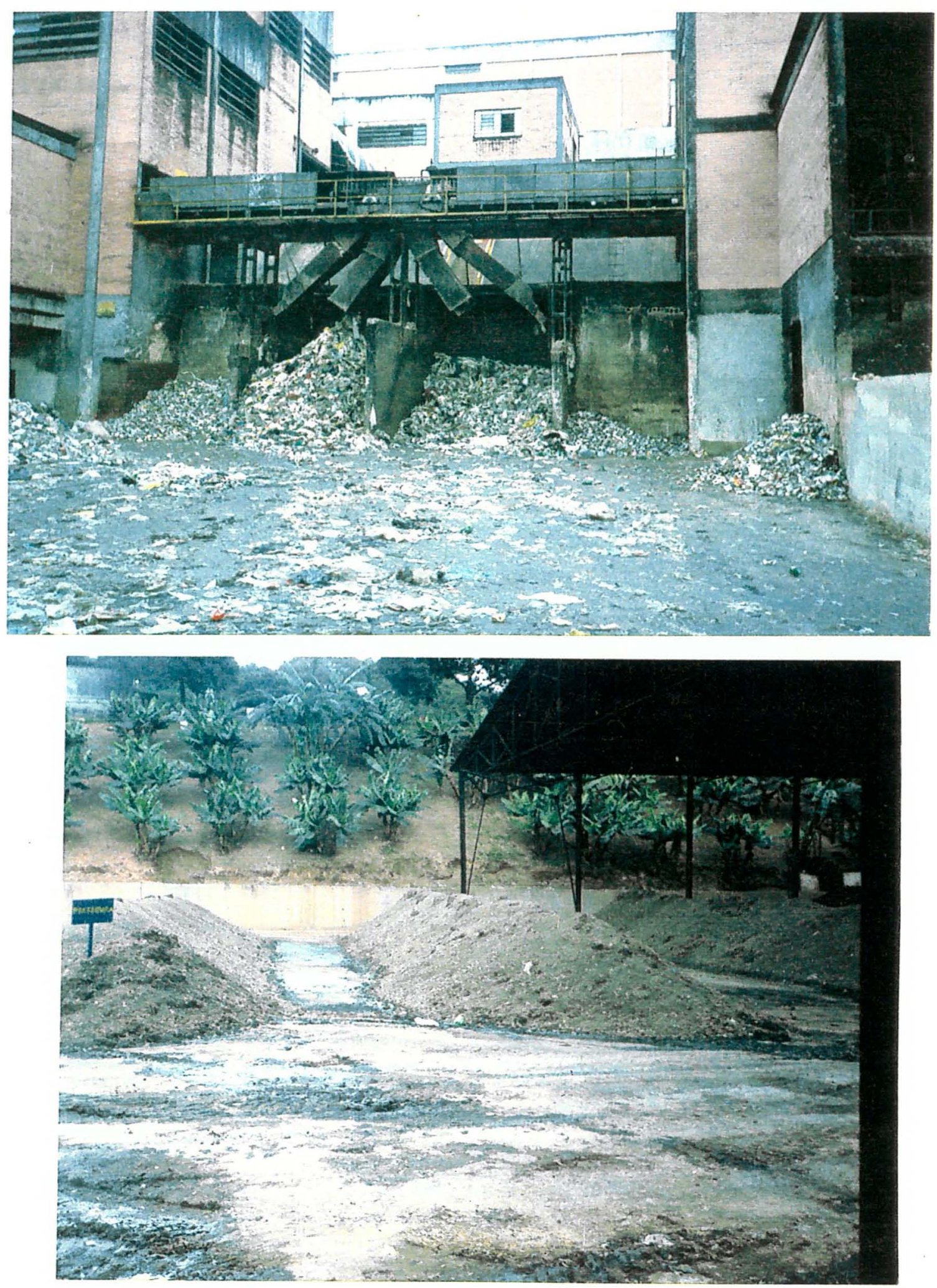

Figura 3. Visão geral da usina de compostagem São Matheus, da cidade de São Paulo, e das pilhas de compostagem. 
Tabela 4. Tratamentos secundários aplicados nos solos alcalinos do experimento I.

\begin{tabular}{lccc}
\hline Subtratamentos & Composto de resíduo urbano & Adubação química & Gessagem \\
\hline T1 $(\mathrm{C})$ & $60 \mathrm{t} \mathrm{ha}^{-1}$ (peso seco) & Ausente & Ausente \\
$\mathrm{T} 2(\mathrm{C}+\mathrm{A})$ & $60 \mathrm{t} \mathrm{ha}^{-1}$ & N-P-K-S-B-Cu-Fe-Mn-Mo-Zn & Ausente \\
$\mathrm{T} 3(\mathrm{C}+\mathrm{G})$ & $60 \mathrm{t} \mathrm{ha}^{-1}$ & Ausente & Gesso natural $6 \mathrm{tha}^{-1}$ \\
$\mathrm{~T} 4(\mathrm{C}+\mathrm{G}+\mathrm{A})$ & $60 \mathrm{t} \mathrm{ha}^{-1}$ & N-P-K-S-B-Cu-Fe-Mn-Mo-Zn & Gesso natural $6 \mathrm{t} \mathrm{ha}^{-1}$ \\
$\mathrm{~T} 5(\mathrm{~A}+\mathrm{G})$ & Ausente & N-P-K-S-B-Cu-Fe-Mn-Mo-Zn & Gesso natural $6 \mathrm{t} \mathrm{ha}^{-1}$ \\
$\mathrm{~T} 6(\mathrm{~T})$ & Ausente & Ausente & Ausente \\
\hline
\end{tabular}

\subsubsection{Condução do experimen to I}

O experimento foi conduzido em condições de casa de vegetação, no Centro de Energia Nuclear na Agricultura (CENA/USP), em Piracicaba, SP. No primeiro cultivo foram utilizados vasos plásticos revestidos com sacos plásticos, nos quais foram adicionados $1,1 \mathrm{dm}^{3}$ de terra e uma quantidade de calcário dolomítico suficiente para elevar a saturação por bases a $70 \%$, de acordo com análise química nas amostras iniciais (Tabela 10), nos respectivos tratamentos. O solo salino-sódico e os solos calcário receberam $3 \mathrm{~g} \mathrm{dm}^{-3}\left(6 \mathrm{tha}^{-1}\right)$ de gesso natural, em substituição à calagem. Após a mistura do calcário com o solo, foi adicionado em todos os vasos, água destiladadeionizada suficiente para manter a umidade em torno de $60 \%$ da capacidade de retenção de água (CRA) do solo, mantendo-se as mesmas condições em todos os tratamentos. Para se estimar a CRA de cada solo, foi tomada uma amostra de $100 \mathrm{~cm}^{3}$ de terra em copo plástico tarado, cuja a base havia sido perfurada com uma agulha fina, e colocado sobre uma placa de vidro contendo água destilada, permitindo-se que houvesse saturação da terra por água. Após a saturação, colocou-se o copo sobre uma peneira e permitiu-se que houvesse drenagem da água retida, por uma noite, anotando-se o peso do conjunto terra + água retida + copo. Assim, a CRA foi calculada através da fórmula:

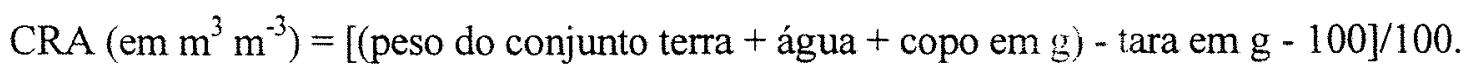


Através de uma ou duas pesagem diária, durante o período de rega, se completava o peso com água destilada-deionizada de acordo com o solo e tratamento. Com o desenvolvimento das plantas, dependendo do subtratamento, tal processo se tornou mais complicado. Todavia, como a pesagem era realizada pela manhã e o vaso se encontrava com menor umidade, adicionava-se uma quantidade de água relacionada com $60 \%$ da CRA e se recalculava a quantidade de água a ser adicionado por subtratamento. Desta forma foi evitado o encharcamento da terra e possivveis condições anaeróbias.

Os solos foram incubados por 30 dias para permitir a correção da reação do solo. Após o que, os vasos ficaram sem receber água até secarem. Foi, entăo, misturado ao solo, o composto de resíduo urbano $\left(60 \mathrm{t} \mathrm{ha}^{-1}\right.$, ou seja $30 \mathrm{~g} \mathrm{dm}^{-3}$ na base de peso seco ao ar) e os adubos contendo macro e micronutrientes, conforme o respectivo tratamento. O N, P e K foram aplicados nas doses de 100,150 e $100 \mathrm{mg} \mathrm{dm}^{-3}$ (equivalente a 200,300 e $200 \mathrm{~kg} \mathrm{ha}^{-\mathrm{t}}$ ) e nas formas de uréia, superfosfato simples (adição simultânea de $\mathrm{S}$ ) e cloreto de potássio, respectivamente. O B, Cu, Fe, Mn, Mo e $\mathrm{Zn}$ foram aplicados nas doses de $1 ; 1 ; 3,2,5 ; 0,05$ e $2,5 \mathrm{mg} \mathrm{dm}^{-3}$ (equivalente a 2, 2, 6, 5, 0,1 e $5 \mathrm{~kg} \mathrm{ha}^{-1}$ ), respectivamente, na forma de solução nutritiva. Novamente, os vasos receberam água destilada-deionizada suficiente para manter a umidade em cerca de $60 \%$ da CRA, sendo as amostras dos solos incubadas por mais 30 dias, para permitir a decomposição e estabilização do material orgânico adicionado ao solo.

Após o término deste novo período de incubação, se interrompeu a rega dos vasos para permitir uma certa secagem da terra, sendo retirada uma amostra de cada vaso, aproximadamente $130 \mathrm{~cm}^{3}$, e procedeu-se, então, a semeadura de arroz, na proporção de doze sementes por vaso. Uma semana após a germinação as plantas foram desbastadas, deixando-se sete plantas por vaso, que foram cultivadas por cerca de 60 dias. No final deste período, foi coletada a parte aérea de todas as plantas, para avaliação da absorção e concentração de nutrientes e metais pesados. As regas foram suspensas e as raizes mantidas nos vasos. No início de dezembro de 1997 (60 dias após a germinação), foram cortadas, lavadas e levadas para secagem em estufa a $60{ }^{\circ} \mathrm{C}$ a parte aérea de todas as plantas. As regas foram suspensas e as raizes mantidas nos vasos e coletadas posteriormente. Para a coleta das raízes, foi retirado o conjunto terra + saco 
plástico de cada vaso, a terra seca foi destorroada mecanicamente com o auxílio de um batedor de madeira. As raízes maiores foram separadas manualmente e as menores através de peneiração. As raízes foram lavadas em água de torneira, solução de ácido clorídrico a $10 \%(\mathrm{v} / \mathrm{v})$, água destilada-deionizada e secas em estufa a $60{ }^{\circ} \mathrm{C}$ e pesadas. Esta etapa foi lenta e morosa, exigindo cuidados, todavia permitiu boa recuperação das raízes e pouca perda de terra, que necessita ser muito bem aproveitada. Na terra passada por peneira de $2 \mathrm{~mm}$ de abertura, retornada para um saco plástico novo, foi retirada uma amostra de cerca de $100 \mathrm{~cm}^{3}$ (amostra menor que da $1^{\mathrm{a}}$ amostragem, pois esta última se encontrava com uma granulometria menor) após uma nova adubação de acordo com o respectivo subtratamento e homogeneização através de revolvimento do saco plástico.

No final de março de 1998, após a $2^{\mathrm{a}}$ amostragem de terra e perfuração dos sacos plásticos pela parte inferior dos vasos, foi feita a semeadura do $2^{\circ}$ cultivo de arroz. A germinação ocorreu no início de abril e a colheita foi realizada 60 dias após a germinação.

\subsection{Experimento II}

\subsubsection{Arranjo dos tratamentos e delineamento experimental}

Nos solos PE, LRa, PV-3, LV-1, LA-5, LA-6 e SS foram aplicados subtratamentos com composto de resíduo urbano enriquecido com $\mathrm{Cd}, \mathrm{Cu}, \mathrm{Mn}, \mathrm{Pb}$ e $\mathrm{Zn}$ de acordo com a Tabela 5. Analogamente ao experimento I, os tratamentos primários foram constituídos pelos solos e os tratamentos secundários pelas doses de enriquecimento do composto. As doses de enriquecimento do composto com $\mathrm{Cd}, \mathrm{Cu}$, $\mathrm{Mn}, \mathrm{Pb}$ e $\mathrm{Zn}$ foram estabelecidas de acordo com sugestões de Melo. ${ }^{4} \mathrm{O}$ experimento II, também, foi instalado em um delineamento em blocos ao acaso com os subtratamentos aleatorizados em faixas subdivididas, com 3 repetições.

\footnotetext{
${ }^{4}$ Melo, W.J. (Faculdade de Ciências Agrárias e Veterinárias, UNESP de Jaboticabal). Comunicação pessoal, 1997.
} 
Tabela 5. Quantidade de metais pesados adicionados ao solo através do composto enriquecido no experimento II.

\begin{tabular}{cccccc}
\hline \multirow{2}{*}{$\begin{array}{c}\text { Tratamentos } \\
\text { secundários }\end{array}$} & \multicolumn{5}{c}{ Quantidade de metais pesados adicionados ao solo } \\
\cline { 2 - 6 } & $\mathrm{Cd}$ & $\mathrm{Cu}$ & $\mathrm{Mn}$ & $\mathrm{Pb}$ & $\mathrm{Zn}$ \\
\hline & 0 & 0 & 0 & 0 & 0 \\
$\mathrm{~S} 0$ & 15 & 15 & 15 & 15 & 15 \\
$\mathrm{~S} 1$ & 30 & 30 & 30 & 30 \\
$\mathrm{~S} 2$ & 60 & 60 & 60 & 60 & 60 \\
S3 & 120 & 120 & 120 & 120 \\
S4 & 120 & 120 & 240 & 240 & 240 \\
S5 & 240 & 240 & & & \\
\hline
\end{tabular}

\subsubsection{Condução do experimen to II}

O experimento II foi conduzido de modo semelhante ao experimento I. Para o enriquecimento do composto de resíduo urbano em $\mathrm{Cd}, \mathrm{Cu}, \mathrm{Mn}, \mathrm{Pb}$ e $\mathrm{Zn}$ foram utilizadas soluções de $\mathrm{CdCl}_{2} \cdot 2 \mathrm{H}_{2} \mathrm{O}, \mathrm{CuCl}_{2} \cdot 2 \mathrm{H}_{2} \mathrm{O}, \mathrm{MnCl}_{2} \cdot 4 \mathrm{H}_{2} \mathrm{O}, \mathrm{PbCl}_{2}$ e $\mathrm{ZnCl}_{2}$, respectivamente, de tal forma que as doses desses elementos adicionadas ao solo foram de $0,15,30,60,120$ e $240 \mathrm{mg} \mathrm{dm}^{-3}$, conjuntamente. As soluções diluídas em água destilada-deionizada foram aplicada em porções individuais do composto, homogeneizadas, secas ao ar antes da aplicação ao solo. Todos os solos receberam calagem, exceto os solos LA-6 e SS que receberam gessagem.

A parte aérea das plantas de arroz do $1^{\circ}$ cultivo foram colhidas em meados de dezembros de 1997 (60 dias após a germinação), sendo o material vegetal lavado e seco em estufa. Em abril de 98, após a $2^{\text {a }}$ amostragem de terra e perfuração dos sacos plásticos pela parte inferior dos vasos, foi feita a semeadura do $2^{\circ}$ cultivo de arroz. A colheita do material vegetal (parte aérea) foi realizada em meados de junho de 98 (60 dias após a germinação). 


\subsection{Caracterização química do composto de resíduo urbano}

Para a análise química do composto, foram tomadas três subamostras, com aproximadamente $500 \mathrm{~g}$ cada uma, das amostras 1,2 e 3 do composto $<4 \mathrm{~mm}$. As subamostra foram secas em estufa com circulação forçada de ar a $60-65{ }^{\circ} \mathrm{C}$, moídas e passadas em peneira de $0,250 \mathrm{~mm}$, para à análise de $\mathrm{C}$ total pelo método da combustão por via seca através do uso de "Carmograph 12A-WOSTHOFF" (Cerri et al., 1995).

Com a finalidade de se verificar a ocorrência ou não de segregação de materiais do composto, de maior resistência à moagem e peneiragem, o composto $<4$ $\mathrm{mm}$, o resíduo da peneiragem e a fração $<0,250 \mathrm{~mm}$ sofreram digestão com $\mathrm{HCl}, \mathrm{HF}$ e $\mathrm{HClO}_{4}$ (Boaventura et al., 1994).

Nos extratos obtidos procedeu-se a determinação dos teores totais de $\mathrm{P}, \mathrm{Ca}$, $\mathrm{Mg}, \mathrm{Al}, \mathrm{B}, \mathrm{Ba}, \mathrm{Cd}, \mathrm{Co}, \mathrm{Cr}, \mathrm{Cu}, \mathrm{Fe}, \mathrm{Mn}, \mathrm{Mo}, \mathrm{Ni}, \mathrm{Pb}, \mathrm{Sr}, \mathrm{Ti}, \mathrm{V}$ e Zn, por ICP-AES e dos teores de $\mathrm{K}$ e Na por fotometria de emissão em chama. $\mathrm{O}$ teor de $\mathrm{N}$ total foi determinado pelo método de Kjeldahl, de modo semelhante ao descrito por Malavolta et al. (1997) para a análise de tecido vegetal.

\subsection{Caracterização física e química dos solos utilizados no experimento}

Para a caracterização química dos solos foram feitas as determinações de $\mathrm{N}$ total pelo método Kjeldahl, $\mathrm{P}, \mathrm{K}, \mathrm{Ca}$ e $\mathrm{Mg}$ pelo método da resina trocadora de íons, matéria orgânica via úmida, $\mathrm{pH}$ em $\mathrm{CaCl}_{2} 0,01 \mathrm{~mol} \mathrm{~L}^{-1}$, acidez potencial pelo tampão SMP (Raij et al., 1987), e de $\mathrm{S}^{-\mathrm{SO}_{4}}$ extraído com $\mathrm{CaCl}_{2}$ 0,15\%, e determinado por turbidimetria do sulfato de bário (Vitti, 1988). Os micronutrientes e metais disponíveis foram extraídos com DTPA e determinados por ICP-AES. A análise granulométrica foi feita pelo método do densímetro no laboratório de Física do Solo, da ESALQ.

A análise dos teores totais foi realizada de modo semelhante à análise do composto de resíduo urbano. 


\subsection{Caracterização química dos fertilizantes e calcário e gesso natural usados no experimento}

Para se verificar se os fertilizantes, o calcário e o gesso natural podiam ser fontes de contaminação do solo, principalmente com metais, procedeu-se a análise química para a determinação dos teores totais de micronutrientes e metais de modo análogo à análise do composto.

\subsection{Análise química dos solos}

Nas amostra de terra, obtidas na primeira amostragem dos experimentos I e II, e passadas em peneira de $0,5 \mathrm{~mm}$ de malha, foram feitas as extrações pelos seguintes métodos:

a) Resina de troca iônica conforme descrito em Raij et al. (1987). Na extração foi utilizado $2,5 \mathrm{~g}$ de terra, $2,5 \mathrm{~cm}^{3}$ de uma mistura de resinas de troca de cátions (resina catiônica código Deion, CGRC-MEL) e de ânions (resina aniônica código Deion, CGRA-MEL) em $25 \mathrm{~mL}$ de água destilada-deionizada, sob agitação contínua de $16 \mathrm{~h}$ e promovida a troca de íons da resina com $50 \mathrm{~mL}$ de uma solução $\mathrm{NH}_{4} \mathrm{Cl} 0,8 \mathrm{~mol} \mathrm{~L}^{-1}+$ $\mathrm{HCl} 0,2 \mathrm{~mol} \mathrm{~L}^{-1}$.

b) DTPA (solução de ácido dietilenotriaminopentacético $0,005 \mathrm{~mol} \mathrm{~L}^{-1}$; trietanolamina 0,1 mol L ${ }^{-1} \mathrm{e} \mathrm{CaCl}_{2} 0,01 \mathrm{~mol} \mathrm{~L}^{-1}$, com pH 7,3) de acordo com Lindsay \& Norvell (1978). O extrato foi obtido a partir de $10 \mathrm{~g}$ de terra e $20 \mathrm{~mL}$ da solução extratora, agitação por 2 horas e filtragem.

c) Mehlich-1 (solução $\mathrm{HCl} 0,05 \mathrm{~mol} \mathrm{~L}^{-1}$ e $\mathrm{H}_{2} \mathrm{SO}_{4}$ 0,025 $\mathrm{mol} \mathrm{L}^{-1}$ ) de acordo com Jones Junior (1990). Para a extração utilizou-se de $10 \mathrm{~g}$ de terra e $50 \mathrm{~mL}$ da solução extratora, agitação vigorosa por 5 minutos e filtragern.

d) Mehlich-3 (solução de ácido acético $0,2 \mathrm{~mol} \mathrm{~L}^{-1}$; nitrato de amônio $0,25 \mathrm{~mol} \mathrm{~L}^{-1}$; fluoreto de amônio $0,015 \mathrm{~mol} \mathrm{~L}^{-1}$; ácido nítrico $0,013 \mathrm{~mol} \mathrm{~L}^{-1} \mathrm{e}$ ácido etilenodiaminotetrácetico EDTA $0,001 \mathrm{~mol} \mathrm{~L}^{-1}$ ) de acordo com Mehlich (1984). Para 
a extração foi utilizado $10 \mathrm{~g}$ de terra e $100 \mathrm{~mL}$ da solução extratora, 5 minutos de agitação vigorosa e filtragem.

e) Wolf-Morgan (solução de acetato de sódio $0,73 \mathrm{~mol} \mathrm{~L}^{-1}$ e DTPA $0,0001 \mathrm{~mol} \mathrm{~L}^{-1}$, com pH 4,8) de acordo com Jones Junior (1990) e Wolf (1982). Para a extração empregouse $10 \mathrm{~g}$ de terra e $20 \mathrm{~mL}$ da solução extratora, agitação vigorosa por 5 minutos e filtragem.

f) $\mathrm{CaCl}_{2} \mathbf{0 , 0 1} \mathrm{mol} \mathrm{L}^{-1}$ de acordo com Houba et al. (1986), com modificações para se permitir a determinação simultânea do $\mathrm{pH}$, de acidez potencial pelo tampão SMP (Raij et al., 1987) e de S-SO $\mathrm{SO}_{4}$ por turbidimetria do sulfato de bário (Vitti, 1988). Procedeu-se, previamente, com as amostra iniciais de terra, uma calibração entre a determinação do $\mathrm{pH}\left(\mathrm{CaCl}_{2} 0,01 \mathrm{~mol} \mathrm{~L}^{-1}\right)$, acidez potencial e de $\mathrm{S}_{-} \mathrm{SO}_{4}$ extraído com $\mathrm{CaCl}_{2} 0,15 \%$ pela metodologia convencional e aqueles determinados através das seguintes modificações:

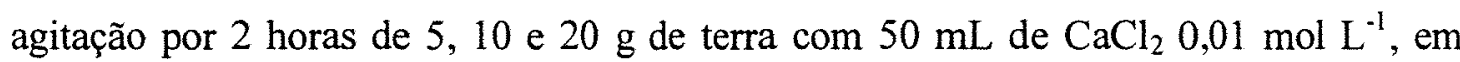
frasco de $100 \mathrm{~mL}(f l)$; leitura do $\mathrm{pH}$ em $f l$; transferência de uma alíquota de $25 \mathrm{~mL}$ do extrato $f 1$ para outro frasco $f 2$; nova leitura do $\mathrm{pH}$ em $f 1$, leitura do $\mathrm{pH}$ SMP em $f 7$ através do procedimento usual e determinação de $\mathrm{S}_{-} \mathrm{SO}_{4}$ em $f 2$. O extrato $f 2$ não foi submetido à determinação multielementar por ICP-AES, pois, como esse não havia sido obtido por filtragem, continha material orgânico em suspensão. Assim, mantendo-se a relação terra:extrator em 1:2,5 (p/v) no momento da leitura do $\mathrm{pH}$ e pH SMP, optou-se pela seguinte marcha para obtenção dos extratos $f 1$ e $f 2$ : agitação por 2 horas de $8 \mathrm{~g}$ de terra com $40 \mathrm{~mL}$ de $\mathrm{CaCl}_{2} 0,01 \mathrm{~mol} \mathrm{~L}^{-1}$, em frasco de $100 \mathrm{~mL}(f l)$; transferência com filtragem de uma alíquota de $20 \mathrm{~mL}$ do extrato $f 1$ para outro frasco $f 2$; leitura do $\mathrm{pH}$ e pH SMP em $f 1$; e determinação multielementar por ICP-AES e de S-SO 4 em $f 2$.

g) AA-EDTA.Na $a_{2}$ (solução acetato de amônio $0,5 \mathrm{~mol} \mathrm{~L}^{-1} \mathrm{e}$ ácido etilenodiaminotetrácetico dissódico $0,02 \mathrm{~mol} \mathrm{~L}^{-1}$ em ácido acético $0,5 \mathrm{~mol} \mathrm{~L}^{-1}$; com $\mathrm{pH} 4,65$ ) de acordo com Sippola (1994). Para a extração utilizou-se de $10 \mathrm{~g}$ de terra e $100 \mathrm{~mL}$ da solução extratora, $1 \mathrm{~h}$ de agitação e filtragem.

h) AB-DTPA (solução bicarbonato de amônio $1 \mathrm{~mol} \mathrm{~L}^{-1}$ e DTPA 0,005 mol L ${ }^{-1}$, pH 7,6) de acordo com Soltanpour \& Workman (1979). Para a obtenção do extrato utilizou-se de 
$10 \mathrm{~g}$ de terra e $20 \mathrm{~mL}$ da solução extratora, agitação por 15 minutos com os frascos mantidos abertos e filtragem.

Procedeu-se, em todos os extratos obtidos, a determinação dos teores de $\mathrm{P}$, $\mathrm{Ca}, \mathrm{Mg}, \mathrm{B}, \mathrm{Ba}, \mathrm{Cd}, \mathrm{Co}, \mathrm{Cr}, \mathrm{Cu}, \mathrm{Fe}, \mathrm{Mn}, \mathrm{Mo}, \mathrm{Ni}, \mathrm{Pb}, \mathrm{Sr}, \mathrm{Ti}, \mathrm{V}$ e $\mathrm{Zn}$ por ICP-AES e dos teores de $\mathrm{K}$ e Na por fotometria de emissão com chama.

\subsection{Análise química do mate rial vegetal}

As amostras de parte aérea das plantas de arroz, de ambos os experimentos. foram lavadas em água destilada-deionizada, secas em estufa com circulação de ar forçada a $60-65{ }^{\circ} \mathrm{C}$, pesadas, moídas e armazenadas em sacos de papel até a análise. $\mathrm{O}$ teor de $\mathrm{N}$ total foi determinado através do método semi-micro Kjeldahl conforme descrito em Malavolta et al. (1997).

As concentrações de $\mathrm{B}, \mathrm{Ba}, \mathrm{Ca}, \mathrm{Cd}, \mathrm{Co}, \mathrm{Cr}, \mathrm{Cu}, \mathrm{Fe}, \mathrm{K}, \mathrm{Mg}, \mathrm{Mn}, \mathrm{Mo}, \mathrm{Na}$, $\mathrm{Ni}, \mathrm{P}, \mathrm{Pb}, \mathrm{S}, \mathrm{Sr}, \mathrm{Ti} \mathrm{V}$ e $\mathrm{Zn}$ foram determinadas a partir de extrato de digestão nítricoperclórica e determinação por ICP-AES. Sempre que necessário, procedeu-se à concentração do extrato para a leitura. Os teores de $\mathrm{K}$ e Na que foram determinados por fotometria de chama e o S por turbidimetria (Vitti, 1988).

\subsection{Parâmetros de operação do ICP-AES}

A análise por ICP-AES foi empregada para a análise dos teores de $\mathrm{B}, \mathrm{Ba}$, $\mathrm{Ca}, \mathrm{Cd}, \mathrm{Co}, \mathrm{Cr}, \mathrm{Cu}, \mathrm{Fe}, \mathrm{Mg}, \mathrm{Mn}, \mathrm{Mo}, \mathrm{Ni}, \mathrm{P}, \mathrm{Pb}, \mathrm{Sr}, \mathrm{Ti} \mathrm{V}$ e $\mathrm{Zn}$ em extratos de solos e materiais vegetais. Utilizou-se de um aparelho da Jarrell-Ash, Plasma Atomcomp 975, do Laboratório de Química Analítica, do CENA/USP, em Piracicaba-SP. Durante a determinação a potência incidente foi de $1,6 \mathrm{~kW}$, com freqüência entre 27 a $40 \mathrm{MHz}$, a potência refletida inferior a $5 \mathrm{~W}$, o fluxo de argônio para manutenção do plasma foi de 15 a $17 \mathrm{~L} \mathrm{~min}^{-1}$, o fluxo de gás auxiliar de $2 \mathrm{~L} \mathrm{~min}^{-1} \mathrm{e}$ a amostra foi injetada no interior do plasma utilizando-se argônio como carregador, com fluxo de cerca de $1 \mathrm{~L} \mathrm{~min}{ }^{-1}$. 


\subsection{Análise estatística dos da dos}

O delineamento utilizado, em ambos os experimentos, foi o de blocos ao acaso com os solos em faixas. Conforme foi definido por Alves ${ }^{5}$ o modelo e a análise estatística são semelhantes ao de um esquema em parcelas subdivididas, diferindo apenas quanto à disposição dos solos em faixas, uma vez que estes se encontravam em vasos. Assim, utilizou-se do seguinte modelo para as análises estatísticas:

$$
y_{i j k}=m+S_{i}+b_{j}+e_{i j}+T_{k}+(S T)_{i k}+\varepsilon_{i j k}
$$

Onde: $\mathrm{y}_{\mathrm{ijk}}=$ valor observado referente ao i-ésimo solo no j-ésimo bloco, no k-ésimo tratamento; $m=$ fator fixo, estimado pela média geral; $S_{i}=$ efeito do $i-$ ésimo solo; $b_{j}=$ efeito do $\mathrm{j}$-ésimo bloco; $\mathrm{e}_{\mathrm{ij}}=$ erros aleatórios correspondentes às parcelas (variação do acaso sobre as observações do i-ésimo solo no j-ésimo blocos), supostos homocedásticos, independentes e normalmente distribuídos; $T_{k}=$ efeito do $\mathrm{k}$ ésimo tratamento; $(\mathrm{ST})_{\mathrm{ik}}=$ efeito da interação do i-ésimo solo com o k-ésimo tratamento; $\varepsilon_{\mathrm{ijk}}=$ erros aleatórios correspondentes às faixas (variação do acaso sobre as observações do i-ésimo solo, k-ésimo tratamento, no j-ésimo bloco), supostos homocedásticos, independentes e normalmente distribuídos.

$O$ esquema de análise da variância e teste $F$ para os tratamentos foi idêntico ao modelo de blocos completos, com parcelas subdivididas. No experimento 1 , quando constatado interação significativa, as médias dos tratamentos dentro de solos, foram testadas através do teste de Tukey, considerando, um nível mínimo de significância de $5 \%$. No experimento 2 as médias dos tratamentos dentro de solos, foram testadas por modelos de regressão linear e quadráticos.

Para se avaliar a eficiência dos extratores, empregou-se a análise de correlação entre os teores de nutrientes e de metais pesados, obtidos para cada extrator, com a absorção destes elementos pela planta de arroz.

Realizou-se, inicialmente a análise exploratória de todos os dados obtidos, antes da análise estatística propriamente dita, para se verificar se os modelos de

\footnotetext{
${ }^{5}$ ALVES, M.I.F. Comunicação pessoal, 1998.
} 
análise descritos eram válidos. Foram verificadas a homogeneidade de variâncias (devem ser comparados tratamentos com variâncias homogêneas entre si), a independência dos erros e a distribuição normal (ou aproximadamente normal) dos erros devido à variação do acaso. Quando qualquer uma das pressuposições foram violadas, fez a análise de variância com os dados transformados.

A análise exploratória dos dados e as correlações foram executadas pelo SAS/SAS lab (SAS Institute Inc., 1998); e as análises de variância, testes de médias e regressões foram obtidas pelo programa estatístico SANEST (Zonta et al., 1987). 


\section{RESULTADOS E DISC USSÃO}

\subsection{Caracterização do comp osto de resíduo urbano, solos, adubos, calcário e gesso natural}

\subsubsection{Análise química e física do composto de resíduo urbano}

Os resultados das análise de $\mathrm{pH}$ e condutividade elétrica (C.E.) das três amostras do composto de resíduo urbano, obtidas por ocasião da coleta do material, mostrou que o mesmo apresentava características alcalinas e acentuada salinidade (Tabela 6). Propriedade semelhantes foram relatadas por Berton \& Valadares (1991). De acordo com Kiehl (1985), o material orgânico humificado em condições aeróbias apresenta reação alcalina devido à formação de humatos alcalinos.

Observou-se que as amostras obtidas por ocasião da coleta do composto apresentaram pouca variação nos valores de pH (média de 7,97) e de C.E. (média de $7,25 \mathrm{dS} \mathrm{m}^{-1}$ ), diferentemente do que foi observado para a umidade e relação fração $<4$ $\mathrm{mm} /$ composto bruto. Essas características refletiram a posição de coleta das amostras na pilha de compostagem. A amostra 1, que foi coletada na parte mais externa da pilha, apresentou menor umidade e maior quantidade de partículas finas (Tabela 6). Os valores de umidade, quando convertidos para a base de peso úmido (média de $39 \%$ ) e de fração $<4 \mathrm{~mm}$, estão dentro da faixa dos valores observados por Cravo (1995) e Cravo et al. (1998) em compostos provenientes das principais capitais do país.

Pela Tabela 7 pode-se observar que os teores de macronutrientes, $\mathrm{Na}, \mathrm{Al}$, Fe e Ti são bastante elevados no composto. O teor de carbono total foi superior no resíduo do processo de peneiragem para a obtenção de amostra $<0,250 \mathrm{~mm}$. Isso indica 
Tabela 6. Características físicas e pH de três amostras do composto de resíduo urbano, da cidade de São Paulo, obtidas por ocasião da coleta do material na usina de compostagem.

\begin{tabular}{|c|c|c|c|c|c|}
\hline Amostra & $\begin{array}{c}\mathrm{pH} \\
\text { água } \\
1: 4\end{array}$ & C.E. & $\begin{array}{l}\text { Umidade da amostra } \\
\text { seca ao ar } \\
\text { (base de matéria seca) }\end{array}$ & $\begin{array}{l}\text { Umidade da amostra } \\
\text { seca em estufa } \\
\text { (base de matéria seca) }\end{array}$ & $\begin{array}{l}\text { Relação entre a fração } \\
<4 \text { mm e o composto } \\
\text { bruto seco ao ar }\end{array}$ \\
\hline & & $\mathrm{dS} \mathrm{m}^{-1}$ & - & $\mathrm{g} \mathrm{kg}^{-1} \ldots$ & \\
\hline$I$ & 8,01 & 69,6 & $585\left(37 \% \%^{\ddagger}\right)$ & 46 & 619 \\
\hline 2 & 7,92 & 74,8 & $644(39 \%)$ & 48 & 658 \\
\hline 3 & 7,95 & 73,1 & $691(41 \%)$ & 53 & 575 \\
\hline
\end{tabular}

$\stackrel{+}{+}$ - os valores entre parênteses se referem à porcentagem de umidade na base de peso úmido.

a ocorrência de segregação de materiais constituintes do composto quando passados por peneira de 0,250 $\mathrm{mm}$ de malha, mesmo que a amostra tenha sido moída. Partículas de madeira, plástico, vegetal e, principalmente, de papel, resistente à moagem, são retidas na peneira, enquanto que o vidro, material inerte facilmente triturado, se concentra no material peneirado. Por outro lado, os teores de todos os outros tenderam a ser inferior no resíduo. Os teores desses elementos nas amostras do composto $<4 \mathrm{~mm}$ foram intermediários ou próximos dos obtidos na fração $<0,250 \mathrm{~mm}$, corroborando com a hipótese de ocorrência de segregação dos elementos, devido à peneiragem. Os teores observados encontram-se dentro da faixa dos valores apresentados por Berton \& Valadares (1991), Cravo (1995) e Cravo et al. (1998) em compostos das principais capitais do país, e por Xin et al. (1992) em compostos de outros países. Excetua-se o $\mathrm{Na}$, cujo valor observado foi aproximadamente 5 vezes superior aos valores observados por Xin et al. (1992).

A relação $\mathrm{C} / \mathrm{N}$ do composto também foi superior no resíduo da peneiragem, o que mais uma vez, parece confirmar a ocorrência de acúmulo de materiais inertes (ex.: papel) nessa fração. A fração $<0,250 \mathrm{~mm}$ apresentou relação $\mathrm{C} / \mathrm{N}$ média de 19, que é superior ao valor indicado por Kiehl (1985) como desejável, que é de 10:1. 


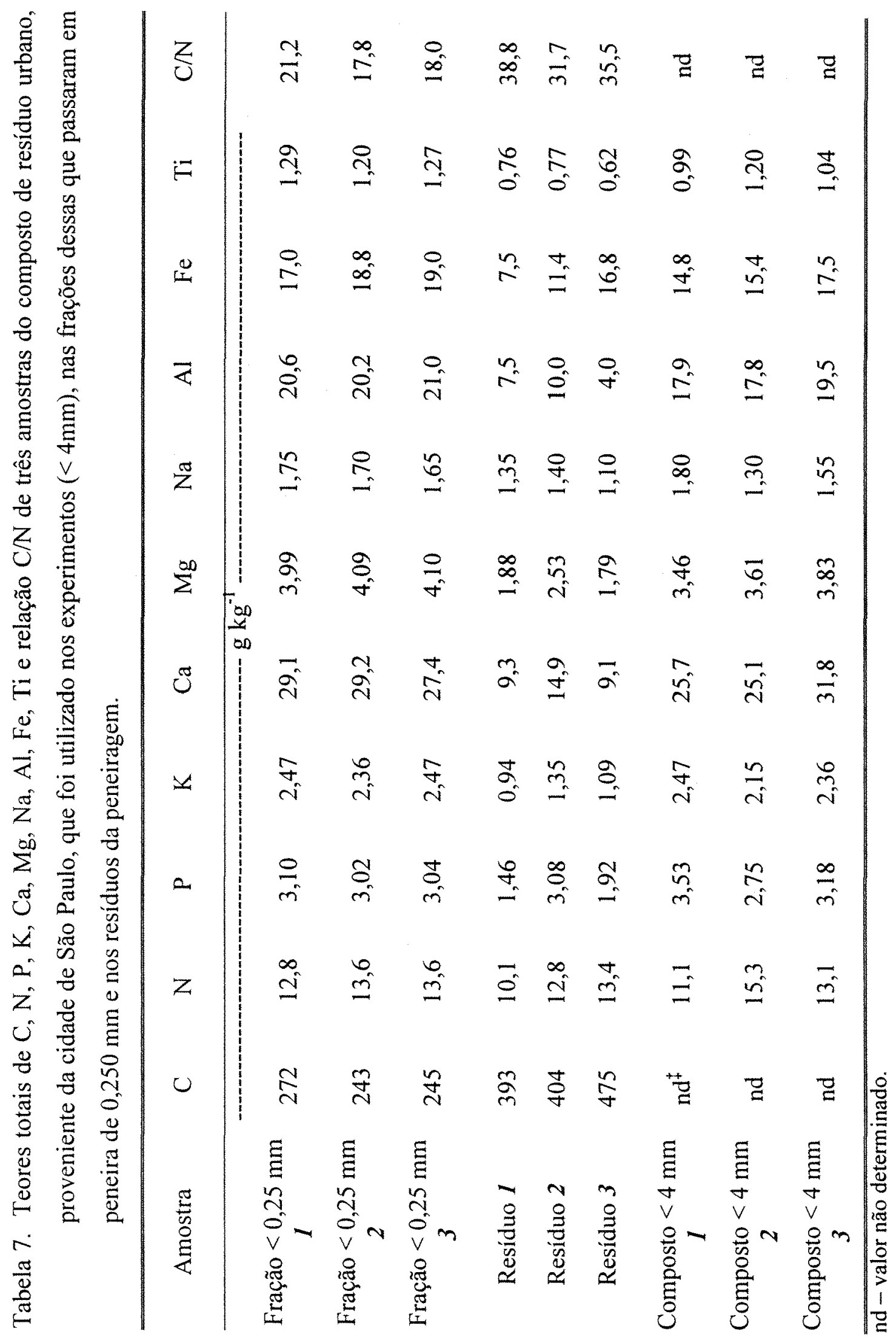


Os teores totais de micronutrientes e de metais (Tabela 8) no composto apresentaram o mesmo comportamento de acúmulo na fração $<0,250 \mathrm{~mm}$ e praticamente todos os elementos se encontram próximos aos valores obtidos por Xin et al. (1992), Cravo (1995) e Cravo et al. (1998). Embora os valores observados encontram-se próximos ou superiores aos respectivos níveis toleráveis em compostos de resíduo urbano da Alemanha (Grossi, 1993), tem sido reportado que apenas uma pequena fração desses totais se encontram na fração disponível. A análise de composto de resíduo urbano, proveniente da cidade de Araraquara (SP), revelou que apenas $1 \%$ dos teores totais de $\mathrm{Cu}, \mathrm{Pb}, \mathrm{Zn}$ e $16 \%$ do total de $\mathrm{Cd}$ estariam presentes na formas disponíveis (Jordão, et al., 1996).

\subsubsection{Análise química e física dos solos}

Pela análise granulométrica, verificou-se que $9,5 \%$ das amostras de terra dos solos ácidos utilizados nos experimentos apresentavam textura arenosa, $24 \%$ textura média arenosa, 9,5\% média arenosa, $33 \%$ argilosa e $24 \%$ muito argilosa (Tabela 9). Dos solos alcalinos, uma amostra apresentou textura média argilosa, duas textura argilosa e outras duas textura muito argilosa. A densidade das amostras variou de 844 a 1.464 $\mathrm{kg} \mathrm{m}^{-3}$ (Tabela 9), estando relacionada com a textura da amostra.

Os resultados da análise química nas amostras iniciais, dos diferentes solos na camada 0-20 cm, para fins de fertilidade são apresentados na Tabela 10. Observa-se que foram utilizados solos com grande variabilidade nas suas propriedades químicas. Nos solos ácidos, o $\mathrm{pH}$ em $\mathrm{CaCl}_{2}$ variou de 3,82 a 5,52; o teor de M.O. de 11,5 a $52,2 \mathrm{~g} \mathrm{dm}^{-3}$, o teor de $\mathrm{N}$ de 0,4 a $3,0 \mathrm{~g} \mathrm{dm}^{-3}$, o S-SO 4 de 2,1 a $21,4 \mathrm{mg} \mathrm{dm}^{-3}$, o P de 1,1 a $62 \mathrm{mg} \mathrm{dm}^{-3}$ e a saturação por bases de 4,3 a $67 \%$. Alguns solos com V\% elevada (>60\%) indicam que as amostras ou foram obtidas de área com alta fertilidade natural ou que haviam recebido calagem e adubação recente, como parece ter sido o caso da amostra da Areia Quartzosa distrófica (AQd). Os solos alcalinos destacam-se pelo elevado $\mathrm{pH}$, alto teores de cátions trocáveis, baixa acidez potencial, ausência de $\mathrm{Al}^{3+} \mathrm{e}$ 


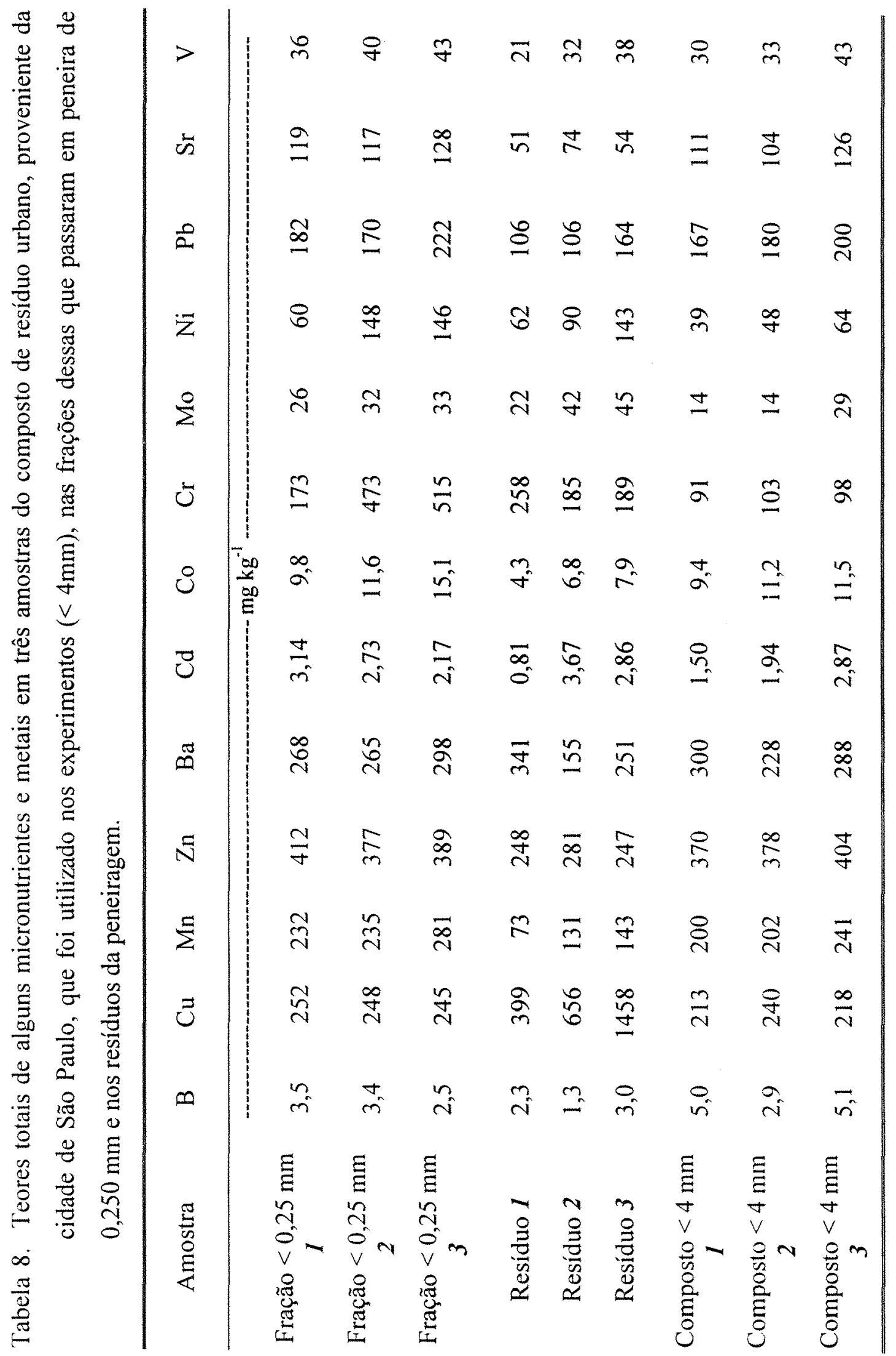


Tabela 9. Resultados da análise granulométrica e da densidade nas amostras dos solos utilizados nos experimentos, na camada de 0 a $20 \mathrm{~cm}$.

\begin{tabular}{|c|c|c|c|c|c|}
\hline Solos & $\begin{array}{l}\text { Areia } \\
\text { Total }\end{array}$ & Silte & $\begin{array}{l}\text { Argila } \\
\text { total }\end{array}$ & Densidade & $\begin{array}{c}\text { Classe de } \\
\text { textura }\end{array}$ \\
\hline & - & $\mathrm{g} \mathrm{kg}^{-1}$ & - - & $\mathrm{kg} \mathrm{m}^{-3}$ & \\
\hline GPH & 110 & 540 & 350 & 904 & argilosa \\
\hline $\mathrm{AQd}$ & 920 & 40 & 40 & 1444 & arenosa \\
\hline LUa & 310 & 40 & 650 & 956 & muito argilosa \\
\hline LE-1 & 500 & 100 & 400 & 1212 & argilosa \\
\hline LE-2 & 250 & 60 & 690 & 940 & muito argilosa \\
\hline LA-1 & 700 & 80 & 220 & 1220 & média arenosa \\
\hline PV-1 & 640 & 60 & 300 & 1160 & média argilosa \\
\hline LA-2 & 290 & 140 & 570 & 984 & argilosa \\
\hline LA-3 & 740 & 60 & 200 & 1216 & média arenosa \\
\hline TR-1 & 60 & 150 & 790 & 1096 & muito argilosa \\
\hline LA-4 & 600 & 80 & 320 & 1208 & média argilosa \\
\hline PV-2 & 700 & 120 & 180 & 1256 & média arenosa \\
\hline LA-5 & 180 & 430 & 390 & 1004 & argilosa \\
\hline PV-3 & 180 & 170 & 650 & 844 & muito argilosa \\
\hline $\mathrm{LRa}$ & 80 & 210 & 710 & 1002 & muito argilosa \\
\hline LE-3 & 250 & 160 & 590 & 1080 & argilosa \\
\hline $\mathrm{PE}$ & 380 & 150 & 470 & 1100 & argilosa \\
\hline PV -4 & 700 & 60 & 240 & 1272 & média arenosa \\
\hline TR-2 & 300 & 270 & 430 & 1112 & argilosa \\
\hline $\mathrm{AQa}$ & 920 & 20 & 60 & 1464 & arenosa \\
\hline LV -1 & 740 & 110 & 150 & 1260 & média arenosa \\
\hline $\mathrm{CL}$ & 120 & 270 & 610 & 1136 & muito argilosa \\
\hline $\mathrm{CV}$ & 140 & 210 & 650 & 1152 & muito argilosa \\
\hline LA- 6 & 490 & 120 & 390 & 1212 & argilosa \\
\hline LV-2 & 330 & 200 & 470 & 1160 & argilosa \\
\hline SS & 440 & 310 & 250 & 1216 & média argilosa \\
\hline
\end{tabular}


saturação por bases muito elevada. Os solos salinos sódicos, por definição, apresentam altos teores de Na trocável e CE elevada, reflexo de sua salinidade.

De modo semelhante aos teores de macronutrientes, os teores de micronutrientes e metais disponíveis nas amostras iniciais (Tabela 11) apresentaram grande variabilidade. Na maioria dos casos, as faixas obtidas para os diversos elementos encontram-se dentro da faixa observada na literatura (Kabata-Pendias \& Pendias, 1986; Abreu et al.,1995; Rodrigues, 1998). Normalmente, a disponibilidade de B, Co e Mo em solos tem sido avaliado empregando-se extratores específicos (Kabata-Pendias \& Pendias, 1986; Bataglia \& Raij, 1989; Santos, 1991; Malavolta, 1994).

Os teores totais de macronutrientes, micronutrientes e metais são apresentados nas Tabelas 12 e 13. De um modo geral, os teores totais observados para os diversos elementos estão em concordância com aqueles reportados por KabataPendias \& Pendias (1986) e Rodrigues (1998), embora haja grande variação entre os diferentes solos. $\mathrm{O} \mathrm{Al}, \mathrm{Fe}$, Ti e $\mathrm{Mn}$ foram os elementos que apareceram com os maiores teores totais, notadamente os dois primeiros elementos que são os constituintes mais abundantes dos minerais do solo.

O Mo e o Cd são os elementos que apresentaram os menores teores totais, seguidos pelo B, Co e Ni. Os solos TR-1, TR-2, LRa e LE-3 apresentaram os maiores teores totais de micronutrientes e de metais. Os teores dos elementos nos solos refletem o material de origem e o processo de intemperismo responsável pela formação do solo. O mesmo ocorre com os metais, exceto onde há ocorrências de ações antrópicas. Parece haver um maior potencial de disponibilidade de metais às plantas, em solos originários de basalto, do que em solos desenvolvidos de gnaisse e arenito + sedimentos do terciário (Oliveira, 1996). Através da análise de solos formados a partir de rochas ultramórfica, pode-se supor a ocorrência de teores tóxicos de metais no solo exclusivamente devido ao material de origem (Ross, 1994).

$\mathrm{O} F \mathrm{Fe}$ o $\mathrm{Ti}$, que se encontram predominantemente na fase mineral dos solos, apresentaram baixa relação entre o teor disponível e teor total (Tabela 14). O mesmo ocorre com o $\mathrm{P}$, que é facilmente adsorvido à fase sólida. Os dados da Tabela 14 sugerem que o $\mathrm{B}, \mathrm{Ni}, \mathrm{Ba}, \mathrm{Cr}, \mathrm{Pb}$ e $\mathrm{Sr}$ estão em formas de baixa disponibilidade, mais 
não muito inferior à do $\mathrm{Co}, \mathrm{Cu}, \mathrm{Zn}$, e $\mathrm{Cd}$, e o $\mathrm{K}, \mathrm{Ca}, \mathrm{Mg}, \mathrm{Na}, \mathrm{Mn}$ e $\mathrm{Mo}$ em formas de maior disponibilidade, principalmente o $\mathrm{Ca}$.

Os resultados obtidos indicam que o $\mathrm{Mn}$ e o $\mathrm{Cd}$ merecem um manejo mais criterioso, pois há indícios de que possa ocorrer condições de toxidade para eles. Isso difere do comentário de Ross (1994), que pressupõe que concentrações tóxicas de $\mathrm{Pb}$ e $\mathrm{Zn}$ devem ocorrer mais prontamente que a de $\mathrm{Cd}, \mathrm{Cr}$ e $\mathrm{Mg}$, uma vez que, normalmente, os teores totais de $\mathrm{Pb}$ e $\mathrm{Zn}$ são maiores.

Todavia, os fatores e processos que atuam sobre a disponibilidade de um elemento no solo são extremamente complexos. Sendo que os fatores $\mathrm{pH}$, matéria orgânica, tipo e quantidade de minerais de argila, óxidos de $\mathrm{Fe}, \mathrm{Al}$ e $\mathrm{Mn}$ (sendo este último de menor importância para os solos tropicais), capacidade de retenção de cátions e o potencial de oxi-redução atuam sobre os processos de dissolução, transporte e de sorção/adsorção regulando à disponibilidade dos elementos no solo (Adriano, 1986; Kabata-Pendias \& Pendias, 1986; Alloway, 1993; Ross, 1994)

\subsubsection{Análise química dos adu bos, calcário e gesso natural}

A análise química dos insumos utilizados nos experimentos (Tabelas 15 e 16 ) revelou que o superfosfato simples continha um maior teor de micronutrientes e metais, exceto para o $\mathrm{Ba}$ que foi maior no $\mathrm{KCl}, \mathrm{o} \mathrm{Cr}$ e Ti que foram maiores no calcário dolomítico, e o $\mathrm{Pb}$ no gesso mineral. Merece atenção os teores de $\mathrm{Fe}, \mathrm{Mn}, \mathrm{Zn}, \mathrm{Cd}, \mathrm{Cr}$, $\mathrm{Pb}$, Sr, Ti, e V no superfosfato simples; o teor de $\mathrm{Ba}$ no $\mathrm{KCl}$; os de $\mathrm{Cr}$, $\mathrm{Pb}$, Sr, Ti e V no calcário dolomítico; e os de $\mathrm{Pb}, \mathrm{Sr}$ e $\mathrm{V}$ no gesso mineral.

De um modo geral os teores observados são semelhantes aos da literatura nacional e internacional (Kabata-Pendias \& Pendias, 1986; Amaral Sobrinho et al., 1992; Malavolta, 1994; Cravo et al., 1998). Entretanto, há algumas diferenças para alguns dos elementos, cuja causa principal pode ser atribuída ao material de origem do insumo. Os teores de $\mathrm{Cd}$ e $\mathrm{Pb}$ no super simples foram superiores aqueles observados por Amaral Sobrinho et al. (1992) e Cravo et al. (1998). Os teores de Cr no superfosfato simples, calcário e gesso foram bem superiores aqueles obtidos por Amaral Sobrinho et 


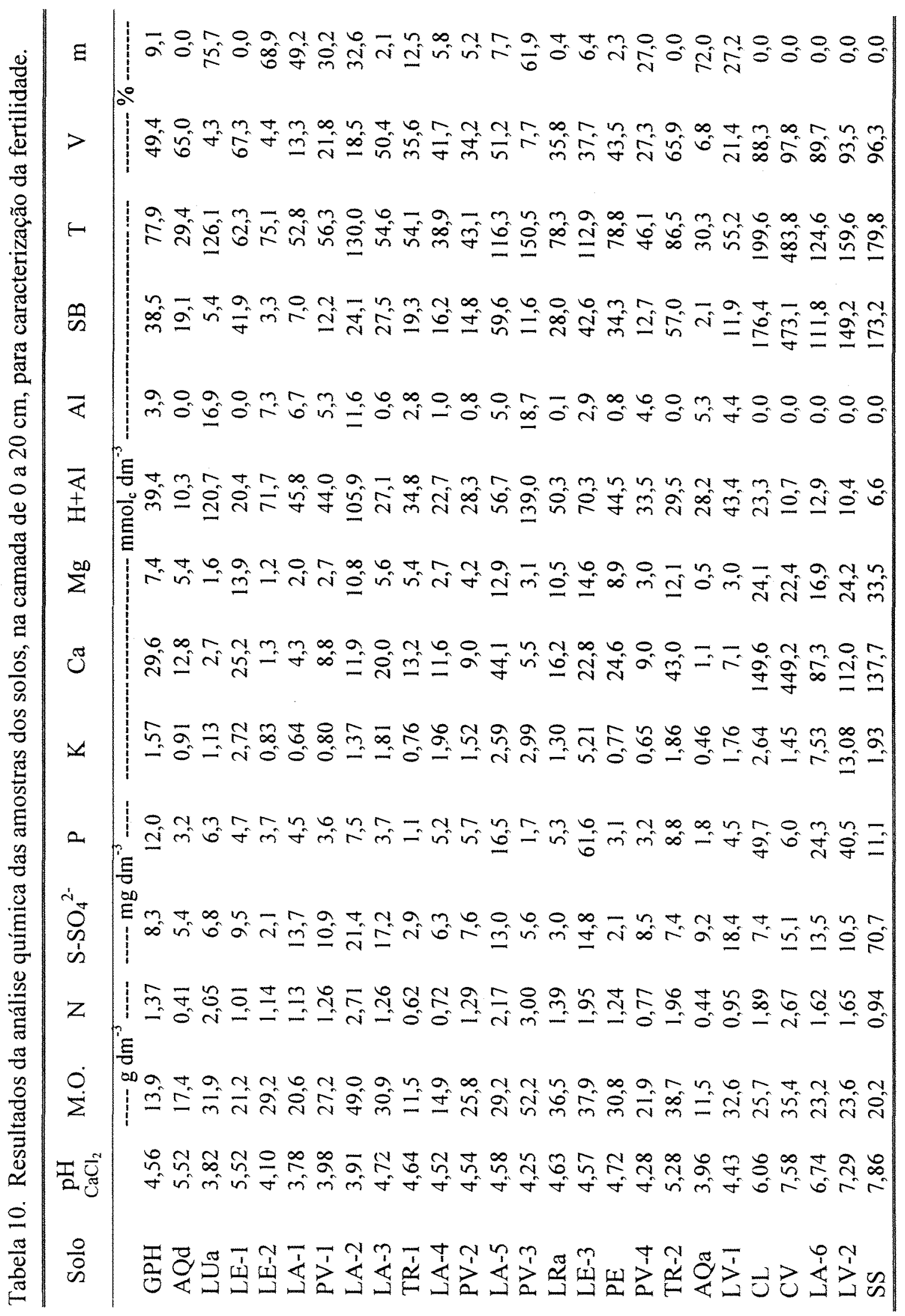




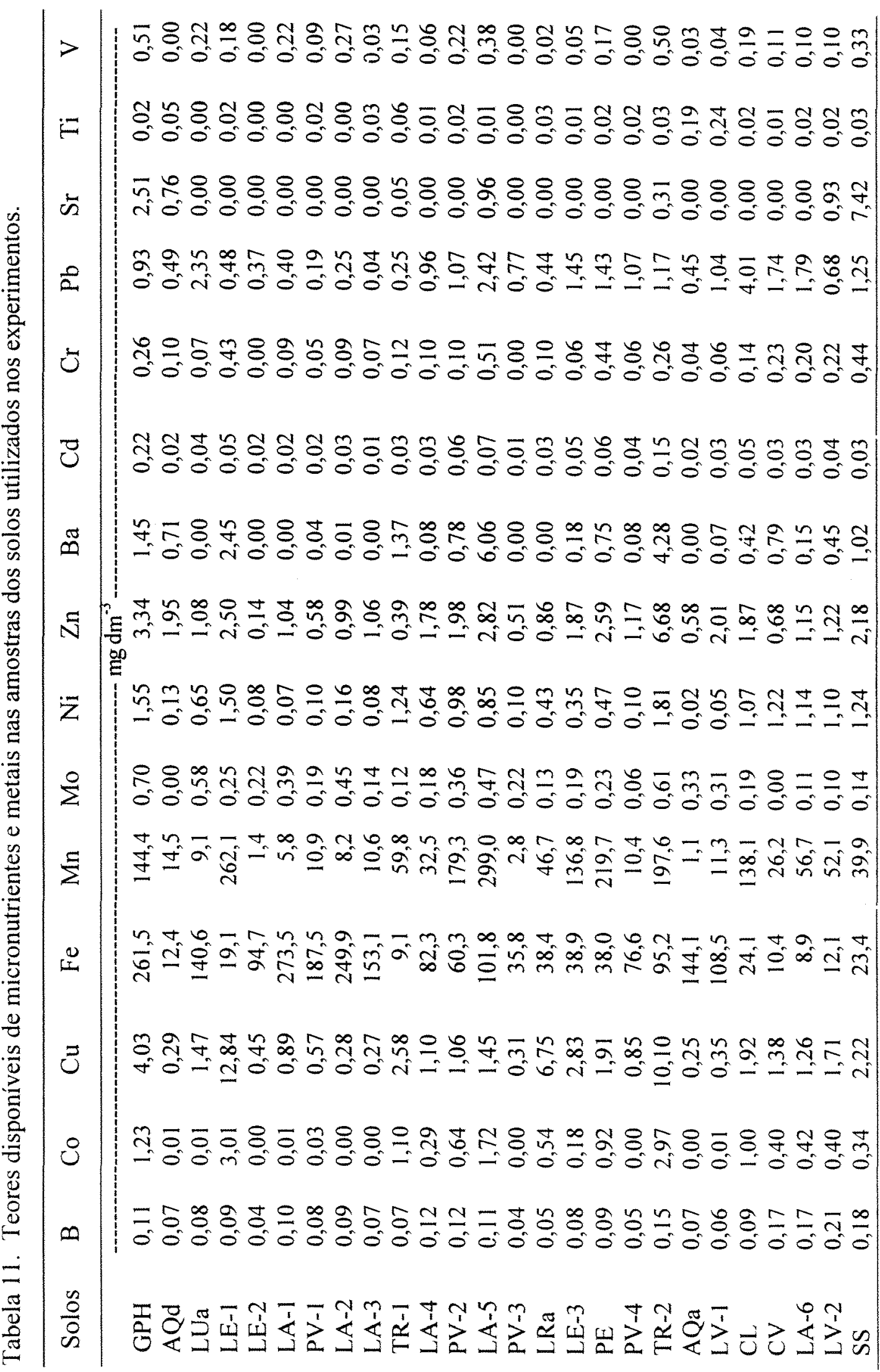


Tabela 12. Teores totais de $\mathrm{P}, \mathrm{K}, \mathrm{Ca}, \mathrm{Mg}, \mathrm{Al}, \mathrm{Na}, \mathrm{Fe}$ e Ti nas amostras dos solos utilizados nos experimentos, na camada de 0 a $20 \mathrm{~cm}$.

\begin{tabular}{lrrrrrrrr}
\hline Solos & \multicolumn{1}{c}{$\mathrm{P}$} & \multicolumn{1}{c}{$\mathrm{K}$} & $\mathrm{Ca}$ & $\mathrm{Mg}$ & $\mathrm{Al}$ & $\mathrm{Na}$ & $\mathrm{Fe}$ & $\mathrm{Ti}$ \\
\hline GPH & 1,01 & 15,43 & 8,35 & 8,54 & 53 & 9,77 & 38 & 3,2 \\
AQd & 0,13 & 1,69 & 0,54 & 0,23 & 13 & 0,21 & 3 & 2,0 \\
LUa & 0,94 & 0,32 & 0,08 & 0,18 & 79 & 0,09 & 73 & 6,6 \\
LE-1 & 0,80 & 0,39 & 0,88 & 0,93 & 50 & 0,13 & 95 & 12,5 \\
LE-2 & 0,81 & 0,17 & 0,04 & 0,15 & 98 & 0,07 & 71 & 5,6 \\
LA-1 & 0,38 & 0,16 & 0,14 & 0,17 & 43 & 0,08 & 13 & 6,7 \\
PV-1 & 0,37 & 0,22 & 0,21 & 0,23 & 49 & 0,09 & 21 & 8,2 \\
LA-2 & 0,64 & 0,18 & 0,26 & 0,35 & 90 & 0,10 & 17 & 17,5 \\
LA-3 & 0,29 & 0,19 & 0,56 & 0,16 & 35 & 0,09 & 7 & 2,8 \\
TR-1 & 1,45 & 0,37 & 0,80 & 2,32 & 102 & 0,29 & 197 & 17,8 \\
L A-4 & 0,57 & 0,90 & 0,46 & 0,50 & 53 & 0,06 & 46 & 5,2 \\
PV-2 & 0,46 & 5,12 & 0,32 & 0,68 & 34 & 0,41 & 22 & 3,4 \\
LA-5 & 0,80 & 15,97 & 1,97 & 3,48 & 50 & 2,80 & 27 & 3,3 \\
PV-3 & 0,92 & 1,39 & 0,13 & 0,39 & 91 & 0,12 & 64 & 6,5 \\
LRa & 1,74 & 0,28 & 0,30 & 0,78 & 105 & 0,18 & 238 & 30,4 \\
LE-3 & 1,71 & 0,92 & 0,62 & 1,19 & 78 & 0,24 & 138 & 26,0 \\
PE & 1,11 & 1,27 & 0,79 & 1,27 & 66 & 0,15 & 81 & 12,1 \\
PV-4 & 0,43 & 0,19 & 0,25 & 0,32 & 38 & 0,09 & 30 & 10,7 \\
TR-2 & 1,91 & 1,08 & 1,74 & 1,50 & 66 & 0,64 & 175 & 34,4 \\
AQa & 0,20 & 0,07 & 0,05 & 0,06 & 14 & 0,02 & 10 & 1,2 \\
LV-1 & 0,30 & 0,23 & 0,22 & 0,30 & 27 & 0,10 & 22 & 5,3 \\
CL & 1,69 & 6,09 & 3,72 & 4,28 & 66 & 0,15 & 55 & 2,8 \\
CV & 0,89 & 6,94 & 11,18 & 4,85 & 59 & 0,25 & 53 & 2,5 \\
LA-6 & 0,88 & 4,18 & 2,38 & 2,24 & 55 & 0,16 & 27 & 2,5 \\
LV-2 & 1,17 & 10,71 & 3,14 & 3,06 & 59 & 0,48 & 39 & 2,6 \\
SS & 0,65 & 35,22 & 11,18 & 5,62 & 62 & 13,64 & 30 & 3,9 \\
\hline
\end{tabular}




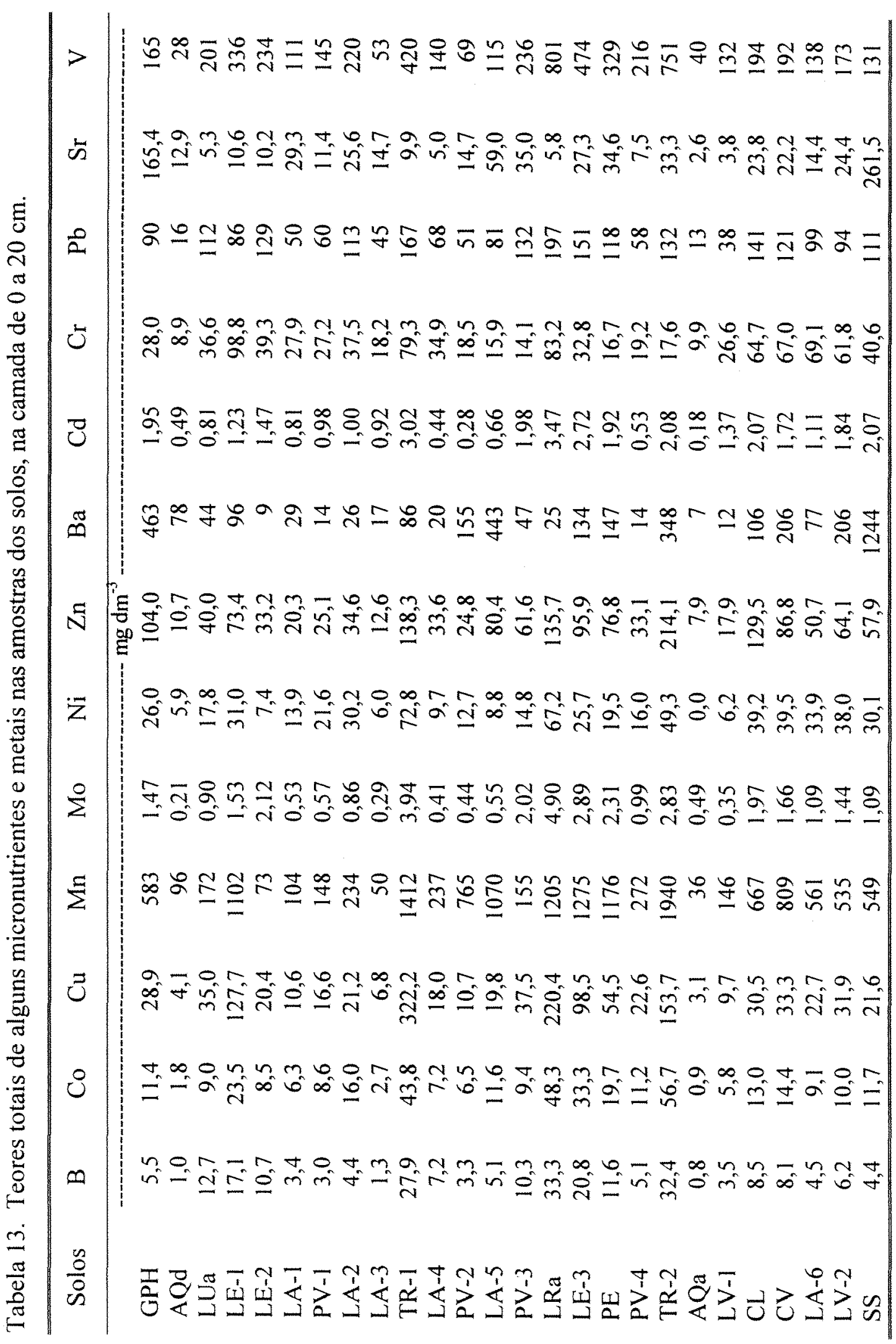




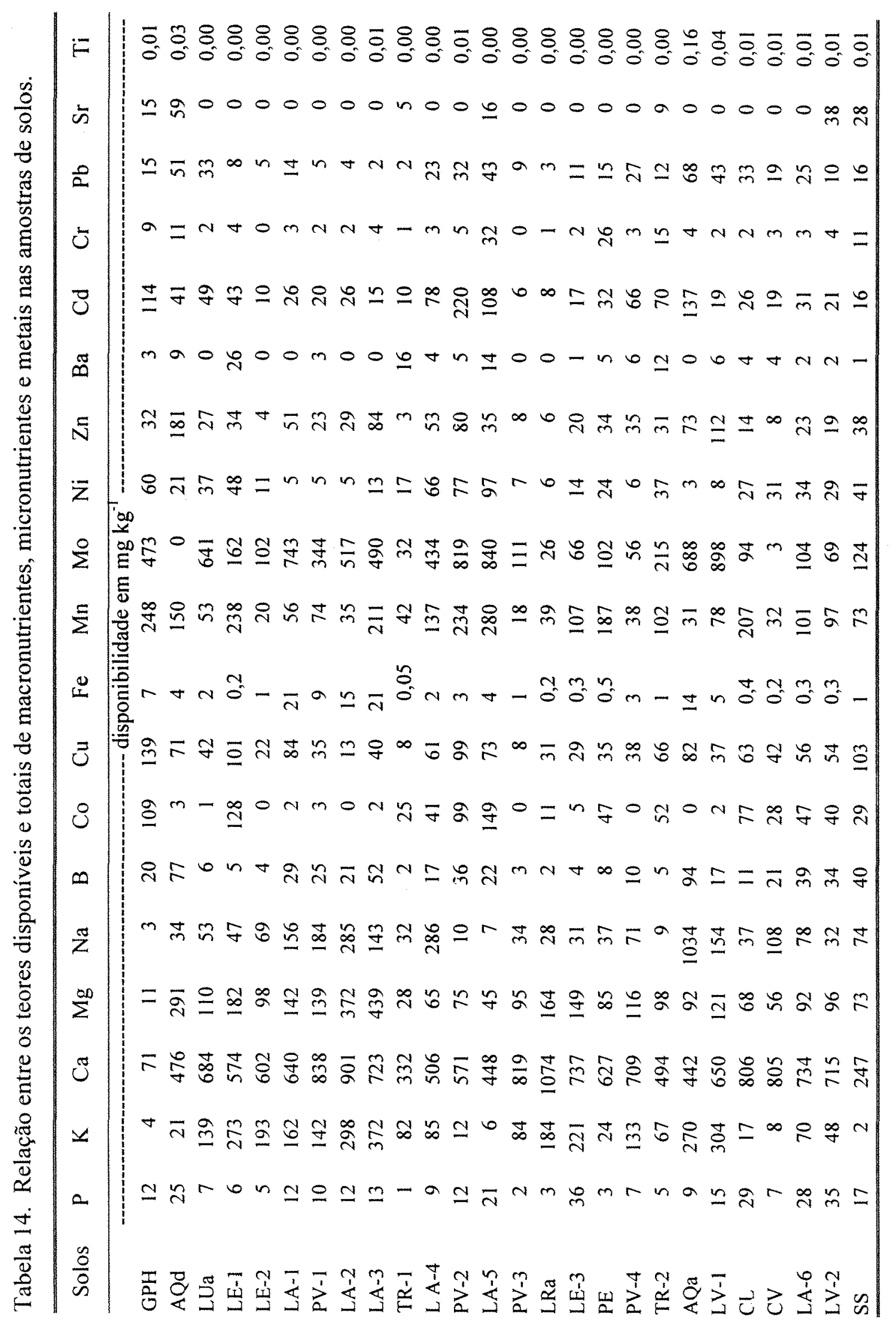


al. (1992). Todavia, conforme Cravo et al. (1998), o teor de Cr no superfosfato simples, observado por foi 3,6 vezes superior.

Considerando porém, que as doses de aplicação de fertilizantes são baixas quando comparadas às de adubos orgânicos, em especial à de composto de resíduo urbano (Cravo et al., 1998), e a calagem quando feita adequadamente apresenta um efeito residual, dispensando à aplicação anual (Malavolta, 1994), pode-se supor que a utilização desses insumos, baseados em critérios agronômicos e no acúmulo de metais em solos, não deverá causar efeitos tóxicos à médio prazo.

\subsection{Propriedades químicas do solo devido à aplicação do composto de resíduo urbano}

\subsubsection{Condutividade elétrica}

A condutividade elétrica dos solos foi um dos atributos mais modificado pela aplicação do composto. Nos solos ácidos, a C.E. foi menor na testemunha, em todos os solos e variou de 1,26 a $9,73 \mathrm{dS} \mathrm{m}^{-1}$ (Tabela 17). A aplicação isolada do composto promoveu aumentos na C.E. que variaram de $3,3 \mathrm{dS} \mathrm{m}^{-1}$, no solo TR-2 a 13,7 $\mathrm{dS} \mathrm{m}^{-1}$ no solo PV-2, e foi semelhante ou superior ao composto + calagem. A aplicação de adubo mineral potencializou o efeito do composto sobre a C.E., sendo que os tratamentos com composto + calagem + adubação e composto + adubação causaram os maiores aumentos na C.E. (de 5 a 10 vezes superior a testemunha), exceto nos solos LUa e LE-1, onde o composto com adubação apresentou valores intermediários.

A aplicação de calcário + adubo, geralmente apresentou valores de C.E. intermediários entre aqueles que receberam composto com adubo, com ou sem calagem, e composto com ou sem calagem, exceto nos solos GPH, LUa, PE e TR-2 onde foram semelhantes a aplicação de composto + calcário + adubo. Os solos de textura muito argilosa (LUa, TR-1, PV-3 e LRa) e arenosa (AQd e AQa) apresentaram aumentos relativamente inferiores aos de textura média arenosa e média argilosa. 

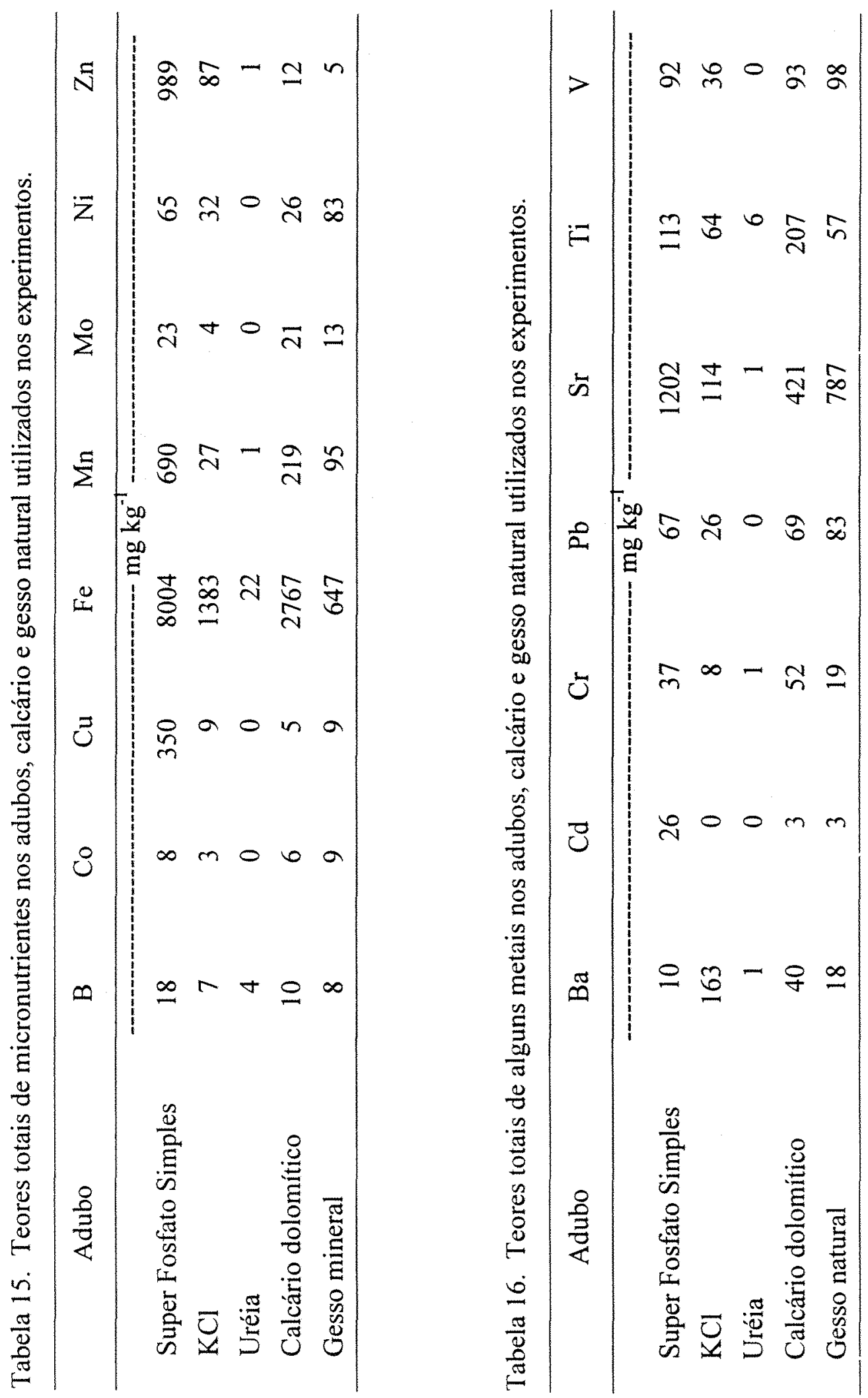
Tabela 17. Condutividade elétrica em solos adubados com composto de residuo urbano.

\begin{tabular}{|c|c|c|c|c|c|c|}
\hline \multirow{3}{*}{$\begin{array}{l}\text { Solos } \\
\text { ácidos }\end{array}$} & \multicolumn{4}{|c|}{ Composto de resíduo urbano } & \multirow{3}{*}{$\begin{array}{c}\text { Calagem } \\
\mathrm{e} \\
\text { adubação }\end{array}$} & \multirow{3}{*}{ Testemunha } \\
\hline & \multicolumn{2}{|c|}{ sem calagem } & \multicolumn{2}{|c|}{ com calagem } & & \\
\hline & sem adubação & com adubação & sem adubação & com adubação & & \\
\hline & - & 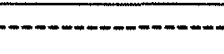 & dS m & $T$ & 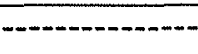 & - n \\
\hline GPH & $15,49 \mathrm{~B}^{\ddagger}$ & $27,56 \mathrm{~A}$ & $17,49 \mathrm{~B}$ & $26,25 \mathrm{~A}$ & $22,27 \mathrm{~A}$ & $4,09 \mathrm{C}$ \\
\hline AQd & $12,15 \mathrm{C}$ & $25,66 \mathrm{~A}$ & $11,68 \mathrm{C}$ & $22,24 \mathrm{AB}$ & $19,64 \mathrm{~B}$ & $2,94 \mathrm{D}$ \\
\hline LUa & $9,96 \mathrm{D}$ & $18,23 \mathrm{~B}$ & $13,12 \mathrm{C}$ & $24,56 \mathrm{~A}$ & $21,41 \mathrm{AB}$ & $3,97 \mathrm{E}$ \\
\hline LE-1 & $14,72 \mathrm{C}$ & $21,73 \mathrm{~B}$ & $11,13 \mathrm{D}$ & $28,19 \mathrm{~A}$ & $16,71 \mathrm{C}$ & $5,51 \mathrm{E}$ \\
\hline LE-2 & $13,64 \mathrm{C}$ & $31,82 \mathrm{~A}$ & $16,33 \mathrm{C}$ & $34,51 \mathrm{~A}$ & $24,63 \mathrm{~B}$ & $4,21 \mathrm{D}$ \\
\hline LA-1 & $15,93 \mathrm{C}$ & $33,13 \mathrm{~A}$ & $16,09 \mathrm{C}$ & $35,66 \mathrm{~A}$ & $25,26 \mathrm{~B}$ & $5,31 \mathrm{D}$ \\
\hline PV-1 & $17,98 \mathrm{C}$ & $32,69 \mathrm{AB}$ & $17,88 \mathrm{C}$ & $34,48 \mathrm{~A}$ & $26,91 \mathrm{~B}$ & $5,57 \mathrm{E}$ \\
\hline LA-2 & $11,63 \mathrm{D}$ & $21,12 \mathrm{AB}$ & $14,64 \mathrm{C}$ & $24,13 \mathrm{~A}$ & $17,27 \mathrm{BC}$ & $5,49 \mathrm{E}$ \\
\hline LA-3 & $15,24 \mathrm{C}$ & $29,62 \mathrm{~A}$ & $16,52 \mathrm{C}$ & $28,31 \mathrm{AB}$ & $23,28 \mathrm{~B}$ & $8,04 \mathrm{D}$ \\
\hline TR-1 & $6,69 \mathrm{D}$ & $18,35 \mathrm{~A}$ & $8,67 \mathrm{C}$ & $18,03 \mathrm{~A}$ & $11,58 \mathrm{~B}$ & $1,26 \mathrm{E}$ \\
\hline LA-4 & $16,02 \mathrm{C}$ & $30,02 \mathrm{~A}$ & $15,34 \mathrm{C}$ & $32,95 \mathrm{~A}$ & $23,95 \mathrm{~B}$ & $3,96 \mathrm{D}$ \\
\hline PV-2 & $18,46 \mathrm{BC}$ & $30,00 \mathrm{~A}$ & $16,09 \mathrm{C}$ & $28,91 \mathrm{~A}$ & $21,12 \mathrm{~B}$ & $4,79 \mathrm{D}$ \\
\hline LA-5 & $16,57 \mathrm{~B}$ & $19,92 \mathrm{AB}$ & $17,61 \mathrm{~B}$ & $22,48 \mathrm{~A}$ & $17,72 \mathrm{~B}$ & $6,42 \mathrm{C}$ \\
\hline PV-3 & $8,05 \mathrm{D}$ & $17,83 \mathrm{~A}$ & $10,83 \mathrm{C}$ & $18,02 \mathrm{~A}$ & $14,04 \mathrm{~B}$ & $3,09 \mathrm{E}$ \\
\hline $\mathrm{LRa}$ & $9,81 \mathrm{C}$ & $22,33 \mathrm{~A}$ & $11,90 \mathrm{C}$ & $24,46 \mathrm{~A}$ & $15,89 \mathrm{~B}$ & $1,67 \mathrm{D}$ \\
\hline LE-3 & $12,28 \mathrm{~B}$ & $20,55 \mathrm{~A}$ & $15,05 \mathrm{~B}$ & $22,99 \mathrm{~A}$ & $15,13 \mathrm{~B}$ & $6,99 \mathrm{C}$ \\
\hline $\mathrm{PE}$ & $10,55 \mathrm{~B}$ & $22,51 \mathrm{~A}$ & $10,90 \mathrm{~B}$ & $25,65 \mathrm{~A}$ & $23,29 \mathrm{~A}$ & $2,03 \mathrm{C}$ \\
\hline PV-4 & $14,71 \mathrm{C}$ & $28,36 \mathrm{~A}$ & $14,83 \mathrm{C}$ & $29,56 \mathrm{~A}$ & $21,79 \mathrm{~B}$ & $4,95 \mathrm{D}$ \\
\hline TR-2 & $13,03 \mathrm{~B}$ & $19,99 \mathrm{~A}$ & $12,62 \mathrm{~B}$ & $18,68 \mathrm{~A}$ & $16,48 \mathrm{~A}$ & $9,73 \mathrm{C}$ \\
\hline $\mathrm{AQa}$ & $10,73 \mathrm{C}$ & $23,69 \mathrm{~A}$ & $10,08 \mathrm{C}$ & $24,99 \mathrm{~A}$ & $18,09 \mathrm{~B}$ & $2,17 \mathrm{D}$ \\
\hline LV-1 & $14,22 \mathrm{C}$ & $29,59 \mathrm{~A}$ & $16,78 \mathrm{C}$ & $30,23 \mathrm{~A}$ & $21,69 \mathrm{~B}$ & $6,71 \mathrm{D}$ \\
\hline \multirow{3}{*}{$\begin{array}{c}\text { Solos } \\
\text { alcalinos }\end{array}$} & \multicolumn{4}{|c|}{ Composto de resíduo urbano } & \multirow{3}{*}{$\begin{array}{c}\text { Gessagem } \\
\text { e } \\
\text { adubação }\end{array}$} & \multirow{3}{*}{ Testemunha } \\
\hline & \multicolumn{2}{|c|}{ sem gessagem } & \multicolumn{2}{|c|}{ com gessagem } & & \\
\hline & sem adubaçào & com adubação & sem adubação & com adubação & & \\
\hline & 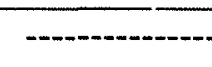 & 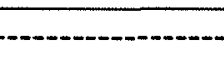 & dS n & -1 & 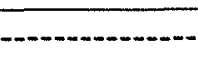 & 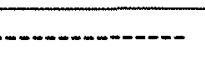 \\
\hline $\mathrm{CL}$ & $12,72 \mathrm{~B}$ & $16,31 \mathrm{~B}$ & $21,67 \mathrm{~A}$ & $24,54 \mathrm{~A}$ & $16,58 \mathrm{~B}$ & $5,22 \mathrm{C}$ \\
\hline $\mathrm{CV}$ & $18,25 \mathrm{~B}$ & $30,29 \mathrm{~A}$ & $23,86 \mathrm{~A}$ & $30,60 \mathrm{~A}$ & $26,80 \mathrm{~A}$ & $9,16 \mathrm{C}$ \\
\hline LA- 6 & $16,08 \mathrm{C}$ & $25,91 \mathrm{AB}$ & $22,86 \mathrm{~B}$ & $30,42 \mathrm{~A}$ & $28,87 \mathrm{AB}$ & $8,60 \mathrm{D}$ \\
\hline LV-2 & $17,19 \mathrm{~B}$ & $23,16 \mathrm{~A}$ & $26,19 \mathrm{~A}$ & $29,59 \mathrm{~A}$ & $23,99 \mathrm{~A}$ & $7,27 \mathrm{C}$ \\
\hline SS & $28,83 \mathrm{~B}$ & $43,93 \mathrm{~A}$ & $41,30 \mathrm{~A}$ & $44,24 \mathrm{~A}$ & $44,40 \mathrm{~A}$ & $21,40 \mathrm{C}$ \\
\hline
\end{tabular}

$\$$-Médias seguidas de mesma letra, nas colunas, não diferem entre si pelo teste de Tukey ao nível de $5 \%$. 
Nos solos alcalinos, a aplicação de composto isoladamente duplicou os valores de C.E. dos solos. Nos solos CV, LV-2 e SS os demais tratamentos apresentaram os mais altos valores de C.E. e não diferiram entre si. Os maiores valores de C.E., no solo CL, foram observados nos tratamentos com composto e gesso, com ou sem adubo, e no solo LA-6, não diferiram do gesso + adubo. Ressalta-se que, independentemente do tratamento aplicado, a C.E. no solo SS foi de 1,6 a 4,1 vezes superior aos valores observados nos demais solos alcalinos.

Resultados semelhantes foram observados por Hortenstine \& Rothwell (1972) que, avaliando a aplicação de composto de resíduo urbano sobre a correção de substrato arenoso derivado da exploração de rochas fosfatadas, verificaram um aumento linear da C.E. da areia em função da dose de aplicação.

Um aspecto importante do aumento da C.E. nos solos está associado ao potencial osmótico $\left(\psi_{0}\right)$ da solução do solo, que pode impedir o desenvolvimento das plantas (Raij, 1991; Marschner, 1995). Uma vez que o $\psi_{0}$ da solução do solo for menor que a da raiz, a planta passa a perder água (pela raiz) para o solo e sofre danos fisiológicos que pode levá-la à morte. A determinação da C.E. é uma forma rápida e simples de se avaliar o potencial osmótico, através da seguinte equação $\psi_{0}=$ C.E. x 0,036 (Marschner, 1995). Porém, de acordo com esse autor, em solos salinos a alta concentração de B pode-se tornar mais limitante ao desenvolvimento das plantas, do que a própria concentração salina..

\subsubsection{Reação do solo e acidez p otencial}

Os resultados da alteração no $\mathrm{pH}$ dos solos, em $\mathrm{CaCl}_{2} 0,01 \mathrm{~mol} \mathrm{~L}^{-1}$ e em água, devido à aplicação do composto de resíduo urbano são apresentados na Tabelas 18 e 19, respectivamente. Foram observadas diferenças entre as diferentes formas de aplicação do composto e calagem com adubação mineral nos solos ácidos ou gessagem com adubação nos solos alcalinos. Nos solos ácidos, de um modo geral, cada tratamento tendeu a promover o mesmo comportamento sobre o $\mathrm{pH}$ dos diferentes solos cujos os valores foram em ordem crescente nos seguintes tratamentos: testemunha $<$ calagem + 
Tabela 18. Variação do $\mathrm{pH}$ em $\mathrm{CaCl}_{2} 0,01 \mathrm{~mol} \mathrm{~L}^{-1}$ em solos adubados com composto de resíduo urbano.

\begin{tabular}{|c|c|c|c|c|c|c|}
\hline \multirow{3}{*}{$\begin{array}{l}\text { Solos } \\
\text { ácidos }\end{array}$} & \multicolumn{4}{|c|}{ Composto de resíduo urbano } & \multirow{3}{*}{$\begin{array}{l}\text { Calagem } \\
\mathrm{e} \\
\text { adubação }\end{array}$} & \multirow{3}{*}{ Testemunha } \\
\hline & \multicolumn{2}{|c|}{ sem calagem } & \multicolumn{2}{|c|}{ com calagem } & & \\
\hline & sem adubação & com adubação & sem adubação & com adubação & & \\
\hline $\mathrm{GPH}$ & $5,71 \mathrm{~B}^{\ddagger}$ & $5,53 \mathrm{C}$ & $5,98 \mathrm{~A}$ & $5,83 \mathrm{AB}$ & $4,87 \mathrm{D}$ & $4,69 \mathrm{E}$ \\
\hline AQd & $7,38 \mathrm{~A}$ & $6,81 \mathrm{~B}$ & $7,39 \mathrm{~A}$ & $6,91 \mathrm{~B}$ & $5,77 \mathrm{D}$ & $5,97 \mathrm{C}$ \\
\hline LUa & $4,85 \mathrm{D}$ & $4,95 \mathrm{D}$ & $6,26 \mathrm{~A}$ & $5,89 \mathrm{~B}$ & $5,18 \mathrm{C}$ & $3,97 \mathrm{E}$ \\
\hline LE-1 & $6,52 \mathrm{~A}$ & $6,25 \mathrm{~B}$ & $6,58 \mathrm{~A}$ & $6,34 \mathrm{~B}$ & $5,19 \mathrm{C}$ & $5,14 \mathrm{C}$ \\
\hline LE-2 & $5,23 \mathrm{CD}$ & $5,13 \mathrm{D}$ & $6,35 \mathrm{~A}$ & $6,15 \mathrm{~B}$ & $5,33 \mathrm{C}$ & $4,18 \mathrm{E}$ \\
\hline LA-1 & $5,36 \mathrm{C}$ & $5,33 \mathrm{C}$ & $6,52 \mathrm{~A}$ & $6,03 \mathrm{~B}$ & $5,35 \mathrm{C}$ & $4,17 \mathrm{D}$ \\
\hline PV-1 & $5,54 \mathrm{C}$ & $5,27 \mathrm{D}$ & $6,41 \mathrm{~A}$ & $6,02 \mathrm{~B}$ & $4,80 \mathrm{E}$ & $4,38 \mathrm{E}$ \\
\hline LA-2 & $5,25 \mathrm{~B}$ & $5,27 \mathrm{~B}$ & $6,15 \mathrm{~A}$ & $6,02 \mathrm{~A}$ & $5,28 \mathrm{~B}$ & $4,41 \mathrm{C}$ \\
\hline LA-3 & $6,17 \mathrm{~B}$ & $5,78 \mathrm{C}$ & $6,52 \mathrm{~A}$ & $6,21 \mathrm{~B}$ & $4,89 \mathrm{D}$ & $4,41 \mathrm{E}$ \\
\hline TR-1 & $5,75 \mathrm{~B}$ & $5,78 \mathrm{~B}$ & $6,28 \mathrm{~A}$ & $6,23 \mathrm{~A}$ & $5,49 \mathrm{C}$ & $4,55 \mathrm{D}$ \\
\hline LA-4 & $6,24 \mathrm{~B}$ & $5,79 \mathrm{C}$ & $6,74 \mathrm{~A}$ & $6,32 \mathrm{~B}$ & $5,09 \mathrm{D}$ & $4,61 \mathrm{E}$ \\
\hline PV -2 & $6,33 \mathrm{~B}$ & $6,05 \mathrm{C}$ & $6,84 \mathrm{~A}$ & $6,47 \mathrm{~B}$ & $5,48 \mathrm{D}$ & $5,04 \mathrm{E}$ \\
\hline LA-5 & $5,25 \mathrm{C}$ & $5,10 \mathrm{D}$ & $5,70 \mathrm{~A}$ & $5,50 \mathrm{~B}$ & $4,65 \mathrm{E}$ & $4,56 \mathrm{E}$ \\
\hline PV-3 & $4,85 \mathrm{D}$ & $5,00 \mathrm{C}$ & $5,71 \mathrm{~A}$ & $5,67 \mathrm{~A}$ & $5,25 \mathrm{~B}$ & $4,20 \mathrm{E}$ \\
\hline $\mathrm{LRa}$ & $5,93 \mathrm{~B}$ & $5,94 \mathrm{~B}$ & $6,41 \mathrm{~A}$ & $6,32 \mathrm{~A}$ & $5,68 \mathrm{C}$ & $4,91 \mathrm{D}$ \\
\hline LE-3 & $5,50 \mathrm{~B}$ & $5,35 \mathrm{C}$ & $6,06 \mathrm{~A}$ & $5,97 \mathrm{~A}$ & $5,16 \mathrm{D}$ & $4,42 \mathrm{E}$ \\
\hline $\mathrm{PE}$ & $5,99 \mathrm{~B}$ & $5,93 \mathrm{~B}$ & $6,41 \mathrm{~A}$ & $6,35 \mathrm{~A}$ & $5,51 \mathrm{C}$ & $4,84 \mathrm{D}$ \\
\hline PV-4 & $5,70 \mathrm{C}$ & $5,49 \mathrm{D}$ & $6,48 \mathrm{~A}$ & $6,17 \mathrm{~B}$ & $5,06 \mathrm{E}$ & $4,17 \mathrm{~F}$ \\
\hline TR-2 & $6,07 \mathrm{AB}$ & $5,96 \mathrm{~B}$ & $6,21 \mathrm{~A}$ & $6,09 \mathrm{AB}$ & $5,25 \mathrm{C}$ & $5,14 \mathrm{C}$ \\
\hline $\mathrm{AQa}$ & $5,85 \mathrm{C}$ & $5,72 \mathrm{C}$ & $6,69 \mathrm{~A}$ & $6,38 \mathrm{~B}$ & $5,29 \mathrm{D}$ & $4,26 \mathrm{E}$ \\
\hline LV-1 & $5,37 \mathrm{C}$ & $5,23 \mathrm{C}$ & $6,22 \mathrm{~A}$ & $5,92 \mathrm{~B}$ & $4,98 \mathrm{D}$ & $4,10 \mathrm{E}$ \\
\hline \multirow{3}{*}{$\begin{array}{c}\text { Solos } \\
\text { alcalinos }\end{array}$} & \multicolumn{4}{|c|}{ Composto de resíduo urbano } & \multirow{3}{*}{$\begin{array}{l}\text { Gessagem } \\
\text { e } \\
\text { adubação }\end{array}$} & \multirow{3}{*}{ Testemunha } \\
\hline & \multicolumn{2}{|c|}{ sem gessagem } & \multicolumn{2}{|c|}{ com gessagem } & & \\
\hline & sem adubação & com adubação & sem adubação & com adubação & & \\
\hline $\mathrm{CL}$ & $6,68 \mathrm{~A}$ & $6,55 \mathrm{~B}$ & $6,66 \mathrm{~A}$ & $6,57 \mathrm{~B}$ & $5,89 \mathrm{C}$ & $5,86 \mathrm{C}$ \\
\hline CV & $7,66 \mathrm{~A}$ & $7,51 \mathrm{BC}$ & $7,67 \mathrm{~A}$ & $7,53 \mathrm{~B}$ & $7,43 \mathrm{C}$ & $7,52 \mathrm{~B}$ \\
\hline LA-6 & $7,40 \mathrm{~A}$ & $7,17 \mathrm{~B}$ & $7,39 \mathrm{~A}$ & $7,18 \mathrm{~B}$ & $6,52 \mathrm{D}$ & $6,65 \mathrm{C}$ \\
\hline$L V-2$ & $7,50 \mathrm{AB}$ & $7,37 \mathrm{C}$ & $7,56 \mathrm{~A}$ & $7,42 \mathrm{BC}$ & $7,01 \mathrm{E}$ & $7,14 \mathrm{D}$ \\
\hline SS & $7,84 \mathrm{~A}$ & $7,55 \mathrm{~B}$ & $7,81 \mathrm{~A}$ & $7,58 \mathrm{~B}$ & $7,51 \mathrm{~B}$ & $7,81 \mathrm{~A}$ \\
\hline
\end{tabular}

$\$$ - Médias seguidas de mesma letra, nas colunas, não diferem entre si pelo teste de Tukey ao nível de $5 \%$. 
Tabela 19. Variação do $\mathrm{pH}$ em água em solos adubados com composto de resíduo urbano.

\begin{tabular}{|c|c|c|c|c|c|c|}
\hline \multirow{3}{*}{$\begin{array}{l}\text { Solos } \\
\text { ácidos }\end{array}$} & \multicolumn{4}{|c|}{ Composto de residuo urbano } & \multirow{3}{*}{$\begin{array}{c}\text { Adubação } \\
\text { e } \\
\text { calagem }\end{array}$} & \multirow{3}{*}{ Testemunha } \\
\hline & \multicolumn{2}{|c|}{ sem calagem } & \multicolumn{2}{|c|}{ com calagem } & & \\
\hline & sem adubação & com adubação & sem adubação & com adubação & & \\
\hline GPH & $5,74 \mathrm{~B}^{\ddagger}$ & $5,49 \mathrm{C}$ & $5,93 \mathrm{~A}$ & $5,59 \mathrm{BC}$ & $4,88 \mathrm{D}$ & $5,01 \mathrm{D}$ \\
\hline AQd & $7,90 \mathrm{~A}$ & $7,15 \mathrm{~B}$ & $7,95 \mathrm{~A}$ & $7,23 \mathrm{~B}$ & $5,89 \mathrm{C}$ & $6,56 \mathrm{C}$ \\
\hline LUa & $5,26 \mathrm{C}$ & $5,08 \mathrm{D}$ & $6,41 \mathrm{~A}$ & $6,01 \mathrm{~B}$ & $5,26 \mathrm{C}$ & $4,37 \mathrm{E}$ \\
\hline LE-1 & $6,62 \mathrm{~A}$ & $6,22 \mathrm{~B}$ & $6,74 \mathrm{~A}$ & $6,20 \mathrm{~B}$ & $5,26 \mathrm{C}$ & $5,38 \mathrm{C}$ \\
\hline LE-2 & $5,48 \mathrm{CD}$ & $5,32 \mathrm{D}$ & $6,64 \mathrm{~A}$ & $6,28 \mathrm{~B}$ & $5,49 \mathrm{C}$ & $4,62 \mathrm{E}$ \\
\hline LA-1 & $5,77 \mathrm{C}$ & $5,53 \mathrm{D}$ & $6,88 \mathrm{~A}$ & $6,30 \mathrm{~B}$ & $5,68 \mathrm{CD}$ & $4,82 \mathrm{E}$ \\
\hline PV -1 & $5,92 \mathrm{C}$ & $5,52 \mathrm{D}$ & $6,71 \mathrm{~A}$ & $6,28 \mathrm{~B}$ & $4,97 \mathrm{E}$ & $5,02 \mathrm{E}$ \\
\hline LA-2 & $5,62 \mathrm{C}$ & $5,48 \mathrm{C}$ & $6,44 \mathrm{~A}$ & $6,22 \mathrm{~B}$ & $5,49 \mathrm{C}$ & $5,15 \mathrm{D}$ \\
\hline LA-3 & $6,49 \mathrm{~B}$ & $6,02 \mathrm{C}$ & $6,82 \mathrm{~A}$ & $6,39 \mathrm{~B}$ & $5,06 \mathrm{D}$ & $4,68 \mathrm{E}$ \\
\hline TR-1 & $6,16 \mathrm{C}$ & $6,00 \mathrm{D}$ & $6,54 \mathrm{~A}$ & $6,35 \mathrm{~B}$ & $5,61 \mathrm{E}$ & $4,99 \mathrm{~F}$ \\
\hline LA-4 & $6,52 \mathrm{~B}$ & $6,09 \mathrm{C}$ & $6,96 \mathrm{~A}$ & $6,51 \mathrm{~B}$ & $5,26 \mathrm{D}$ & $5,18 \mathrm{D}$ \\
\hline PV-2 & $6,62 \mathrm{~B}$ & $6,33 \mathrm{C}$ & $7,04 \mathrm{~A}$ & $6,63 \mathrm{~B}$ & $5,68 \mathrm{D}$ & $5,75 \mathrm{D}$ \\
\hline LA-5 & $5,30 \mathrm{~B}$ & $5,06 \mathrm{C}$ & $5,68 \mathrm{~A}$ & $5,41 \mathrm{~B}$ & $4,61 \mathrm{D}$ & $4,75 \mathrm{D}$ \\
\hline PV-3 & $5,16 \mathrm{D}$ & $5,13 \mathrm{D}$ & $5,95 \mathrm{~A}$ & $5,76 \mathrm{~B}$ & $5,34 \mathrm{C}$ & $4,28 \mathrm{E}$ \\
\hline LRa & $6,26 \mathrm{BC}$ & $6,14 \mathrm{C}$ & $6,69 \mathrm{~A}$ & $6,38 \mathrm{~B}$ & $5,79 \mathrm{D}$ & $5,47 \mathrm{E}$ \\
\hline LE-3 & $5,86 \mathrm{~B}$ & $5,57 \mathrm{C}$ & $6,21 \mathrm{~A}$ & $6,09 \mathrm{~A}$ & $5,36 \mathrm{D}$ & $4,66 \mathrm{E}$ \\
\hline PE & $6,18 \mathrm{C}$ & $5,96 \mathrm{D}$ & $6,62 \mathrm{~A}$ & $6,41 \mathrm{~B}$ & $5,76 \mathrm{E}$ & $5,44 \mathrm{~F}$ \\
\hline PV-4 & $6,03 \mathrm{C}$ & $5,68 \mathrm{D}$ & $6,78 \mathrm{~A}$ & $6,36 \mathrm{~B}$ & $5,29 \mathrm{E}$ & $4,44 \mathrm{~F}$ \\
\hline TR-2 & $6,39 \mathrm{~B}$ & $6,22 \mathrm{C}$ & $6,54 \mathrm{~A}$ & $6,30 \mathrm{BC}$ & $5,51 \mathrm{D}$ & $5,46 \mathrm{D}$ \\
\hline $\mathrm{AQa}$ & $6,25 \mathrm{C}$ & $5,79 \mathrm{D}$ & $6,94 \mathrm{~A}$ & $6,42 \mathrm{~B}$ & $5,36 \mathrm{E}$ & $4,89 \mathrm{~F}$ \\
\hline LV-1 & $5,81 \mathrm{C}$ & $5,45 \mathrm{D}$ & $6,56 \mathrm{~A}$ & $6,17 \mathrm{~B}$ & $5,24 \mathrm{E}$ & $4,20 \mathrm{~F}$ \\
\hline \multirow{3}{*}{$\begin{array}{l}\text { Solos } \\
\text { alcalinos }\end{array}$} & \multicolumn{4}{|c|}{ Composto de resíduo urbano } & \multirow{3}{*}{$\begin{array}{c}\text { Gessagem } \\
\mathrm{e} \\
\text { adubação }\end{array}$} & \multirow{3}{*}{ Testemunha } \\
\hline & sem ge & sagem & com ge & ssagem & & \\
\hline & sem adubação & com adubação & sem adubação & com adubação & & \\
\hline $\mathrm{CL}$ & $6,82 \mathrm{~A}$ & $6,67 \mathrm{BC}$ & $6,72 \mathrm{~B}$ & $6,59 \mathrm{C}$ & $5,95 \mathrm{E}$ & $6,05 \mathrm{D}$ \\
\hline $\mathrm{CV}$ & $7,75 \mathrm{~A}$ & $7,46 \mathrm{C}$ & $7,72 \mathrm{~A}$ & $7,57 \mathrm{~B}$ & $7,38 \mathrm{C}$ & $7,69 \mathrm{~A}$ \\
\hline LA-6 & $7,62 \mathrm{~A}$ & $7,28 \mathrm{C}$ & $7,51 \mathrm{~B}$ & $7,24 \mathrm{C}$ & $6,57 \mathrm{E}$ & $6,89 \mathrm{D}$ \\
\hline LV-2 & $7,60 \mathrm{~A}$ & $7,39 \mathrm{BC}$ & $7,55 \mathrm{~A}$ & $7,44 \mathrm{~B}$ & $7,03 \mathrm{D}$ & $7,32 \mathrm{C}$ \\
\hline SS & $8,19 \mathrm{~A}$ & $7,77 \mathrm{C}$ & $7,95 \mathrm{~B}$ & $7,73 \mathrm{C}$ & $7,63 \mathrm{D}$ & $8,22 \mathrm{~A}$ \\
\hline
\end{tabular}

$\$$ - Médias seguidas de mesma letra, nas colunas, não diferem entre si pelo teste de Tukey ao nível de $5 \%$. 
adubação $\leq$ composto + adubo $\leq$ composto $\leq$ composto com calagem + adubação $\leq$ composto com calagem. Exceto nos solos LE-1, LA-5 e TR-2, onde não houve diferença significativa entre testemunha e calagem + adubação, e no solos AQd aonde o pH na testemunha $(5,97)$ foi superior a calagem + adubação $(5,77)$. Esse efeito, se deve principalmente ao elevado poder acidificante da adubação nitrogenada com uréia, associado a dose baixa de calcário aplicado a esses solos, que apresentavam inicialmente pH elevado e/ou alta saturação por base, uma vez que a dose de calcário foi em função deste parâmetro.

Esse efeito da adubação nitrogenada foi ainda mais acentuado sobre o $\mathrm{pH}$ em água, o que pode ser observado pela menor diferença entre os valores de $\mathrm{pH}$, entre os tratamentos testemunha e calagem + adubação (Tabela 19). Enquanto que, os adubos nitrogenados, sulfato de amônio e uréia apresentaram alto índice de acidificação do solo, superfosfato simples e KCl não modificam a reação do solo (Raij, 1991).

Verificou-se que a aplicação de composto + adubo aumentou o pH em $\mathrm{CaCl}_{2}$ do solo em média de 1 unidade, o composto isoladamente em 1,2 unidades, o composto + calcário + adubo em 1,6 unidades e o composto + calcário em 1,8 unidades. O efeito da aplicação de composto sobre a reação do solo foi mais acentuada nos solos arenosos do que nos solos de textura mais argilosa. Resultados semelhantes foram observados por Hortenstine \& Rothwell (1972), entretanto Mazur et al. (1983) constataram resultados diferentes quanto a forma de aplicação do composto, obtendo valor de pH superior para a aplicação simultânea de composto $\left(30 \mathrm{t} \mathrm{ha}^{-1}\right)$, calagem $(2,5$ $t$ ha $\left.{ }^{-1}\right)$ e nitrogênio (60 $\mathrm{tha}^{-1}$, na forma de uréia) em relação à aplicação de composto e calagem.

A aplicação do composto promoveu efeito distinto sobre a reação de cada um dos solos alcalinos (Tabelas 18 e 19, respectivamente). Nos solos CL, LA-6 e LV-2, a aplicação de composto, na ausência ou presença de gesso, promoveu os maiores valores de $\mathrm{pH}$, enquanto que o composto + adubo, com ou sem gesso, apresentou valores intermediários de pH. Nos solos CV e SS, a aplicação isolada de composto não diferiu da testemunha, e os demais tratamentos com composto abaixaram significativamente $o$ $\mathrm{pH}$ do solo. Em todos os solos alcalinos, a maior redução no $\mathrm{pH}$ foi promovida pela 
gessagem + adubação, exceto no CL. No CV a aplicação de composto + adubação não diferiu da testemunha.

$\mathrm{O}$ aumento de $\mathrm{pH}$ dos solos ácidos devido à aplicação do composto é proporcionado pelo aumento nos teores de bases trocáveis do solo (Mazur et al., 1983) e pela presença de humatos alcalinos no composto (Kiehl, 1985). De acordo com Glória (1992), a matéria orgânica adicionada ao solo sofre uma oxidação e libera elétrons, esses elétrons são recebidos por $\mathrm{H}^{+}$resultando na neutralização direta da acidez, ou pelo $\mathrm{O}_{2}$ com a formação de íons $\mathrm{O}^{2-}$, que apresentam forte característica básica, promovendo à neutralização indireta. Conclui-se que efeito alcalinizante do composto é diretamente proporcional à carga orgânica adicionada ao solo.

Em todos os solos, ácidos e alcalinos, houve alta correlação entre o $\mathrm{pH}$ em $\mathrm{CaCl}_{2}$ e em água (Figura 4). Pode-se observar, pelas equações de regressões, que o $\mathrm{pH}$ em água foi superior ao $\mathrm{pH}$ em $\mathrm{CaCl}_{2}$ em 0,46 unidades, em média. Diferença que é muito próxima a da que tem sido verificado para solos do Estado de São Paulo, que é de 0,6 unidades (Raij, 1991). Os valores de $\mathrm{pH}$ em $\mathrm{CaCl}_{2}$ e em água nos solos alcalinos foram muito próximos entre si, sendo que o $\mathrm{pH}$ em água foi 0,1 unidades inferior ao medido em $\mathrm{CaCl}_{2} \quad 0,01 \mathrm{~mol} \mathrm{~L}^{-1}$.

A diferença entre os valores de $\mathrm{pH}$ em água e em $\mathrm{CaCl}_{2}$ foi influenciado significativamente pela condutividade elétrica (Figura 5). Esse fato está associado ao efeito da concentração salina dos adubos e composto sobre o valor de $\mathrm{pH}$. Assim, nos solos ácidos, existe uma maior diferença entre o $\mathrm{pH}$ em água e em $\mathrm{CaCl}_{2}$ em solos com menor C.E. $\left(<10 \mathrm{dS} \mathrm{m}^{-1}\right)$ do que em solos com alta C.E. $\left(>15 \mathrm{dS} \mathrm{m}^{-1}\right)$, como ocorreu nos solos AQd, LUa, LA-1, PV-1, LA-2, etc. em que apresentaram valores de $\mathrm{pH}$ em água inferiores do que em $\mathrm{CaCl}_{2}$. Nos solos alcalinos, onde normalmente a concentração salina já é elevada, não houve efeito da regressão linear entre a diferença de $\mathrm{pH}$ e a C.E. De acordo com Raij (1991), a medida do pH em água fornece valores variáveis em função da época do ano, manuseio da amostra, mineralização nas amostras e adubações recentes, enquanto que a solução de $\mathrm{CaCl}_{2}$ permite equilibrar os efeitos dos sais e os resultados são pouco modificados pela reação do solo. 


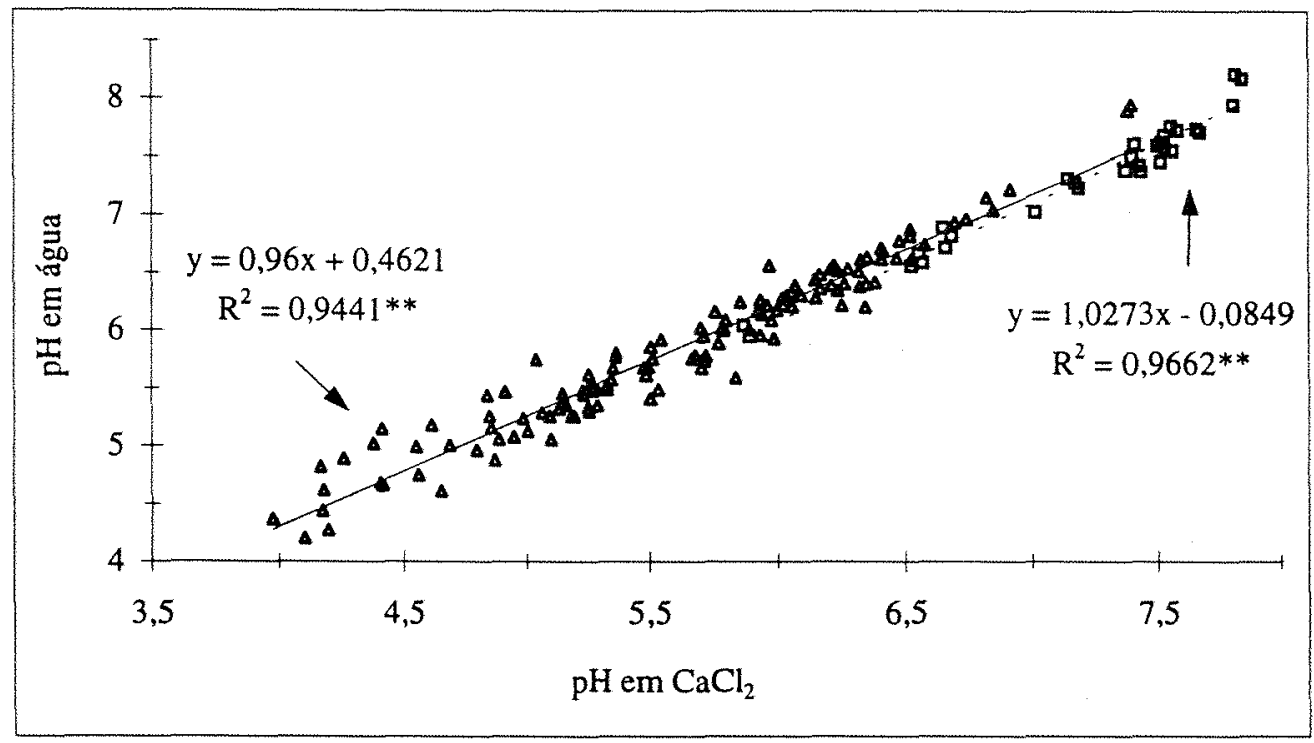

Figura 4. Relação entre o pH em $\mathrm{CaCl}_{2}$ e o pH em água nos solos ácidos (alinha contínua) e solos alcalinos (clinha pontilhada).

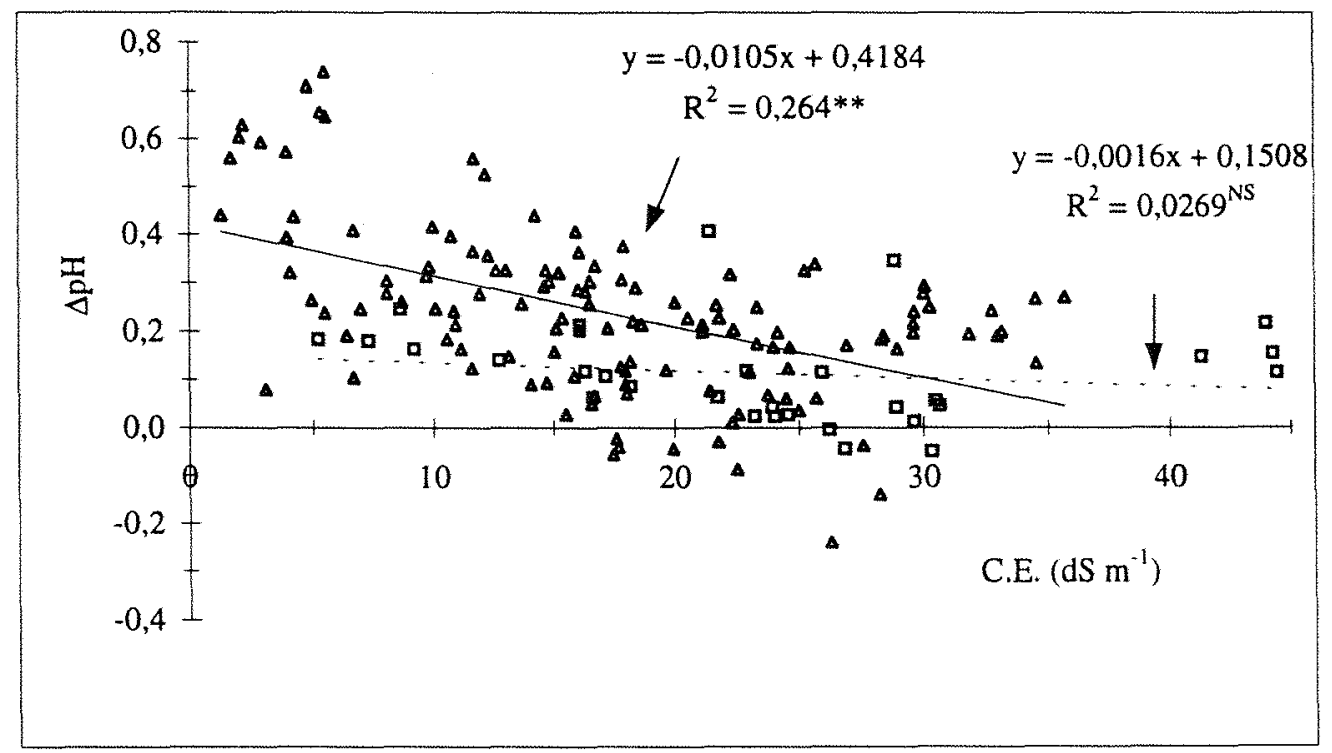

Figura 5. Efeito da condutividade elétrica do solo sobre a diferença entre o pH em água e o $\mathrm{pH}$ em $\mathrm{CaCl}_{2}(\Delta \mathrm{pH})$, devido à aplicação de composto de resíduo urbano, com e sem calagem e adubação, em solos ácidos ( $\Delta$ linha contínua) e solos alcalinos (linha pontilhada). 
A acidez potencial $\left(\mathrm{H}^{+}+\mathrm{Al}^{3+}\right)$, nos solos ácidos, variou de 13,9 a 109 mmol $_{c} \mathrm{dm}^{-3}$ nos tratamentos testemunha, sendo o menor valor observado no solo AQd e o maior no PV-3 (Tabela 20). A aplicação do composto + calagem causou a maior redução da concentração de $\mathrm{H}+\mathrm{Al}$, exceto nos solos $\mathrm{PV}-3$, LE-3 e PE, onde não diferiu do composto + calcário + adubação; e nos solos AQd, LE-1 e TR-2, onde não diferiu da aplicação isolada do composto. O tratamento com composto + adubo, dentre os tratamentos com composto, foi o que apresentou menor redução do $\mathrm{H}+\mathrm{Al}$ em todos os solos. A redução do $\mathrm{H}+\mathrm{Al}$ devido à calagem + adubação, de modo semelhante ao que ocorreu com o $\mathrm{pH}$, foi proporcional à dose de calcário aplicado, não diferindo da testemunha nos solos GPH, LE-1, LA-4, LA-5 e TR-2, e no solo AQd foi superior, devido à acidificação residual da uréia e baixa dose de calcário aplicado. Resultados semelhantes foram obtidos por Ferro Neto (1994), que relatou redução de $30 \%$ na acidez potencial devido à aplicação de $30 \mathrm{tha}^{-1}$ de composto de resíduo urbano.

Nos solos alcalinos, a acidez potencial, que é baixa pela própria natureza desses solos, foi aumentada em média de $1 \mathrm{mmol}_{\mathrm{c}} \mathrm{dm}^{-3}$ devido à gessagem + adubação, exceto no solo CL onde não houve diferença com a testemunha. Em todos os solos, a aplicação de composto + adubo, com ou sem gesso, causou a maior redução do $\mathrm{H}+\mathrm{Al}$; porém no solo CL, não diferiram composto e composto + adubo. No solo SS a aplicação do composto, com ou sem adubo, não diferiu da testemunha.

Pode-se observar pela Figura 6 que houve uma relação significativa entre os teores de $\mathrm{H}+\mathrm{Al}$ e o $\mathrm{pH}$ dos solos. A redução da acidez potencial está em concordância com os processos alcalinizantes descritos por Kiehl (1985) e Glória (1992), onde há neutralização direta de $\mathrm{H}^{+}$, neutralização do $\mathrm{Al}^{3+}$ devido à elevação do pH e a formação de complexos. 
Tabela 20. Acidez potencial em solos adubados com composto de resíduo urbano.

\begin{tabular}{|c|c|c|c|c|c|c|}
\hline \multirow{3}{*}{$\begin{array}{l}\text { Solos } \\
\text { ácidos }\end{array}$} & \multicolumn{4}{|c|}{ Composto de resíduo urbano } & \multirow{3}{*}{$\begin{array}{c}\text { Calagem } \\
\mathrm{e} \\
\text { adubação }\end{array}$} & \multirow{3}{*}{ Testemunha } \\
\hline & \multicolumn{2}{|c|}{ sem calagem } & \multicolumn{2}{|c|}{ com calagem } & & \\
\hline & sem adubação & com adubação & sem adubação & com adubação & & \\
\hline & & & $\ldots-\mathrm{mmol}_{\mathrm{c}}$ & $\mathrm{dm}^{-3}$ & - & (n) \\
\hline GPH & $19,8 \mathrm{C}^{\dagger}$ & $22,8 \mathrm{~B}$ & $17,5 \mathrm{D}$ & $19,5 \mathrm{C}$ & $32,1 \mathrm{~A}$ & $35,2 \mathrm{~A}$ \\
\hline $\mathrm{AQd}$ & $11,2 \mathrm{D}$ & $12,7 \mathrm{C}$ & $11,2 \mathrm{D}$ & $12,5 \mathrm{C}$ & $15,7 \mathrm{~A}$ & $13,9 \mathrm{~B}$ \\
\hline LUa & $45,8 \mathrm{~B}$ & $45,6 \mathrm{~B}$ & $18,7 \mathrm{E}$ & $23,6 \mathrm{D}$ & $36,3 \mathrm{C}$ & $86,0 \mathrm{~A}$ \\
\hline LE-1 & $17,5 \mathrm{CD}$ & $19,7 \mathrm{~B}$ & $17,0 \mathrm{D}$ & $18,5 \mathrm{BC}$ & $29,6 \mathrm{~A}$ & $28,1 \mathrm{~A}$ \\
\hline LE-2 & $31,5 \mathrm{C}$ & $37,8 \mathrm{~B}$ & $16,9 \mathrm{E}$ & $19,5 \mathrm{D}$ & $31,5 \mathrm{C}$ & $60,1 \mathrm{~A}$ \\
\hline LA-1 & $22,8 \mathrm{C}$ & $25,1 \mathrm{~B}$ & $14,7 \mathrm{E}$ & $18,1 \mathrm{D}$ & $22,9 \mathrm{C}$ & $38,7 \mathrm{~A}$ \\
\hline PV-1 & $20,6 \mathrm{D}$ & $24,8 \mathrm{C}$ & $15,0 \mathrm{~F}$ & $17,6 \mathrm{E}$ & $29,5 \mathrm{~B}$ & $32,7 \mathrm{~A}$ \\
\hline LA-2 & $29,8 \mathrm{~B}$ & $30,8 \mathrm{~B}$ & $17,7 \mathrm{D}$ & $19,4 \mathrm{C}$ & $29,3 \mathrm{~B}$ & $50,1 \mathrm{~A}$ \\
\hline LA-3 & $17,4 \mathrm{D}$ & $20,7 \mathrm{C}$ & $14,6 E$ & $17,0 \mathrm{D}$ & $31,0 \mathrm{~B}$ & $37,2 \mathrm{~A}$ \\
\hline TR-1 & $27,1 \mathrm{C}$ & $27,8 \mathrm{C}$ & $20,1 \mathrm{E}$ & $22,3 \mathrm{D}$ & $31,7 \mathrm{~B}$ & $47,7 \mathrm{~A}$ \\
\hline LA-4 & $17,5 \mathrm{C}$ & $21,4 \mathrm{~B}$ & $14,6 \mathrm{D}$ & $17,5 \mathrm{C}$ & $27,6 \mathrm{~A}$ & $29,9 \mathrm{~A}$ \\
\hline PV-2 & $16,6 \mathrm{D}$ & $18,5 \mathrm{C}$ & $13,9 \mathrm{E}$ & $16,2 \mathrm{D}$ & $22,1 \mathrm{~B}$ & $24,3 \mathrm{~A}$ \\
\hline LA-5 & $33,2 \mathrm{C}$ & $37,7 \mathrm{~B}$ & $25,9 \mathrm{E}$ & $30,0 \mathrm{D}$ & $49,2 \mathrm{~A}$ & $51,2 \mathrm{~A}$ \\
\hline PV-3 & $67,4 \mathrm{~B}$ & $61,6 \mathrm{~B}$ & $35,0 \mathrm{D}$ & $36,2 \mathrm{D}$ & $49,3 \mathrm{C}$ & $109,0 \mathrm{~A}$ \\
\hline LRa & $22,6 \mathrm{C}$ & $24,1 \mathrm{C}$ & $17,7 \mathrm{E}$ & $19,3 \mathrm{D}$ & $27,7 \mathrm{~B}$ & $37,5 \mathrm{~A}$ \\
\hline LE-3 & $32,5 \mathrm{C}$ & $35,6 \mathrm{C}$ & $23,6 \mathrm{D}$ & $24,8 \mathrm{D}$ & $39,6 \mathrm{~B}$ & $58,6 \mathrm{~A}$ \\
\hline $\mathrm{PE}$ & $22,1 \mathrm{D}$ & $24,0 \mathrm{C}$ & $18,0 \mathrm{E}$ & $18,9 \mathrm{E}$ & $29,4 \mathrm{~B}$ & $38,5 \mathrm{~A}$ \\
\hline PV-4 & $22,1 \mathrm{D}$ & $26,0 \mathrm{C}$ & $16,7 \mathrm{~F}$ & $18,8 \mathrm{E}$ & $30,0 \mathrm{~B}$ & $43,9 \mathrm{~A}$ \\
\hline TR-2 & $24,8 \mathrm{CD}$ & $27,5 \mathrm{~B}$ & $23,1 \mathrm{D}$ & $25,4 \mathrm{BC}$ & $42,2 \mathrm{~A}$ & $42,6 \mathrm{~A}$ \\
\hline $\mathrm{AQa}$ & $23,1 \mathrm{C}$ & $25,0 \mathrm{C}$ & $16,7 \mathrm{E}$ & $19,2 \mathrm{D}$ & $29,3 \mathrm{~B}$ & $45,8 \mathrm{~A}$ \\
\hline LV-1 & $30,7 \mathrm{D}$ & $34,4 \mathrm{C}$ & $19,5 \mathrm{~F}$ & $23,8 \mathrm{E}$ & $38,4 \mathrm{~B}$ & $62,2 \mathrm{~A}$ \\
\hline \multirow{3}{*}{$\begin{array}{l}\text { Solos } \\
\text { alcalinos }\end{array}$} & \multicolumn{4}{|c|}{ Composto de resíduo urbano } & \multirow{3}{*}{$\begin{array}{c}\text { Gessagem } \\
\text { e } \\
\text { adubação }\end{array}$} & \multirow{3}{*}{ Testemunha } \\
\hline & \multicolumn{2}{|c|}{ sem gessagem } & \multicolumn{2}{|c|}{ com gessagem } & & \\
\hline & sem adubação & com adubação & sem adubação & com adubação & & \\
\hline & - & .................. & mmol & $\mathrm{dm}^{-3}$ & (n) & - \\
\hline $\mathrm{CL}$ & $17,8 \mathrm{~B}$ & $18,0 \mathrm{~B}$ & $17,4 \mathrm{~B}$ & $18,2 \mathrm{~B}$ & $26,3 \mathrm{~A}$ & $26,4 \mathrm{~A}$ \\
\hline $\mathrm{CV}$ & $10,0 \mathrm{C}$ & $10,8 \mathrm{~B}$ & $10,0 \mathrm{C}$ & $10,7 \mathrm{~B}$ & $11,5 \mathrm{~A}$ & $11,0 \mathrm{~B}$ \\
\hline LA-6 & $11,5 \mathrm{D}$ & $12,7 \mathrm{C}$ & $11,5 \mathrm{D}$ & $12,7 \mathrm{C}$ & $16,9 \mathrm{~A}$ & $15,8 \mathrm{~B}$ \\
\hline LV-2 & $10,5 \mathrm{D}$ & $11,4 \mathrm{C}$ & $10,3 \mathrm{D}$ & $11,1 \mathrm{C}$ & $13,7 \mathrm{~A}$ & $12,9 \mathrm{~B}$ \\
\hline SS & $9,3 \mathrm{C}$ & $10,3 \mathrm{AB}$ & $9,3 \mathrm{C}$ & $10,1 \mathrm{~B}$ & $10,5 \mathrm{~A}$ & $9,5 \mathrm{C}$ \\
\hline
\end{tabular}

$\$$ - Médias seguidas de mesma letra, nas colunas, não diferem entre si pelo teste de Tukey ao nível de $5 \%$. 


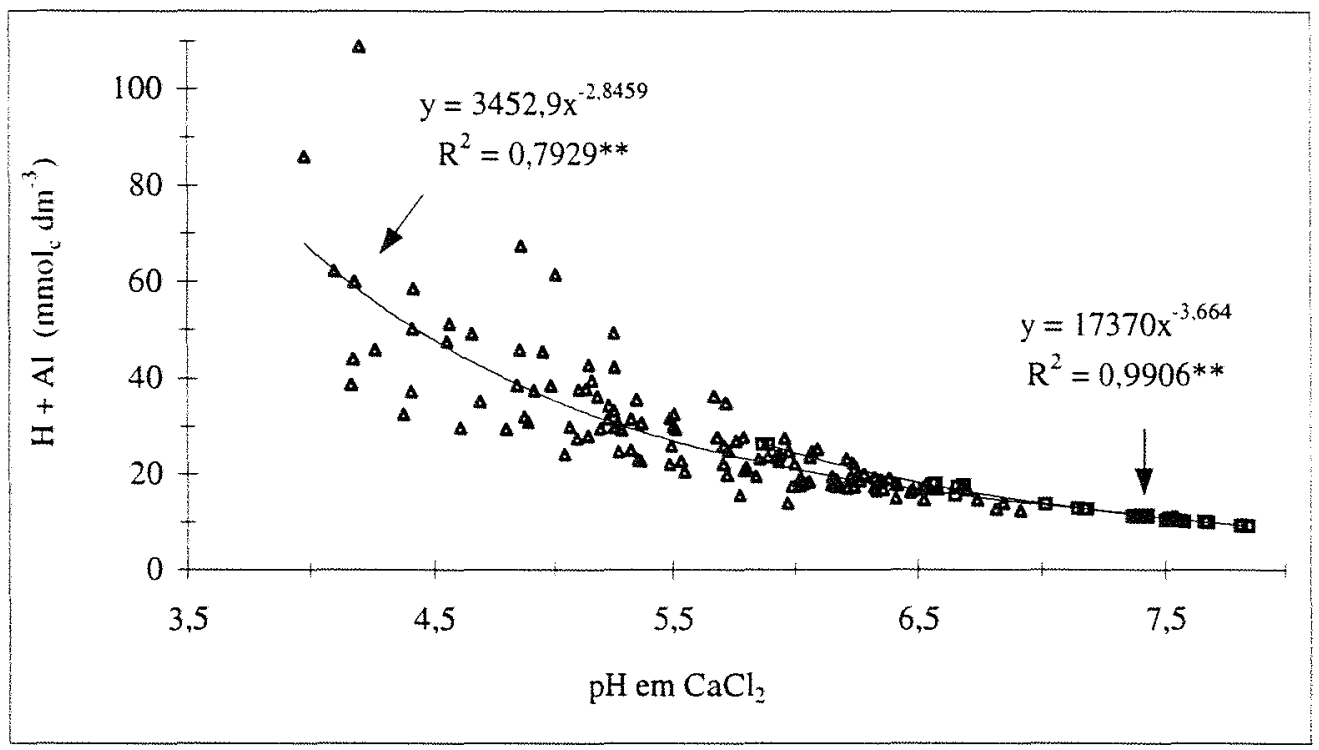

Figura 6. Relação entre a acidez ativa $\left(\mathrm{pH}\right.$ em $\left.\mathrm{CaCl}_{2}\right)$ e a acidez potencial devido à aplicação do composto de resíduo urbano, com e sem calagem e adubação, em solos ácidos ( $\Delta$ ) e solos alcalinos ( $)$.

\subsubsection{Carbono orgânico, nitrogênio total e relação $\mathrm{C} / \mathrm{N}$}

A aplicação do composto, independentemente da calagem e adubação, aumentou significativamente os teores de carbono orgânico nos solos ácidos, exceto nos solos GPH, PV-1 e PV-3 (Tabela 21). A aplicação de calagem + adubo mineral causou um comportamento indefinido sobre os teores de $\mathrm{C}$ orgânico, que às vezes apresentou tendência de aumento e outras de diminuição; entretanto não diferindo significativamente da testemunha em nenhum dos solos e foi semelhante a qualquer forma de aplicação do composto nos solos LE-2, PV-1, TR-1, PV-3, LRa e AQa. Em geral, a aplicação de composto, independentemente do modo, promoveu um aumento no C orgânico de 2 a $3 \mathrm{mg} \mathrm{dm}^{-3}$, excluindo-se o solo AQd.

Nesse solo a aplicação de composto duplicou o teor de C, porém, observando-se uma redução do teor apresentado na amostra inicial (Tabela 10), 
Tabela 21. Carbono orgânico em solos adubados com composto de resíduo urbano.

\begin{tabular}{|c|c|c|c|c|c|c|}
\hline \multirow{3}{*}{$\begin{array}{l}\text { Solos } \\
\text { ácidos }\end{array}$} & \multicolumn{4}{|c|}{ Composto de resíduo urbano } & \multirow{3}{*}{$\begin{array}{c}\text { Calagem } \\
\text { e } \\
\text { adubação }\end{array}$} & \multirow{3}{*}{ Testemunha } \\
\hline & \multicolumn{2}{|c|}{ sem calagem } & \multicolumn{2}{|c|}{ com calagem } & & \\
\hline & sem adubação & com adubação & sem adubação & com adubação & & \\
\hline & 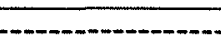 & & 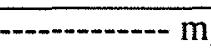 & $\mathrm{dm}^{-3}-\cdots$ & & \\
\hline GPH & $14,2 \mathrm{~A}^{\ddagger}$ & $14,8 \mathrm{~A}$ & $12,2 \mathrm{AB}$ & $14,6 \mathrm{~A}$ & $10,7 \mathrm{~B}$ & $12,1 \mathrm{AB}$ \\
\hline AQd & $10,7 \mathrm{~A}$ & $11,0 \mathrm{~A}$ & $10,7 \mathrm{~A}$ & $12,7 \mathrm{~A}$ & $5,8 \mathrm{~B}$ & $5,5 \mathrm{~B}$ \\
\hline LUa & $27,1 \mathrm{~A}$ & $25,6 \mathrm{AB}$ & $26,0 \mathrm{~A}$ & $25,0 \mathrm{ABC}$ & $22,9 \mathrm{C}$ & $23,0 \mathrm{BC}$ \\
\hline LE-1 & $18,6 \mathrm{~A}$ & $17,3 \mathrm{~A}$ & $17,7 \mathrm{~A}$ & $19,0 \mathrm{~A}$ & $13,5 \mathrm{~B}$ & $14,2 \mathrm{~B}$ \\
\hline LE-2 & $27,1 \mathrm{~A}$ & $27,9 \mathrm{~A}$ & $26,1 \mathrm{AB}$ & $27,3 \mathrm{~A}$ & $25,4 \mathrm{AB}$ & $24,4 \mathrm{~B}$ \\
\hline LA-1 & $19,8 \mathrm{~A}$ & $19,4 \mathrm{~A}$ & $19,1 \mathrm{~A}$ & $19,1 \mathrm{~A}$ & $14,7 \mathrm{~B}$ & $15,8 \mathrm{~B}$ \\
\hline PV-1 & $19,2 \mathrm{~A}$ & $18,2 \mathrm{~A}$ & $18,6 \mathrm{~A}$ & $18,8 \mathrm{~A}$ & $17,2 \mathrm{~A}$ & $18,0 \mathrm{~A}$ \\
\hline LA-2 & $30,3 \mathrm{AB}$ & $31,6 \mathrm{~A}$ & $30,9 \mathrm{~A}$ & $31,0 \mathrm{~A}$ & $28,1 \mathrm{BC}$ & $27,0 \mathrm{C}$ \\
\hline LA-3 & $20,4 \mathrm{ABC}$ & $21,2 \mathrm{AB}$ & $21,6 \mathrm{AB}$ & $22,0 \mathrm{~A}$ & $19,1 \mathrm{BC}$ & $17,8 \mathrm{C}$ \\
\hline TR-1 & $12,8 \mathrm{AB}$ & $13,8 \mathrm{AB}$ & $13,6 \mathrm{AB}$ & $15,0 \mathrm{~A}$ & $13,0 \mathrm{AB}$ & $11,1 \mathrm{~B}$ \\
\hline LA-4 & $13,4 \mathrm{AB}$ & $13,2 \mathrm{AB}$ & $13,2 \mathrm{ABC}$ & $15,0 \mathrm{~A}$ & $10,4 \mathrm{BC}$ & $9,9 \mathrm{C}$ \\
\hline PV-2 & $15,1 \mathrm{~A}$ & $14,7 \mathrm{AB}$ & $14,4 \mathrm{AB}$ & $16,5 \mathrm{~A}$ & $10,8 \mathrm{C}$ & $11,5 \mathrm{BC}$ \\
\hline LA-5 & $22,3 \mathrm{~A}$ & $21,3 \mathrm{~A}$ & $21,7 \mathrm{~A}$ & $22,5 \mathrm{~A}$ & $18,2 \mathrm{~B}$ & $18,4 \mathrm{~B}$ \\
\hline PV -3 & $36,0 \mathrm{~A}$ & $36,0 \mathrm{~A}$ & $36,0 \mathrm{~A}$ & $35,9 \mathrm{~A}$ & $34,7 \mathrm{~A}$ & $34,4 \mathrm{~A}$ \\
\hline LRa & $26,9 \mathrm{AB}$ & $27,5 \mathrm{~A}$ & $25,1 \mathrm{AB}$ & $27,1 \mathrm{AB}$ & $26,8 \mathrm{AB}$ & 24,7 B \\
\hline LE-3 & $24,7 \mathrm{~A}$ & $23,5 \mathrm{~A}$ & $23,5 \mathrm{~A}$ & $22,3 \mathrm{~A}$ & $19,2 \mathrm{~B}$ & $19,2 \mathrm{~B}$ \\
\hline PE & $20,9 \mathrm{AB}$ & $20,9 \mathrm{AB}$ & $21,0 \mathrm{AB}$ & $21,8 \mathrm{~A}$ & $17,3 \mathrm{C}$ & $18,8 \mathrm{BC}$ \\
\hline PV-4 & $15,8 \mathrm{AB}$ & $17,7 \mathrm{~A}$ & $17,2 \mathrm{~A}$ & $15,1 \mathrm{AB}$ & $12,9 \mathrm{~B}$ & $14,1 \mathrm{~B}$ \\
\hline TR-2 & $33,2 \mathrm{~A}$ & $30,8 \mathrm{BC}$ & $32,5 \mathrm{AB}$ & $32,5 \mathrm{AB}$ & $29,6 \mathrm{C}$ & $29,4 \mathrm{C}$ \\
\hline $\mathrm{AQa}$ & $12,0 \mathrm{AB}$ & $13,2 \mathrm{AB}$ & $14,3 \mathrm{~A}$ & $14,6 \mathrm{~A}$ & $12,3 \mathrm{AB}$ & $10,9 \mathrm{~B}$ \\
\hline LV-1 & $24,1 \mathrm{AB}$ & $24,9 \mathrm{AB}$ & $23,3 \mathrm{AB}$ & $25,8 \mathrm{~A}$ & $20,4 \mathrm{C}$ & $22,6 \mathrm{BC}$ \\
\hline \multirow{3}{*}{$\begin{array}{c}\text { Solos } \\
\text { alcalinos }\end{array}$} & \multicolumn{4}{|c|}{ Composto de resíduo urbano } & \multirow{3}{*}{$\begin{array}{c}\text { Gessagem } \\
\mathrm{e} \\
\text { adubação }\end{array}$} & \multirow{3}{*}{ Testemunha } \\
\hline & \multicolumn{2}{|c|}{ sem gessagem } & \multicolumn{2}{|c|}{ com gessagem } & & \\
\hline & sem adubação & com adubação & sem adubação & com adubação & & \\
\hline & - & - & nn & $\mathrm{g} \mathrm{dm}^{-3}$ & 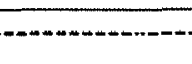 & 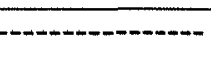 \\
\hline $\mathrm{CL}$ & $21,5 \mathrm{~A}$ & $19,8 \mathrm{AB}$ & $20,4 \mathrm{AB}$ & $19,6 \mathrm{AB}$ & $17,2 \mathrm{~B}$ & $17,0 \mathrm{~B}$ \\
\hline $\mathrm{CV}$ & $24,1 \mathrm{AB}$ & $23,2 \mathrm{~B}$ & $26,5 \mathrm{AB}$ & $27,6 \mathrm{~A}$ & $19,4 \mathrm{C}$ & $25,4 \mathrm{AB}$ \\
\hline LA- 6 & $19,0 \mathrm{~A}$ & $16,6 \mathrm{AB}$ & $16,0 \mathrm{AB}$ & $16,8 \mathrm{AB}$ & $16,0 \mathrm{AB}$ & $14,2 \mathrm{~B}$ \\
\hline LV-2 & $21,4 \mathrm{~A}$ & $19,2 \mathrm{AB}$ & $21,4 \mathrm{~A}$ & $21,0 \mathrm{AB}$ & $18,6 \mathrm{AB}$ & $17,8 \mathrm{~B}$ \\
\hline SS & $18,0 \mathrm{AB}$ & $16,9 \mathrm{~A}$ & $19,9 \mathrm{~A}$ & $19,1 \mathrm{~A}$ & $15,1 \mathrm{~B}$ & $16,9 \mathrm{~A}$ \\
\hline
\end{tabular}

¥-Médias seguidas de mesma letra, nas colunas, não diferem entre si pelo teste de Tukey ao nível de $5 \%$. 
indicando ter ocorrido uma degradação da M.O. desse solo durante o período de incubação, o que parece, também ter ocorrido em outros solos, mas em menor escala.

Nos solos alcalinos CL, LA-6 e LV-2 a aplicação do composto, em qualquer uma das formas, também levou ao aumento no teor do $\mathrm{C}$ orgânico. No solos CV e SS a aplicação de composto não diferiu da testemunha e a aplicação de gesso + adubo causou a redução no $\mathrm{C}$ orgânico. No solo $\mathrm{CV}$, a aplicação do composto + adubo reduziu o teor de $\mathrm{C}$ orgânico.

Os resultados obtidos concordam com os apresentados pela literatura científica (Hortenstine \& Rothwell, 1972; Kiehl, 1985; Ferro Neto, 1994; Sikora \& Yakovchenko, 1996). De acordo com os dados obtidos por Hortenstine \& Rothwell, o aumento no teor de M.O. foi proporcional à dose de aplicação do composto. Ferro Neto (1994) observou um aumento de $15 \%$ no teor de M.O. devido à aplicação de $30 \mathrm{tha}^{-1}$ de composto. Sikora \& Yakovchenko (1996) observaram que a aplicação de composto não estimulou a decomposição da matéria orgânica nativa do solo e que aproximadamente $95 \%$ do $\mathrm{C}$ adicionado como composto permaneceu no solo por pelo menos 60 dias.

A aplicação de composto + adubação mineral promoveu os maiores teores de nitrogênio total em todos os solos ácidos (Tabela 22). As demais formas de aplicação do composto também promoveram elevação no $\mathrm{N}$ total, mas o tratamento com composto isoladamente não diferiu da testemunha nos solos LE-1, PV-1 e AQa; o composto + calcário não diferiu da testemunha nos solos LA-1, PV-1 e LA-2, e o composto + calcário + adubo foi semelhante à testemunha nos solos PV-1 e AQa. Em todos os solos não houve efeito significativo da calagem + adubação sobre o teor de $\mathrm{N}$ total. Os solos AQd e AQa apresentaram os menores teores de $\mathrm{N}\left(<1 \mathrm{mg} \mathrm{dm}^{-3}\right)$ e os solos LA-2, PV-3 e TR-2 os maiores $\left(>2 \mathrm{mg} \mathrm{dm}^{-3}\right.$ ).

Todos os solos alcalinos tiveram o teor de $\mathrm{N}$ total aumentado em 0,2 a 0,3 $\mathrm{mg} \mathrm{dm}{ }^{-3}$ pela aplicação do composto, independentemente do modo de aplicação. A aplicação de gesso + adubo não diferiu da testemunha, porém no solo LA-6, esse tratamento foi semelhante à aplicação do composto + gesso.

Efeitos semelhantes da adição de composto ao solo sobre os teores de $\mathrm{N}$ foram relatados por Sikora \& Yakovchenko (1996) e Melo et al. (1997). Resultados 
Tabela 22. Nitrogênio total em solos adubados com composto de resíduo urbano.

\begin{tabular}{|c|c|c|c|c|c|c|}
\hline \multirow{3}{*}{$\begin{array}{l}\text { Solos } \\
\text { ácidos }\end{array}$} & \multicolumn{4}{|c|}{ Composto de resíduo urbano } & \multirow{3}{*}{$\begin{array}{c}\text { Calagem } \\
\mathrm{e} \\
\text { adubaçăo }\end{array}$} & \multirow{3}{*}{ Testemunha } \\
\hline & \multicolumn{2}{|c|}{ sem calagem } & \multicolumn{2}{|c|}{ com calagem } & & \\
\hline & sem adubação & com adubação & sem adubação & com adubação & & \\
\hline & (3) & - & $m$ & $\mathrm{dm}^{-3} \cdots$ & - & - \\
\hline GPH & $1,47 \mathrm{~A}^{\ddagger}$ & $1,50 \mathrm{~A}$ & $1,43 \mathrm{~A}$ & $1,45 \mathrm{~A}$ & $1,26 \mathrm{~B}$ & $1,23 \mathrm{~B}$ \\
\hline$A Q d$ & $0,77 \mathrm{~A}$ & $0,79 \mathrm{~A}$ & $0,68 \mathrm{AB}$ & $0,76 \mathrm{~A}$ & $0,59 \mathrm{BC}$ & $0,49 \mathrm{C}$ \\
\hline LUa & $1,91 \mathrm{~A}$ & $1,97 \mathrm{~A}$ & $1,86 \mathrm{~A}$ & $1,84 \mathrm{~A}$ & $1,68 \mathrm{~B}$ & $1,66 \mathrm{~B}$ \\
\hline LE-1 & $1,13 \mathrm{BC}$ & $1,31 \mathrm{~A}$ & $1,27 \mathrm{AB}$ & $1,31 \mathrm{~A}$ & $1,10 \mathrm{C}$ & $1,01 \mathrm{C}$ \\
\hline LE-2 & $1,25 \mathrm{~A}$ & $1,37 \mathrm{~A}$ & $1,29 \mathrm{~A}$ & $1,32 \mathrm{~A}$ & $1,10 \mathrm{~B}$ & $1,02 \mathrm{~B}$ \\
\hline LA-1 & $1,40 \mathrm{ABC}$ & $1,50 \mathrm{~A}$ & $1,33 \mathrm{BCD}$ & $1,46 \mathrm{AB}$ & $1,31 \mathrm{CD}$ & $1,22 \mathrm{D}$ \\
\hline PV-1 & $1,35 \mathrm{AB}$ & $1,46 \mathrm{~A}$ & $1,35 \mathrm{AB}$ & $1,38 \mathrm{AB}$ & $1,29 \mathrm{~B}$ & $1,25 \mathrm{~B}$ \\
\hline LA-2 & $2,23 \mathrm{AB}$ & $2,35 \mathrm{~A}$ & $2,14 \mathrm{BC}$ & $2,26 \mathrm{AB}$ & $1,95 \mathrm{D}$ & $2,04 \mathrm{CD}$ \\
\hline LA-3 & $1,58 \mathrm{AB}$ & $1,63 \mathrm{~A}$ & $1,53 \mathrm{AB}$ & $1,61 \mathrm{AB}$ & $1,47 \mathrm{BC}$ & $1,35 \mathrm{C}$ \\
\hline TR-1 & $1,09 \mathrm{~A}$ & $1,08 \mathrm{~A}$ & $0,98 \mathrm{AB}$ & $1,06 \mathrm{~A}$ & $0,86 \mathrm{BC}$ & $0,78 \mathrm{C}$ \\
\hline LA-4 & $1,24 \mathrm{~A}$ & $1,25 \mathrm{~A}$ & $1,17 \mathrm{AB}$ & $1,25 \mathrm{~A}$ & $1,08 \mathrm{BC}$ & $0,96 \mathrm{C}$ \\
\hline PV-2 & $1,24 \mathrm{~A}$ & $1,28 \mathrm{~A}$ & $1,20 \mathrm{AB}$ & $1,28 \mathrm{~A}$ & $1,10 \mathrm{BC}$ & $1,05 \mathrm{C}$ \\
\hline LA-5 & $1,99 \mathrm{~A}$ & $2,01 \mathrm{~A}$ & $2,02 \mathrm{~A}$ & $2,04 \mathrm{~A}$ & $1,81 \mathrm{~B}$ & $1,78 \mathrm{~B}$ \\
\hline PV-3 & $2,55 \mathrm{ABC}$ & $2,70 \mathrm{~A}$ & $2,53 \mathrm{BC}$ & $2,68 \mathrm{AB}$ & $2,46 \mathrm{CD}$ & $2,35 \mathrm{D}$ \\
\hline LRa & $1,42 \mathrm{~A}$ & $1,52 \mathrm{~A}$ & $1,52 \mathrm{~A}$ & $1,50 \mathrm{~A}$ & $1,26 \mathrm{~B}$ & $1,17 \mathrm{~B}$ \\
\hline LE-3 & $1,68 \mathrm{~A}$ & $1,71 \mathrm{~A}$ & $1,62 \mathrm{~A}$ & $1,70 \mathrm{~A}$ & $1,42 \mathrm{~B}$ & $1,41 \mathrm{~B}$ \\
\hline $\mathrm{PE}$ & $1,54 \mathrm{~A}$ & $1,61 \mathrm{~A}$ & $1,55 \mathrm{~A}$ & $1,65 \mathrm{~A}$ & $1,32 \mathrm{~B}$ & $1,27 \mathrm{~B}$ \\
\hline PV-4 & $1,07 \mathrm{~A}$ & $1,09 \mathrm{~A}$ & $1,05 \mathrm{AB}$ & $1,07 \mathrm{~A}$ & $0,92 \mathrm{BC}$ & $0,87 \mathrm{C}$ \\
\hline TR-2 & $2,50 \mathrm{~A}$ & $2,51 \mathrm{~A}$ & $2,44 \mathrm{AB}$ & $2,52 \mathrm{~A}$ & $2,28 \mathrm{BC}$ & $2,26 \mathrm{C}$ \\
\hline $\mathrm{AQa}$ & $0,79 \mathrm{BC}$ & $0,94 \mathrm{~A}$ & $0,81 \mathrm{AB}$ & $0,77 \mathrm{BC}$ & $0,75 \mathrm{BC}$ & $0,68 \mathrm{C}$ \\
\hline LV-1 & $1,37 \mathrm{AB}$ & $1,51 \mathrm{~A}$ & $1,43 \mathrm{~A}$ & $1,47 \mathrm{~A}$ & $1,25 \mathrm{BC}$ & $1,21 \mathrm{C}$ \\
\hline \multirow{3}{*}{$\begin{array}{l}\text { Solos } \\
\text { alcalinos }\end{array}$} & \multicolumn{4}{|c|}{ Composto de resíduo urbano } & \multirow{3}{*}{$\begin{array}{c}\text { Gessagem } \\
\mathrm{e} \\
\text { adubação }\end{array}$} & \multirow{3}{*}{ Testemunha } \\
\hline & \multicolumn{2}{|c|}{ sem gessagem } & \multicolumn{2}{|c|}{ com gessagem } & & \\
\hline & sem adubação & com adubação & sem adubação & com adubação & & \\
\hline & - & - & $m$ & $\mathrm{dm}^{-3} \ldots$ & - & (n-m \\
\hline $\mathrm{CL}$ & $1,98 \mathrm{~A}$ & $2,08 \mathrm{~A}$ & $1,99 \mathrm{~A}$ & $2,07 \mathrm{~A}$ & $1,82 \mathrm{~B}$ & $1,80 \mathrm{~B}$ \\
\hline CV & $2,79 \mathrm{~A}$ & $2,82 \mathrm{~A}$ & $2,79 \mathrm{~A}$ & $2,88 \mathrm{~A}$ & $2,56 \mathrm{~B}$ & $2,53 \mathrm{~B}$ \\
\hline LA-6 & $1,79 \mathrm{~A}$ & $1,87 \mathrm{~A}$ & $1,76 \mathrm{AB}$ & $1,79 \mathrm{~A}$ & $1,66 \mathrm{BC}$ & $1,61 \mathrm{C}$ \\
\hline LV-2 & $1,95 \mathrm{~A}$ & $1,91 \mathrm{~A}$ & $1,96 \mathrm{~A}$ & $2,00 \mathrm{~A}$ & $1,76 \mathrm{~B}$ & $1,66 \mathrm{~B}$ \\
\hline SS & $1,39 \mathrm{~A}$ & $1,44 \mathrm{~A}$ & $1,43 \mathrm{~A}$ & $1,42 \mathrm{~A}$ & $1,14 \mathrm{~B}$ & $1,10 \mathrm{~B}$ \\
\hline
\end{tabular}

$\ddagger$ - Médias seguidas de mesma letra, nas colunas, não diferem entre si pelo teste de Tukey ao nível de $5 \%$. 
obtidos por Sikora \& Yakovchenko (1996) mostraram que a adição de composto ao solo não causou decomposição da matéria orgânica do solo e concluíram que o aumento no teor de $\mathrm{N}$ foi devido à decomposição do composto. Assim, esses autores sugerem que $\mathrm{o}$ efeito sinérgico observado quando da aplicação de composto + adubo mineral é, provavelmente, resultado do aumento da mineralização do composto e não da matéria orgânica nativa do solo.

Para a grande maioria dos solos ácidos, não houve efeito do composto sobre a relação $\mathrm{C} / \mathrm{N}$ (Tabela 23). Todavia, observou-se uma tendência do tratamento com composto + calcário + adubo apresentar uma relação $\mathrm{C} / \mathrm{N}$ mais elevada. Houve redução na relação $\mathrm{C} / \mathrm{N}$ solos $\mathrm{LE}-1$ e $\mathrm{AQa}$ devido à aplicação de composto + adubo; no solo TR-1 devido ao composto isoladamente; e no solo LRa devido ao composto + calcário. A aplicação de calagem + adubo, nos solos AQd, LE-1, LA-1, LA-4 e PV-2, também reduziu a relação $\mathrm{C} / \mathrm{N}$ devido à baixa fertilidade e a, provável, degradação da M.O. desses solos. A aplicação de composto + adubo nos solos CV e SS reduziu a relação $\mathrm{C} / \mathrm{N}$. Embora no solo $\mathrm{CV}$, efeito mais acentuado tenha sido causado pelo gesso + adubo. Nos demais solos alcalinos, não houve diferença entre os tratamentos.

\subsubsection{Disponibilidade de fósfo ro e enxofre}

A disponibilidade de fósforo foi altamente modificada pelas diferentes formas de aplicação do composto (Tabela 24). Dentre os tratamentos com composto, a aplicação do composto com adubo promoveu os maiores teores de $\mathrm{P}$ disponível em todos os solos ácidos, independentemente de calagem ou não, exceto no solo AQa, onde a calagem propiciou teores mais elevados. Os tratamentos com composto, sem e com calcário, apresentaram teores intermediários de $\mathrm{P}$, mas não diferiram da testemunha nos solos GPH e LE-3. No solo AQd, o composto + calcário, também não diferiu da testemunha. A aplicação de calcário + adubo produziu resultados semelhantes ao composto + calcário + adubo, exceto nos solos PV-1 e AQa, onde foi inferior. Sugere-se que há um sinergismo da adubação mineral sobre à mineralização do $\mathrm{P}$ do composto, assim como ocorre com o $\mathrm{N}$. 
Tabela 23. Relação $\mathrm{C} / \mathrm{N}$ em solos adubados com composto de resíduo urbano.

\begin{tabular}{|c|c|c|c|c|c|c|}
\hline \multirow{3}{*}{$\begin{array}{l}\text { Solos } \\
\text { ácidos }\end{array}$} & \multicolumn{4}{|c|}{ Composto de residuo urbano } & \multirow{3}{*}{$\begin{array}{c}\text { Calagem } \\
\mathrm{e} \\
\text { adubação }\end{array}$} & \multirow{3}{*}{ Testemunha } \\
\hline & \multicolumn{2}{|c|}{ sem calagem } & \multicolumn{2}{|c|}{ com calagem } & & \\
\hline & sem adubação & com adubação & sem adubação & com adubação & & \\
\hline & - & 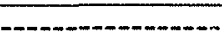 & 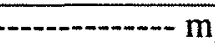 & $\mathrm{dm}^{-3} \ldots$ & & . \\
\hline GPH & $9,7 \mathrm{~A}^{\ddagger}$ & $9,9 \mathrm{~A}$ & $8,5 \mathrm{~A}$ & $10,1 \mathrm{~A}$ & $8,5 \mathrm{~A}$ & $9,9 \mathrm{~A}$ \\
\hline $\mathrm{AQd}$ & $13,8 \mathrm{~A}$ & $13,9 \mathrm{~A}$ & $15,9 \mathrm{~A}$ & $16,7 \mathrm{~A}$ & $9,7 \mathrm{~B}$ & $11,2 \mathrm{~B}$ \\
\hline LUa & $14,2 \mathrm{~A}$ & $13,0 \mathrm{~A}$ & $14,0 \mathrm{~A}$ & $13,6 \mathrm{~A}$ & $13,6 \mathrm{~A}$ & $13,9 \mathrm{~A}$ \\
\hline LE-1 & $16,9 \mathrm{~A}$ & $13,2 \mathrm{~B}$ & $14,0 \mathrm{AB}$ & $14,5 \mathrm{AB}$ & $12,3 \mathrm{~B}$ & $14,0 \mathrm{AB}$ \\
\hline LE-2 & $21,7 \mathrm{~A}$ & $20,3 \mathrm{~A}$ & $20,1 \mathrm{~A}$ & $20,8 \mathrm{~A}$ & $23,0 \mathrm{~A}$ & $24,0 \mathrm{~A}$ \\
\hline LA-1 & $14,1 \mathrm{~A}$ & $12,9 \mathrm{AB}$ & $14,4 \mathrm{~A}$ & $13,2 \mathrm{AB}$ & $11,2 \mathrm{~B}$ & $13,0 \mathrm{AB}$ \\
\hline PV-1 & $14,3 \mathrm{~A}$ & $12,5 \mathrm{~A}$ & $13,8 \mathrm{~A}$ & $13,7 \mathrm{~A}$ & $13,4 \mathrm{~A}$ & $14,5 \mathrm{~A}$ \\
\hline LA-2 & $13,6 \mathrm{~A}$ & $13,4 \mathrm{~A}$ & $14,4 \mathrm{~A}$ & $13,8 \mathrm{~A}$ & $14,4 \mathrm{~A}$ & $13,3 \mathrm{~A}$ \\
\hline LA-3 & $12,9 \mathrm{~A}$ & $13,0 \mathrm{~A}$ & $14,1 \mathrm{~A}$ & $13,7 \mathrm{~A}$ & $12,9 \mathrm{~A}$ & $13,1 \mathrm{~A}$ \\
\hline TR-1 & $11,7 \mathrm{~B}$ & $12,8 \mathrm{AB}$ & $13,8 \mathrm{AB}$ & $14,2 \mathrm{AB}$ & $15,1 \mathrm{~A}$ & $14,2 \mathrm{AB}$ \\
\hline LA-4 & $10,9 \mathrm{AB}$ & $10,5 \mathrm{AB}$ & $11,3 \mathrm{AB}$ & $12,0 \mathrm{~A}$ & $9,6 \mathrm{~B}$ & $10,4 \mathrm{AB}$ \\
\hline PV-2 & $12,2 \mathrm{AB}$ & $11,4 \mathrm{AB}$ & $12,0 \mathrm{AB}$ & $12,9 \mathrm{~A}$ & $9,9 \mathrm{~B}$ & $10,9 \mathrm{AB}$ \\
\hline LA-5 & $11,2 \mathrm{~A}$ & $10,6 \mathrm{~A}$ & $10,7 \mathrm{~A}$ & $11,0 \mathrm{~A}$ & $10,1 \mathrm{~A}$ & $10,3 \mathrm{~A}$ \\
\hline PV -3 & $14,2 \mathrm{~A}$ & $13,4 \mathrm{~A}$ & $14,2 \mathrm{~A}$ & $13,4 \mathrm{~A}$ & $14,1 \mathrm{~A}$ & $14,7 \mathrm{~A}$ \\
\hline $\mathrm{LRa}$ & $19,0 \mathrm{AB}$ & $18,0 \mathrm{AB}$ & $16,6 \mathrm{~B}$ & $18,0 \mathrm{AB}$ & $21,3 \mathrm{~A}$ & $21,1 \mathrm{~A}$ \\
\hline LE-3 & $14,7 \mathrm{~A}$ & $13,7 \mathrm{~A}$ & $14,5 \mathrm{~A}$ & $13,1 \mathrm{~A}$ & $13,6 \mathrm{~A}$ & $13,5 \mathrm{~A}$ \\
\hline $\mathrm{PE}$ & $13,6 \mathrm{~A}$ & $13,0 \mathrm{~A}$ & $13,6 \mathrm{~A}$ & $13,2 \mathrm{~A}$ & $13,1 \mathrm{~A}$ & $14,9 \mathrm{~A}$ \\
\hline PV-4 & $14,7 \mathrm{~A}$ & $16,2 \mathrm{~A}$ & $16,4 \mathrm{~A}$ & $14,1 \mathrm{~A}$ & $14,0 \mathrm{~A}$ & $16,3 \mathrm{~A}$ \\
\hline TR-2 & $13,3 \mathrm{~A}$ & $12,3 \mathrm{~A}$ & $13,4 \mathrm{~A}$ & $12,9 \mathrm{~A}$ & $12,9 \mathrm{~A}$ & $13,0 \mathrm{~A}$ \\
\hline $\mathrm{AQa}$ & $15,3 \mathrm{BC}$ & $14,2 \mathrm{C}$ & $17,8 \mathrm{AB}$ & $19,1 \mathrm{~A}$ & $16,5 \mathrm{ABC}$ & $15,9 \mathrm{ABC}$ \\
\hline LV-1 & $17,7 \mathrm{~A}$ & $16,5 \mathrm{~A}$ & $16,3 \mathrm{~A}$ & $17,6 \mathrm{~A}$ & $16,3 \mathrm{~A}$ & $18,7 \mathrm{~A}$ \\
\hline \multirow{3}{*}{$\begin{array}{c}\text { Solos } \\
\text { alcalinos }\end{array}$} & \multicolumn{4}{|c|}{ Composto de resíduo urbano } & \multirow{3}{*}{$\begin{array}{c}\text { Gessagem } \\
\text { e } \\
\text { adubação }\end{array}$} & \multirow{3}{*}{ Testemunha } \\
\hline & \multicolumn{2}{|c|}{ sem gessagem } & \multicolumn{2}{|c|}{ com gessagem } & & \\
\hline & sem adubação & com adubação & sem adubação & com adubação & & \\
\hline & & - & $-\cdots n$ & $\mathrm{~g} \mathrm{dm}^{-3}$ & - & (n) \\
\hline $\mathrm{CL}$ & $10,9 \mathrm{~A}$ & $9,5 \mathrm{~A}$ & $10,2 \mathrm{~A}$ & $9,5 \mathrm{~A}$ & $9,5 \mathrm{~A}$ & $9,4 \mathrm{~A}$ \\
\hline $\mathrm{CV}$ & $8,6 \mathrm{ABC}$ & $8,2 \mathrm{BC}$ & $9,5 \mathrm{AB}$ & 9,6 AB & $7,6 \mathrm{C}$ & $10,0 \mathrm{~A}$ \\
\hline LA-6 & $10,6 \mathrm{~A}$ & $8,9 \mathrm{~A}$ & $9,1 \mathrm{~A}$ & $9,4 \mathrm{~A}$ & $9,6 \mathrm{~A}$ & $8,8 \mathrm{~A}$ \\
\hline LV-2 & $11,0 \mathrm{~A}$ & $10,1 \mathrm{~A}$ & $11,0 \mathrm{~A}$ & $10,5 \mathrm{~A}$ & $10,6 \mathrm{~A}$ & $10,7 \mathrm{~A}$ \\
\hline SS & $12,9 \mathrm{AB}$ & $11,8 \mathrm{C}$ & $14,0 \mathrm{AB}$ & $13,5 \mathrm{AB}$ & $13,3 \mathrm{AB}$ & $15,4 \mathrm{~A}$ \\
\hline
\end{tabular}

$\$$-Médias seguidas de mesma letra, nas colunas, não diferem entre si pelo teste de Tukey ao nível de $5 \%$. 
A aplicação de composto e composto + gesso não modificou a disponibilidade de $\mathrm{P}$ nos solos alcalinos, cujo aumento foi devido à adubação, uma vez que não se observou diferenças entre os tratamentos com composto + adubação, com ou sem gesso, e gesso + adubação. Excluindo-se no solo CV, onde as aplicações de gesso + adubo e de composto + gesso + adubo, apresentaram teores de $\mathrm{P}$ inferiores à aplicação de composto + adubo.

Efeitos mais expressivos sobre a disponibilidade de $\mathrm{P}$ foram assinalados por Mazur et al. (1983), que atribuíram um aumento de $57 \%$ na disponibilidade de $\mathrm{P}$ devido exclusivamente à aplicação de composto. Esses autores observaram resultados diferentes quanto ao efeito da calagem em combinação com o composto sobre a disponibilidade de $P$.

A aplicação do composto aumentou os teores enxofre na forma de sulfato nos solos ácidos e dependeu do modo de aplicação (Tabela 25). Em parte, de modo semelhante ao que ocorreu com o fósforo, o acentuado aumento na disponibilidade de $\mathrm{S}^{-\mathrm{SO}_{4}}$ nos solos foi devido principalmente à adubação mineral. Os tratamentos com composto + adubo, na ausência ou presença de calcário, e calcário + adubo não diferiram entre si e aumentaram os teores de $\mathrm{S}_{-} \mathrm{SO}_{4}$ em mais de 20 vezes os valores na testemunha. Exceto no solo GPH, onde o composto + adubo foi superior. Nos solos LUa, LE-1, TR-1 e PV-3, o tratamento com composto + calcário foi superior à aplicação isolada de composto, sendo que esses dois tratamentos aumentaram de 2 a 5 vezes os valores de $\mathrm{S}-\mathrm{SO}_{4}$.

Nos solos alcalinos, excluindo-se o solo SS, a aplicação isolada do composto aumentou em mais de $100 \%$ os teores de $\mathrm{S}-\mathrm{SO}_{4}$. Todavia, a aplicação do gesso natural, juntamente com o composto, composto + adubo e com o adubo, foi o fator preponderante no aumento da disponibilidade de $S$, notadamente nos solos CL, LA-6 e LV-2. Teores elevados de $\mathrm{S}^{-} \mathrm{SO}_{4}$ (próximo a $1.000 \mathrm{mg} \mathrm{dm}^{-3}$ ) foram notados nos tratamentos com composto + gesso + adubo e gesso +adubo no solo SS.

Supõe-se que, assim como discutido para o $\mathrm{N}$ e $\mathrm{C}$, o aumento no teor de $\mathrm{S} \mathrm{SO}_{4}$ devido à aplicação do composto é efeito da mineralização da matéria orgânica do composto e não do solo, e está relacionada com as transformações do C, $\mathrm{N}$ e P. 
Tabela 24. Disponibilidade de fósforo em solos adubados com composto de resíduo urbanos.

\begin{tabular}{|c|c|c|c|c|c|c|}
\hline \multirow{3}{*}{$\begin{array}{l}\text { Solos } \\
\text { ácidos }\end{array}$} & \multicolumn{4}{|c|}{ Composto de resíduo urbano } & \multirow{3}{*}{$\begin{array}{c}\text { Calagem } \\
\mathrm{e} \\
\text { adubação }\end{array}$} & \multirow{3}{*}{ Testemunha } \\
\hline & \multicolumn{2}{|c|}{ sem calagem } & \multicolumn{2}{|c|}{ com calagem } & & \\
\hline & sem adubação & com adubação & sem adubação & com adubação & & \\
\hline & \multicolumn{6}{|c|}{ mg dm ${ }^{-3}$} \\
\hline GPH & $29,3 \mathrm{~B}^{\ddagger}$ & $129,8 \mathrm{~A}$ & $32,5 \mathrm{~B}$ & $125,8 \mathrm{~A}$ & $109,1 \mathrm{~A}$ & $22,8 \mathrm{~B}$ \\
\hline $\mathrm{AQd}$ & $25,5 \mathrm{~B}$ & $201,6 \mathrm{~A}$ & $22,3 \mathrm{BC}$ & $175,9 \mathrm{~A}$ & $191,5 \mathrm{~A}$ & $14,7 \mathrm{C}$ \\
\hline LUa & $17,1 \mathrm{~B}$ & $132,3 \mathrm{~A}$ & $25,2 \mathrm{~B}$ & $134,9 \mathrm{~A}$ & $106,3 \mathrm{~A}$ & $2,3 \mathrm{C}$ \\
\hline LE-1 & $25,1 \mathrm{~B}$ & $135,3 \mathrm{~A}$ & $24,0 \mathrm{~B}$ & $165,1 \mathrm{~A}$ & $118,5 \mathrm{~A}$ & $8,6 \mathrm{C}$ \\
\hline LE-2 & $14,0 \mathrm{~B}$ & $145,5 \mathrm{~A}$ & $20,0 \mathrm{~B}$ & $156,3 \mathrm{~A}$ & $155,5 \mathrm{~A}$ & $3,7 \mathrm{C}$ \\
\hline LA-1 & $22,4 \mathrm{~B}$ & $201,3 \mathrm{~A}$ & $21,9 \mathrm{~B}$ & $173,7 \mathrm{~A}$ & $154,7 \mathrm{~A}$ & $8,6 \mathrm{C}$ \\
\hline PV-1 & $12,5 \mathrm{C}$ & $194,2 \mathrm{AB}$ & $18,3 \mathrm{C}$ & $242,4 \mathrm{~A}$ & $168,2 \mathrm{~B}$ & $6,5 \mathrm{D}$ \\
\hline LA-2 & $20,4 \mathrm{~B}$ & $133,6 \mathrm{~A}$ & $20,5 \mathrm{~B}$ & $152,7 \mathrm{~A}$ & $145,5 \mathrm{~A}$ & $5,2 \mathrm{C}$ \\
\hline LA-3 & $16,1 \mathrm{~B}$ & $158,5 \mathrm{~A}$ & $18,2 \mathrm{~B}$ & $173,4 \mathrm{~A}$ & $140,3 \mathrm{~A}$ & $6,1 \mathrm{C}$ \\
\hline TR-1 & 13,7 B & $116,7 \mathrm{~A}$ & $19,1 \mathrm{~B}$ & $160,2 \mathrm{~A}$ & $144,1 \mathrm{~A}$ & $5,5 \mathrm{C}$ \\
\hline LA-4 & $22,1 \mathrm{~B}$ & $182,1 \mathrm{~A}$ & $21,8 \mathrm{~B}$ & $169,9 \mathrm{~A}$ & $146,0 \mathrm{~A}$ & $5,2 \mathrm{C}$ \\
\hline PV-2 & $23,0 \mathrm{~B}$ & $142,1 \mathrm{~A}$ & 24,8 B & $149,4 \mathrm{~A}$ & $116,4 \mathrm{~A}$ & $8,7 \mathrm{C}$ \\
\hline LA-5 & $29,5 \mathrm{~B}$ & $111,5 \mathrm{~A}$ & $33,0 \mathrm{~B}$ & $137,2 \mathrm{~A}$ & $116,3 \mathrm{~A}$ & $15,1 \mathrm{C}$ \\
\hline PV-3 & $12,3 \mathrm{~B}$ & $99,3 \mathrm{~A}$ & $13,4 \mathrm{~B}$ & $93,9 \mathrm{~A}$ & $84,1 \mathrm{~A}$ & $3,7 \mathrm{C}$ \\
\hline LRa & $21,6 \mathrm{~B}$ & $128,2 \mathrm{~A}$ & $22,5 \mathrm{~B}$ & $113,5 \mathrm{~A}$ & $110,5 \mathrm{~A}$ & $7,4 \mathrm{C}$ \\
\hline LE-3 & $88,8 \mathrm{C}$ & $151,9 \mathrm{AB}$ & $110,3 \mathrm{BC}$ & $179,3 \mathrm{~A}$ & $166,2 \mathrm{~A}$ & $76,7 \mathrm{C}$ \\
\hline PE & $13,3 \mathrm{C}$ & $159,9 \mathrm{~A}$ & $22,4 \mathrm{~B}$ & $138,0 \mathrm{~A}$ & $126,2 \mathrm{~A}$ & $4,2 \mathrm{D}$ \\
\hline PV-4 & $15,3 \mathrm{~B}$ & $146,9 \mathrm{~A}$ & $17,1 \mathrm{~B}$ & $152,7 \mathrm{~A}$ & $136,0 \mathrm{~A}$ & $5,2 \mathrm{C}$ \\
\hline TR-2 & $26,4 \mathrm{~B}$ & $92,9 \mathrm{~A}$ & $25,9 \mathrm{~B}$ & $109,1 \mathrm{~A}$ & $94,0 \mathrm{~A}$ & $14,7 \mathrm{C}$ \\
\hline $\mathrm{AQa}$ & $19,9 \mathrm{C}$ & 89,9 B & $15,7 \mathrm{C}$ & $178,8 \mathrm{~A}$ & $107,8 \mathrm{~B}$ & $7,9 \mathrm{D}$ \\
\hline LV-1 & $18,7 \mathrm{~B}$ & $153,4 \mathrm{~A}$ & $22,0 \mathrm{~B}$ & $143,2 \mathrm{~A}$ & $114,9 \mathrm{~A}$ & $2,9 \mathrm{C}$ \\
\hline \multirow{3}{*}{$\begin{array}{l}\text { Solos } \\
\text { alcalinos }\end{array}$} & \multicolumn{4}{|c|}{ Composto de resíduo urbano } & \multirow{3}{*}{$\begin{array}{c}\text { Gessagem } \\
\text { e } \\
\text { adubação }\end{array}$} & \multirow{3}{*}{ Testemunha } \\
\hline & \multicolumn{2}{|c|}{ sem gessagem } & \multicolumn{2}{|c|}{ com gessagem } & & \\
\hline & sem adubação & com adubação & sem adubação & com adubação & & \\
\hline & - & ................ & $\mathrm{mg}$ & $\mathrm{Im}^{-3}-\ldots$ & - & - \\
\hline $\mathrm{CL}$ & $73,3 \mathrm{C}$ & $141,5 \mathrm{~A}$ & $76,8 \mathrm{BC}$ & $127,7 \mathrm{~A}$ & $108,2 \mathrm{AB}$ & $62,6 \mathrm{C}$ \\
\hline $\mathrm{CV}$ & $21,9 \mathrm{C}$ & $178,4 \mathrm{~A}$ & $21,6 \mathrm{C}$ & $129,5 \mathrm{~B}$ & $124,0 \mathrm{~B}$ & $11,0 \mathrm{C}$ \\
\hline LA-6 & $49,0 \mathrm{~B}$ & $114,7 \mathrm{~A}$ & $45,3 \mathrm{~B}$ & $120,4 \mathrm{~A}$ & $117,1 \mathrm{~A}$ & 35,7 B \\
\hline LV-2 & $62,4 \mathrm{~B}$ & $124,3 \mathrm{~A}$ & $61,1 \mathrm{~B}$ & $129,5 \mathrm{~A}$ & $104,2 \mathrm{~A}$ & $48,1 \mathrm{~B}$ \\
\hline SS & $36,1 \mathrm{~B}$ & $189,0 \mathrm{~A}$ & $39,7 \mathrm{~B}$ & $161,6 \mathrm{~A}$ & $173,8 \mathrm{~A}$ & $22,5 \mathrm{~B}$ \\
\hline
\end{tabular}

‡-Médias seguidas de mesma letra, nas colunas, não diferem entre si pelo teste de Tukey ao nível de $5 \%$. 
Tabela 25. Disponibilidade de enxofre em solos adubados com composto de resíduo urbano.

\begin{tabular}{|c|c|c|c|c|c|c|}
\hline \multirow{3}{*}{$\begin{array}{l}\text { Solos } \\
\text { ácidos }\end{array}$} & \multicolumn{4}{|c|}{ Composto de resíduo urbano } & \multirow{3}{*}{$\begin{array}{c}\text { Calagem } \\
\text { e } \\
\text { adubação }\end{array}$} & \multirow{3}{*}{ Testemunha } \\
\hline & \multicolumn{2}{|c|}{ sem calagem } & \multicolumn{2}{|c|}{ com calagem } & & \\
\hline & sem adubação & com adubação & sem adubaçāo & com adubação & & \\
\hline & \multicolumn{6}{|c|}{$\mathrm{mg} \mathrm{dm}^{-3}$} \\
\hline GPH & $50,9 \mathrm{C}^{\dagger}$ & $274,4 \mathrm{~A}$ & $43,1 \mathrm{C}$ & $255,6 \mathrm{AB}$ & $157,0 \mathrm{~B}$ & $22,6 \mathrm{D}$ \\
\hline AQd & $35,9 \mathrm{~B}$ & $277,6 \mathrm{~A}$ & $34,6 \mathrm{~B}$ & $242,2 \mathrm{~A}$ & $321,0 \mathrm{~A}$ & $16,9 \mathrm{C}$ \\
\hline LUa & $45,2 \mathrm{C}$ & $309,1 \mathrm{~A}$ & $77,5 \mathrm{~B}$ & $378,5 \mathrm{~A}$ & $349,3 \mathrm{~A}$ & $11,7 \mathrm{D}$ \\
\hline LE-1 & $47,5 \mathrm{~B}$ & $258,5 \mathrm{~A}$ & $38,6 \mathrm{~B}$ & $299,5 \mathrm{~A}$ & $245,5 \mathrm{~A}$ & $14,4 \mathrm{C}$ \\
\hline LE-2 & $11,3 \mathrm{C}$ & $270,5 \mathrm{~A}$ & $20,4 \mathrm{~B}$ & $266,2 \mathrm{~A}$ & $244,1 \mathrm{~A}$ & $6,9 \mathrm{D}$ \\
\hline LA-1 & $58,2 \mathrm{~B}$ & $378,6 \mathrm{~A}$ & $77,6 \mathrm{~B}$ & $392,1 \mathrm{~A}$ & $346,7 \mathrm{~A}$ & $22,6 \mathrm{C}$ \\
\hline PV-1 & $52,1 \mathrm{~B}$ & $380,4 \mathrm{~A}$ & $50,0 \mathrm{~B}$ & $362,8 \mathrm{~A}$ & $318,7 \mathrm{~A}$ & $16,2 \mathrm{C}$ \\
\hline LA-2 & $59,5 \mathrm{~B}$ & $312,8 \mathrm{~A}$ & $87,6 \mathrm{~B}$ & $382,1 \mathrm{~A}$ & $374,4 \mathrm{~A}$ & $27,0 \mathrm{C}$ \\
\hline LA-3 & $48,8 \mathrm{~B}$ & $297,5 \mathrm{~A}$ & $46,2 \mathrm{~B}$ & $300,7 \mathrm{~A}$ & $257,2 \mathrm{~A}$ & $16,4 \mathrm{C}$ \\
\hline TR-1 & $25,5 \mathrm{C}$ & $227,3 \mathrm{~A}$ & $47,2 \mathrm{~B}$ & $228,8 \mathrm{~A}$ & $149,1 \mathrm{~A}$ & $8,2 \mathrm{D}$ \\
\hline LA-4 & $73,1 \mathrm{~B}$ & $413,1 \mathrm{~A}$ & $60,3 \mathrm{~B}$ & $376,5 \mathrm{~A}$ & $335,3 \mathrm{~A}$ & $17,4 \mathrm{C}$ \\
\hline PV-2 & $57,1 \mathrm{~B}$ & $402,9 \mathrm{~A}$ & $49,3 \mathrm{~B}$ & $365,6 \mathrm{~A}$ & $324,1 \mathrm{~A}$ & $20,5 \mathrm{C}$ \\
\hline LA-5 & $34,0 \mathrm{~B}$ & $220,3 \mathrm{~A}$ & 40,7 B & $238,3 \mathrm{~A}$ & $223,3 \mathrm{~A}$ & $13,1 \mathrm{C}$ \\
\hline PV-3 & $17,7 \mathrm{C}$ & $205,7 \mathrm{~A}$ & $39,9 \mathrm{~B}$ & $201,2 \mathrm{~A}$ & $174,0 \mathrm{~A}$ & $7,1 \mathrm{D}$ \\
\hline $\mathrm{LRa}$ & $15,9 \mathrm{~B}$ & $183,9 \mathrm{~A}$ & $20,1 \mathrm{~B}$ & $184,0 \mathrm{~A}$ & $160,3 \mathrm{~A}$ & $8,9 \mathrm{C}$ \\
\hline LE-3 & $50,4 \mathrm{C}$ & $148,8 \mathrm{~A}$ & $77,1 \mathrm{BC}$ & $162,0 \mathrm{~A}$ & $120,8 \mathrm{AB}$ & $14,4 \mathrm{D}$ \\
\hline $\mathrm{PE}$ & $23,9 \mathrm{~B}$ & $321,8 \mathrm{~A}$ & $30,6 \mathrm{~B}$ & $295,7 \mathrm{~A}$ & $291,8 \mathrm{~A}$ & $8,5 \mathrm{C}$ \\
\hline PV -4 & $55,6 \mathrm{~B}$ & $277,7 \mathrm{~A}$ & $50,7 \mathrm{~B}$ & $317,4 \mathrm{~A}$ & $259,3 \mathrm{~A}$ & $13,8 \mathrm{C}$ \\
\hline TR-2 & $37,6 \mathrm{~B}$ & $268,5 \mathrm{~A}$ & $38,1 \mathrm{~B}$ & $272,4 \mathrm{~A}$ & $196,2 \mathrm{~A}$ & $11,8 \mathrm{C}$ \\
\hline $\mathrm{AQa}$ & $53,8 \mathrm{~B}$ & $303,9 \mathrm{~A}$ & $47,2 \mathrm{~B}$ & $345,2 \mathrm{~A}$ & $243,3 \mathrm{~A}$ & $20,2 \mathrm{C}$ \\
\hline LV-1 & $41,3 \mathrm{~B}$ & $329,4 \mathrm{~A}$ & $52,4 \mathrm{~B}$ & $296,0 \mathrm{~A}$ & $213,9 \mathrm{~A}$ & $16,1 \mathrm{C}$ \\
\hline \multirow{3}{*}{$\begin{array}{c}\text { Solos } \\
\text { alcalinos }\end{array}$} & \multicolumn{4}{|c|}{ Composto de resíduo urbano } & \multirow{3}{*}{$\begin{array}{c}\text { Gessagem } \\
\mathrm{e} \\
\text { adubação }\end{array}$} & \multirow{3}{*}{ Testemunha } \\
\hline & \multicolumn{2}{|c|}{ sem gessagem } & \multicolumn{2}{|c|}{ com gessagem } & & \\
\hline & sem adubação & com adubação & sem adubação & com adubação & & \\
\hline & - & - & mg & $\mathrm{lm}^{-3}$ & - & - \\
\hline $\mathrm{CL}$ & $33,1 \mathrm{C}$ & $141,0 \mathrm{~B}$ & $463,6 \mathrm{~A}$ & $515,5 \mathrm{~A}$ & $436,9 \mathrm{~A}$ & $12,9 \mathrm{D}$ \\
\hline $\mathrm{CV}$ & $44,5 \mathrm{C}$ & $341,9 \mathrm{~B}$ & $430,6 \mathrm{~B}$ & $711,1 \mathrm{~A}$ & $739,3 \mathrm{~A}$ & $18,1 \mathrm{D}$ \\
\hline LA-6 & $43,9 \mathrm{C}$ & $170,6 \mathrm{~B}$ & $414,5 \mathrm{~A}$ & $570,4 \mathrm{~A}$ & 556,9 A & $19,9 \mathrm{D}$ \\
\hline LV-2 & $44,6 \mathrm{C}$ & $144,9 \mathrm{~B}$ & $483,2 \mathrm{~A}$ & $576,3 \mathrm{~A}$ & $575,2 \mathrm{~A}$ & $16,9 \mathrm{D}$ \\
\hline SS & $161,2 \mathrm{C}$ & $465,1 \mathrm{~B}$ & $597,9 \mathrm{~B}$ & $909,6 \mathrm{~A}$ & $997,8 \mathrm{~A}$ & $151,5 \mathrm{C}$ \\
\hline
\end{tabular}

† - Médias seguidas de mesma letra, nas colunas, não diferem entre si pelo teste de Tukey ao nível de 5\%. 


\subsubsection{Bases trocáveis, Soma de bases, capacidade de troca de cátions e saturação por bases}

No estudo do efeito da aplicação do composto, na ausência e presença de calcário e adubo mineral nos ácidos; e na ausência e presença de gesso e adubo mineral nos solos alcalinos foram utilizados os teores de $\mathrm{Ca}, \mathrm{Mg}$ e $\mathrm{K}$ obtidos pelo método da resina de troca iônica, e os teores de Na determinado pelo extrator Mehlich-1.

As Tabelas 26, 27, 28 e 29 apresentam os efeitos da aplicação do composto sobre a disponibilidade de $\mathrm{K}, \mathrm{Ca}, \mathrm{Mg}$ e $\mathrm{Na}$ nos solos, respectivamente.

A aplicação de composto + adubo, na presença ou ausência de calcário, promoveu os maiores teores de $\mathrm{K}$ trocável em todos os solos ácidos. A aplicação do composto, sem ou com calagem resultou em teores intermediários de $\mathrm{K}$ e semelhante à adubação + calagem. Exceto nos solos LA-3, PV-2 e PV onde os teores foram superiores para o composto isoladamente, e nos solos LE-1 e AQa, onde os tratamentos composto + calcário e calcário + adubo não se diferiram. Todos os tratamentos foram superiores à testemunha. Nos solos alcalinos a aplicação de composto + adubo, com ou sem calagem, também promoveu maiores teores de $\mathrm{K}$ disponível. Exceto no solo LV-2, onde não houve diferença entre a aplicação de composto com e sem adubo. Neste solo, diferentemente dos demais, a adubação + calagem não diferiu da testemunha.

Esperava-se que os teores de $\mathrm{Ca}$ e $\mathrm{Mg}$ tivessem o mesmo comportamento nos solos ácidos devido à aplicação de calcário (Tabelas 27 e 28). Todavia, isto não foi observado, uma vez que o $\mathrm{Ca}$ apresentou um comportamento mais irregular, em parte devido às diferentes doses de calcário que foram aplicadas em cada solo. A disponibilidade de $\mathrm{Ca}$ e $\mathrm{Mg}$ foi superior no tratamento com composto + calcário + adubo. Em nove dos solos ácidos, os teores de Ca não diferiram entre os tratamentos com composto + adubo e composto + calcário + adubo. A aplicação de composto + calcário, geralmente, foi semelhante à calagem + adubação.

Os teores de $\mathrm{Mg}$ foram semelhantes nos tratamentos com composto + calcário e composto + calcário + adubação, e estes superiores ao calcário + adubo (exceto nos solos LE-2, PV-1, TR-2 e AQa). Outro fator importante a se destacar, é o 
maior aumento relativo dos teores de $\mathrm{Ca}$ do que de $\mathrm{Mg}$, principalmente nos tratamentos com composto + adubo, composto + calcário e composto + calcário + adubo.

Os solos alcalinos, que já apresentavam uma relação $\mathrm{Ca} / \mathrm{Mg}$ elevada, tiveram esse efeito acentuado devido à aplicação do gesso natural, com ou sem composto. A aplicação do composto a esses solos, com ou sem adubo, não aumentou os teores de Ca nos solos, a não ser no solo SS onde houve diferença com a testemunha. O $\mathrm{Mg}$ apresentou um comportamento bastante heterogêneo entre os tratamentos nos solos alcalinos. De uma forma geral, a aplicação do composto tendeu a aumentar os teores de $\mathrm{Mg}$ disponível no solo, independentemente do modo de aplicação, e os efeitos também não foram tão acentuados quanto aos verificados nos solos ácidos.

A aplicação do composto promoveu um aumento muito significativo nos teores de $\mathrm{Na}$ trocável (Tabela 29), independentemente do modo de aplicação, tanto nos solos ácidos quanto nos alcalinos, excluindo-se o solo SS, cujo teor inicial de $\mathrm{Na}$ era muito alto $\left(40,5 \mathrm{mmol}_{\mathrm{c}} \mathrm{dm}^{-3}\right)$. Observou-se, considerando solos ácidos e alcalinos, que a aplicação do composto aumentou em aproximadamente dez vezes os teores de $\mathrm{Na}$ trocável. Excluindo-se os solos GPH, PV-1, LA-5, LRa, CL, CV, LV-2 e SS, a aplicação de calcário + adubo, no caso dos solos ácidos; e de gesso + adubo no solo alcalino LA-6, também promoveu uma elevação nos teores de $\mathrm{Na}$, porém este aumento foi da ordem de 0,5 a $0,8 \mathrm{mmol}_{\mathrm{c}} \mathrm{kg}^{-1}$.

Aumentos nos teores de $\mathrm{K}, \mathrm{Ca}$ e $\mathrm{Mg}$ no solo devido à aplicação de composto foram observados por Hortenstine \& Rothwell (1972), Ferro Neto (1994), Cravo (1995) e Trindade et al. (1996). Todavia, o efeito do composto sobre os teores de $\mathrm{K}, \mathrm{Ca}$ e $\mathrm{Mg}$ depende da procedência, do modo de produção deste material e do número de cultivos (Cravo, 1995).

Há um forte efeito dos cultivos sobre os teores desses nutrientes. Cravo (1995) verificou a diminuição nos teores de K, em termos absoluto, do primeiro para o segundo cultivo de alface em um solo arenoso. A remoção dos nutrientes ocorre devido à remoção pelas plantas indicando a necessidade de adubação, pelo menos potássica, no próximo cultivo. 
Tabela 26. Potássio trocável em solos adubados com composto de resíduo urbano.

\begin{tabular}{|c|c|c|c|c|c|c|}
\hline \multirow{3}{*}{$\begin{array}{l}\text { Solos } \\
\text { ácidos }\end{array}$} & \multicolumn{4}{|c|}{ Composto de resíduo urbano } & \multirow{3}{*}{$\begin{array}{c}\text { Calagem } \\
\mathrm{e} \\
\text { adubação }\end{array}$} & \multirow{3}{*}{ Testemunha } \\
\hline & \multicolumn{2}{|c|}{ sem calagem } & \multicolumn{2}{|c|}{ com calagem } & & \\
\hline & sem adubação & com adubação & sem adubação & com adubação & & \\
\hline & \multicolumn{6}{|c|}{ - $\mathrm{mg} \mathrm{dm}^{-3}$ - } \\
\hline GPH & $2,63 \mathrm{~B}^{\ddagger}$ & $3,61 \mathrm{~A}$ & $2,29 \mathrm{~B}$ & $3,39 \mathrm{~A}$ & $2,56 \mathrm{~B}$ & $1,58 \mathrm{C}$ \\
\hline AQd & $4,97 \mathrm{~B}$ & $6,98 \mathrm{~A}$ & $4,82 \mathrm{~B}$ & $6,90 \mathrm{~A}$ & $4,49 \mathrm{~B}$ & $1,13 \mathrm{C}$ \\
\hline LUa & $4,33 \mathrm{~B}$ & $6,24 \mathrm{~A}$ & $4,06 \mathrm{~B}$ & $6,04 \mathrm{~A}$ & $3,89 \mathrm{~B}$ & $1,11 \mathrm{C}$ \\
\hline LE-1 & $5,98 \mathrm{BC}$ & $7,02 \mathrm{AB}$ & $5,55 \mathrm{CD}$ & $7,77 \mathrm{~A}$ & $5,02 \mathrm{D}$ & $2,91 \mathrm{E}$ \\
\hline LE-2 & $4,02 \mathrm{~B}$ & $6,64 \mathrm{~A}$ & $4,23 \mathrm{~B}$ & $6,42 \mathrm{~A}$ & $3,61 \mathrm{~B}$ & $0,76 \mathrm{C}$ \\
\hline LA-1 & $4,32 \mathrm{~B}$ & $7,64 \mathrm{~A}$ & $4,23 \mathrm{~B}$ & $7,03 \mathrm{~A}$ & $3,83 \mathrm{~B}$ & $0,67 \mathrm{C}$ \\
\hline PV-1 & $4,37 \mathrm{~B}$ & $6,89 \mathrm{~A}$ & $3,85 \mathrm{~B}$ & $6,39 \mathrm{~A}$ & $3,87 \mathrm{~B}$ & $0,76 \mathrm{C}$ \\
\hline LA-2 & $4,14 \mathrm{~B}$ & $6,71 \mathrm{~A}$ & $3,89 \mathrm{~B}$ & $5,89 \mathrm{~A}$ & $3,48 \mathrm{~B}$ & $0,95 \mathrm{C}$ \\
\hline LA-3 & $5,50 \mathrm{~B}$ & $7,68 \mathrm{~A}$ & $5,32 \mathrm{~B}$ & $6,89 \mathrm{~A}$ & $4,37 \mathrm{C}$ & $1,72 \mathrm{D}$ \\
\hline TR-1 & $3,14 \mathrm{~B}$ & $4,77 \mathrm{~A}$ & $2,80 \mathrm{~B}$ & $4,72 \mathrm{~A}$ & $3,02 \mathrm{~B}$ & $0,97 \mathrm{C}$ \\
\hline LA-4 & $6,21 \mathrm{~B}$ & $9,17 \mathrm{~A}$ & $5,99 \mathrm{~B}$ & $8,23 \mathrm{~A}$ & $5,72 \mathrm{~B}$ & $2,32 \mathrm{C}$ \\
\hline PV-2 & $5,34 \mathrm{~B}$ & $7,64 \mathrm{~A}$ & $5,28 \mathrm{~B}$ & $7,19 \mathrm{~A}$ & $4,26 \mathrm{C}$ & $1,43 \mathrm{D}$ \\
\hline LA-5 & $3,66 \mathrm{~B}$ & $4,96 \mathrm{~A}$ & $3,61 \mathrm{~B}$ & $5,01 \mathrm{~A}$ & $3,64 \mathrm{~B}$ & $2,36 \mathrm{C}$ \\
\hline PV-3 & $4,98 \mathrm{~B}$ & $7,28 \mathrm{~A}$ & $4,62 \mathrm{~B}$ & $6,20 \mathrm{~A}$ & $3,82 \mathrm{C}$ & $2,24 \mathrm{D}$ \\
\hline $\mathrm{LRa}$ & $4,44 \mathrm{~B}$ & $6,95 \mathrm{~A}$ & $4,39 \mathrm{~B}$ & $6,60 \mathrm{~A}$ & 3,77 B & $1,24 \mathrm{C}$ \\
\hline LE-3 & $5,69 \mathrm{~B}$ & $8,53 \mathrm{~A}$ & $5,74 \mathrm{~B}$ & $8,26 \mathrm{~A}$ & $5,39 \mathrm{~B}$ & $3,83 \mathrm{C}$ \\
\hline $\mathrm{PE}$ & $2,97 \mathrm{~B}$ & $5,24 \mathrm{~A}$ & $3,04 \mathrm{~B}$ & $4,83 \mathrm{~A}$ & $2,99 \mathrm{~B}$ & $0,67 \mathrm{C}$ \\
\hline PV -4 & $4,19 \mathrm{~B}$ & $6,57 \mathrm{~A}$ & $4,32 \mathrm{~B}$ & $6,34 \mathrm{~A}$ & $3,94 \mathrm{~B}$ & $0,78 \mathrm{C}$ \\
\hline TR-2 & $4,70 \mathrm{~B}$ & $6,30 \mathrm{~A}$ & $4,67 \mathrm{~B}$ & $6,24 \mathrm{~A}$ & $4,25 \mathrm{~B}$ & $2,19 \mathrm{C}$ \\
\hline $\mathrm{AQa}$ & $5,14 \mathrm{~B}$ & $8,04 \mathrm{~A}$ & $4,81 \mathrm{BC}$ & $7,60 \mathrm{~A}$ & $4,12 \mathrm{C}$ & $0,92 \mathrm{D}$ \\
\hline LV-1 & $5,28 \mathrm{~B}$ & $7,92 \mathrm{~A}$ & $5,49 \mathrm{~B}$ & $6,95 \mathrm{~A}$ & $4,15 \mathrm{C}$ & $1,91 \mathrm{D}$ \\
\hline \multirow{3}{*}{$\begin{array}{c}\text { Solos } \\
\text { alcalinos }\end{array}$} & \multicolumn{4}{|c|}{ Composto de resíduo urbano } & \multirow{3}{*}{$\begin{array}{l}\text { Gessagem } \\
\text { e } \\
\text { adubação }\end{array}$} & \multirow{3}{*}{ Testemunha } \\
\hline & \multicolumn{2}{|c|}{ sem gessagem } & \multicolumn{2}{|c|}{ com gessagem } & & \\
\hline & sem adubação & com adubação & sem adubação & com adubação & & \\
\hline & - & - & mg & $\mathrm{Im}^{-3} \cdots$ & (-)-- & 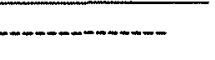 \\
\hline $\mathrm{CL}$ & $3,16 \mathrm{~B}$ & $4,30 \mathrm{~A}$ & $2,90 \mathrm{~B}$ & $4,31 \mathrm{~A}$ & $2,76 \mathrm{~B}$ & $1,84 \mathrm{C}$ \\
\hline $\mathrm{CV}$ & $1,81 \mathrm{~B}$ & $2,68 \mathrm{~A}$ & $1,75 \mathrm{~B}$ & $2,51 \mathrm{~A}$ & $1,74 \mathrm{~B}$ & $0,99 \mathrm{C}$ \\
\hline LA-6 & $7,98 \mathrm{BC}$ & $10,25 \mathrm{~A}$ & $7,81 \mathrm{BC}$ & $9,96 \mathrm{~A}$ & $8,43 \mathrm{~B}$ & $7,03 \mathrm{C}$ \\
\hline LV-2 & $13,50 \mathrm{AB}$ & $14,82 \mathrm{~A}$ & $13,36 \mathrm{AB}$ & $14,80 \mathrm{~A}$ & $12,32 \mathrm{BC}$ & $11,60 \mathrm{C}$ \\
\hline SS & $3,45 \mathrm{~B}$ & $5,10 \mathrm{~A}$ & $3,54 \mathrm{~B}$ & $4,55 \mathrm{~A}$ & $3,53 \mathrm{~B}$ & $2,00 \mathrm{C}$ \\
\hline
\end{tabular}

$¥$ - Médias seguidas de mesma letra, nas colunas, não diferem entre si pelo teste de Tukey ao nível de $5 \%$. 
Tabela 27. Cálcio trocável em solos adubados com composto de resíduo urbano.

\begin{tabular}{|c|c|c|c|c|c|c|}
\hline \multirow{3}{*}{$\begin{array}{l}\text { Solos } \\
\text { ácidos }\end{array}$} & \multicolumn{4}{|c|}{ Composto de resíduo urbano } & \multirow{3}{*}{$\begin{array}{c}\text { Calagem } \\
\mathrm{e} \\
\text { adubação }\end{array}$} & \multirow{3}{*}{ Testemunha } \\
\hline & \multicolumn{2}{|c|}{ sem calagem } & \multicolumn{2}{|c|}{ com calagem } & & \\
\hline & sem adubação & com adubação & sem adubação & com adubação & & \\
\hline & \multicolumn{6}{|c|}{$\mathrm{mg} \mathrm{dm}^{-3}$} \\
\hline GPH & $97,8 \mathrm{~B}^{\ddagger}$ & $123,9 \mathrm{~A}$ & $109,7 \mathrm{AB}$ & $124,6 \mathrm{~A}$ & $95,1 \mathrm{~B}$ & $29,6 \mathrm{C}$ \\
\hline AQd & 40,9 B & $70,1 \mathrm{~A}$ & $41,0 \mathrm{~B}$ & $66,3 \mathrm{~A}$ & $44,9 \mathrm{~B}$ & $17,9 \mathrm{C}$ \\
\hline LUa & $31,5 \mathrm{D}$ & $54,7 \mathrm{C}$ & $69,5 \mathrm{~B}$ & $88,0 \mathrm{~A}$ & $67,7 \mathrm{~B}$ & $1,9 \mathrm{E}$ \\
\hline LE-1 & $53,8 \mathrm{~B}$ & $72,1 \mathrm{~A}$ & $58,4 \mathrm{~B}$ & $84,7 \mathrm{~A}$ & $56,0 \mathrm{~B}$ & $25,8 \mathrm{C}$ \\
\hline LE-2 & $30,3 \mathrm{D}$ & $56,6 \mathrm{C}$ & $56,9 \mathrm{C}$ & $113,5 \mathrm{~A}$ & $81,1 \mathrm{~B}$ & $1,3 \mathrm{E}$ \\
\hline LA-1 & $34,8 \mathrm{C}$ & $65,8 \mathrm{~A}$ & $47,6 \mathrm{~B}$ & $70,2 \mathrm{~A}$ & $46,1 \mathrm{~B}$ & $3,9 \mathrm{D}$ \\
\hline PV -1 & $37,3 \mathrm{D}$ & $63,4 \mathrm{~B}$ & $47,8 \mathrm{C}$ & $86,1 \mathrm{~A}$ & $52,2 \mathrm{C}$ & $8,1 \mathrm{E}$ \\
\hline LA-2 & $32,7 \mathrm{C}$ & $52,0 \mathrm{~B}$ & $58,5 \mathrm{~B}$ & $82,8 \mathrm{~A}$ & $60,2 \mathrm{~B}$ & $8,2 \mathrm{D}$ \\
\hline LA-3 & $44,4 \mathrm{~B}$ & $62,9 \mathrm{~A}$ & $51,7 \mathrm{~B}$ & $74,4 \mathrm{~A}$ & $48,0 \mathrm{~B}$ & $19,5 \mathrm{C}$ \\
\hline TR-1 & $50,8 \mathrm{C}$ & $87,9 \mathrm{~B}$ & $81,3 \mathrm{~B}$ & $113,9 \mathrm{~A}$ & $76,7 \mathrm{~B}$ & $23,9 \mathrm{D}$ \\
\hline LA-4 & $44,6 \mathrm{C}$ & $72,7 \mathrm{~A}$ & $54,7 \mathrm{~B}$ & $83,9 \mathrm{~A}$ & $55,1 \mathrm{~B}$ & $11,4 \mathrm{D}$ \\
\hline PV-2 & $38,9 \mathrm{~B}$ & $64,9 \mathrm{~A}$ & $46,6 \mathrm{~B}$ & $70,6 \mathrm{~A}$ & $39,9 \mathrm{~B}$ & $7,3 \mathrm{C}$ \\
\hline LA-5 & $91,1 \mathrm{BC}$ & $105,8 \mathrm{~B}$ & $106,3 \mathrm{~B}$ & $125,4 \mathrm{~A}$ & $86,0 \mathrm{C}$ & $29,3 \mathrm{D}$ \\
\hline PV -3 & $38,3 \mathrm{C}$ & $69,0 \mathrm{~B}$ & $83,1 \mathrm{~A}$ & $93,3 \mathrm{~A}$ & $68,5 \mathrm{~B}$ & $4,3 \mathrm{D}$ \\
\hline LRa & $41,1 \mathrm{C}$ & $62,4 \mathrm{~A}$ & $51,8 \mathrm{~B}$ & $63,9 \mathrm{~A}$ & $42,5 \mathrm{C}$ & $9,5 \mathrm{D}$ \\
\hline LE-3 & $47,9 \mathrm{C}$ & $56,5 \mathrm{BC}$ & $63,9 \mathrm{AB}$ & $72,0 \mathrm{~A}$ & $49,4 \mathrm{C}$ & $17,2 \mathrm{D}$ \\
\hline $\mathrm{PE}$ & $50,6 \mathrm{C}$ & $87,5 \mathrm{~A}$ & $71,5 \mathrm{~B}$ & $92,8 \mathrm{~A}$ & $71,0 \mathrm{~B}$ & $23,4 \mathrm{D}$ \\
\hline PV -4 & $36,6 \mathrm{D}$ & $58,8 \mathrm{~B}$ & $48,4 \mathrm{C}$ & $70,6 \mathrm{~A}$ & $45,7 \mathrm{C}$ & $10,1 \mathrm{E}$ \\
\hline TR-2 & $85,5 \mathrm{C}$ & $103,5 \mathrm{~B}$ & $86,8 \mathrm{C}$ & $120,5 \mathrm{~A}$ & $95,4 \mathrm{BC}$ & $61,0 \mathrm{E}$ \\
\hline $\mathrm{AQa}$ & $29,9 \mathrm{C}$ & $36,7 \mathrm{BC}$ & $35,7 \mathrm{BC}$ & $84,4 \mathrm{~A}$ & $41,0 \mathrm{~B}$ & $1,5 \mathrm{D}$ \\
\hline LV-1 & $30,3 \mathrm{D}$ & $52,0 \mathrm{~B}$ & $46,4 \mathrm{~B}$ & $63,3 \mathrm{~A}$ & $37,9 \mathrm{C}$ & $4,4 \mathrm{E}$ \\
\hline \multirow{3}{*}{$\begin{array}{c}\text { Solos } \\
\text { alcalinos }\end{array}$} & \multicolumn{4}{|c|}{ Composto de resíduo urbano } & \multirow{3}{*}{$\begin{array}{c}\text { Gessagem } \\
\text { e } \\
\text { adubação }\end{array}$} & \multirow{3}{*}{ Testemunha } \\
\hline & \multicolumn{2}{|c|}{ sem gessagem } & \multicolumn{2}{|c|}{ com gessagem } & & \\
\hline & sem adubação & com adubação & sem adubação & com adubação & & \\
\hline & 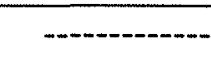 & - n & $\mathrm{mg}$ & $\mathrm{m}^{-3} \ldots$ & - & - \\
\hline $\mathrm{CL}$ & $151,0 \mathrm{C}$ & $166,9 \mathrm{~B}$ & $198,5 \mathrm{~A}$ & $190,3 \mathrm{~A}$ & $188,5 \mathrm{~A}$ & $153,9 \mathrm{BC}$ \\
\hline $\mathrm{CV}$ & $444,6 \mathrm{~A}$ & $468,3 \mathrm{~A}$ & $474,7 \mathrm{~A}$ & $482,3 \mathrm{~A}$ & $398,5 \mathrm{~A}$ & $417,1 \mathrm{~A}$ \\
\hline LA-6 & $125,6 \mathrm{C}$ & $134,3 \mathrm{C}$ & $150,5 \mathrm{~B}$ & $167,3 \mathrm{~A}$ & $146,5 \mathrm{~B}$ & $109,4 \mathrm{D}$ \\
\hline LV-2 & $142,3 \mathrm{C}$ & $144,8 \mathrm{C}$ & $175,5 \mathrm{~A}$ & $187,3 \mathrm{~A}$ & $158,5 \mathrm{~B}$ & $135,3 \mathrm{C}$ \\
\hline SS & $175,2 \mathrm{~B}$ & $179,1 \mathrm{~B}$ & $211,8 \mathrm{~A}$ & $212,7 \mathrm{~A}$ & $211,6 \mathrm{~A}$ & $148,7 \mathrm{C}$ \\
\hline
\end{tabular}

¥-Médias seguidas de mesma letra, nas colunas, não diferem entre si pelo teste de Tukey ao nível de $5 \%$. 
Tabela 28. Magnésio trocável em solos adubados com composto de resíduo urbano.

\begin{tabular}{|c|c|c|c|c|c|c|}
\hline \multirow{3}{*}{$\begin{array}{l}\text { Solos } \\
\text { ácidos }\end{array}$} & \multicolumn{4}{|c|}{ Composto de resíduo urbano } & \multirow{3}{*}{$\begin{array}{c}\text { Calagem } \\
e \\
\text { adubação }\end{array}$} & \multirow{3}{*}{ Testemunha } \\
\hline & \multicolumn{2}{|c|}{ sem calagem } & \multicolumn{2}{|c|}{ com calagem } & & \\
\hline & sem adubação & com adubação & sem adubação & com adubação & & \\
\hline & \multicolumn{6}{|c|}{ - mg dm ${ }^{-3}$} \\
\hline GPH & $27,5 \mathrm{C}^{\ddagger}$ & $28,2 \mathrm{BC}$ & $31,4 \mathrm{~A}$ & $30,8 \mathrm{AB}$ & $26,0 \mathrm{C}$ & $10,3 \mathrm{D}$ \\
\hline $\mathrm{AQd}$ & $12,1 \mathrm{~A}$ & $12,6 \mathrm{~A}$ & $12,6 \mathrm{~A}$ & $13,2 \mathrm{~A}$ & $9,6 \mathrm{~B}$ & $9,3 \mathrm{~B}$ \\
\hline LUa & $7,0 \mathrm{~B}$ & $6,9 \mathrm{~B}$ & $24,3 \mathrm{~A}$ & $22,6 \mathrm{~A}$ & $22,2 \mathrm{~A}$ & $1,2 \mathrm{C}$ \\
\hline LE-1 & $21,2 \mathrm{AB}$ & $19,9 \mathrm{~B}$ & $21,9 \mathrm{AB}$ & $23,1 \mathrm{~A}$ & $19,9 \mathrm{~B}$ & $16,2 \mathrm{C}$ \\
\hline LE-2 & $6,2 \mathrm{D}$ & $6,5 \mathrm{D}$ & $18,6 \mathrm{C}$ & $25,2 \mathrm{~A}$ & $22,6 \mathrm{~B}$ & $1,1 \mathrm{E}$ \\
\hline LA-1 & $8,3 \mathrm{C}$ & $9,7 \mathrm{C}$ & $17,1 \mathrm{~A}$ & $17,4 \mathrm{~A}$ & $13,6 \mathrm{~B}$ & $2,2 \mathrm{D}$ \\
\hline PV-1 & $8,7 \mathrm{D}$ & $8,4 \mathrm{D}$ & $14,5 \mathrm{~B}$ & $17,2 \mathrm{~A}$ & $12,5 \mathrm{C}$ & $3,0 \mathrm{E}$ \\
\hline LA-2 & $12,2 \mathrm{~B}$ & $13,0 \mathrm{~B}$ & $26,4 \mathrm{~A}$ & $25,9 \mathrm{~A}$ & $24,0 \mathrm{~A}$ & $8,5 \mathrm{C}$ \\
\hline LA-3 & $11,4 \mathrm{~B}$ & $11,3 \mathrm{~B}$ & $14,6 \mathrm{~A}$ & $15,1 \mathrm{~A}$ & $11,6 \mathrm{~B}$ & $6,7 \mathrm{C}$ \\
\hline TR-1 & $16,0 \mathrm{D}$ & $18,5 \mathrm{C}$ & $26,7 \mathrm{~A}$ & $28,3 \mathrm{~A}$ & $22,9 \mathrm{~B}$ & $9,6 \mathrm{E}$ \\
\hline LA-4 & $9,7 \mathrm{~B}$ & $10,4 \mathrm{~B}$ & $14,4 \mathrm{~A}$ & $14,8 \mathrm{~A}$ & $10,8 \mathrm{~B}$ & $3,3 \mathrm{C}$ \\
\hline PV-2 & $10,9 \mathrm{~B}$ & $11,1 \mathrm{~B}$ & $14,4 \mathrm{~A}$ & $14,5 \mathrm{~A}$ & $10,7 \mathrm{~B}$ & $5,0 \mathrm{C}$ \\
\hline LA-5 & $28,9 \mathrm{~B}$ & 26,7 B & $33,1 \mathrm{~A}$ & $32,5 \mathrm{~A}$ & $27,2 \mathrm{~B}$ & $11,7 \mathrm{C}$ \\
\hline PV -3 & $9,0 \mathrm{C}$ & $10,4 \mathrm{C}$ & $30,7 \mathrm{~A}$ & $26,7 \mathrm{~B}$ & $25,6 \mathrm{~B}$ & $2,9 \mathrm{D}$ \\
\hline $\mathrm{LRa}$ & $15,4 \mathrm{C}$ & $15,3 \mathrm{C}$ & $20,6 \mathrm{~A}$ & $18,9 \mathrm{AB}$ & $16,8 \mathrm{BC}$ & $9,2 \mathrm{D}$ \\
\hline LE-3 & $19,0 \mathrm{C}$ & $18,3 \mathrm{C}$ & $26,9 \mathrm{~A}$ & $26,0 \mathrm{AB}$ & $24,2 \mathrm{~B}$ & $12,8 \mathrm{D}$ \\
\hline $\mathrm{PE}$ & $15,4 \mathrm{C}$ & $18,6 \mathrm{~B}$ & $23,7 \mathrm{~A}$ & $22,5 \mathrm{~A}$ & $19,8 \mathrm{~B}$ & $10,0 \mathrm{D}$ \\
\hline PV -4 & $8,7 \mathrm{C}$ & $9,2 \mathrm{C}$ & $14,5 \mathrm{~A}$ & $14,8 \mathrm{~A}$ & $12,0 \mathrm{~B}$ & $3,8 \mathrm{D}$ \\
\hline TR-2 & $23,6 \mathrm{BC}$ & $22,7 \mathrm{BC}$ & $24,1 \mathrm{BC}$ & $27,5 \mathrm{~A}$ & $25,0 \mathrm{AB}$ & $22,4 \mathrm{C}$ \\
\hline $\mathrm{AQa}$ & $6,3 \mathrm{C}$ & $6,0 \mathrm{C}$ & $11,7 \mathrm{~B}$ & $16,0 \mathrm{~A}$ & $12,1 \mathrm{~B}$ & $1,2 \mathrm{D}$ \\
\hline LV-1 & $8,2 \mathrm{C}$ & $8,9 \mathrm{C}$ & $17,0 \mathrm{~A}$ & $16,0 \mathrm{~A}$ & $12,8 \mathrm{~B}$ & $3,1 \mathrm{D}$ \\
\hline \multirow{3}{*}{$\begin{array}{c}\text { Solos } \\
\text { alcalinos }\end{array}$} & \multicolumn{4}{|c|}{ Composto de resíduo urbano } & \multirow{3}{*}{$\begin{array}{c}\text { Gessagem } \\
\mathrm{e} \\
\text { adubação }\end{array}$} & \multirow{3}{*}{ Testemunha } \\
\hline & \multicolumn{2}{|c|}{ sem gessagem } & \multicolumn{2}{|c|}{ com gessagem } & & \\
\hline & sem adubação & com adubação & sem adubação & com adubação & & \\
\hline & 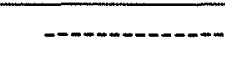 & 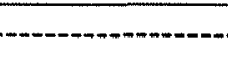 & mg & $\mathrm{Im}^{-3}-\cdots$ & (-) & 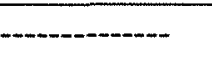 \\
\hline $\mathrm{CL}$ & $25,3 \mathrm{~B}$ & $26,6 \mathrm{AB}$ & $28,9 \mathrm{~A}$ & $26,5 \mathrm{AB}$ & $25,9 \mathrm{~B}$ & 26,2 B \\
\hline $\mathrm{CV}$ & $26,8 \mathrm{~A}$ & $24,4 \mathrm{~B}$ & $22,8 \mathrm{BC}$ & $23,5 \mathrm{BC}$ & $21,6 \mathrm{CD}$ & $20,5 \mathrm{D}$ \\
\hline LA-6 & $22,4 \mathrm{AB}$ & $22,5 \mathrm{AB}$ & $24,2 \mathrm{~A}$ & $24,0 \mathrm{~A}$ & $21,1 \mathrm{~B}$ & $21,0 \mathrm{~B}$ \\
\hline LV-2 & $32,0 \mathrm{AB}$ & $30,2 \mathrm{BC}$ & $33,0 \mathrm{AB}$ & $33,4 \mathrm{~A}$ & $28,8 \mathrm{C}$ & $32,4 \mathrm{AB}$ \\
\hline SS & $44,7 \mathrm{BC}$ & $41,9 \mathrm{C}$ & $50,3 \mathrm{~A}$ & $48,9 \mathrm{AB}$ & $45,5 \mathrm{ABC}$ & $41,8 \mathrm{C}$ \\
\hline
\end{tabular}

$\ddagger$ - Médias seguidas de mesma letra, nas colunas, não diferem entre si pelo teste de Tukey ao nível de $5 \%$. 
Tabela 29. Sódio trocável em solos adubados com composto de resíduo urbano.

\begin{tabular}{|c|c|c|c|c|c|c|}
\hline \multirow{3}{*}{$\begin{array}{l}\text { Solos } \\
\text { ácidos }\end{array}$} & \multicolumn{4}{|c|}{ Composto de resíduo urbano } & \multirow{3}{*}{$\begin{array}{c}\text { Calagem } \\
\text { e } \\
\text { adubação }\end{array}$} & \multirow{3}{*}{ Testemunha } \\
\hline & \multicolumn{2}{|c|}{ sem calagem } & \multicolumn{2}{|c|}{ com calagem } & & \\
\hline & sem adubação & com adubação & sem adubação & com adubação & & \\
\hline & \multicolumn{6}{|c|}{ …… $\mathrm{mg} \mathrm{dm}^{-3}$} \\
\hline GPH & $10,0 \mathrm{~A}^{\ddagger}$ & $9,2 \mathrm{~A}$ & $10,2 \mathrm{~A}$ & $8,7 \mathrm{~A}$ & $2,1 \mathrm{~B}$ & $1,8 \mathrm{~B}$ \\
\hline AQd & $8,6 \mathrm{~A}$ & $8,3 \mathrm{~A}$ & $8,0 \mathrm{~A}$ & $7,9 \mathrm{~A}$ & $1,3 \mathrm{~B}$ & $0,3 \mathrm{C}$ \\
\hline LUa & $8,9 \mathrm{~A}$ & $8,2 \mathrm{~A}$ & $8,0 \mathrm{~A}$ & $8,2 \mathrm{~A}$ & $1,2 \mathrm{~B}$ & $0,5 \mathrm{C}$ \\
\hline LE-1 & $9,2 \mathrm{~A}$ & $7,1 \mathrm{~B}$ & $7,6 \mathrm{AB}$ & $8,4 \mathrm{AB}$ & $1,0 \mathrm{C}$ & $0,3 \mathrm{D}$ \\
\hline LE-2 & $7,3 \mathrm{~A}$ & $8,0 \mathrm{~A}$ & $7,2 \mathrm{~A}$ & $7,2 \mathrm{~A}$ & $1,0 \mathrm{~B}$ & $0,5 \mathrm{C}$ \\
\hline LA-1 & $9,1 \mathrm{~A}$ & $10,2 \mathrm{~A}$ & $8,8 \mathrm{~A}$ & $9,7 \mathrm{~A}$ & $1,3 \mathrm{~B}$ & $0,7 \mathrm{C}$ \\
\hline PV-1 & $9,7 \mathrm{~A}$ & $8,7 \mathrm{~A}$ & $8,0 \mathrm{~A}$ & $8,5 \mathrm{~A}$ & $1,7 \mathrm{~B}$ & $0,8 \mathrm{C}$ \\
\hline LA-2 & $8,8 \mathrm{~A}$ & $8,8 \mathrm{~A}$ & $8,6 \mathrm{~A}$ & $8,8 \mathrm{~A}$ & $1,9 \mathrm{~B}$ & $1,4 \mathrm{~B}$ \\
\hline LA-3 & $9,6 \mathrm{~A}$ & $8,5 \mathrm{~A}$ & $9,3 \mathrm{~A}$ & $8,1 \mathrm{~A}$ & $1,1 \mathrm{~B}$ & $0,4 \mathrm{C}$ \\
\hline TR-1 & $6,8 \mathrm{~A}$ & $7,1 \mathrm{~A}$ & $6,4 \mathrm{~A}$ & $6,4 \mathrm{~A}$ & $1,3 \mathrm{~B}$ & $0,6 \mathrm{C}$ \\
\hline LA-4 & $11,1 \mathrm{~A}$ & $10,7 \mathrm{~A}$ & $9,4 \mathrm{~A}$ & $10,0 \mathrm{~A}$ & $1,6 \mathrm{~B}$ & $1,0 \mathrm{C}$ \\
\hline PV-2 & $10,9 \mathrm{~A}$ & $10,1 \mathrm{~A}$ & $10,0 \mathrm{~A}$ & $9,8 \mathrm{~A}$ & $1,0 \mathrm{~B}$ & $0,4 \mathrm{C}$ \\
\hline LA-5 & $10,6 \mathrm{~A}$ & $9,3 \mathrm{~A}$ & $10,6 \mathrm{~A}$ & $9,4 \mathrm{~A}$ & $1,7 \mathrm{~B}$ & $1,3 \mathrm{~B}$ \\
\hline PV-3 & $8,2 \mathrm{~A}$ & $8,6 \mathrm{~A}$ & $8,2 \mathrm{~A}$ & $8,0 \mathrm{~A}$ & $0,8 \mathrm{~B}$ & $0,4 \mathrm{C}$ \\
\hline $\mathrm{LRa}$ & $6,5 \mathrm{~A}$ & $7,2 \mathrm{~A}$ & $6,3 \mathrm{~A}$ & $7,0 \mathrm{~A}$ & $0,7 \mathrm{~B}$ & $0,4 \mathrm{~B}$ \\
\hline LE-3 & $8,6 \mathrm{~A}$ & $8,1 \mathrm{~A}$ & $9,2 \mathrm{~A}$ & $8,1 \mathrm{~A}$ & $0,9 \mathrm{~B}$ & $0,2 \mathrm{C}$ \\
\hline $\mathrm{PE}$ & $8,4 \mathrm{~A}$ & $8,0 \mathrm{~A}$ & $7,6 \mathrm{~A}$ & $7,3 \mathrm{~A}$ & $1,0 \mathrm{~B}$ & $0,5 \mathrm{C}$ \\
\hline$P V-4$ & $8,8 \mathrm{~A}$ & $8,1 \mathrm{~A}$ & $8,1 \mathrm{~A}$ & $7,9 \mathrm{~A}$ & $1,1 \mathrm{~B}$ & $0,4 \mathrm{C}$ \\
\hline TR-2 & $9,0 \mathrm{~A}$ & $8,6 \mathrm{~A}$ & $8,7 \mathrm{~A}$ & $8,3 \mathrm{~A}$ & $1,2 \mathrm{~B}$ & $0,6 \mathrm{C}$ \\
\hline $\mathrm{AQa}$ & $9,2 \mathrm{~A}$ & $10,2 \mathrm{~A}$ & $9,1 \mathrm{~A}$ & $9,1 \mathrm{~A}$ & $1,7 \mathrm{~B}$ & $1,4 \mathrm{C}$ \\
\hline LV-1 & $8,9 \mathrm{~A}$ & $9,2 \mathrm{~A}$ & $10,2 \mathrm{~A}$ & $8,4 \mathrm{~A}$ & $1,2 \mathrm{~B}$ & $0,6 \mathrm{C}$ \\
\hline \multirow{3}{*}{$\begin{array}{l}\text { Solos } \\
\text { alcalinos }\end{array}$} & \multicolumn{4}{|c|}{ Composto de resíduo urbano } & \multirow{3}{*}{$\begin{array}{c}\text { Gessagem } \\
\mathrm{e} \\
\text { adubação }\end{array}$} & \multirow{3}{*}{ Testemunha } \\
\hline & \multicolumn{2}{|c|}{ sem gessagem } & \multicolumn{2}{|c|}{ com gessagem } & & \\
\hline & sem adubação & com adubação & sem adubação & com adubação & & \\
\hline & - & - & mg & $\mathrm{dm}^{-3}-\ldots$ & - & 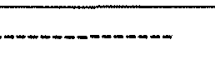 \\
\hline $\mathrm{CL}$ & $7,9 \mathrm{~A}$ & $7,3 \mathrm{~A}$ & $8,2 \mathrm{~A}$ & $7,1 \mathrm{~A}$ & $1,0 \mathrm{~B}$ & $0,7 \mathrm{~B}$ \\
\hline $\mathrm{CV}$ & $9,6 \mathrm{~A}$ & $9,5 \mathrm{~A}$ & $8,9 \mathrm{~A}$ & $9,2 \mathrm{~A}$ & $1,8 \mathrm{~B}$ & $1,7 \mathrm{~B}$ \\
\hline LA-6 & $8,5 \mathrm{~A}$ & $8,1 \mathrm{~A}$ & $8,3 \mathrm{~A}$ & $7,6 \mathrm{~A}$ & $1,4 \mathrm{~B}$ & $0,6 \mathrm{C}$ \\
\hline LV -2 & $9,3 \mathrm{~A}$ & $8,2 \mathrm{~A}$ & $9,3 \mathrm{~A}$ & $8,4 \mathrm{~A}$ & $1,3 \mathrm{~B}$ & $1,2 \mathrm{~B}$ \\
\hline SS & $40,5 \mathrm{~A}$ & $39,9 \mathrm{~A}$ & $41,8 \mathrm{~A}$ & $40,2 \mathrm{~A}$ & $40,7 \mathrm{~A}$ & $40,5 \mathrm{~A}$ \\
\hline
\end{tabular}

$\ddagger$ - Médias seguidas de mesma letra, nas colunas, não diferem entre si pelo teste de Tukey ao nível de $5 \%$. 
Outro problema sério que pode ocorrer quando da aplicação de altas doses de composto, é a salinização. Melo et al. (1997) explicam que a aplicação de composto rico em $\mathrm{Na}$ e $\mathrm{K}$ ao solo promove o aumento dos teores destes elementos na solução do solo, segue-se com o aumento da condutividade elétrica, o deslocamento de $\mathrm{Ca}$ e $\mathrm{Mg}$ adsorvidos ao complexo de troca, a dispersão dos colóides e a redução na condutividade elétrica. Estes eventos concordam com os resultados observados neste estudo.

Pode-se inferir dois aspectos da utilização do composto. O primeiro, é o fato da aplicação do composto ter acentuado os problemas dos solos alcalinos, notadamente no solo SS. Pode-se concluir, de ante mão, que a aplicação do composto neste solos deve ser evitada. O segundo é com relação a adição de $\mathrm{Ca}$ e $\mathrm{Mg}$ pela calagem, em solos ácidos, que pode minimizar os efeitos do sódio proveniente do composto.

Em decorrência dos aumentos de $\mathrm{K}, \mathrm{Ca}, \mathrm{Mg}$ e $\mathrm{Na}$ devido à aplicação do composto, do adubo e do calcário, verificou-se aumentos proporcionais na soma de bases dos solos (Tabela 30), na capacidade de troca de cátions (Tabela 31) e, conseqüentemente, na saturação por bases (Tabela 32).

Os maiores valores de soma de bases e de capacidade de troca de cátions (CTC) foram decorrentes da aplicação do composto + calcário + adubo, seguido pelo composto + adubo, composto + calcário e composto isoladamente. A intensidade do efeito da aplicação de calcário + adubo sobre estas propriedades foi dependente da dose de calcário aplicado ao solo. Nos solos GPH, AQd, LE-1, LA-5, e TR-2 não houve diferenças entre os modos de aplicação do composto sobre a saturação por bases. Nos demais solos a saturação por bases foi maior nos tratamentos com calagem. Nos solos alcalinos prevaleceu o efeito do gesso sobre os teores de $\mathrm{Ca}$, com aumento da soma de bases, CTC e saturação por bases.

Os resultados obtidos estão em concordância com Melo et al. (1997) e foram semelhantes àqueles obtidos por Ferro Neto (1994). 
Tabela 30. Soma de bases em solos adubados com composto de resíduo urbano.

\begin{tabular}{|c|c|c|c|c|c|c|}
\hline \multirow{3}{*}{$\begin{array}{l}\text { Solos } \\
\text { ácidos }\end{array}$} & \multicolumn{4}{|c|}{ Composto de resíduo urbano } & \multirow{3}{*}{$\begin{array}{l}\text { Calagem } \\
\mathrm{e} \\
\text { adubação }\end{array}$} & \multirow{3}{*}{ Testemunha } \\
\hline & \multicolumn{2}{|c|}{ sem calagem } & \multicolumn{2}{|c|}{ com calagem } & & \\
\hline & sem adubação & com adubação & sem adubação & com adubação & & \\
\hline & \multicolumn{6}{|c|}{ - $\mathrm{mg} \mathrm{dm}^{-3}$} \\
\hline GPH & $137,9 \mathrm{BC}^{\ddagger}$ & $164,9 \mathrm{~A}$ & $153,7 \mathrm{AB}$ & $167,4 \mathrm{~A}$ & $125,7 \mathrm{C}$ & $43,1 \mathrm{D}$ \\
\hline AQd & $66,6 \mathrm{~B}$ & $97,9 \mathrm{~A}$ & $66,4 \mathrm{~B}$ & $94,3 \mathrm{~A}$ & 60,2 B & $28,6 \mathrm{C}$ \\
\hline LUa & $51,8 \mathrm{D}$ & $76,1 \mathrm{C}$ & $105,8 \mathrm{~B}$ & $124,9 \mathrm{~A}$ & $95,1 \mathrm{~B}$ & $4,8 \mathrm{E}$ \\
\hline LE-1 & $90,2 \mathrm{C}$ & $106,2 \mathrm{~B}$ & $93,4 \mathrm{BC}$ & $124,0 \mathrm{~A}$ & $81,9 \mathrm{C}$ & $45,2 \mathrm{D}$ \\
\hline LE-2 & $47,8 \mathrm{D}$ & $77,9 \mathrm{C}$ & $87,0 \mathrm{C}$ & $152,4 \mathrm{~A}$ & $108,3 \mathrm{~B}$ & $3,6 \mathrm{E}$ \\
\hline LA-1 & $56,6 \mathrm{C}$ & $93,3 \mathrm{~A}$ & $77,6 \mathrm{~B}$ & $104,3 \mathrm{~A}$ & $64,9 \mathrm{C}$ & $7,5 \mathrm{D}$ \\
\hline PV -1 & $60,0 \mathrm{D}$ & $87,5 \mathrm{~B}$ & $74,1 \mathrm{C}$ & $118,1 \mathrm{~A}$ & $70,3 \mathrm{CD}$ & $12,7 \mathrm{E}$ \\
\hline LA-2 & $57,9 \mathrm{D}$ & $80,5 \mathrm{C}$ & $97,4 \mathrm{~B}$ & $123,4 \mathrm{~A}$ & $89,5 \mathrm{BC}$ & $19,0 \mathrm{E}$ \\
\hline LA-3 & $70,9 \mathrm{CD}$ & $90,3 \mathrm{AB}$ & $80,9 \mathrm{BC}$ & $104,6 \mathrm{~A}$ & $65,1 \mathrm{D}$ & $28,3 \mathrm{E}$ \\
\hline TR-1 & $76,7 \mathrm{C}$ & $118,3 \mathrm{~B}$ & $117,1 \mathrm{~B}$ & $153,3 \mathrm{~A}$ & $103,9 \mathrm{~B}$ & $35,0 \mathrm{D}$ \\
\hline LA-4 & $71,7 \mathrm{C}$ & $103,0 \mathrm{~A}$ & 84,4 B & $116,9 \mathrm{~A}$ & $73,2 \mathrm{BC}$ & $18,1 \mathrm{D}$ \\
\hline PV-2 & $66,1 \mathrm{BC}$ & $93,7 \mathrm{~A}$ & 76,3 B & $102,1 \mathrm{~A}$ & $55,9 \mathrm{C}$ & $14,0 \mathrm{D}$ \\
\hline LA-5 & $134,3 \mathrm{CD}$ & $146,8 \mathrm{BC}$ & $153,6 \mathrm{AB}$ & $172,4 \mathrm{~A}$ & $118,5 \mathrm{D}$ & $44,7 \mathrm{E}$ \\
\hline PV-3 & $60,5 \mathrm{C}$ & $95,3 \mathrm{~B}$ & $126,6 \mathrm{~A}$ & $134,2 \mathrm{~A}$ & $98,8 \mathrm{~B}$ & $9,9 \mathrm{D}$ \\
\hline $\mathrm{LRa}$ & $67,5 \mathrm{~B}$ & $91,9 \mathrm{~A}$ & $83,1 \mathrm{~A}$ & $96,4 \mathrm{~A}$ & $63,8 \mathrm{~B}$ & $20,4 \mathrm{C}$ \\
\hline LE-3 & $81,2 \mathrm{C}$ & $91,4 \mathrm{BC}$ & $105,7 \mathrm{AB}$ & $114,4 \mathrm{~A}$ & $79,9 \mathrm{C}$ & $34,0 \mathrm{D}$ \\
\hline $\mathrm{PE}$ & $77,3 \mathrm{D}$ & $119,4 \mathrm{AB}$ & $105,9 \mathrm{BC}$ & $127,4 \mathrm{~A}$ & $94,9 \mathrm{C}$ & $34,5 \mathrm{E}$ \\
\hline PV -4 & $58,2 \mathrm{C}$ & 82,7 B & $75,4 \mathrm{~B}$ & $99,6 \mathrm{~A}$ & $62,8 \mathrm{C}$ & $15,0 \mathrm{D}$ \\
\hline TR-2 & $122,9 \mathrm{C}$ & $141,1 \mathrm{~B}$ & $124,3 \mathrm{BC}$ & $162,6 \mathrm{~A}$ & $125,9 \mathrm{BC}$ & $86,2 \mathrm{D}$ \\
\hline $\mathrm{AQa}$ & $50,5 \mathrm{C}$ & $60,9 \mathrm{~B}$ & $61,3 \mathrm{~B}$ & $117,1 \mathrm{~A}$ & $58,9 \mathrm{BC}$ & $5,1 \mathrm{C}$ \\
\hline LV-1 & $52,6 \mathrm{C}$ & $78,0 \mathrm{~B}$ & $79,2 \mathrm{~B}$ & $94,7 \mathrm{~A}$ & $56,1 \mathrm{C}$ & $10,0 \mathrm{D}$ \\
\hline \multirow{3}{*}{$\begin{array}{c}\text { Solos } \\
\text { alcalinos }\end{array}$} & \multicolumn{4}{|c|}{ Composto de resíduo urbano } & \multirow{3}{*}{$\begin{array}{c}\text { Gessagem } \\
\mathrm{e} \\
\text { adubação }\end{array}$} & \multirow{3}{*}{ Testemunha } \\
\hline & \multicolumn{2}{|c|}{ sem gessagem } & \multicolumn{2}{|c|}{ com gessagem } & & \\
\hline & sem adubação & com adubação & sem adubação & com adubação & & \\
\hline & - & …….......... & mg & $\mathrm{lm}^{-3}-\ldots$ & 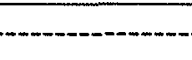 & - \\
\hline $\mathrm{CL}$ & $187,4 \mathrm{C}$ & $205,1 \mathrm{~B}$ & $238,5 \mathrm{~A}$ & $228,2 \mathrm{~A}$ & $218,2 \mathrm{AB}$ & $182,6 \mathrm{C}$ \\
\hline $\mathrm{CV}$ & $482,8 \mathrm{AB}$ & $504,9 \mathrm{AB}$ & $508,2 \mathrm{~A}$ & $517,5 \mathrm{~A}$ & $423,6 \mathrm{~B}$ & $440,2 \mathrm{AB}$ \\
\hline LA- 6 & $164,6 \mathrm{D}$ & $175,1 \mathrm{CD}$ & 190,9 B & $208,9 \mathrm{~A}$ & $177,5 \mathrm{C}$ & $138,1 \mathrm{E}$ \\
\hline LV-2 & $197,0 \mathrm{~B}$ & $198,1 \mathrm{~B}$ & $231,2 \mathrm{~A}$ & $243,9 \mathrm{~A}$ & $201,0 \mathrm{~B}$ & $180,5 \mathrm{C}$ \\
\hline SS & $263,8 \mathrm{~B}$ & $266,1 \mathrm{~B}$ & $307,4 \mathrm{~A}$ & $306,3 \mathrm{~A}$ & $301,4 \mathrm{~A}$ & $233,0 \mathrm{C}$ \\
\hline
\end{tabular}

\$-Médias seguidas de mesma letra, nas colunas, não diferem entre si pelo teste de Tukey ao nível de $5 \%$. 
Tabela 31. Capacidade de troca de cátions em solos adubados com composto de resíduo urbano.

\begin{tabular}{|c|c|c|c|c|c|c|}
\hline \multirow{3}{*}{$\begin{array}{l}\text { Solos } \\
\text { ácidos }\end{array}$} & \multicolumn{4}{|c|}{ Composto de resíduo urbano } & \multirow{3}{*}{$\begin{array}{c}\text { Calagem } \\
\mathrm{e} \\
\text { adubação }\end{array}$} & \multirow{3}{*}{ Testemunha } \\
\hline & \multicolumn{2}{|c|}{ sem calagem } & \multicolumn{2}{|c|}{ com calagem } & & \\
\hline & sem adubaçāo & com adubação & sem adubação & com adubação & & \\
\hline \multicolumn{7}{|c|}{$\mathrm{mg} \mathrm{dm}^{-3}$} \\
\hline GPH & $157,8 \mathrm{~B}^{\ddagger}$ & $187,8 \mathrm{~A}$ & $171,2 \mathrm{AB}$ & $186,9 \mathrm{~A}$ & $157,8 \mathrm{~B}$ & $78,2 \mathrm{C}$ \\
\hline AQd & $77,8 \mathrm{~B}$ & $110,6 \mathrm{~A}$ & 77,6 B & $106,7 \mathrm{~A}$ & $75,9 \mathrm{~B}$ & $42,5 \mathrm{C}$ \\
\hline LUa & $97,5 \mathrm{C}$ & $121,6 \mathrm{~B}$ & $124,5 \mathrm{~B}$ & $148,5 \mathrm{~A}$ & $131,3 \mathrm{~B}$ & $90,8 \mathrm{C}$ \\
\hline LE-1 & $107,8 \mathrm{C}$ & 125,9 B & $110,4 \mathrm{C}$ & $142,5 \mathrm{~A}$ & $111,5 \mathrm{C}$ & $73,3 \mathrm{D}$ \\
\hline LE-2 & $79,3 \mathrm{D}$ & $115,7 \mathrm{C}$ & $103,8 \mathrm{C}$ & $171,9 \mathrm{~A}$ & $139,8 \mathrm{~B}$ & $63,7 \mathrm{E}$ \\
\hline LA-1 & $79,4 \mathrm{C}$ & $118,4 \mathrm{~A}$ & $92,3 \mathrm{~B}$ & $122,3 \mathrm{~A}$ & $87,9 \mathrm{BC}$ & $46,2 \mathrm{D}$ \\
\hline PV -1 & $80,5 \mathrm{D}$ & $112,2 \mathrm{~B}$ & $89,2 \mathrm{CD}$ & $135,8 \mathrm{~A}$ & $99,7 \mathrm{BC}$ & $45,4 \mathrm{E}$ \\
\hline LA-2 & $87,7 \mathrm{C}$ & $111,3 \mathrm{~B}$ & $115,1 \mathrm{~B}$ & $142,8 \mathrm{~A}$ & $118,8 \mathrm{~B}$ & $69,2 \mathrm{D}$ \\
\hline LA-3 & 88,3 B & $111,0 \mathrm{~A}$ & $95,5 \mathrm{~B}$ & $121,6 \mathrm{~A}$ & 96,2 B & $65,5 \mathrm{C}$ \\
\hline TR-1 & $103,8 \mathrm{C}$ & $146,0 \mathrm{~B}$ & $137,2 \mathrm{~B}$ & $175,6 \mathrm{~A}$ & $135,6 \mathrm{~B}$ & $82,7 \mathrm{D}$ \\
\hline LA-4 & $89,1 \mathrm{~B}$ & $124,4 \mathrm{~A}$ & $99,0 \mathrm{~B}$ & $134,3 \mathrm{~A}$ & $100,8 \mathrm{~B}$ & $47,9 \mathrm{C}$ \\
\hline PV-2 & $82,7 \mathrm{BC}$ & $112,2 \mathrm{~A}$ & $90,3 \mathrm{~B}$ & $118,4 \mathrm{~A}$ & $78,0 \mathrm{C}$ & $38,3 \mathrm{D}$ \\
\hline LA-5 & $167,5 \mathrm{~B}$ & $184,5 \mathrm{AB}$ & $179,5 \mathrm{~B}$ & $202,3 \mathrm{~A}$ & $167,7 \mathrm{~B}$ & $95,9 \mathrm{C}$ \\
\hline PV-3 & $127,9 \mathrm{C}$ & $156,9 \mathrm{AB}$ & $161,6 \mathrm{AB}$ & $170,4 \mathrm{~A}$ & $148,1 \mathrm{~B}$ & $118,8 \mathrm{C}$ \\
\hline $\mathrm{LRa}$ & $90,1 \mathrm{~B}$ & $115,9 \mathrm{~A}$ & $100,9 \mathrm{~B}$ & $115,7 \mathrm{~A}$ & $91,5 \mathrm{~B}$ & $57,9 \mathrm{C}$ \\
\hline LE-3 & $113,7 \mathrm{C}$ & $127,0 \mathrm{ABC}$ & $129,2 \mathrm{AB}$ & $139,2 \mathrm{~A}$ & $119,5 \mathrm{BC}$ & $92,6 \mathrm{D}$ \\
\hline $\mathrm{PE}$ & $99,4 \mathrm{C}$ & $143,3 \mathrm{~A}$ & $123,8 \mathrm{~B}$ & $146,3 \mathrm{~A}$ & $124,3 \mathrm{~B}$ & $73,0 \mathrm{D}$ \\
\hline PV -4 & $80,3 \mathrm{C}$ & $108,7 \mathrm{~A}$ & $92,0 \mathrm{~B}$ & $118,4 \mathrm{~A}$ & $92,8 \mathrm{~B}$ & $58,9 \mathrm{D}$ \\
\hline TR-2 & $147,7 \mathrm{~B}$ & $168,6 \mathrm{~A}$ & $147,4 \mathrm{~B}$ & $187,9 \mathrm{~A}$ & $168,1 \mathrm{~A}$ & $128,9 \mathrm{C}$ \\
\hline $\mathrm{AQa}$ & $73,7 \mathrm{C}$ & $85,8 \mathrm{~B}$ & $78,1 \mathrm{BC}$ & $136,3 \mathrm{~A}$ & 88,3 B & $50,9 \mathrm{D}$ \\
\hline LV-1 & $83,3 \mathrm{C}$ & $112,3 \mathrm{~A}$ & $98,7 \mathrm{~B}$ & $118,5 \mathrm{~A}$ & $94,6 \mathrm{~B}$ & $72,2 \mathrm{D}$ \\
\hline \multirow{3}{*}{$\begin{array}{l}\text { Solos } \\
\text { alcalinos }\end{array}$} & \multicolumn{4}{|c|}{ Composto de resíduo urbano } & \multirow{3}{*}{$\begin{array}{c}\text { Gessagem } \\
\text { e } \\
\text { adubação }\end{array}$} & \multirow{3}{*}{ Testemunha } \\
\hline & \multicolumn{2}{|c|}{ sem gessagem } & \multicolumn{2}{|c|}{ com gessagem } & & \\
\hline & sem adubação & com adubação & sem adubação & com adubação & & \\
\hline & $-\cdots-\cdots$ & -non & $\mathrm{mg}$ & $m^{-3}-\ldots$ & - & 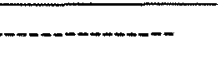 \\
\hline $\mathrm{CL}$ & $205,2 \mathrm{C}$ & $223,1 \mathrm{~B}$ & $255,9 \mathrm{~A}$ & $246,0 \mathrm{~A}$ & $244,5 \mathrm{~A}$ & $209,0 \mathrm{BC}$ \\
\hline $\mathrm{CV}$ & $492,8 \mathrm{AB}$ & $515,7 \mathrm{AB}$ & $518,3 \mathrm{AB}$ & $528,2 \mathrm{~A}$ & $434,5 \mathrm{~B}$ & $451,2 \mathrm{AB}$ \\
\hline LA-6 & $176,1 \mathrm{D}$ & $187,8 \mathrm{C}$ & $202,5 \mathrm{~B}$ & $221,6 \mathrm{~A}$ & $194,4 \mathrm{BC}$ & $153,8 \mathrm{E}$ \\
\hline LV-2 & $207,6 \mathrm{~B}$ & 209,4 B & $241,5 \mathrm{~A}$ & $255,0 \mathrm{~A}$ & $214,7 \mathrm{~B}$ & $193,4 \mathrm{C}$ \\
\hline SS & $273,1 \mathrm{~B}$ & $276,4 \mathrm{~B}$ & $316,7 \mathrm{~A}$ & $316,5 \mathrm{~A}$ & $312,0 \mathrm{~A}$ & $242,5 \mathrm{C}$ \\
\hline
\end{tabular}

¥-Médias seguidas de mesma letra, nas colunas, não diferem entre si pelo teste de Tukey ao nível de $5 \%$. 
Tabela 32. Saturação por bases em solos adubados com composto de resíduo urbano.

\begin{tabular}{|c|c|c|c|c|c|c|}
\hline \multirow{3}{*}{$\begin{array}{l}\text { Solos } \\
\text { ácidos }\end{array}$} & \multicolumn{4}{|c|}{ Composto de resíduo urbano } & \multirow{3}{*}{$\begin{array}{c}\text { Calagem } \\
\mathrm{e} \\
\text { adubação }\end{array}$} & \multirow{3}{*}{ Testemunha } \\
\hline & \multicolumn{2}{|c|}{ sem calagem } & \multicolumn{2}{|c|}{ com calagem } & & \\
\hline & sem adubação & com adubação & sem adubação & com adubação & & \\
\hline & \multicolumn{6}{|c|}{$\mathrm{mg} \mathrm{dm}^{3}$} \\
\hline GPH & $87,4 \mathrm{~A}^{\frac{\ddagger}{7}}$ & $87,8 \mathrm{~A}$ & $89,8 \mathrm{~A}$ & $89,6 \mathrm{~A}$ & $79,7 \mathrm{~B}$ & $55,1 \mathrm{C}$ \\
\hline AQd & $85,6 \mathrm{~A}$ & $88,5 \mathrm{~A}$ & $85,6 \mathrm{~A}$ & $88,3 \mathrm{~A}$ & $79,3 \mathrm{~B}$ & $67,3 \mathrm{C}$ \\
\hline LUa & $53,1 \mathrm{D}$ & $62,5 \mathrm{C}$ & $85,0 \mathrm{~A}$ & $84,1 \mathrm{~A}$ & $72,4 \mathrm{~B}$ & $5,2 \mathrm{E}$ \\
\hline LE-1 & $83,7 \mathrm{~A}$ & $84,3 \mathrm{~A}$ & $84,6 \mathrm{~A}$ & $87,0 \mathrm{~A}$ & $73,4 \mathrm{~B}$ & $61,6 \mathrm{C}$ \\
\hline LE-2 & $60,3 \mathrm{E}$ & $67,3 \mathrm{D}$ & $83,7 \mathrm{~B}$ & $88,7 \mathrm{~A}$ & $77,4 \mathrm{C}$ & $5,7 \mathrm{~F}$ \\
\hline LA-1 & $71,3 \mathrm{C}$ & $78,8 \mathrm{~B}$ & $84,1 \mathrm{~A}$ & $85,2 \mathrm{~A}$ & $73,9 \mathrm{C}$ & $16,2 \mathrm{D}$ \\
\hline PV-1 & $74,5 \mathrm{D}$ & $77,9 \mathrm{C}$ & $83,1 \mathrm{~B}$ & $87,0 \mathrm{~A}$ & $70,4 \mathrm{E}$ & $28,0 \mathrm{E}$ \\
\hline LA-2 & $66,0 \mathrm{C}$ & $72,3 \mathrm{~B}$ & $84,6 \mathrm{~A}$ & $86,4 \mathrm{~A}$ & $75,3 \mathrm{~B}$ & $27,5 \mathrm{D}$ \\
\hline LA-3 & $80,2 \mathrm{C}$ & $81,4 \mathrm{BC}$ & $84,7 \mathrm{AB}$ & $86,0 \mathrm{~A}$ & $67,7 \mathrm{D}$ & $43,2 \mathrm{E}$ \\
\hline TR-1 & $73,9 \mathrm{C}$ & $81,0 \mathrm{~B}$ & $85,3 \mathrm{~A}$ & $87,3 \mathrm{~A}$ & $76,6 \mathrm{C}$ & $42,3 \mathrm{D}$ \\
\hline LA-4 & $80,4 \mathrm{C}$ & $82,8 \mathrm{BC}$ & $85,2 \mathrm{AB}$ & $87,0 \mathrm{~A}$ & $72,7 \mathrm{D}$ & $37,7 \mathrm{E}$ \\
\hline PV -2 & $79,9 \mathrm{~B}$ & $83,5 \mathrm{~A}$ & $84,5 \mathrm{~A}$ & $86,3 \mathrm{~A}$ & $71,7 \mathrm{C}$ & $36,6 \mathrm{D}$ \\
\hline LA-5 & $80,2 \mathrm{~A}$ & $79,6 \mathrm{~A}$ & $85,6 \mathrm{~A}$ & $85,2 \mathrm{~A}$ & $70,7 \mathrm{C}$ & $46,6 \mathrm{D}$ \\
\hline PV -3 & $47,3 \mathrm{D}$ & $60,7 \mathrm{C}$ & $78,4 \mathrm{~A}$ & $78,8 \mathrm{~A}$ & $66,7 \mathrm{~B}$ & $8,3 \mathrm{E}$ \\
\hline LRa & $74,9 \mathrm{C}$ & $79,2 \mathrm{~B}$ & $82,4 \mathrm{AB}$ & $83,3 \mathrm{~A}$ & $69,7 \mathrm{D}$ & $35,3 \mathrm{E}$ \\
\hline LE-3 & $71,4 \mathrm{~B}$ & $72,0 \mathrm{~B}$ & $81,8 \mathrm{~A}$ & $82,2 \mathrm{~A}$ & $66,9 \mathrm{C}$ & $36,7 \mathrm{D}$ \\
\hline $\mathrm{PE}$ & $77,8 \mathrm{C}$ & 83,3 B & $85,5 \mathrm{AB}$ & $87,1 \mathrm{~A}$ & $76,4 \mathrm{C}$ & $47,3 \mathrm{D}$ \\
\hline PV -4 & $72,5 \mathrm{C}$ & $76,1 \mathrm{~B}$ & $81,9 \mathrm{~A}$ & $84,1 \mathrm{~A}$ & $67,6 \mathrm{D}$ & $25,5 \mathrm{E}$ \\
\hline TR-2 & $83,2 \mathrm{~A}$ & $83,7 \mathrm{~A}$ & $84,3 \mathrm{~A}$ & $86,5 \mathrm{~A}$ & 74,9 B & $66,9 \mathrm{C}$ \\
\hline $\mathrm{AQa}$ & $68,6 \mathrm{CD}$ & $70,9 \mathrm{C}$ & $78,6 \mathrm{~B}$ & $85,9 \mathrm{~A}$ & $66,8 \mathrm{D}$ & $10,0 \mathrm{E}$ \\
\hline LV-1 & $63,1 \mathrm{C}$ & $69,4 \mathrm{~B}$ & $80,2 \mathrm{~A}$ & $79,9 \mathrm{~A}$ & $59,3 \mathrm{D}$ & $13,8 \mathrm{E}$ \\
\hline \multirow{3}{*}{$\begin{array}{l}\text { Solos } \\
\text { alcalinos }\end{array}$} & \multicolumn{4}{|c|}{ Composto de resíduo urbano } & \multirow{3}{*}{$\begin{array}{c}\text { Gessagem } \\
\mathrm{e} \\
\text { adubação }\end{array}$} & \multirow{3}{*}{ Testemunha } \\
\hline & \multicolumn{2}{|c|}{ sem gessagem } & \multicolumn{2}{|c|}{ com gessagem } & & \\
\hline & sem adubação & com adubaçāo & sem adubação & com adubação & & \\
\hline & - & - & $\mathrm{mg}$ & $\mathrm{Im}^{-3}$ & - & 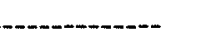 \\
\hline $\mathrm{CL}$ & $91,3 \mathrm{D}$ & $91,9 \mathrm{C}$ & $93,2 \mathrm{~A}$ & $92,6 \mathrm{~B}$ & $89,3 \mathrm{E}$ & $87,4 \mathrm{~F}$ \\
\hline $\mathrm{CV}$ & $98,0 \mathrm{~A}$ & $97,9 \mathrm{AB}$ & $98,1 \mathrm{~A}$ & $98,0 \mathrm{~A}$ & $97,4 \mathrm{~B}$ & $97,6 \mathrm{AB}$ \\
\hline LA-6 & $93,5 \mathrm{~B}$ & $93,2 \mathrm{~B}$ & $94,3 \mathrm{~A}$ & $94,3 \mathrm{~A}$ & $91,3 \mathrm{C}$ & $89,8 \mathrm{D}$ \\
\hline LV-2 & $94,9 \mathrm{~B}$ & $94,6 \mathrm{~B}$ & $95,7 \mathrm{~A}$ & $95,7 \mathrm{~A}$ & $93,6 \mathrm{C}$ & $93,3 \mathrm{C}$ \\
\hline SS & $96,6 \mathrm{ABC}$ & $96,3 \mathrm{BC}$ & $97,1 \mathrm{~A}$ & $96,8 \mathrm{AB}$ & $96,6 \mathrm{ABC}$ & $96,1 \mathrm{C}$ \\
\hline
\end{tabular}

¥- Médias seguidas de mesma letra, nas colunas, não diferem entre si pelo teste de Tukey ao nível de $5 \%$. 


\subsubsection{Disponibilidade de micro nutrientes}

Para a avaliação do efeito da aplicação do composto sobre à disponibilidade de micronutrientes no solo foram utilizados os resultados obtidos pelo extrator DTPA. Com base em Malavolta (1994) e Malavolta et al. (1997), os elementos $\mathrm{Co}$ e $\mathrm{Ni}$ foram considerados como micronutrientes. Normalmente, a disponibilidade de $\mathrm{B}$, Co e Mo em solos tem sido avaliado empregando-se extratores específicos (Bataglia \& Raij, 1990; Santos, 1991; Kabata-Pendias \& Pendias, 1986; Malavolta, 1994).

Os efeitos da a aplicação do composto sobre os teores disponíveis de $\mathrm{B}$, $\mathrm{Co}, \mathrm{Cu}, \mathrm{Fe}, \mathrm{Mn}, \mathrm{Mo}$, Ni e $\mathrm{Zn}$ são apresentados nas Tabelas 33, 34, 35, 36, 37, 38,39 e 40 , respectivamente. Observou-se, de um modo geral, que a aplicação de composto com adubo, na presença ou ausência de calcário, promoveu aumentos significativos nos teores de $\mathrm{B}, \mathrm{Cu}$, Ni e $\mathrm{Zn}$, notadamente nos solos ácidos.

No caso do B (Tabela 33), a adubação foi o fator mais importante no aumento de sua disponibilidade, todavia houve um efeito positivo do composto + adubação sobre este nutriente, tanto nos solos ácidos quanto nos alcalinos, devido ao B contido na matéria orgânica do composto. Embora não seja usual a utilização do extrator DTPA para a determinação de B, a determinação multielementar com esse extrator por ICP-AES forneceu teores de B consistentes com os resultados obtidos por Bataglia \& Raij (1989), com os extratores água quente, $\mathrm{CaCl}_{2}$ 0,01 mol L $\mathrm{L}^{-1}$ e Mehlich-1, e por Rodrigues (1998) com o extrator Mehlich-1 e determinação por ICP-AES.

No caso do Cu e do $\mathrm{Zn}$ (Tabelas 35 e 40), os tratamentos com composto + adubo e composto + calcário + adubo foram superiores à calagem + adubação, excluindo-se o solo GPH, onde o teor de $\mathrm{Zn}$ (de modo semelhante ao B) não diferiu do tratamento com calcário + adubo. A aplicação de composto, na ausência ou presença de calcário, não diferiu do calcário + adubo, e estes tratamentos foram superiores à testemunha. Nos solos alcalinos o efeito devido ao composto + adubo foi o mesmo, mas os tratamentos com composto e com composto + gesso, que não diferiram entre si, promoveram maior disponibilidade de $\mathrm{Cu}$ e $\mathrm{Zn}$ do que o tratamento com gesso + adubo. Enquanto que os teores de $\mathrm{Zn}$ nos tratamentos com composto + adubo e com composto + 
Tabela 33. Disponibilidade de B em solos adubados com composto de resíduo urbano.

\begin{tabular}{|c|c|c|c|c|c|c|}
\hline \multirow{3}{*}{$\begin{array}{l}\text { Solos } \\
\text { ácidos }\end{array}$} & \multicolumn{4}{|c|}{ Composto de resíduo urbano } & \multirow{3}{*}{$\begin{array}{c}\text { Calagem } \\
\mathrm{e} \\
\text { adubação }\end{array}$} & \multirow{3}{*}{ Testemunha } \\
\hline & \multicolumn{2}{|c|}{ sem calagem } & \multicolumn{2}{|c|}{ com calagem } & & \\
\hline & sem adubação & com adubação & sem adubação & com adubação & & \\
\hline & \multicolumn{6}{|c|}{ - } \\
\hline $\mathrm{GPH}$ & $0,11 \mathrm{CD}^{\ddagger}$ & $0,33 \mathrm{~A}$ & $0,11 \mathrm{CD}$ & $0,26 \mathrm{AB}$ & $0,18 \mathrm{BC}$ & $0,08 \mathrm{D}$ \\
\hline AQd & $0,20 \mathrm{~B}$ & $0,69 \mathrm{~A}$ & $0,19 \mathrm{~B}$ & $0,66 \mathrm{~A}$ & $0,47 \mathrm{~A}$ & $0,05 \mathrm{C}$ \\
\hline LUa & $0,06 \mathrm{~B}$ & $0,21 \mathrm{~A}$ & $0,08 \mathrm{~B}$ & $0,29 \mathrm{~A}$ & $0,25 \mathrm{~A}$ & $0,05 \mathrm{~B}$ \\
\hline LE-1 & $0,08 \mathrm{CD}$ & $0,20 \mathrm{AB}$ & $0,08 \mathrm{CD}$ & $0,28 \mathrm{~A}$ & $0,13 \mathrm{BC}$ & $0,06 \mathrm{D}$ \\
\hline LE-2 & $0,11 \mathrm{~B}$ & $0,29 \mathrm{~A}$ & $0,10 \mathrm{~B}$ & $0,29 \mathrm{~A}$ & $0,23 \mathrm{~A}$ & $0,06 \mathrm{C}$ \\
\hline LA-1 & $0,13 \mathrm{~B}$ & $0,49 \mathrm{~A}$ & $0,14 \mathrm{~B}$ & $0,51 \mathrm{~A}$ & $0,38 \mathrm{~A}$ & $0,10 \mathrm{~B}$ \\
\hline PV-1 & $0,10 \mathrm{~B}$ & $0,44 \mathrm{~A}$ & $0,11 \mathrm{~B}$ & $0,43 \mathrm{~A}$ & $0,32 \mathrm{~A}$ & $0,08 \mathrm{~B}$ \\
\hline LA-2 & $0,12 \mathrm{~B}$ & $0,27 \mathrm{~A}$ & $0,12 \mathrm{~B}$ & $0,26 \mathrm{~A}$ & $0,24 \mathrm{~A}$ & $0,10 \mathrm{~B}$ \\
\hline LA-3 & $0,12 \mathrm{BC}$ & $0,31 \mathrm{~A}$ & $0,10 \mathrm{C}$ & $0,42 \mathrm{~A}$ & $0,18 \mathrm{~B}$ & $0,05 \mathrm{D}$ \\
\hline TR-1 & $0,11 \mathrm{BC}$ & $0,14 \mathrm{AB}$ & $0,08 \mathrm{C}$ & $0,19 \mathrm{~A}$ & $0,20 \mathrm{~A}$ & $0,11 \mathrm{BC}$ \\
\hline LA-4 & $0,16 \mathrm{~B}$ & $0,44 \mathrm{~A}$ & $0,14 \mathrm{~B}$ & $0,44 \mathrm{~A}$ & $0,35 \mathrm{~A}$ & $0,06 \mathrm{C}$ \\
\hline PV-2 & $0,12 \mathrm{~B}$ & $0,44 \mathrm{~A}$ & $0,12 \mathrm{~B}$ & $0,49 \mathrm{~A}$ & $0,35 \mathrm{~A}$ & $0,06 \mathrm{C}$ \\
\hline LA-5 & $0,14 \mathrm{BC}$ & $0,28 \mathrm{~A}$ & $0,15 \mathrm{~B}$ & $0,27 \mathrm{~A}$ & $0,21 \mathrm{AB}$ & $0,09 \mathrm{C}$ \\
\hline PV-3 & $0,11 \mathrm{C}$ & $0,26 \mathrm{~A}$ & $0,09 \mathrm{C}$ & $0,20 \mathrm{AB}$ & $0,15 \mathrm{BC}$ & $0,03 \mathrm{D}$ \\
\hline $\mathrm{LRa}$ & $0,02 \mathrm{~B}$ & $0,18 \mathrm{~A}$ & $0,03 \mathrm{~B}$ & $0,17 \mathrm{~A}$ & $0,13 \mathrm{~A}$ & $0,02 \mathrm{~B}$ \\
\hline LE-3 & $0,11 \mathrm{C}$ & $0,24 \mathrm{~A}$ & $0,13 \mathrm{BC}$ & $0,28 \mathrm{~A}$ & $0,19 \mathrm{AB}$ & $0,09 \mathrm{C}$ \\
\hline PE & $0,07 \mathrm{~B}$ & $0,18 \mathrm{~A}$ & $0,07 \mathrm{~B}$ & $0,21 \mathrm{~A}$ & $0,15 \mathrm{~A}$ & $0,05 \mathrm{~B}$ \\
\hline $\mathrm{PV}-4$ & $0,09 \mathrm{CD}$ & $0,31 \mathrm{AB}$ & $0,12 \mathrm{C}$ & $0,43 \mathrm{~A}$ & $0,25 \mathrm{~B}$ & $0,07 \mathrm{D}$ \\
\hline TR-2 & $0,11 \mathrm{BC}$ & $0,22 \mathrm{~A}$ & $0,10 \mathrm{BC}$ & $0,16 \mathrm{AB}$ & $0,14 \mathrm{AB}$ & $0,08 \mathrm{C}$ \\
\hline $\mathrm{AQa}$ & $0,21 \mathrm{~B}$ & $0,78 \mathrm{~A}$ & $0,20 \mathrm{~B}$ & $0,78 \mathrm{~A}$ & $0,61 \mathrm{~A}$ & $0,08 \mathrm{C}$ \\
\hline LV-1 & $0,17 \mathrm{C}$ & $0,65 \mathrm{~A}$ & $0,19 \mathrm{C}$ & $0,63 \mathrm{~A}$ & $0,37 \mathrm{~B}$ & $0,08 \mathrm{D}$ \\
\hline \multirow{3}{*}{$\begin{array}{c}\text { Solos } \\
\text { alcalinos }\end{array}$} & \multicolumn{4}{|c|}{ Composto de resíduo urbano } & \multirow{3}{*}{$\begin{array}{c}\text { Gessagem } \\
e^{-} \\
\text {adubação }\end{array}$} & \multirow{3}{*}{ Testemunha } \\
\hline & \multicolumn{2}{|c|}{ sem gessagem } & \multicolumn{2}{|c|}{ com gessagem } & & \\
\hline & sem adubação & com adubação & sem adubação & com adubação & & \\
\hline & - & 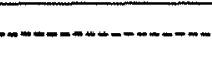 & mg & $\mathrm{m}^{-3}$ & 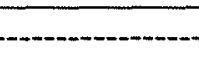 & --.-- \\
\hline $\mathrm{CL}$ & $0,07 \mathrm{C}$ & $0,11 \mathrm{AB}$ & $0,07 \mathrm{C}$ & $0,13 \mathrm{~A}$ & $0,09 \mathrm{BC}$ & $0,05 \mathrm{D}$ \\
\hline $\mathrm{CV}$ & $0,18 \mathrm{~B}$ & $0,31 \mathrm{~A}$ & $0,18 \mathrm{~B}$ & $0,32 \mathrm{~A}$ & $0,26 \mathrm{AB}$ & $0,18 \mathrm{~B}$ \\
\hline LA-6 & $0,21 \mathrm{C}$ & $0,48 \mathrm{~A}$ & $0,22 \mathrm{C}$ & $0,39 \mathrm{AB}$ & $0,30 \mathrm{BC}$ & $0,14 \mathrm{D}$ \\
\hline LV-2 & $0,21 \mathrm{C}$ & $0,36 \mathrm{~A}$ & $0,23 \mathrm{BC}$ & $0,40 \mathrm{~A}$ & $0,32 \mathrm{AB}$ & $0,19 \mathrm{C}$ \\
\hline SS & $0,23 \mathrm{~B}$ & $0,71 \mathrm{~A}$ & $0,24 \mathrm{~B}$ & $0,67 \mathrm{~A}$ & $0,60 \mathrm{~A}$ & $0,18 \mathrm{~B}$ \\
\hline
\end{tabular}

\$-Médias seguidas de mesma letra, nas colunas, não diferem entre si pelo teste de Tukey ao nível de $5 \%$. 
Tabela 34. Disponibilidade de cobalto em solos adubados com composto de resíduo urbano.

\begin{tabular}{|c|c|c|c|c|c|c|}
\hline \multirow{3}{*}{$\begin{array}{l}\text { Solos } \\
\text { ácidos }\end{array}$} & \multicolumn{4}{|c|}{ Composto de resíduo urbano } & \multirow{3}{*}{$\begin{array}{c}\text { Calagem } \\
\mathrm{e} \\
\text { adubação }\end{array}$} & \multirow{3}{*}{ Testemunha } \\
\hline & \multicolumn{2}{|c|}{ sem calagem } & \multicolumn{2}{|c|}{ com calagem } & & \\
\hline & sem adubação & com adubação & sem adubação & com adubação & & \\
\hline & \multicolumn{6}{|c|}{ - $\mathrm{mg} \mathrm{dm}^{-3}$} \\
\hline GPH & $0,14 \mathrm{~B}^{\ddagger}$ & $0,16 \mathrm{~B}$ & $0,13 \mathrm{~B}$ & $0,16 \mathrm{~B}$ & $0,23 \mathrm{~A}$ & $0,27 \mathrm{~A}$ \\
\hline AQd & $0,03 \mathrm{~A}$ & $0,03 \mathrm{~A}$ & $0,01 \mathrm{~B}$ & $0,02 \mathrm{AB}$ & $0,03 \mathrm{~A}$ & $0,01 \mathrm{~B}$ \\
\hline LUa & $0,04 \mathrm{~A}$ & $0,06 \mathrm{~A}$ & $0,05 \mathrm{~A}$ & $0,06 \mathrm{~A}$ & $0,06 \mathrm{~A}$ & $0,01 \mathrm{~B}$ \\
\hline LE-1 & $0,96 \mathrm{C}$ & $0,88 \mathrm{C}$ & $0,93 \mathrm{C}$ & $0,92 \mathrm{C}$ & $1,61 \mathrm{~B}$ & $1,89 \mathrm{~A}$ \\
\hline LE-2 & $0,02 \mathrm{C}$ & $0,09 \mathrm{~A}$ & $0,08 \mathrm{~A}$ & $0,05 \mathrm{~B}$ & $0,04 \mathrm{~B}$ & $0,00 \mathrm{C}$ \\
\hline LA-1 & $0,03 \mathrm{~A}$ & $0,04 \mathrm{~A}$ & $0,02 \mathrm{AB}$ & $0,03 \mathrm{~A}$ & $0,01 \mathrm{~B}$ & $0,00 \mathrm{~B}$ \\
\hline PV-1 & $0,03 \mathrm{AB}$ & $0,04 \mathrm{~A}$ & $0,03 \mathrm{AB}$ & $0,04 \mathrm{~A}$ & $0,04 \mathrm{~A}$ & $0,02 \mathrm{~B}$ \\
\hline LA-2 & $0,02 \mathrm{AB}$ & $0,04 \mathrm{~A}$ & $0,02 \mathrm{AB}$ & $0,02 \mathrm{AB}$ & $0,00 \mathrm{~B}$ & $0,00 \mathrm{~B}$ \\
\hline LA-3 & $0,02 \mathrm{AB}$ & $0,03 \mathrm{~A}$ & $0,01 \mathrm{~B}$ & $0,02 \mathrm{AB}$ & $0,03 \mathrm{~A}$ & $0,01 \mathrm{~B}$ \\
\hline TR-1 & $0,63 \mathrm{~A}$ & $0,46 \mathrm{~B}$ & $0,39 \mathrm{C}$ & $0,48 \mathrm{~B}$ & 0,49 B & $0,50 \mathrm{~B}$ \\
\hline LA-4 & $0,21 \mathrm{~A}$ & $0,24 \mathrm{~A}$ & $0,16 \mathrm{~B}$ & $0,21 \mathrm{~A}$ & $0,23 \mathrm{~A}$ & $0,15 \mathrm{~B}$ \\
\hline PV-2 & $0,20 \mathrm{D}$ & $0,28 \mathrm{C}$ & $0,17 \mathrm{D}$ & $0,20 \mathrm{D}$ & $0,41 \mathrm{~A}$ & $0,36 \mathrm{~B}$ \\
\hline LA-5 & $0,44 \mathrm{D}$ & $0,55 \mathrm{C}$ & $0,33 \mathrm{E}$ & $0,39 \mathrm{D}$ & $0,64 \mathrm{~B}$ & $0,74 \mathrm{~A}$ \\
\hline PV-3 & $0,00 \mathrm{~B}$ & $0,02 \mathrm{AB}$ & $0,00 \mathrm{~B}$ & $0,03 \mathrm{~A}$ & $0,00 \mathrm{~B}$ & $0,00 \mathrm{~B}$ \\
\hline LRa & $0,22 \mathrm{C}$ & $0,23 \mathrm{BC}$ & $0,21 \mathrm{C}$ & $0,22 \mathrm{C}$ & $0,26 \mathrm{AB}$ & $0,27 \mathrm{~A}$ \\
\hline LE-3 & $0,08 \mathrm{~A}$ & $0,08 \mathrm{~A}$ & $0,05 \mathrm{~B}$ & $0,06 \mathrm{AB}$ & $0,08 \mathrm{~A}$ & $0,08 \mathrm{~A}$ \\
\hline $\mathrm{PE}$ & $0,39 \mathrm{~B}$ & $0,32 \mathrm{C}$ & $0,29 \mathrm{CD}$ & $0,26 \mathrm{D}$ & $0,38 \mathrm{~B}$ & $0,67 \mathrm{~A}$ \\
\hline PV-4 & $0,00 \mathrm{~A}$ & $0,00 \mathrm{~A}$ & $0,00 \mathrm{~A}$ & $0,02 \mathrm{~A}$ & $0,00 \mathrm{~A}$ & $0,00 \mathrm{~A}$ \\
\hline TR-2 & $1,56 \mathrm{C}$ & $1,51 \mathrm{C}$ & $1,56 \mathrm{C}$ & $1,44 \mathrm{C}$ & $2,16 \mathrm{~B}$ & $2,50 \mathrm{~A}$ \\
\hline $\mathrm{AQa}$ & $0,04 \mathrm{~A}$ & $0,04 \mathrm{~A}$ & $0,02 \mathrm{AB}$ & $0,03 \mathrm{~A}$ & $0,01 \mathrm{~B}$ & $0,00 \mathrm{~B}$ \\
\hline LV-1 & $0,00 \mathrm{~B}$ & $0,03 \mathrm{~A}$ & $0,00 \mathrm{~B}$ & $0,02 \mathrm{AB}$ & $0,03 \mathrm{~A}$ & $0,00 \mathrm{~B}$ \\
\hline \multirow{3}{*}{$\begin{array}{c}\text { Solos } \\
\text { alcalinos }\end{array}$} & \multicolumn{4}{|c|}{ Composto de resíduo urbano } & \multirow{3}{*}{$\begin{array}{c}\text { Gessagem } \\
\mathrm{e} \\
\text { adubação }\end{array}$} & \multirow{3}{*}{ Testemunha } \\
\hline & \multicolumn{2}{|c|}{ sem gessagem } & \multicolumn{2}{|c|}{ com gessagem } & & \\
\hline & sem adubação & com adubação & sem adubação & com adubação & & \\
\hline & - & - & mg & $\mathrm{Im}^{-3}$ & - & - \\
\hline $\mathrm{CL}$ & $0,36 \mathrm{~B}$ & $0,40 \mathrm{~B}$ & $0,38 \mathrm{~B}$ & $0,41 \mathrm{~B}$ & $0,69 \mathrm{~A}$ & $0,64 \mathrm{~A}$ \\
\hline $\mathrm{CV}$ & $0,22 \mathrm{~B}$ & $0,30 \mathrm{~A}$ & $0,29 \mathrm{AB}$ & $0,25 \mathrm{AB}$ & $0,29 \mathrm{AB}$ & $0,24 \mathrm{AB}$ \\
\hline LA-6 & $0,33 \mathrm{ABC}$ & $0,34 \mathrm{ABC}$ & $0,26 \mathrm{C}$ & $0,29 \mathrm{BC}$ & $0,43 \mathrm{~A}$ & $0,38 \mathrm{AB}$ \\
\hline LV-2 & $0,19 \mathrm{AB}$ & $0,19 \mathrm{AB}$ & $0,18 \mathrm{~B}$ & $0,19 \mathrm{AB}$ & $0,21 \mathrm{AB}$ & $0,25 \mathrm{~A}$ \\
\hline SS & $0,15 \mathrm{AB}$ & $0,17 \mathrm{~A}$ & $0,15 \mathrm{AB}$ & $0,14 \mathrm{AB}$ & $0,12 \mathrm{AB}$ & $0,11 \mathrm{~B}$ \\
\hline
\end{tabular}

$\ddagger$-Médias seguidas de mesma letra, nas colunas, não diferem entre si pelo teste de Tukey ao nível de $5 \%$. 
Tabela 35. Disponibilidade de cobre em solos adubados com composto de resíduo urbano.

\begin{tabular}{|c|c|c|c|c|c|c|}
\hline \multirow{3}{*}{$\begin{array}{l}\text { Solos } \\
\text { ácidos }\end{array}$} & \multicolumn{4}{|c|}{ Composto de resíduo urbano } & \multirow{3}{*}{$\begin{array}{l}\text { Calagem } \\
\text { e } \\
\text { adubação }\end{array}$} & \multirow{3}{*}{ Testemunha } \\
\hline & \multicolumn{2}{|c|}{ sem calagem } & \multicolumn{2}{|c|}{ com calagem } & & \\
\hline & sem adubação & com adubação & sem adubação & com adubação & & \\
\hline & \multicolumn{6}{|c|}{ - $\mathrm{mg} \mathrm{dm}^{-3}$} \\
\hline $\mathrm{GPH}$ & $5,25 \mathrm{AB}^{\ddagger}$ & $5,78 \mathrm{~A}$ & $5,43 \mathrm{AB}$ & $5,54 \mathrm{~A}$ & $4,43 \mathrm{~B}$ & $4,35 \mathrm{~B}$ \\
\hline AQd & $2,62 \mathrm{AB}$ & $3,29 \mathrm{~A}$ & $2,35 \mathrm{BC}$ & $3,36 \mathrm{~A}$ & $1,61 \mathrm{C}$ & $0,89 \mathrm{D}$ \\
\hline LUa & $2,78 \mathrm{AB}$ & $3,46 \mathrm{~A}$ & $2,34 \mathrm{BC}$ & $3,19 \mathrm{AB}$ & $1,65 \mathrm{CD}$ & $1,26 \mathrm{D}$ \\
\hline LE-1 & $13,76 \mathrm{~A}$ & $14,88 \mathrm{~A}$ & $13,35 \mathrm{~A}$ & $14,50 \mathrm{~A}$ & $14,88 \mathrm{~A}$ & $14,00 \mathrm{~A}$ \\
\hline LE-2 & $2,02 \mathrm{~A}$ & $2,74 \mathrm{~A}$ & $2,22 \mathrm{~A}$ & $2,23 \mathrm{~A}$ & $0,95 \mathrm{~B}$ & $0,51 \mathrm{~B}$ \\
\hline LA-1 & $3,28 \mathrm{AB}$ & $4,21 \mathrm{~A}$ & 2,99 B & $3,72 \mathrm{AB}$ & $1,83 \mathrm{C}$ & $1,24 \mathrm{C}$ \\
\hline PV-1 & $2,22 \mathrm{~B}$ & $3,41 \mathrm{~A}$ & $1,75 \mathrm{~B}$ & $3,30 \mathrm{~A}$ & $1,87 \mathrm{~B}$ & $1,01 \mathrm{C}$ \\
\hline LA-2 & $2,49 \mathrm{AB}$ & $2,86 \mathrm{~A}$ & $1,80 \mathrm{~B}$ & $2,61 \mathrm{~A}$ & $1,07 \mathrm{C}$ & $0,40 \mathrm{D}$ \\
\hline LA-3 & $2,46 \mathrm{~A}$ & $2,44 \mathrm{~A}$ & $2,20 \mathrm{~A}$ & $2,64 \mathrm{~A}$ & $1,37 \mathrm{~B}$ & $0,79 \mathrm{~B}$ \\
\hline TR-1 & $3,44 \mathrm{~A}$ & $3,33 \mathrm{AB}$ & $2,37 \mathrm{CD}$ & $3,23 \mathrm{ABC}$ & $2,48 \mathrm{BCD}$ & $1,72 \mathrm{D}$ \\
\hline LA-4 & $3,11 \mathrm{BC}$ & $4,29 \mathrm{~A}$ & $3,17 \mathrm{BC}$ & $3,92 \mathrm{AB}$ & $2,66 \mathrm{C}$ & $1,25 \mathrm{D}$ \\
\hline PV-2 & $2,77 \mathrm{BC}$ & $4,15 \mathrm{~A}$ & $2,72 \mathrm{C}$ & $3,70 \mathrm{AB}$ & $1,87 \mathrm{D}$ & $1,18 \mathrm{E}$ \\
\hline LA-5 & $4,01 \mathrm{AB}$ & $4,79 \mathrm{~A}$ & $3,64 \mathrm{~B}$ & $3,93 \mathrm{AB}$ & $2,21 \mathrm{C}$ & $2,18 \mathrm{C}$ \\
\hline PV-3 & $1,51 \mathrm{AB}$ & $2,25 \mathrm{~A}$ & $1,36 \mathrm{~B}$ & $2,06 \mathrm{AB}$ & $0,68 \mathrm{C}$ & $0,31 \mathrm{C}$ \\
\hline LRa & $7,15 \mathrm{ABC}$ & $7,83 \mathrm{~A}$ & $6,87 \mathrm{ABC}$ & $7,38 \mathrm{AB}$ & $6,39 \mathrm{BC}$ & $6,03 \mathrm{C}$ \\
\hline LE-3 & $3,93 \mathrm{AB}$ & $4,48 \mathrm{~A}$ & $3,82 \mathrm{AB}$ & $4,53 \mathrm{~A}$ & $2,98 \mathrm{BC}$ & $2,54 \mathrm{C}$ \\
\hline $\mathrm{PE}$ & $3,27 \mathrm{AB}$ & $4,07 \mathrm{~A}$ & $2,99 \mathrm{~B}$ & $4,20 \mathrm{~A}$ & $2,61 \mathrm{~B}$ & $1,75 \mathrm{C}$ \\
\hline PV -4 & $2,05 \mathrm{~B}$ & $3,07 \mathrm{~A}$ & $1,68 \mathrm{~B}$ & $3,10 \mathrm{~A}$ & $1,85 \mathrm{~B}$ & $0,74 \mathrm{C}$ \\
\hline TR-2 & $10,06 \mathrm{AB}$ & $10,78 \mathrm{AB}$ & $10,05 \mathrm{AB}$ & $10,99 \mathrm{~A}$ & $10,33 \mathrm{AB}$ & $9,48 \mathrm{~B}$ \\
\hline $\mathrm{AQa}$ & $2,42 \mathrm{AB}$ & $2,81 \mathrm{~A}$ & $1,88 \mathrm{BC}$ & $2,90 \mathrm{~A}$ & $1,22 \mathrm{C}$ & $0,58 \mathrm{D}$ \\
\hline LV-1 & $1,91 \mathrm{BC}$ & $2,77 \mathrm{~A}$ & $1,85 \mathrm{C}$ & $2,71 \mathrm{AB}$ & $0,86 \mathrm{D}$ & $0,44 \mathrm{D}$ \\
\hline \multirow{3}{*}{$\begin{array}{c}\text { Solos } \\
\text { alcalinos }\end{array}$} & \multicolumn{4}{|c|}{ Composto de resíduo urbano } & \multirow{3}{*}{$\begin{array}{c}\text { Gessagem } \\
\mathrm{e} \\
\text { adubação }\end{array}$} & \multirow{3}{*}{ Testemunha } \\
\hline & \multicolumn{2}{|c|}{ sem gessagem } & \multicolumn{2}{|c|}{ com gessagem } & & \\
\hline & sem adubação & com adubação & sem adubação & com adubação & & \\
\hline & - & 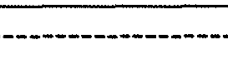 & mg & $\mathrm{Im}^{-3}$ & - & 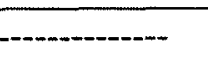 \\
\hline $\mathrm{CL}$ & $2,84 \mathrm{~B}$ & $3,49 \mathrm{~A}$ & $3,06 \mathrm{~B}$ & $3,59 \mathrm{~A}$ & $2,36 \mathrm{C}$ & $1,93 \mathrm{D}$ \\
\hline $\mathrm{CV}$ & $3,10 \mathrm{BC}$ & $3,64 \mathrm{~A}$ & $2,88 \mathrm{C}$ & $3,33 \mathrm{AB}$ & $2,08 \mathrm{D}$ & $1,32 \mathrm{E}$ \\
\hline LA-6 & $3,34 \mathrm{AB}$ & $3,75 \mathrm{~A}$ & $2,77 \mathrm{C}$ & $3,28 \mathrm{BC}$ & $2,17 \mathrm{D}$ & $1,52 \mathrm{E}$ \\
\hline LV-2 & $3,03 \mathrm{~B}$ & $3,69 \mathrm{~A}$ & $2,80 \mathrm{~B}$ & $3,75 \mathrm{~A}$ & $2,18 \mathrm{C}$ & $1,74 \mathrm{D}$ \\
\hline SS & $3,55 \mathrm{C}$ & $4,60 \mathrm{~A}$ & $4,00 \mathrm{~B}$ & $4,44 \mathrm{~A}$ & $2,96 \mathrm{D}$ & $2,00 \mathrm{E}$ \\
\hline
\end{tabular}

†-Médias seguidas de mesma letra, nas colunas, não diferem entre si pelo teste de Tukey ao nível de $5 \%$. 
calcário + adubo foram superiores aos máximos relatados por Bataglia \& Raij (1989); enquanto que os teores de Cu estiveram dentro da mesma faixa.

O Ni (Tabela 39) teve sua disponibilidade aumentada devido à aplicação de composto + adubo, principalmente na ausência da calagem. Nos solos GPH, LE-1, TR-1 e TR-2, cujas amostras iniciais apresentaram elevados teores disponíveis e totais, a disponibilidade de $\mathrm{Ni}$ foi superior na testemunha. Os teores disponíveis de $\mathrm{Ni}$, nestes solos, na testemunha $\left(1,29\right.$ a $\left.1,60 \mathrm{mg} \mathrm{dm}^{-3}\right)$ foram superiores aos máximos valores $(0,84$ a $0,90 \mathrm{mg} \mathrm{dm}^{-3}$ ) reportados por Abreu et al. (1995) para solos não contaminados. Nos demais solos, exceto no LA-5, independentemente do tratamento, os teores observados foram inferiores a estes máximos. Nos solos alcalinos o Ni teve sua disponibilidade aumentada pelo composto independentemente do modo de aplicação, exceto nos solos nos solos CL e LA-6. Os teores de $\mathrm{Ni}$ observados nestes solos foram superiores aos observados por Abreu et al. (1995).

Verificou-se médios a altos teores de Co na testemunha dos solos GPH, LE-1, LA-5, PE e TR-2 (Tabela 34). A aplicação do composto nestes solos, independentemente da forma de aplicação, reduziu significativamente os teores desse elemento. Nos demais solos ácidos houve tendência da aplicação do composto aumentar a disponibilidade do Co. Embora os altos teores estejam em concordância com os teores totais, observou-se uma amplitude muito grande entre os teores de Co disponível determinado pelo DTPA, o que pode ser devido à impropriedade do extrator para esse micronutriente. Cravo (1995) observou um aumento na disponibilidade de Co proporcional à dose de aplicação do composto.

Os teores de Fe e Mo, também apresentaram comportamento semelhantes nos solos ácidos (Tabelas 36 e 38). Esses dois elementos, excluindo-se os solos AQd, LA-5 e PE, tiveram seus teores diminuídos devido à aplicação de composto + calcário, com ou sem adubo. Nos solos alcalinos o Fe teve um comportamento diferente, sendo que em qualquer dos tratamentos com composto ocorreu um significativo aumento no teor de $\mathrm{Fe}$, exceto no solo CL. O Mo praticamente não foi modificado pelos tratamentos nos solos alcalinos, exceto no solo CV onde o seu teor foi aumentado pela aplicação do composto. 
Tabela 36. Disponibilidade de ferro em solos adubados com composto de resíduo urbano.

\begin{tabular}{|c|c|c|c|c|c|c|}
\hline \multirow{3}{*}{$\begin{array}{l}\text { Solos } \\
\text { ácidos }\end{array}$} & \multicolumn{4}{|c|}{ Composto de resíduo urbano } & \multirow{3}{*}{$\begin{array}{c}\text { Calagem } \\
\mathrm{e} \\
\text { adubação }\end{array}$} & \multirow{3}{*}{ Testemunha } \\
\hline & \multicolumn{2}{|c|}{ sem calagem } & \multicolumn{2}{|c|}{ com calagem } & & \\
\hline & sem adubação & com adubação & sem adubação & com adubação & & \\
\hline & \multicolumn{6}{|c|}{$\mathrm{mg} \mathrm{dm}^{-3}$} \\
\hline GPH & $170,0 \mathrm{~B}^{\ddagger}$ & $175,1 \mathrm{~B}$ & $146,7 \mathrm{~B}$ & $166,5 \mathrm{~B}$ & $220,2 \mathrm{~A}$ & $236,6 \mathrm{~A}$ \\
\hline AQd & $24,5 \mathrm{~A}$ & $18,4 \mathrm{C}$ & $22,9 \mathrm{AB}$ & $19,9 \mathrm{BC}$ & $10,7 \mathrm{D}$ & $12,2 \mathrm{D}$ \\
\hline LUa & $95,1 \mathrm{~B}$ & $96,0 \mathrm{~B}$ & $63,1 \mathrm{C}$ & $56,6 \mathrm{C}$ & $60,7 \mathrm{C}$ & $118,5 \mathrm{~A}$ \\
\hline LE-1 & $25,0 \mathrm{~A}$ & $24,6 \mathrm{~A}$ & $26,4 \mathrm{~A}$ & $22,8 \mathrm{~A}$ & $25,3 \mathrm{~A}$ & $23,8 \mathrm{~A}$ \\
\hline LE-2 & $55,3 \mathrm{~A}$ & $63,5 \mathrm{~A}$ & $43,7 \mathrm{~B}$ & $38,2 \mathrm{~B}$ & $39,9 \mathrm{~B}$ & 59,9 A \\
\hline LA-1 & $128,8 \mathrm{~B}$ & $128,5 \mathrm{~B}$ & $93,1 \mathrm{CD}$ & $84,0 \mathrm{D}$ & $101,9 \mathrm{C}$ & $213,7 \mathrm{~A}$ \\
\hline PV-1 & 84,4 B & $92,9 \mathrm{~B}$ & $58,6 \mathrm{C}$ & $65,0 \mathrm{C}$ & $98,4 \mathrm{~B}$ & $130,0 \mathrm{~A}$ \\
\hline LA-2 & $151,4 \mathrm{~B}$ & $133,7 \mathrm{~B}$ & $90,7 \mathrm{C}$ & $93,8 \mathrm{C}$ & $105,8 \mathrm{C}$ & $185,7 \mathrm{~A}$ \\
\hline LA-3 & $94,5 \mathrm{BC}$ & $98,0 \mathrm{~B}$ & $80,4 \mathrm{C}$ & $81,1 \mathrm{C}$ & $130,1 \mathrm{~A}$ & $146,7 \mathrm{~A}$ \\
\hline TR-1 & $12,8 \mathrm{~A}$ & 10,9 B & $7,8 \mathrm{D}$ & $9,1 \mathrm{C}$ & $7,2 \mathrm{D}$ & $5,8 \mathrm{E}$ \\
\hline LA-4 & $49,4 \mathrm{BC}$ & $58,0 \mathrm{AB}$ & $37,1 \mathrm{D}$ & $43,7 \mathrm{CD}$ & $56,4 \mathrm{~B}$ & $67,3 \mathrm{~A}$ \\
\hline PV-2 & $35,2 \mathrm{CD}$ & $42,5 \mathrm{AB}$ & $30,0 \mathrm{D}$ & $32,1 \mathrm{CD}$ & $37,5 \mathrm{BC}$ & $49,7 \mathrm{~A}$ \\
\hline LA-5 & $85,6 \mathrm{ABC}$ & $94,4 \mathrm{~A}$ & $71,6 \mathrm{C}$ & $76,3 \mathrm{BC}$ & $87,9 \mathrm{AB}$ & $91,5 \mathrm{AB}$ \\
\hline PV-3 & $36,6 \mathrm{AB}$ & $40,7 \mathrm{~A}$ & $26,7 \mathrm{D}$ & $31,7 \mathrm{BC}$ & $24,2 \mathrm{D}$ & $27,6 \mathrm{CD}$ \\
\hline LRa & $27,7 \mathrm{~A}$ & $28,0 \mathrm{~A}$ & $25,8 \mathrm{AB}$ & $24,9 \mathrm{AB}$ & $22,0 \mathrm{~B}$ & $26,4 \mathrm{~A}$ \\
\hline LE-3 & $34,6 \mathrm{~A}$ & $35,0 \mathrm{~A}$ & $28,8 \mathrm{BC}$ & $28,9 \mathrm{~B}$ & $24,5 \mathrm{C}$ & $33,5 \mathrm{AB}$ \\
\hline PE & $31,6 \mathrm{~A}$ & $30,4 \mathrm{~A}$ & $24,9 \mathrm{~B}$ & $25,7 \mathrm{~B}$ & $22,1 \mathrm{~B}$ & $30,3 \mathrm{~A}$ \\
\hline PV-4 & $43,2 \mathrm{BC}$ & 50,5 в & $30,7 \mathrm{D}$ & $37,5 \mathrm{C}$ & 44,7 B & $63,2 \mathrm{~A}$ \\
\hline TR-2 & $67,9 \mathrm{BC}$ & $68,1 \mathrm{BC}$ & $67,5 \mathrm{BC}$ & $64,4 \mathrm{C}$ & $78,4 \mathrm{AB}$ & $83,2 \mathrm{~A}$ \\
\hline $\mathrm{AQa}$ & $103,7 \mathrm{~B}$ & $101,0 \mathrm{~B}$ & $67,2 \mathrm{C}$ & $78,2 \mathrm{C}$ & $110,5 \mathrm{~B}$ & $180,6 \mathrm{~A}$ \\
\hline LV-1 & $83,7 \mathrm{~B}$ & $81,1 \mathrm{~B}$ & $60,3 \mathrm{D}$ & $63,9 \mathrm{CD}$ & $74,7 \mathrm{BC}$ & $148,8 \mathrm{~A}$ \\
\hline \multirow{3}{*}{$\begin{array}{c}\text { Solos } \\
\text { alcalinos }\end{array}$} & \multicolumn{4}{|c|}{ Composto de resíduo urbano } & \multirow{3}{*}{$\begin{array}{c}\text { Gessagem } \\
\mathrm{e} \\
\text { adubação }\end{array}$} & \multirow{3}{*}{ Testemunha } \\
\hline & \multicolumn{2}{|c|}{ sem gessagem } & \multicolumn{2}{|c|}{ com gessagem } & & \\
\hline & sem adubação & com adubação & sem adubação & com adubação & & \\
\hline & $\cdots$ & . & mg & $\mathrm{m}^{-3}$ & - & (-n) \\
\hline $\mathrm{CL}$ & $24,0 \mathrm{AB}$ & $24,4 \mathrm{AB}$ & $25,3 \mathrm{~A}$ & $24,5 \mathrm{AB}$ & $21,7 \mathrm{~B}$ & $22,4 \mathrm{AB}$ \\
\hline $\mathrm{CV}$ & $16,8 \mathrm{~A}$ & $18,0 \mathrm{~A}$ & $18,6 \mathrm{~A}$ & $15,5 \mathrm{~A}$ & $10,9 \mathrm{~B}$ & $9,8 \mathrm{~B}$ \\
\hline LA- 6 & $19,2 \mathrm{~A}$ & $16,5 \mathrm{~A}$ & $17,4 \mathrm{~A}$ & $15,7 \mathrm{~A}$ & $9,6 \mathrm{~B}$ & $7,8 \mathrm{~B}$ \\
\hline LV-2 & $20,5 \mathrm{~A}$ & $19,1 \mathrm{~A}$ & $19,0 \mathrm{~A}$ & $18,8 \mathrm{~A}$ & $9,8 \mathrm{~B}$ & $10,4 \mathrm{~B}$ \\
\hline SS & $30,9 \mathrm{AB}$ & $27,4 \mathrm{BC}$ & $31,6 \mathrm{~A}$ & $27,0 \mathrm{C}$ & $18,3 \mathrm{D}$ & $21,7 \mathrm{D}$ \\
\hline
\end{tabular}

‡-Médias seguidas de mesma letra, nas colunas, não diferem entre si pelo teste de Tukey ao nível de $5 \%$. 
Tabela 37. Disponibilidade de manganês em solos adubados com composto de resíduo urbano.

\begin{tabular}{|c|c|c|c|c|c|c|}
\hline \multirow{3}{*}{$\begin{array}{l}\text { Solos } \\
\text { ácidos }\end{array}$} & \multicolumn{4}{|c|}{ Composto de resíduo urbano } & \multirow{3}{*}{$\begin{array}{c}\text { Calagem } \\
\mathrm{e} \\
\text { adubação }\end{array}$} & \multirow{3}{*}{ Testemunha } \\
\hline & \multicolumn{2}{|c|}{ sem calagem } & \multicolumn{2}{|c|}{ com calagem } & & \\
\hline & sem adubação & com adubação & sem adubação & com adubação & & \\
\hline & - & 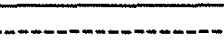 & $\mathrm{mg} \mathrm{d}$ & $m^{-3} \ldots$ & & -non \\
\hline GPH & $30,1 \mathrm{BC}^{\ddagger}$ & $33,2 \mathrm{~B}$ & $27,6 \mathrm{C}$ & $34,3 \mathrm{~B}$ & $46,4 \mathrm{~A}$ & $43,9 \mathrm{~A}$ \\
\hline AQd & $7,5 \mathrm{C}$ & $9,5 \mathrm{BC}$ & $7,4 \mathrm{C}$ & $9,7 \mathrm{AB}$ & $12,1 \mathrm{~A}$ & $8,5 \mathrm{BC}$ \\
\hline LUa & $6,3 \mathrm{BC}$ & $9,7 \mathrm{~A}$ & $5,6 \mathrm{C}$ & $9,0 \mathrm{~A}$ & $8,3 \mathrm{~A}$ & $7,9 \mathrm{AB}$ \\
\hline LE-1 & $78,9 \mathrm{C}$ & $81,4 \mathrm{C}$ & $76,8 \mathrm{C}$ & $83,9 \mathrm{C}$ & $108,9 \mathrm{~B}$ & $129,2 \mathrm{~A}$ \\
\hline LE-2 & $2,7 \mathrm{~B}$ & $6,4 \mathrm{~A}$ & $2,9 \mathrm{~B}$ & $5,3 \mathrm{~A}$ & $3,6 \mathrm{~B}$ & $1,5 \mathrm{C}$ \\
\hline LA-1 & $7,4 \mathrm{CD}$ & $11,7 \mathrm{~A}$ & $7,7 \mathrm{CD}$ & $10,4 \mathrm{AB}$ & $8,2 \mathrm{BC}$ & $6,1 \mathrm{D}$ \\
\hline PV-1 & $5,5 \mathrm{~B}$ & $11,1 \mathrm{~A}$ & $5,9 \mathrm{~B}$ & $10,7 \mathrm{~A}$ & $11,3 \mathrm{~A}$ & $6,2 \mathrm{~B}$ \\
\hline LA-2 & $6,9 \mathrm{C}$ & $7,3 \mathrm{BC}$ & $6,6 \mathrm{C}$ & $9,8 \mathrm{~A}$ & $9,2 \mathrm{AB}$ & $4,0 \mathrm{D}$ \\
\hline LA-3 & $4,8 \mathrm{C}$ & $7,0 \mathrm{~B}$ & $4,3 \mathrm{C}$ & $7,5 \mathrm{AB}$ & $8,2 \mathrm{AB}$ & $9,5 \mathrm{~A}$ \\
\hline TR-1 & $37,0 \mathrm{~A}$ & $31,2 \mathrm{AB}$ & $18,3 \mathrm{D}$ & $24,7 \mathrm{C}$ & $23,1 \mathrm{C}$ & $26,0 \mathrm{BC}$ \\
\hline LA-4 & $17,0 \mathrm{C}$ & $21,9 \mathrm{~B}$ & $15,6 \mathrm{C}$ & $23,2 \mathrm{~B}$ & $30,7 \mathrm{~A}$ & $17,0 \mathrm{C}$ \\
\hline PV-2 & $66,2 \mathrm{C}$ & 87,9 B & $53,3 \mathrm{D}$ & $62,9 \mathrm{C}$ & $205,0 \mathrm{~A}$ & $91,5 \mathrm{~B}$ \\
\hline LA-5 & $106,6 \mathrm{C}$ & $137,5 \mathrm{~B}$ & $88,2 \mathrm{D}$ & $95,9 \mathrm{CD}$ & $157,3 \mathrm{~A}$ & $172,7 \mathrm{~A}$ \\
\hline PV-3 & $1,9 \mathrm{D}$ & $4,9 \mathrm{~A}$ & $1,1 \mathrm{E}$ & $3,6 \mathrm{~B}$ & $3,0 \mathrm{BC}$ & $2,5 \mathrm{CD}$ \\
\hline LRa & $25,0 \mathrm{BC}$ & $26,6 \mathrm{AB}$ & $21,7 \mathrm{C}$ & $24,0 \mathrm{BC}$ & $27,6 \mathrm{AB}$ & $31,3 \mathrm{~A}$ \\
\hline LE-3 & $49,6 \mathrm{~B}$ & $53,3 \mathrm{~B}$ & $36,8 \mathrm{C}$ & $38,9 \mathrm{C}$ & $51,6 \mathrm{~B}$ & $82,1 \mathrm{~A}$ \\
\hline PE & $82,5 \mathrm{~B}$ & $80,4 \mathrm{~B}$ & $64,6 \mathrm{C}$ & $65,9 \mathrm{C}$ & $85,6 \mathrm{~B}$ & $125,4 \mathrm{~A}$ \\
\hline PV-4 & $3,0 \mathrm{C}$ & $6,8 \mathrm{~B}$ & $3,8 \mathrm{C}$ & $8,7 \mathrm{AB}$ & $7,5 \mathrm{~B}$ & $10,6 \mathrm{~A}$ \\
\hline TR-2 & $119,2 \mathrm{BC}$ & $125,1 \mathrm{~B}$ & $111,1 \mathrm{C}$ & $118,3 \mathrm{BC}$ & $160,9 \mathrm{~A}$ & $168,7 \mathrm{~A}$ \\
\hline $\mathrm{AQa}$ & $3,3 \mathrm{C}$ & $7,5 \mathrm{~A}$ & $1,8 \mathrm{D}$ & $6,5 \mathrm{~A}$ & $4,9 \mathrm{~B}$ & $1,9 \mathrm{D}$ \\
\hline LV-1 & $2,7 \mathrm{C}$ & $7,2 \mathrm{AB}$ & $3,1 \mathrm{C}$ & $7,1 \mathrm{AB}$ & $6,3 \mathrm{~B}$ & $8,9 \mathrm{~A}$ \\
\hline \multirow{3}{*}{$\begin{array}{l}\text { Solos } \\
\text { alcalinos }\end{array}$} & \multicolumn{4}{|c|}{ Composto de resíduo urbano } & \multirow{3}{*}{$\begin{array}{c}\text { Gessagem } \\
\mathrm{e} \\
\text { adubação }\end{array}$} & \multirow{3}{*}{ Testemunha } \\
\hline & \multicolumn{2}{|c|}{ sem gessagem } & \multicolumn{2}{|c|}{ com gessagem } & & \\
\hline & sem adubação & com adubação & sem adubação & com adubação & & \\
\hline & --n-- & - & $\mathrm{mg}$ & $\mathrm{Im}^{-3}-\cdots$ & 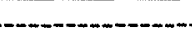 & 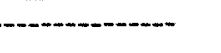 \\
\hline $\mathrm{CL}$ & $42,8 \mathrm{C}$ & $49,2 \mathrm{BC}$ & $44,0 \mathrm{C}$ & $49,8 \mathrm{BC}$ & $68,1 \mathrm{~A}$ & $59,7 \mathrm{AB}$ \\
\hline $\mathrm{CV}$ & $16,2 \mathrm{C}$ & $24,7 \mathrm{~A}$ & $22,5 \mathrm{AB}$ & $17,6 \mathrm{BC}$ & $24,3 \mathrm{~A}$ & $19,5 \mathrm{ABC}$ \\
\hline LA-6 & $42,7 \mathrm{~B}$ & $46,1 \mathrm{~B}$ & $33,9 \mathrm{C}$ & $40,9 \mathrm{BC}$ & $57,3 \mathrm{~A}$ & $46,5 \mathrm{~B}$ \\
\hline LV-2 & $30,3 \mathrm{AB}$ & $31,8 \mathrm{AB}$ & $26,7 \mathrm{~B}$ & $30,2 \mathrm{AB}$ & $35,2 \mathrm{~A}$ & $35,1 \mathrm{~A}$ \\
\hline SS & $15,2 \mathrm{~A}$ & $16,6 \mathrm{~A}$ & $16,0 \mathrm{~A}$ & $15,9 \mathrm{~A}$ & $15,8 \mathrm{~A}$ & $14,3 \mathrm{~A}$ \\
\hline
\end{tabular}

¥-Médias seguidas de mesma letra, nas colunas, não diferem entre si pelo teste de Tukey ao nível de $5 \%$. 
Tabela 38. Disponibilidade de Molibdênio em solos adubados com composto de resíduo urbano.

\begin{tabular}{|c|c|c|c|c|c|c|}
\hline \multirow{3}{*}{$\begin{array}{l}\text { Solos } \\
\text { ácidos }\end{array}$} & \multicolumn{4}{|c|}{ Composto de resíduo urbano } & \multirow{3}{*}{$\begin{array}{c}\text { Calagem } \\
\mathrm{e} \\
\text { adubação }\end{array}$} & \multirow{3}{*}{ Testemunha } \\
\hline & \multicolumn{2}{|c|}{ sem calagem } & \multicolumn{2}{|c|}{ com calagem } & & \\
\hline & sem adubação & com adubação & sem adubação & com adubaçāo & & \\
\hline & \multicolumn{6}{|c|}{$-\mathrm{mg} \mathrm{dm}^{-3}$} \\
\hline GPH & $0,66 \mathrm{~B}^{\ddagger}$ & $0,71 \mathrm{~B}$ & $0,61 \mathrm{~B}$ & $0,71 \mathrm{~B}$ & $0,92 \mathrm{~A}$ & $0,90 \mathrm{~A}$ \\
\hline AQd & $0,24 \mathrm{AB}$ & $0,29 \mathrm{~A}$ & $0,23 \mathrm{AB}$ & $0,29 \mathrm{~A}$ & $0,21 \mathrm{~B}$ & $0,12 \mathrm{C}$ \\
\hline LUa & $0,51 \mathrm{BC}$ & $0,55 \mathrm{~B}$ & $0,35 \mathrm{D}$ & $0,45 \mathrm{C}$ & $0,50 \mathrm{BC}$ & $0,85 \mathrm{~A}$ \\
\hline LE-1 & $0,36 \mathrm{C}$ & $0,39 \mathrm{C}$ & $0,42 \mathrm{BC}$ & $0,53 \mathrm{AB}$ & $0,59 \mathrm{~A}$ & $0,52 \mathrm{AB}$ \\
\hline LE-2 & $0,59 \mathrm{BC}$ & $0,79 \mathrm{~A}$ & $0,52 \mathrm{C}$ & $0,37 \mathrm{D}$ & $0,40 \mathrm{D}$ & $0,71 \mathrm{AB}$ \\
\hline LA-1 & $0,80 \mathrm{BC}$ & $0,82 \mathrm{~B}$ & $0,62 \mathrm{D}$ & $0,66 \mathrm{D}$ & $0,68 \mathrm{CD}$ & $1,25 \mathrm{~A}$ \\
\hline PV-1 & $0,40 \mathrm{BC}$ & $0,49 \mathrm{AB}$ & $0,32 \mathrm{C}$ & $0,44 \mathrm{AB}$ & $0,53 \mathrm{~A}$ & $0,54 \mathrm{~A}$ \\
\hline LA-2 & $0,86 \mathrm{AB}$ & $0,79 \mathrm{BC}$ & $0,59 \mathrm{D}$ & $0,64 \mathrm{D}$ & $0,68 \mathrm{CD}$ & $0,97 \mathrm{~A}$ \\
\hline LA-3 & $0,38 \mathrm{D}$ & $0,48 \mathrm{BC}$ & $0,39 \mathrm{CD}$ & $0,46 \mathrm{CD}$ & $0,57 \mathrm{AB}$ & $0,61 \mathrm{~A}$ \\
\hline TR-1 & $0,19 \mathrm{C}$ & $0,52 \mathrm{~A}$ & $0,40 \mathrm{~B}$ & $0,36 \mathrm{~B}$ & $0,32 \mathrm{~B}$ & $0,31 \mathrm{~B}$ \\
\hline LA-4 & $0,38 \mathrm{~B}$ & $0,50 \mathrm{~A}$ & $0,25 \mathrm{C}$ & $0,36 \mathrm{~B}$ & $0,37 \mathrm{~B}$ & $0,36 \mathrm{~B}$ \\
\hline PV-2 & $0,43 \mathrm{BC}$ & $0,67 \mathrm{~A}$ & $0,37 \mathrm{C}$ & $0,49 \mathrm{~B}$ & $0,67 \mathrm{~A}$ & $0,63 \mathrm{~A}$ \\
\hline LA-5 & $0,86 \mathrm{AB}$ & $0,92 \mathrm{~A}$ & $0,81 \mathrm{ABC}$ & $0,79 \mathrm{ABC}$ & $0,78 \mathrm{BC}$ & $0,73 \mathrm{C}$ \\
\hline PV-3 & $0,76 \mathrm{~A}$ & $0,72 \mathrm{AB}$ & $0,60 \mathrm{BC}$ & $0,60 \mathrm{C}$ & $0,64 \mathrm{ABC}$ & $0,65 \mathrm{ABC}$ \\
\hline $\mathrm{LRa}$ & $0,19 \mathrm{AB}$ & $0,20 \mathrm{AB}$ & $0,17 \mathrm{~B}$ & $0,22 \mathrm{AB}$ & $0,24 \mathrm{AB}$ & $0,25 \mathrm{~A}$ \\
\hline LE-3 & $0,35 \mathrm{BC}$ & $0,38 \mathrm{BC}$ & $0,27 \mathrm{D}$ & $0,33 \mathrm{CD}$ & $0,43 \mathrm{~B}$ & $0,62 \mathrm{~A}$ \\
\hline $\mathrm{PE}$ & $0,48 \mathrm{~A}$ & $0,51 \mathrm{~A}$ & 0,31 B & $0,44 \mathrm{~A}$ & 0,49 A & $0,54 \mathrm{~A}$ \\
\hline PV-4 & $0,34 \mathrm{BC}$ & 0,42 B & $0,29 \mathrm{C}$ & $0,38 \mathrm{BC}$ & $0,42 \mathrm{~A}$ & $0,60 \mathrm{~A}$ \\
\hline TR-2 & $0,84 \mathrm{~A}$ & $0,87 \mathrm{~A}$ & $0,85 \mathrm{~A}$ & $0,74 \mathrm{~A}$ & $0,84 \mathrm{~A}$ & $0,81 \mathrm{~A}$ \\
\hline $\mathrm{AQa}$ & $0,73 \mathrm{~B}$ & $0,78 \mathrm{~B}$ & $0,66 \mathrm{~B}$ & $0,68 \mathrm{~B}$ & $0,73 \mathrm{~B}$ & $1,20 \mathrm{~A}$ \\
\hline LV-1 & $0,64 \mathrm{~B}$ & $0,62 \mathrm{~B}$ & $0,45 \mathrm{D}$ & $0,49 \mathrm{CD}$ & $0,59 \mathrm{BC}$ & $1,45 \mathrm{~A}$ \\
\hline \multirow{3}{*}{$\begin{array}{c}\text { Solos } \\
\text { alcalinos }\end{array}$} & \multicolumn{4}{|c|}{ Composto de resíduo urbano } & \multirow{3}{*}{$\begin{array}{c}\text { Gessagem } \\
\mathrm{e} \\
\text { adubação }\end{array}$} & \multirow{3}{*}{ Testemunha } \\
\hline & \multicolumn{2}{|c|}{ sem gessagem } & \multicolumn{2}{|c|}{ com gessagem } & & \\
\hline & sem adubação & com adubaçāo & sem adubaçāo & com adubação & & \\
\hline & - n & (n)-1 & $\mathrm{mg}$ & $\mathrm{m}^{-3}$ & (-n-n & -1-n--- \\
\hline $\mathrm{CL}$ & $0,19 \mathrm{~B}$ & $0,26 \mathrm{AB}$ & $0,30 \mathrm{AB}$ & $0,28 \mathrm{AB}$ & $0,34 \mathrm{~A}$ & $0,29 \mathrm{AB}$ \\
\hline $\mathrm{CV}$ & $0,21 \mathrm{~B}$ & $0,16 \mathrm{~B}$ & $0,19 \mathrm{~B}$ & $0,37 \mathrm{~A}$ & $0,13 \mathrm{~B}$ & $0,05 \mathrm{C}$ \\
\hline LA-6 & $0,23 \mathrm{~A}$ & $0,28 \mathrm{~A}$ & $0,31 \mathrm{~A}$ & $0,24 \mathrm{~A}$ & $0,21 \mathrm{~A}$ & $0,23 \mathrm{~A}$ \\
\hline LV -2 & $0,25 \mathrm{~A}$ & $0,22 \mathrm{~A}$ & $0,26 \mathrm{~A}$ & $0,26 \mathrm{~A}$ & $0,21 \mathrm{~A}$ & $0,16 \mathrm{~A}$ \\
\hline SS & $0,42 \mathrm{~A}$ & $0,49 \mathrm{~A}$ & $0,42 \mathrm{~A}$ & $0,42 \mathrm{~A}$ & $0,35 \mathrm{AB}$ & $0,25 \mathrm{~B}$ \\
\hline
\end{tabular}

$\ddagger$ - Médias seguidas de mesma letra, nas colunas, não diferem entre si pelo teste de Tukey ao nível de $5 \%$. 
Tabela 39. Disponibilidade de níquel em solos adubados com composto de resíduo urbano.

\begin{tabular}{|c|c|c|c|c|c|c|}
\hline \multirow{3}{*}{$\begin{array}{l}\text { Solos } \\
\text { ácidos }\end{array}$} & \multicolumn{4}{|c|}{ Composto de resíduo urbano } & \multirow{3}{*}{$\begin{array}{c}\text { Calagem } \\
\mathrm{e} \\
\text { adubação }\end{array}$} & \multirow{3}{*}{ Testemunha } \\
\hline & \multicolumn{2}{|c|}{ sem calagem } & \multicolumn{2}{|c|}{ com calagem } & & \\
\hline & sem adubação & com adubação & sem adubação & com adubação & & \\
\hline & \multicolumn{6}{|c|}{ - $\mathrm{mg} \mathrm{dm}^{-3}$} \\
\hline GPH & $1,26 \mathrm{C}^{\ddagger}$ & $1,45 \mathrm{~B}$ & $1,16 \mathrm{D}$ & $1,37 \mathrm{~B}$ & $1,57 \mathrm{~A}$ & $1,57 \mathrm{~A}$ \\
\hline AQd & $0,36 \mathrm{~B}$ & $0,48 \mathrm{~A}$ & $0,26 \mathrm{C}$ & $0,35 \mathrm{~B}$ & $0,15 \mathrm{D}$ & $0,07 \mathrm{E}$ \\
\hline LUa & $0,41 \mathrm{~A}$ & $0,52 \mathrm{~A}$ & $0,38 \mathrm{~A}$ & $0,51 \mathrm{~A}$ & $0,42 \mathrm{~A}$ & $0,37 \mathrm{~A}$ \\
\hline LE-1 & $1,20 \mathrm{C}$ & $1,36 \mathrm{~B}$ & $1,16 \mathrm{C}$ & $1,39 \mathrm{~B}$ & $1,67 \mathrm{~A}$ & $1,60 \mathrm{~A}$ \\
\hline LE-2 & $0,36 \mathrm{~B}$ & $0,51 \mathrm{~A}$ & $0,37 \mathrm{~B}$ & $0,33 \mathrm{~B}$ & $0,32 \mathrm{~B}$ & $0,21 \mathrm{C}$ \\
\hline LA-1 & $0,30 \mathrm{~B}$ & $0,46 \mathrm{~A}$ & $0,28 \mathrm{BC}$ & $0,40 \mathrm{~A}$ & $0,24 \mathrm{C}$ & $0,11 \mathrm{D}$ \\
\hline PV-1 & $0,27 \mathrm{~B}$ & $0,42 \mathrm{~A}$ & $0,27 \mathrm{~B}$ & $0,43 \mathrm{~A}$ & $0,33 \mathrm{~B}$ & $0,20 \mathrm{C}$ \\
\hline LA-2 & $0,38 \mathrm{AB}$ & $0,43 \mathrm{~A}$ & $0,23 \mathrm{C}$ & $0,34 \mathrm{~B}$ & $0,19 \mathrm{C}$ & $0,10 \mathrm{D}$ \\
\hline LA-3 & $0,29 \mathrm{~B}$ & $0,37 \mathrm{~A}$ & $0,22 \mathrm{BC}$ & $0,36 \mathrm{~A}$ & $0,20 \mathrm{C}$ & $0,12 \mathrm{D}$ \\
\hline TR-1 & $1,01 \mathrm{C}$ & $1,17 \mathrm{~B}$ & $1,03 \mathrm{C}$ & $0,97 \mathrm{C}$ & $1,14 \mathrm{~B}$ & $1,29 \mathrm{~A}$ \\
\hline LA-4 & $0,66 \mathrm{~B}$ & $0,83 \mathrm{~A}$ & $0,42 \mathrm{D}$ & $0,60 \mathrm{BC}$ & $0,53 \mathrm{C}$ & $0,41 \mathrm{D}$ \\
\hline PV-2 & $0,56 \mathrm{C}$ & $0,74 \mathrm{~A}$ & $0,47 \mathrm{D}$ & $0,65 \mathrm{~B}$ & $0,55 \mathrm{C}$ & $0,52 \mathrm{CD}$ \\
\hline LA-5 & $1,05 \mathrm{~B}$ & $1,17 \mathrm{~A}$ & $0,95 \mathrm{C}$ & $1,05 \mathrm{~B}$ & $0,96 \mathrm{C}$ & $0,88 \mathrm{C}$ \\
\hline PV -3 & $0,33 \mathrm{C}$ & $0,46 \mathrm{~B}$ & $0,64 \mathrm{~A}$ & $0,34 \mathrm{C}$ & $0,21 \mathrm{D}$ & $0,12 \mathrm{E}$ \\
\hline $\mathrm{LRa}$ & $0,36 \mathrm{AB}$ & $0,41 \mathrm{~A}$ & $0,32 \mathrm{~B}$ & $0,37 \mathrm{AB}$ & $0,36 \mathrm{AB}$ & $0,39 \mathrm{AB}$ \\
\hline LE-3 & $0,53 \mathrm{AB}$ & $0,57 \mathrm{~A}$ & $0,49 \mathrm{~B}$ & $0,52 \mathrm{AB}$ & $0,41 \mathrm{C}$ & $0,41 \mathrm{C}$ \\
\hline PE & $0,54 \mathrm{AB}$ & $0,60 \mathrm{~A}$ & $0,46 \mathrm{C}$ & $0,54 \mathrm{AB}$ & $0,54 \mathrm{AB}$ & $0,52 \mathrm{BC}$ \\
\hline PV-4 & $0,16 \mathrm{~B}$ & $0,30 \mathrm{~A}$ & $0,13 \mathrm{~B}$ & $0,29 \mathrm{~A}$ & $0,16 \mathrm{~B}$ & $0,05 \mathrm{C}$ \\
\hline TR-2 & $1,40 \mathrm{BC}$ & $1,50 \mathrm{~A}$ & $1,42 \mathrm{ABC}$ & $1,33 \mathrm{C}$ & $1,48 \mathrm{AB}$ & $1,43 \mathrm{AB}$ \\
\hline $\mathrm{AQa}$ & $0,25 \mathrm{BC}$ & $0,30 \mathrm{AB}$ & $0,19 \mathrm{C}$ & $0,33 \mathrm{~A}$ & $0,11 \mathrm{D}$ & $0,07 \mathrm{D}$ \\
\hline LV-1 & $0,34 \mathrm{~B}$ & $0,48 \mathrm{~A}$ & $0,31 \mathrm{~B}$ & $0,43 \mathrm{~A}$ & $0,20 \mathrm{C}$ & $0,15 \mathrm{C}$ \\
\hline \multirow{3}{*}{$\begin{array}{l}\text { Solos } \\
\text { alcalinos }\end{array}$} & \multicolumn{4}{|c|}{ Composto de resíduo urbano } & \multirow{3}{*}{$\begin{array}{c}\text { Gessagem } \\
\text { e } \\
\text { adubação }\end{array}$} & \multirow{3}{*}{ Testemunha } \\
\hline & \multicolumn{2}{|c|}{ sem gessagem } & \multicolumn{2}{|c|}{ com gessagem } & & \\
\hline & sem adubaçāo & com adubação & sem adubação & com adubação & & \\
\hline & - & - & mg c & $m^{-3} \ldots$ & - & -nen-n \\
\hline $\mathrm{CL}$ & $0,89 \mathrm{~A}$ & $0,96 \mathrm{~A}$ & $0,93 \mathrm{~A}$ & $0,99 \mathrm{~A}$ & $1,00 \mathrm{~A}$ & $0,90 \mathrm{~A}$ \\
\hline $\mathrm{CV}$ & $1,18 \mathrm{~B}$ & $1,27 \mathrm{AB}$ & $1,22 \mathrm{~B}$ & $1,38 \mathrm{~A}$ & $1,19 \mathrm{~B}$ & $1,02 \mathrm{C}$ \\
\hline LA- 6 & $0,98 \mathrm{~A}$ & $1,05 \mathrm{~A}$ & $1,06 \mathrm{~A}$ & $1,07 \mathrm{~A}$ & $1,06 \mathrm{~A}$ & $0,94 \mathrm{~A}$ \\
\hline$L V-2$ & $0,95 \mathrm{AB}$ & $1,03 \mathrm{~A}$ & $0,94 \mathrm{AB}$ & $1,06 \mathrm{~A}$ & $0,98 \mathrm{AB}$ & $0,88 \mathrm{~B}$ \\
\hline SS & $1,14 \mathrm{AB}$ & $1,25 \mathrm{~A}$ & $1,14 \mathrm{AB}$ & $1,17 \mathrm{AB}$ & $1,04 \mathrm{BC}$ & $0,95 \mathrm{C}$ \\
\hline
\end{tabular}

‡-Médias seguidas de mesma letra, nas colunas, não diferem entre si pelo teste de Tukey ao nível de $5 \%$. 
A disponibilidade de Mn disponibilidade de Mn devido à aplicação do composto foi influenciada pelo teor inicial de $\mathrm{Mn}$ na amostra de solo e foi extremamente variável entre os solos ácidos (Tabela 37). De um modo geral, em solos no qual a testemunha continha teores médios a altos a aplicação do composto, principalmente em combinação com a com calagem, diminuiu os teores desse elemento, como nos solos GPH, LE-1, LA-3, TR-1, PV-2, LA-5, LRa, LE-3, PE, PV-4, TR-2 e LV-1. Por outro lado, solos com teores muito baixo de $\mathrm{Mn}$, tiveram um aumento da disponibilidade devido ao composto. Dos modos de aplicação do composto, o tratamento com composto + adubo promoveu os maiores teores de Mn e o composto + calcário os menores. Nos solos alcalino, o Mn tendeu a ser menor no tratamento composto + gesso e maior no composto + adubo. A aplicação de calcário + adubo ou gesso + adubo, independentemente do solo, promoveu o aumento nos teores de Mn do solo.

Cravo (1995), utilizando composto de resíduo urbano da cidade de São Paulo, relatou resultados semelhantes quanto à disponibilidade de $\mathrm{Cu}, \mathrm{Fe}, \mathrm{Mn}$ e $\mathrm{Zn}$, e diferentes quanto ao Mo, Co e Ni nos solos ácidos.

\subsubsection{Disponibilidade de meta is}

Os teores de Ba disponível, assim como ocorreu com o Co, apresentaram comportamento diversos para cada solo ácido (Tabela 41). Verificou-se altos teores de Ba na testemunha dos solos GPH, AQd, LE-1, TR-1, PV-2, LA-5, PE e TR-2. A aplicação do composto com adução, com ou sem calagem, nestes solos, promoveu uma redução significativa nos teores de $\mathrm{Ba}$. Nos demais solos ácidos, cujos os teores de $\mathrm{Ba}$ eram baixos $\left(<0,10 \mathrm{mg} \mathrm{dm}^{-3}\right)$ ou não foram detectados, a aplicação do composto aumentou significativamente os teores desse elemento. Os teores totais de Ba não tiveram muita influencia sobre os teores disponíveis.

Os teores disponíveis de $\mathrm{Cd}, \mathrm{Cr}, \mathrm{Pb}$ e $\mathrm{Sr}$ foram aumentados significativamente devido à aplicação do composto (Tabelas 42, 43, 44 e 45). Nos solos ácidos, a aplicação de composto + calcário + adubo promoveu os maiores teores destes metais. 
Tabela 40. Disponibilidade de zinco em solos adubados com composto de resíduo urbano.

\begin{tabular}{|c|c|c|c|c|c|c|}
\hline \multirow{3}{*}{$\begin{array}{l}\text { Solos } \\
\text { ácidos }\end{array}$} & \multicolumn{4}{|c|}{ Composto de resíduo urbano } & \multirow{3}{*}{$\begin{array}{c}\text { Calagem } \\
\mathrm{e} \\
\text { adubação }\end{array}$} & \multirow{3}{*}{ Testemunha } \\
\hline & \multicolumn{2}{|c|}{ sem calagem } & \multicolumn{2}{|c|}{ com calagem } & & \\
\hline & sem adubaçāo & com adubação & sem adubação & com adubação & & \\
\hline & - & 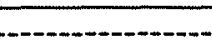 & $\mathrm{mg}$ & $\mathrm{m}^{-3}-\ldots$ & - & (n) \\
\hline GPH & $5,15 \mathrm{~A}^{\ddagger}$ & $7,41 \mathrm{~A}$ & $5,04 \mathrm{~A}$ & $6,86 \mathrm{~A}$ & $3,97 \mathrm{~A}$ & $2,36 \mathrm{C}$ \\
\hline AQd & $6,46 \mathrm{~B}$ & $8,27 \mathrm{~A}$ & 5,97 B & $8,35 \mathrm{~A}$ & $5,43 \mathrm{~B}$ & $2,36 \mathrm{C}$ \\
\hline LUa & $4,00 \mathrm{~B}$ & $6,96 \mathrm{~A}$ & $4,08 \mathrm{~B}$ & $6,42 \mathrm{~A}$ & $3,09 \mathrm{~B}$ & $0,58 \mathrm{C}$ \\
\hline LE-1 & $6,24 \mathrm{~B}$ & $8,23 \mathrm{~A}$ & 5,95 B & $9,19 \mathrm{~A}$ & $5,18 \mathrm{~B}$ & $2,52 \mathrm{C}$ \\
\hline LE-2 & $3,72 \mathrm{~B}$ & $6,49 \mathrm{~A}$ & $4,07 \mathrm{~B}$ & $5,87 \mathrm{~A}$ & $2,21 \mathrm{C}$ & $0,29 \mathrm{D}$ \\
\hline LA-1 & $5,19 \mathrm{~B}$ & $9,01 \mathrm{~A}$ & $4,58 \mathrm{BC}$ & $8,34 \mathrm{~A}$ & $3,95 \mathrm{C}$ & $1,14 \mathrm{D}$ \\
\hline PV-1 & $3,88 \mathrm{~B}$ & $7,94 \mathrm{~A}$ & $3,57 \mathrm{~B}$ & $7,22 \mathrm{~A}$ & $4,18 \mathrm{~B}$ & $0,73 \mathrm{C}$ \\
\hline LA-2 & $5,65 \mathrm{~B}$ & $7,63 \mathrm{~A}$ & $4,83 \mathrm{~B}$ & $7,26 \mathrm{~A}$ & $3,52 \mathrm{C}$ & $0,97 \mathrm{D}$ \\
\hline LA-3 & $5,02 \mathrm{~B}$ & $7,25 \mathrm{~A}$ & $4,76 \mathrm{~B}$ & $7,63 \mathrm{~A}$ & $3,38 \mathrm{C}$ & $1,09 \mathrm{D}$ \\
\hline TR-1 & $2,53 \mathrm{~B}$ & $3,61 \mathrm{~A}$ & $1,88 \mathrm{~B}$ & $3,69 \mathrm{~A}$ & $1,87 \mathrm{~B}$ & $0,21 \mathrm{C}$ \\
\hline LA-4 & $5,39 \mathrm{~B}$ & $8,70 \mathrm{~A}$ & $4,93 \mathrm{~B}$ & $8,76 \mathrm{~A}$ & $4,48 \mathrm{~B}$ & $1,01 \mathrm{C}$ \\
\hline PV-2 & $5,41 \mathrm{~B}$ & $9,07 \mathrm{~A}$ & $5,23 \mathrm{~B}$ & $8,12 \mathrm{~A}$ & $4,48 \mathrm{~B}$ & $1,52 \mathrm{C}$ \\
\hline LA-5 & $6,61 \mathrm{~B}$ & $9,75 \mathrm{~A}$ & $6,68 \mathrm{~B}$ & $7,67 \mathrm{~B}$ & $4,88 \mathrm{C}$ & $2,78 \mathrm{D}$ \\
\hline PV-3 & $3,07 \mathrm{~B}$ & $5,56 \mathrm{~A}$ & $3,29 \mathrm{~B}$ & $5,05 \mathrm{~A}$ & $1,79 \mathrm{C}$ & $0,46 \mathrm{D}$ \\
\hline LRa & $3,46 \mathrm{~B}$ & $5,58 \mathrm{~A}$ & $3,41 \mathrm{~B}$ & $5,68 \mathrm{~A}$ & $2,09 \mathrm{C}$ & $0,54 \mathrm{D}$ \\
\hline LE-3 & $4,99 \mathrm{~B}$ & $7,36 \mathrm{~A}$ & $4,85 \mathrm{~B}$ & $7,13 \mathrm{~A}$ & $3,61 \mathrm{C}$ & $1,67 \mathrm{D}$ \\
\hline $\mathrm{PE}$ & $5,35 \mathrm{~B}$ & $7,99 \mathrm{~A}$ & $4,77 \mathrm{~B}$ & $7,71 \mathrm{~A}$ & $4,57 \mathrm{~B}$ & $2,33 \mathrm{C}$ \\
\hline PV-4 & $4,03 \mathrm{~B}$ & $6,83 \mathrm{~A}$ & $3,81 \mathrm{~B}$ & $6,98 \mathrm{~A}$ & $3,78 \mathrm{~B}$ & $1,16 \mathrm{C}$ \\
\hline TR-2 & $8,90 \mathrm{BC}$ & $11,36 \mathrm{~A}$ & 9,02 в & $10,64 \mathrm{AB}$ & $7,29 \mathrm{C}$ & $4,98 \mathrm{D}$ \\
\hline $\mathrm{AQa}$ & $4,51 \mathrm{~B}$ & $7,70 \mathrm{~A}$ & $4,16 \mathrm{~B}$ & $8,63 \mathrm{~A}$ & $3,73 \mathrm{~B}$ & $1,37 \mathrm{C}$ \\
\hline LV-1 & $5,11 \mathrm{~B}$ & $8,63 \mathrm{~A}$ & $4,96 \mathrm{~B}$ & $7,92 \mathrm{~A}$ & $3,50 \mathrm{C}$ & $2,12 \mathrm{D}$ \\
\hline
\end{tabular}

\begin{tabular}{|c|c|c|c|c|c|c|}
\hline \multirow{3}{*}{$\begin{array}{l}\text { Solos } \\
\text { alcalinos }\end{array}$} & \multicolumn{4}{|c|}{ Composto de resíduo urbano } & \multirow{3}{*}{$\begin{array}{c}\text { Gessagem } \\
e^{-} \\
\text {adubação }\end{array}$} & \multirow{3}{*}{ Testemunha } \\
\hline & \multicolumn{2}{|c|}{ sem gessagem } & \multicolumn{2}{|c|}{ com gessagem } & & \\
\hline & sem adubação & com adubação & sem adubação & com adubação & & \\
\hline & - - & 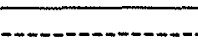 & mg & $\mathrm{Im}^{-3} \ldots$ & 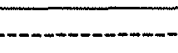 & -1.n- \\
\hline $\mathrm{CL}$ & $5,01 \mathrm{~A}$ & $6,78 \mathrm{~A}$ & $5,51 \mathrm{~A}$ & $6,95 \mathrm{~A}$ & $3,14 \mathrm{~B}$ & $1,54 \mathrm{C}$ \\
\hline $\mathrm{CV}$ & $4,24 \mathrm{~B}$ & $5,95 \mathrm{AB}$ & $4,30 \mathrm{~B}$ & $6,57 \mathrm{~A}$ & $2,69 \mathrm{C}$ & $0,85 \mathrm{D}$ \\
\hline LA- 6 & $5,25 \mathrm{BC}$ & $7,92 \mathrm{~A}$ & $5,04 \mathrm{BC}$ & $6,77 \mathrm{AB}$ & $3,70 \mathrm{C}$ & $1,26 \mathrm{D}$ \\
\hline LV-2 & $4,86 \mathrm{AB}$ & $6,69 \mathrm{~A}$ & $4,56 \mathrm{~B}$ & $6,90 \mathrm{~A}$ & $3,12 \mathrm{C}$ & $1,25 \mathrm{D}$ \\
\hline SS & $4,89 \mathrm{BC}$ & $7,32 \mathrm{~A}$ & $5,11 \mathrm{ABC}$ & 7,06 AB & $4,38 \mathrm{C}$ & $1,32 \mathrm{D}$ \\
\hline
\end{tabular}


Tabela 41. Disponibilidade de bário em solos adubados com composto de resíduo urbano.

\begin{tabular}{|c|c|c|c|c|c|c|}
\hline \multirow{3}{*}{$\begin{array}{l}\text { Solos } \\
\text { ácidos }\end{array}$} & \multicolumn{4}{|c|}{ Composto de resíduo urbano } & \multirow{3}{*}{$\begin{array}{c}\text { Calagem } \\
\text { e } \\
\text { adubação }\end{array}$} & \multirow{3}{*}{ Testemunha } \\
\hline & \multicolumn{2}{|c|}{ sem calagem } & \multicolumn{2}{|c|}{ com calagem } & & \\
\hline & sem adubação & com adubação & sem adubação & com adubação & & \\
\hline & - & 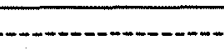 & $\mathrm{mg}$ & $m^{-3}$ & 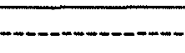 & -.........- \\
\hline GPH & $0,74 \mathrm{~B}^{\ddagger}$ & $0,30 \mathrm{D}$ & $0,78 \mathrm{~B}$ & $0,33 \mathrm{CD}$ & $0,41 \mathrm{C}$ & $1,59 \mathrm{~A}$ \\
\hline AQd & $0,41 \mathrm{~B}$ & $0,08 \mathrm{C}$ & 0,42 B & $0,11 \mathrm{C}$ & $0,07 \mathrm{C}$ & $0,70 \mathrm{~A}$ \\
\hline LUa & $0,03 \mathrm{~B}$ & $0,19 \mathrm{~A}$ & $0,01 \mathrm{~B}$ & $0,20 \mathrm{~A}$ & $0,23 \mathrm{~A}$ & $0,00 \mathrm{~B}$ \\
\hline LE-1 & $0,79 \mathrm{~B}$ & $0,45 \mathrm{C}$ & $0,88 \mathrm{~B}$ & $0,47 \mathrm{C}$ & $0,52 \mathrm{C}$ & $1,51 \mathrm{~A}$ \\
\hline LE-2 & $0,02 \mathrm{~B}$ & $0,25 \mathrm{~A}$ & 0,02 B & $0,27 \mathrm{~A}$ & $0,26 \mathrm{~A}$ & $0,01 \mathrm{~B}$ \\
\hline LA-1 & $0,04 \mathrm{~B}$ & $0,12 \mathrm{~A}$ & $0,00 \mathrm{~B}$ & $0,11 \mathrm{~A}$ & $0,12 \mathrm{~A}$ & $0,00 \mathrm{~B}$ \\
\hline PV-1 & $0,05 \mathrm{~B}$ & $0,16 \mathrm{~A}$ & $0,05 \mathrm{~B}$ & $0,18 \mathrm{~A}$ & $0,21 \mathrm{~A}$ & $0,09 \mathrm{~B}$ \\
\hline LA-2 & $0,02 \mathrm{~B}$ & $0,14 \mathrm{~A}$ & $0,02 \mathrm{~B}$ & $0,14 \mathrm{~A}$ & $0,17 \mathrm{~A}$ & $0,01 \mathrm{~B}$ \\
\hline LA-3 & $0,00 \mathrm{~B}$ & $0,11 \mathrm{~A}$ & $0,00 \mathrm{~B}$ & $0,09 \mathrm{~A}$ & $0,13 \mathrm{~A}$ & $0,00 \mathrm{~B}$ \\
\hline TR-1 & $1,43 \mathrm{~A}$ & $0,47 \mathrm{D}$ & $1,01 \mathrm{~B}$ & $0,45 \mathrm{D}$ & $0,64 \mathrm{C}$ & $1,80 \mathrm{~A}$ \\
\hline LA-4 & $0,11 \mathrm{C}$ & $0,23 \mathrm{~B}$ & $0,07 \mathrm{C}$ & $0,24 \mathrm{~B}$ & $0,33 \mathrm{~A}$ & $0,17 \mathrm{~B}$ \\
\hline PV-2 & $0,21 \mathrm{~B}$ & $0,21 \mathrm{~B}$ & $0,11 \mathrm{C}$ & $0,21 \mathrm{~B}$ & $0,38 \mathrm{~A}$ & $0,42 \mathrm{~A}$ \\
\hline LA-5 & $1,24 \mathrm{~B}$ & $0,44 \mathrm{D}$ & $1,09 \mathrm{~B}$ & $0,46 \mathrm{CD}$ & $0,57 \mathrm{C}$ & $3,45 \mathrm{~A}$ \\
\hline PV -3 & $0,00 \mathrm{~B}$ & $0,12 \mathrm{~A}$ & $0,00 \mathrm{~B}$ & $0,11 \mathrm{~A}$ & $0,10 \mathrm{~A}$ & $0,00 \mathrm{~B}$ \\
\hline $\mathrm{LRa}$ & $0,00 \mathrm{~B}$ & $0,12 \mathrm{~A}$ & $0,00 \mathrm{~B}$ & $0,09 \mathrm{~A}$ & $0,11 \mathrm{~A}$ & $0,00 \mathrm{~B}$ \\
\hline LE-3 & $0,16 \mathrm{C}$ & $0,29 \mathrm{~A}$ & $0,16 \mathrm{C}$ & $0,25 \mathrm{AB}$ & $0,30 \mathrm{~A}$ & $0,19 \mathrm{BC}$ \\
\hline $\mathrm{PE}$ & $0,82 \mathrm{~A}$ & $0,56 \mathrm{C}$ & $0,75 \mathrm{AB}$ & $0,61 \mathrm{BC}$ & $0,54 \mathrm{C}$ & $0,67 \mathrm{ABC}$ \\
\hline PV -4 & $0,06 \mathrm{~B}$ & $0,25 \mathrm{~A}$ & $0,06 \mathrm{~B}$ & $0,26 \mathrm{~A}$ & $0,29 \mathrm{~A}$ & $0,07 \mathrm{~B}$ \\
\hline TR-2 & $1,12 \mathrm{~B}$ & $0,54 \mathrm{D}$ & $1,04 \mathrm{BC}$ & $0,59 \mathrm{D}$ & $0,85 \mathrm{C}$ & $3,80 \mathrm{~A}$ \\
\hline $\mathrm{AQa}$ & $0,00 \mathrm{~B}$ & $0,20 \mathrm{~A}$ & $0,00 \mathrm{~B}$ & $0,20 \mathrm{~A}$ & $0,18 \mathrm{~A}$ & $0,00 \mathrm{~B}$ \\
\hline LV-1 & $0,11 \mathrm{~B}$ & $0,23 \mathrm{~A}$ & $0,10 \mathrm{~B}$ & $0,24 \mathrm{~A}$ & $0,27 \mathrm{~A}$ & $0,09 \mathrm{~B}$ \\
\hline \multirow{3}{*}{$\begin{array}{l}\text { Solos } \\
\text { alcalinos }\end{array}$} & \multicolumn{4}{|c|}{ Composto de resíduo urbano } & \multirow{3}{*}{$\begin{array}{c}\text { Gessagem } \\
\mathrm{e} \\
\text { adubação }\end{array}$} & \multirow{3}{*}{ Testemunha } \\
\hline & \multicolumn{2}{|c|}{ sem gessagem } & \multicolumn{2}{|c|}{ com gessagem } & & \\
\hline & sem adubação & com adubação & sem adubaçāo & com adubação & & \\
\hline & (n-n & 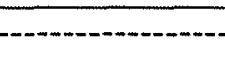 & $\mathrm{mg}$ & $\mathrm{m}^{-3}-\ldots$ & - & (n) \\
\hline $\mathrm{CL}$ & $0,33 \mathrm{~B}$ & $0,48 \mathrm{~A}$ & $0,10 \mathrm{D}$ & $0,15 \mathrm{C}$ & $0,14 \mathrm{C}$ & $0,30 \mathrm{~B}$ \\
\hline $\mathrm{CV}$ & $0,89 \mathrm{~B}$ & $1,04 \mathrm{~A}$ & $0,58 \mathrm{D}$ & $0,68 \mathrm{CD}$ & $0,73 \mathrm{C}$ & $0,74 \mathrm{C}$ \\
\hline LA- 6 & $0,11 \mathrm{D}$ & $0,25 \mathrm{~A}$ & $0,14 \mathrm{C}$ & $0,20 \mathrm{~B}$ & $0,24 \mathrm{~A}$ & $0,15 \mathrm{C}$ \\
\hline LV -2 & $0,34 \mathrm{~B}$ & $0,44 \mathrm{~A}$ & $0,29 \mathrm{~B}$ & $0,29 \mathrm{~B}$ & $0,32 \mathrm{~B}$ & $0,42 \mathrm{~A}$ \\
\hline SS & $0,81 \mathrm{~A}$ & $0,54 \mathrm{~B}$ & $0,22 \mathrm{C}$ & $0,16 \mathrm{D}$ & $0,17 \mathrm{D}$ & $0,83 \mathrm{~A}$ \\
\hline
\end{tabular}

¥-Médias seguidas de mesma letra, nas colunas, não diferem entre si pelo teste de Tukey ao nível de $5 \%$. 
Tabela 42. Disponibilidade de cádmio em solos adubados com composto de resíduo urbano.

\begin{tabular}{|c|c|c|c|c|c|c|}
\hline \multirow{3}{*}{$\begin{array}{l}\text { Solos } \\
\text { ácidos }\end{array}$} & \multicolumn{4}{|c|}{ Composto de resíduo urbano } & \multirow{3}{*}{$\begin{array}{c}\text { Calagem } \\
\mathrm{e} \\
\text { adubação }\end{array}$} & \multirow{3}{*}{ Testemunha } \\
\hline & \multicolumn{2}{|c|}{ sem calagem } & \multicolumn{2}{|c|}{ com calagem } & & \\
\hline & sem adubação & com adubação & sem adubação & com adubação & & \\
\hline & - - & 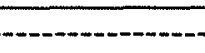 & mg c & $m^{-3}$ & -...-.... & - \\
\hline GPH & $0,22 \mathrm{AB}^{\ddagger}$ & $0,24 \mathrm{~A}$ & $0,22 \mathrm{AB}$ & $0,24 \mathrm{~A}$ & $0,22 \mathrm{AB}$ & $0,21 \mathrm{~B}$ \\
\hline AQd & $0,06 \mathrm{~A}$ & $0,06 \mathrm{~A}$ & $0,05 \mathrm{~A}$ & $0,06 \mathrm{~A}$ & $0,02 \mathrm{~B}$ & $0,03 \mathrm{~B}$ \\
\hline LUa & $0,04 \mathrm{~A}$ & $0,04 \mathrm{~A}$ & $0,04 \mathrm{~A}$ & $0,05 \mathrm{~A}$ & $0,03 \mathrm{~A}$ & $0,03 \mathrm{~A}$ \\
\hline LE-1 & $0,07 \mathrm{~A}$ & $0,08 \mathrm{~A}$ & $0,07 \mathrm{~A}$ & $0,07 \mathrm{~A}$ & $0,07 \mathrm{~A}$ & $0,06 \mathrm{~A}$ \\
\hline LE-2 & $0,03 \mathrm{AB}$ & $0,04 \mathrm{~A}$ & $0,02 \mathrm{AB}$ & $0,03 \mathrm{AB}$ & $0,01 \mathrm{~B}$ & $0,01 \mathrm{~B}$ \\
\hline LA-1 & $0,03 \mathrm{~B}$ & $0,05 \mathrm{~A}$ & $0,05 \mathrm{~A}$ & $0,06 \mathrm{~A}$ & $0,02 \mathrm{~B}$ & $0,03 \mathrm{~B}$ \\
\hline PV -1 & $0,04 \mathrm{~A}$ & $0,04 \mathrm{~A}$ & $0,04 \mathrm{~A}$ & $0,04 \mathrm{~A}$ & 0,02 B & $0,02 \mathrm{~B}$ \\
\hline LA-2 & $0,05 \mathrm{ABC}$ & $0,06 \mathrm{AB}$ & $0,05 \mathrm{ABC}$ & $0,07 \mathrm{~A}$ & $0,04 \mathrm{BC}$ & $0,04 \mathrm{C}$ \\
\hline LA-3 & $0,04 \mathrm{AB}$ & $0,06 \mathrm{~A}$ & $0,04 \mathrm{AB}$ & $0,05 \mathrm{AB}$ & $0,04 \mathrm{AB}$ & $0,03 \mathrm{~B}$ \\
\hline TR-1 & $0,05 \mathrm{~A}$ & $0,05 \mathrm{~A}$ & $0,04 \mathrm{AB}$ & $0,04 \mathrm{AB}$ & $0,04 \mathrm{AB}$ & $0,03 \mathrm{~B}$ \\
\hline LA-4 & $0,07 \mathrm{~A}$ & $0,07 \mathrm{~A}$ & $0,05 \mathrm{AB}$ & $0,05 \mathrm{AB}$ & $0,03 \mathrm{~B}$ & $0,03 \mathrm{~B}$ \\
\hline PV-2 & $0,06 \mathrm{~A}$ & $0,06 \mathrm{~A}$ & $0,06 \mathrm{~A}$ & $0,07 \mathrm{~A}$ & $0,05 \mathrm{AB}$ & $0,03 \mathrm{~B}$ \\
\hline LA-5 & $0,09 \mathrm{~A}$ & $0,10 \mathrm{~A}$ & $0,09 \mathrm{~A}$ & $0,09 \mathrm{~A}$ & $0,09 \mathrm{~A}$ & $0,08 \mathrm{~A}$ \\
\hline PV-3 & $0,03 \mathrm{~B}$ & $0,04 \mathrm{AB}$ & $0,05 \mathrm{~A}$ & $0,04 \mathrm{AB}$ & $0,01 \mathrm{C}$ & $0,01 \mathrm{C}$ \\
\hline LRa & $0,05 \mathrm{~A}$ & $0,05 \mathrm{~A}$ & $0,04 \mathrm{~A}$ & $0,05 \mathrm{~A}$ & $0,04 \mathrm{~A}$ & $0,05 \mathrm{~A}$ \\
\hline LE-3 & $0,06 \mathrm{~A}$ & $0,06 \mathrm{~A}$ & $0,05 \mathrm{~A}$ & $0,06 \mathrm{~A}$ & $0,04 \mathrm{~A}$ & $0,04 \mathrm{~A}$ \\
\hline $\mathrm{PE}$ & $0,09 \mathrm{~A}$ & $0,08 \mathrm{~A}$ & $0,08 \mathrm{~A}$ & $0,09 \mathrm{~A}$ & $0,07 \mathrm{~A}$ & $0,08 \mathrm{~A}$ \\
\hline PV -4 & $0,06 \mathrm{~A}$ & $0,07 \mathrm{~A}$ & $0,07 \mathrm{~A}$ & $0,07 \mathrm{~A}$ & $0,05 \mathrm{~A}$ & $0,05 \mathrm{~A}$ \\
\hline TR-2 & $0,14 \mathrm{AB}$ & $0,15 \mathrm{~A}$ & $0,14 \mathrm{AB}$ & $0,14 \mathrm{AB}$ & $0,13 \mathrm{AB}$ & $0,12 \mathrm{~B}$ \\
\hline $\mathrm{AQa}$ & $0,06 \mathrm{~A}$ & $0,04 \mathrm{~A}$ & $0,04 \mathrm{~A}$ & $0,04 \mathrm{~A}$ & $0,04 \mathrm{~A}$ & $0,04 \mathrm{~A}$ \\
\hline LV-1 & $0,04 \mathrm{~A}$ & $0,05 \mathrm{~A}$ & $0,04 \mathrm{~A}$ & $0,06 \mathrm{~A}$ & $0,04 \mathrm{~A}$ & $0,05 \mathrm{~A}$ \\
\hline
\end{tabular}

\begin{tabular}{|c|c|c|c|c|c|c|}
\hline \multirow{3}{*}{$\begin{array}{c}\text { Solos } \\
\text { alcalinos }\end{array}$} & \multicolumn{4}{|c|}{ Composto de resíduo urbano } & \multirow{3}{*}{$\begin{array}{c}\text { Gessagem } \\
\mathrm{e} \\
\text { adubação }\end{array}$} & \multirow{3}{*}{ Testemunh: } \\
\hline & \multicolumn{2}{|c|}{ sem gessagem } & \multicolumn{2}{|c|}{ com gessagem } & & \\
\hline & sem adubação & com adubação & sem adubação & com adubação & & \\
\hline & & & mg & $m^{-3}$ & & \\
\hline $\mathrm{CL}$ & $0,06 \mathrm{AB}$ & $0,07 \mathrm{~A}$ & $0,07 \mathrm{~A}$ & $0,07 \mathrm{~A}$ & $0,05 \mathrm{~B}$ & $0,05 \mathrm{~B}$ \\
\hline $\mathrm{CV}$ & $0,05 \mathrm{AB}$ & $0,06 \mathrm{~A}$ & $0,07 \mathrm{~A}$ & $0,06 \mathrm{~A}$ & $0,04 \mathrm{~B}$ & $0,03 \mathrm{~B}$ \\
\hline LA- 6 & $0,06 \mathrm{~A}$ & $0,06 \mathrm{~A}$ & $0,05 \mathrm{AB}$ & $0,06 \mathrm{~A}$ & $0,05 \mathrm{AB}$ & $0,04 \mathrm{~B}$ \\
\hline LV-2 & $0,06 \mathrm{AB}$ & $0,06 \mathrm{AB}$ & $0,05 \mathrm{ABC}$ & $0,08 \mathrm{~A}$ & $0,05 \mathrm{ABC}$ & $0,03 \mathrm{~B}$ \\
\hline SS & $0,06 \mathrm{~A}$ & $0,05 \mathrm{AB}$ & $0,06 \mathrm{~A}$ & $0,06 \mathrm{~A}$ & $0,04 \mathrm{~B}$ & $0,04 \mathrm{~B}$ \\
\hline
\end{tabular}


Tabela 43. Disponibilidade de cromo em solos adubados com composto de resíduo urbano.

\begin{tabular}{|c|c|c|c|c|c|c|}
\hline \multirow{3}{*}{$\begin{array}{l}\text { Solos } \\
\text { ácidos }\end{array}$} & \multicolumn{4}{|c|}{ Composto de resíduo urbano } & \multirow{3}{*}{$\begin{array}{c}\text { Calagem } \\
e \\
\text { adubação }\end{array}$} & \multirow{3}{*}{ Testemunha } \\
\hline & \multicolumn{2}{|c|}{ sem calagem } & \multicolumn{2}{|c|}{ com calagem } & & \\
\hline & sem adubação & com adubação & sem adubação & com adubação & & \\
\hline & \multicolumn{6}{|c|}{ mg dm ${ }^{-3}$} \\
\hline GPH & $0,26 \mathrm{~B}^{\ddagger}$ & $0,32 \mathrm{~A}$ & $0,32 \mathrm{~A}$ & $0,36 \mathrm{~A}$ & $0,36 \mathrm{~A}$ & $0,31 \mathrm{AB}$ \\
\hline AQd & $0,21 \mathrm{~A}$ & $0,23 \mathrm{~A}$ & $0,24 \mathrm{~A}$ & $0,24 \mathrm{~A}$ & $0,23 \mathrm{~A}$ & $0,21 \mathrm{~A}$ \\
\hline LUa & $0,06 \mathrm{BC}$ & $0,09 \mathrm{~B}$ & $0,18 \mathrm{~A}$ & $0,22 \mathrm{~A}$ & $0,22 \mathrm{~A}$ & $0,04 \mathrm{C}$ \\
\hline LE-1 & $0,23 \mathrm{C}$ & $0,27 \mathrm{BC}$ & $0,29 \mathrm{AB}$ & $0,33 \mathrm{~A}$ & $0,29 \mathrm{AB}$ & $0,17 \mathrm{D}$ \\
\hline LE-2 & $0,07 \mathrm{~B}$ & $0,14 \mathrm{~A}$ & $0,17 \mathrm{~A}$ & $0,16 \mathrm{~A}$ & $0,17 \mathrm{~A}$ & $0,01 \mathrm{C}$ \\
\hline LA-1 & $0,16 \mathrm{AB}$ & $0,14 \mathrm{~B}$ & $0,18 \mathrm{AB}$ & $0,21 \mathrm{~A}$ & $0,17 \mathrm{AB}$ & $0,07 \mathrm{C}$ \\
\hline PV-1 & $0,12 \mathrm{CD}$ & $0,14 \mathrm{BC}$ & $0,18 \mathrm{AB}$ & $0,22 \mathrm{~A}$ & $0,21 \mathrm{~A}$ & $0,10 \mathrm{D}$ \\
\hline LA-2 & $0,15 \mathrm{C}$ & $0,18 \mathrm{BC}$ & $0,21 \mathrm{AB}$ & $0,24 \mathrm{~A}$ & $0,22 \mathrm{AB}$ & $0,04 \mathrm{D}$ \\
\hline LA-3 & $0,11 \mathrm{~B}$ & $0,14 \mathrm{AB}$ & $0,14 \mathrm{AB}$ & $0,17 \mathrm{~A}$ & $0,15 \mathrm{AB}$ & $0,13 \mathrm{AB}$ \\
\hline TR-1 & $0,31 \mathrm{AB}$ & $0,24 \mathrm{C}$ & $0,26 \mathrm{BC}$ & $0,34 \mathrm{~A}$ & $0,32 \mathrm{~A}$ & $0,18 \mathrm{D}$ \\
\hline LA-4 & $0,11 \mathrm{BC}$ & $0,12 \mathrm{AB}$ & $0,12 \mathrm{AB}$ & $0,16 \mathrm{~A}$ & $0,13 \mathrm{AB}$ & $0,07 \mathrm{C}$ \\
\hline PV-2 & $0,19 \mathrm{AB}$ & $0,23 \mathrm{~A}$ & $0,17 \mathrm{~B}$ & $0,20 \mathrm{AB}$ & $0,20 \mathrm{AB}$ & $0,11 \mathrm{C}$ \\
\hline LA-5 & $0,34 \mathrm{AB}$ & $0,29 \mathrm{BC}$ & $0,38 \mathrm{~A}$ & $0,40 \mathrm{~A}$ & $0,27 \mathrm{C}$ & $0,22 \mathrm{D}$ \\
\hline PV-3 & $0,01 \mathrm{C}$ & 0,09 B & $0,16 \mathrm{~A}$ & $0,16 \mathrm{~A}$ & $0,13 \mathrm{~A}$ & $0,00 \mathrm{C}$ \\
\hline LRa & $0,17 \mathrm{BC}$ & $0,21 \mathrm{AB}$ & $0,21 \mathrm{AB}$ & $0,24 \mathrm{~A}$ & $0,24 \mathrm{~A}$ & $0,15 \mathrm{C}$ \\
\hline LE-3 & $0,16 \mathrm{~B}$ & $0,16 \mathrm{~B}$ & $0,18 \mathrm{AB}$ & $0,20 \mathrm{AB}$ & $0,23 \mathrm{~A}$ & $0,18 \mathrm{AB}$ \\
\hline $\mathrm{PE}$ & $0,25 \mathrm{~A}$ & $0,28 \mathrm{~A}$ & $0,24 \mathrm{~A}$ & $0,27 \mathrm{~A}$ & $0,29 \mathrm{~A}$ & $0,18 \mathrm{~B}$ \\
\hline PV-4 & $0,11 \mathrm{C}$ & $0,13 \mathrm{BC}$ & $0,16 \mathrm{AB}$ & $0,19 \mathrm{~A}$ & $0,17 \mathrm{AB}$ & $0,11 \mathrm{C}$ \\
\hline TR-2 & $0,19 \mathrm{~B}$ & $0,26 \mathrm{~A}$ & $0,22 \mathrm{AB}$ & $0,24 \mathrm{~A}$ & $0,20 \mathrm{AB}$ & $0,18 \mathrm{~B}$ \\
\hline $\mathrm{AQa}$ & $0,14 \mathrm{C}$ & $0,17 \mathrm{ABC}$ & $0,21 \mathrm{~A}$ & $0,19 \mathrm{AB}$ & $0,16 \mathrm{BC}$ & $0,08 \mathrm{D}$ \\
\hline LV-1 & $0,15 \mathrm{C}$ & $0,17 \mathrm{BC}$ & $0,20 \mathrm{AB}$ & $0,23 \mathrm{~A}$ & $0,12 \mathrm{CD}$ & $0,09 \mathrm{D}$ \\
\hline \multirow{3}{*}{$\begin{array}{c}\text { Solos } \\
\text { alcalinos }\end{array}$} & \multicolumn{4}{|c|}{ Composto de resíduo urbano } & \multirow{3}{*}{$\begin{array}{c}\text { Gessagem } \\
\mathrm{e} \\
\text { adubação }\end{array}$} & \multirow{3}{*}{ Testemunha } \\
\hline & \multicolumn{2}{|c|}{ sem gessagem } & \multicolumn{2}{|c|}{ com gessagem } & & \\
\hline & sem adubação & com adubação & sem adubaçāo & com adubação & & \\
\hline & - $-\cdots$ & - & -.--- mg & $\mathrm{lm}^{-3}$ & - & 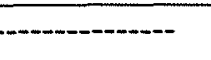 \\
\hline $\mathrm{CL}$ & $0,31 \mathrm{~B}$ & $0,34 \mathrm{AB}$ & $0,39 \mathrm{~A}$ & $0,38 \mathrm{AB}$ & $0,37 \mathrm{AB}$ & $0,32 \mathrm{AB}$ \\
\hline $\mathrm{CV}$ & $0,29 \mathrm{~B}$ & $0,35 \mathrm{AB}$ & $0,38 \mathrm{~A}$ & $0,33 \mathrm{AB}$ & $0,37 \mathrm{~A}$ & $0,33 \mathrm{AB}$ \\
\hline LA-6 & $0,34 \mathrm{AB}$ & $0,37 \mathrm{~A}$ & $0,29 \mathrm{~B}$ & $0,32 \mathrm{AB}$ & $0,37 \mathrm{~A}$ & $0,26 \mathrm{~B}$ \\
\hline LV-2 & $0,32 \mathrm{~B}$ & $0,34 \mathrm{AB}$ & $0,38 \mathrm{AB}$ & $0,40 \mathrm{~A}$ & $0,37 \mathrm{AB}$ & $0,34 \mathrm{AB}$ \\
\hline SS & $0,47 \mathrm{~B}$ & $0,51 \mathrm{AB}$ & $0,54 \mathrm{~A}$ & $0,56 \mathrm{~A}$ & $0,53 \mathrm{AB}$ & $0,47 \mathrm{~B}$ \\
\hline
\end{tabular}

‡-Médias seguidas de mesma letra, nas colunas, não diferem entre si pelo teste de Tukey ao nível de $5 \%$. 
Tabela 44. Disponibilidade de chumbo em solos adubados com composto de resíduo urbano.

\begin{tabular}{|c|c|c|c|c|c|c|}
\hline \multirow{3}{*}{$\begin{array}{l}\text { Solos } \\
\text { ácidos }\end{array}$} & \multicolumn{4}{|c|}{ Composto de resíduo urbano } & \multirow{3}{*}{$\begin{array}{l}\text { Calagem } \\
\mathrm{e} \\
\text { adubação }\end{array}$} & \multirow{3}{*}{ Testemunha } \\
\hline & \multicolumn{2}{|c|}{ sem calagem } & \multicolumn{2}{|c|}{ com calagem } & & \\
\hline & sem adubação & com adubação & sem adubação & com adubação & & \\
\hline & \multicolumn{6}{|c|}{ - mg dm ${ }^{-3}$} \\
\hline GPH & $0,99 \mathrm{ABC}^{\ddagger}$ & $1,11 \mathrm{~A}$ & $1,03 \mathrm{ABC}$ & $1,10 \mathrm{AB}$ & $0,88 \mathrm{C}$ & $0,92 \mathrm{BC}$ \\
\hline AQd & $1,03 \mathrm{~A}$ & $0,95 \mathrm{~A}$ & $0,92 \mathrm{~A}$ & $0,96 \mathrm{~A}$ & $0,43 \mathrm{~B}$ & $0,42 \mathrm{~B}$ \\
\hline LUa & $1,92 \mathrm{~A}$ & $2,12 \mathrm{~A}$ & $1,39 \mathrm{C}$ & $1,65 \mathrm{~B}$ & $1,43 \mathrm{BC}$ & $2,03 \mathrm{~A}$ \\
\hline LE-1 & $0,77 \mathrm{~A}$ & $0,77 \mathrm{~A}$ & $0,78 \mathrm{~A}$ & $0,78 \mathrm{~A}$ & $0,55 \mathrm{~B}$ & $0,57 \mathrm{~B}$ \\
\hline LE-2 & $0,86 \mathrm{~B}$ & $1,09 \mathrm{~A}$ & $0,87 \mathrm{~B}$ & $0,65 \mathrm{C}$ & $0,39 \mathrm{D}$ & $0,40 \mathrm{D}$ \\
\hline LA-1 & $0,78 \mathrm{~A}$ & $0,86 \mathrm{~A}$ & $0,78 \mathrm{~A}$ & $0,81 \mathrm{~A}$ & $0,31 \mathrm{C}$ & $0,44 \mathrm{~B}$ \\
\hline PV-1 & $0,49 \mathrm{BC}$ & $0,71 \mathrm{~A}$ & $0,41 \mathrm{CD}$ & $0,61 \mathrm{AB}$ & $0,30 \mathrm{DE}$ & $0,23 \mathrm{E}$ \\
\hline LA-2 & $0,79 \mathrm{~A}$ & $0,76 \mathrm{~A}$ & $0,55 \mathrm{~B}$ & $0,72 \mathrm{~A}$ & $0,15 \mathrm{C}$ & $0,09 \mathrm{C}$ \\
\hline LA-3 & $0,42 \mathrm{AB}$ & $0,56 \mathrm{~A}$ & $0,40 \mathrm{~B}$ & $0,50 \mathrm{AB}$ & $0,14 \mathrm{C}$ & $0,13 \mathrm{C}$ \\
\hline TR-1 & $0,34 \mathrm{C}$ & $0,68 \mathrm{~A}$ & $0,49 \mathrm{~B}$ & $0,50 \mathrm{~B}$ & $0,47 \mathrm{BC}$ & $0,38 \mathrm{BC}$ \\
\hline LA-4 & $1,48 \mathrm{~A}$ & $1,61 \mathrm{~A}$ & $0,94 \mathrm{C}$ & $1,16 \mathrm{~B}$ & $0,87 \mathrm{C}$ & $0,95 \mathrm{C}$ \\
\hline PV-2 & $0,93 \mathrm{BC}$ & $1,12 \mathrm{~A}$ & $0,85 \mathrm{BC}$ & $0,95 \mathrm{AB}$ & $0,68 \mathrm{D}$ & $0,77 \mathrm{CD}$ \\
\hline LA-5 & $2,53 \mathrm{~B}$ & $2,89 \mathrm{~A}$ & $2,46 \mathrm{~B}$ & $2,53 \mathrm{~B}$ & $2,35 \mathrm{~B}$ & $2,34 \mathrm{~B}$ \\
\hline PV-3 & $1,33 \mathrm{~A}$ & $1,46 \mathrm{~A}$ & $1,43 \mathrm{~A}$ & $1,30 \mathrm{~A}$ & $0,90 \mathrm{~B}$ & $0,62 \mathrm{C}$ \\
\hline $\mathrm{LRa}$ & $0,50 \mathrm{AB}$ & $0,63 \mathrm{~A}$ & $0,50 \mathrm{AB}$ & $0,55 \mathrm{~A}$ & $0,37 \mathrm{C}$ & $0,39 \mathrm{BC}$ \\
\hline LE-3 & $1,52 \mathrm{~A}$ & $1,51 \mathrm{AB}$ & $1,31 \mathrm{~B}$ & $1,36 \mathrm{AB}$ & $1,09 \mathrm{C}$ & $1,38 \mathrm{AB}$ \\
\hline $\mathrm{PE}$ & $1,54 \mathrm{~A}$ & $1,60 \mathrm{~A}$ & $1,40 \mathrm{AB}$ & $1,41 \mathrm{AB}$ & $1,22 \mathrm{~B}$ & $1,41 \mathrm{AB}$ \\
\hline PV-4 & $0,88 \mathrm{BC}$ & $1,15 \mathrm{~A}$ & $0,68 \mathrm{D}$ & $1,00 \mathrm{AB}$ & $0,77 \mathrm{CD}$ & $1,01 \mathrm{AB}$ \\
\hline TR-2 & $1,09 \mathrm{AB}$ & $1,24 \mathrm{~A}$ & $1,25 \mathrm{~A}$ & $1,05 \mathrm{~B}$ & $0,81 \mathrm{C}$ & $0,76 \mathrm{C}$ \\
\hline $\mathrm{AQa}$ & $0,76 \mathrm{AB}$ & $0,89 \mathrm{~A}$ & $0,51 \mathrm{D}$ & $0,72 \mathrm{BC}$ & $0,30 \mathrm{E}$ & $0,59 \mathrm{CD}$ \\
\hline LV-1 & $1,18 \mathrm{~B}$ & $1,30 \mathrm{AB}$ & $0,96 \mathrm{C}$ & $1,20 \mathrm{~B}$ & $0,85 \mathrm{C}$ & $1,44 \mathrm{~A}$ \\
\hline \multirow{3}{*}{$\begin{array}{l}\text { Solos } \\
\text { alcalinos }\end{array}$} & \multicolumn{4}{|c|}{ Composto de resíduo urbano } & \multirow{3}{*}{$\begin{array}{c}\text { Gessagem } \\
\text { e } \\
\text { adubação }\end{array}$} & \multirow{3}{*}{ Testemunha } \\
\hline & \multicolumn{2}{|c|}{ sem gessagem } & \multicolumn{2}{|c|}{ com gessagem } & & \\
\hline & sem adubação & com adubação & sem adubação & com adubação & & \\
\hline & -non & - n & mg & $m^{-3}-\ldots$ & - & 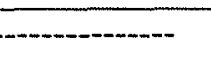 \\
\hline $\mathrm{CL}$ & $4,12 \mathrm{~B}$ & $4,63 \mathrm{~A}$ & $4,08 \mathrm{~B}$ & $4,35 \mathrm{AB}$ & $4,44 \mathrm{AB}$ & $4,45 \mathrm{AB}$ \\
\hline $\mathrm{CV}$ & $2,19 \mathrm{AB}$ & $2,25 \mathrm{~A}$ & $2,27 \mathrm{~A}$ & $2,40 \mathrm{~A}$ & $1,93 \mathrm{BC}$ & $1,78 \mathrm{C}$ \\
\hline LA- 6 & $2,59 \mathrm{~A}$ & $2,37 \mathrm{AB}$ & $2,37 \mathrm{AB}$ & $2,26 \mathrm{AB}$ & $2,10 \mathrm{~B}$ & $2,08 \mathrm{~B}$ \\
\hline LV-2 & $1,08 \mathrm{~A}$ & $1,09 \mathrm{~A}$ & $0,99 \mathrm{~A}$ & $1,09 \mathrm{~A}$ & $0,75 \mathrm{~B}$ & $0,71 \mathrm{~B}$ \\
\hline SS & $1,86 \mathrm{~A}$ & $1,82 \mathrm{~A}$ & $1,84 \mathrm{~A}$ & $1,74 \mathrm{~A}$ & $1,35 \mathrm{~B}$ & $1,4 \mathrm{~B}$ \\
\hline
\end{tabular}

\$-Médias seguidas de mesma letra, nas colunas, não diferem entre si pelo teste de Tukey ao nível de 5\%. 
Observou-se aumento significativos nos teores de $\mathrm{Cd}$ nos solos GPH, AQd, LE-2, LA-1, PV-1, LA-2, LA-3, TR-1, LA-4, PV-2, PV-3 e TR-2, que geralmente foram semelhante aos teores devido à aplicação de composto + adubo. Os tratamentos com composto e composto + calcário, também, causaram aumentos no teor de $\mathrm{Cd}$, mas em menor intensidade. A aplicação de calcário + adubo não diferiu da testemunha em nenhum dos solos ácidos. Nos solos alcalinos, ficou evidente o efeito do aumento dos teores de Cd devido à aplicação do composto.

Com relação ao cromo, foi observado efeito do composto em praticamente todos os solos ácidos, excluindo-se os solos GPH, AQd, LA-3 e LE-3. Praticamente não houve diferenças entre a aplicação de composto com calcário na presença e na ausência de adubo, exceto no solo TR-1, onde se verificou maiores teores de Cr para o composto + calcário + adubo. Todavia, observou-se que a aplicação de calcário + adubo promoveu efeito semelhante aos tratamentos referido acima, exceto no solo LA-5. Nos solos alcalinos, verificou-se somente o efeito da aplicação do composto + adubo e gesso + adubo sobre os teores de Cr no solo LA-6.

O efeito da aplicação de composto sobre os teores de $\mathrm{Pb}$ nos solos ácidos foi semelhante aos do $\mathrm{Cd}$. Assim, observou-se aumento dos teores de $\mathrm{Pb}$ devido à aplicação de composto + adubo, na presença ou ausência de calcário, em praticamente todos os solos, excluindo-se os solos LUa, LA-5, LE-3, PE, PV-4 e LV-1, cujos os teores de $\mathrm{Pb}$ na testemunha foram elevados $\left(1,01\right.$ a $\left.2,34 \mathrm{mg} \mathrm{dm}^{-3}\right)$. Todavia, no solo LA-5 foi observado que o composto + adubo aumentou sobremaneira o teor de $\mathrm{Pb}$, que já era alto neste solo. A aplicação de calcário + adubo, diferentemente do que ocorreu com o $\mathrm{Cr}$, não teve efeito sobre o teor de $\mathrm{Pb}$ (exceto no solo PV-3), ou então, causou sua diminuição (solos LA-1 e PV-4). A aplicação do composto com ou sem calcário promoveu resultados intermediários. Nos solos alcalinos $\mathrm{CV}, \mathrm{LV}-2$ e $\mathrm{SS}$, todos os tratamentos com composto levaram ao aumento na disponibilidade de $\mathrm{Pb}$. Nestes solos, também não foi observado efeito da aplicação de gesso + adubo mineral.

A aplicação de composto + adubo, com ou sem calagem e a calagem + adubação promoveram aumentos significativos nos teores disponíveis de estrôncio (Tabela 45) em todos os solos ácidos. Assim como, o mesmo foi observado para a 
Tabela 45. Disponibilidade de estrôncio em solos adubados com composto de resíduo urbano.

\begin{tabular}{|c|c|c|c|c|c|c|}
\hline \multirow{3}{*}{$\begin{array}{l}\text { Solos } \\
\text { ácidos }\end{array}$} & \multicolumn{4}{|c|}{ Composto de resíduo urbano } & \multirow{3}{*}{$\begin{array}{c}\text { Calagem } \\
\mathrm{e} \\
\text { adubação }\end{array}$} & \multirow{3}{*}{ Testemunha } \\
\hline & \multicolumn{2}{|c|}{ sem calagem } & \multicolumn{2}{|c|}{ com calagem } & & \\
\hline & sem adubação & com adubação & sem adubação & com adubação & & \\
\hline & \multicolumn{6}{|c|}{ - $\mathrm{mg} \mathrm{dm}^{-3}$} \\
\hline GPH & $3,22 \mathrm{BC}^{\ddagger}$ & $6,09 \mathrm{~A}$ & $3,31 \mathrm{BC}$ & $5,97 \mathrm{~A}$ & $5,36 \mathrm{AB}$ & $2,73 \mathrm{C}$ \\
\hline AQd & $1,17 \mathrm{~B}$ & $2,98 \mathrm{~A}$ & $1,28 \mathrm{~B}$ & $3,08 \mathrm{~A}$ & $3,53 \mathrm{~A}$ & $0,96 \mathrm{~B}$ \\
\hline LUa & $0,00 \mathrm{~B}$ & $3,02 \mathrm{~A}$ & $0,00 \mathrm{~B}$ & $4,64 \mathrm{~A}$ & $4,25 \mathrm{~A}$ & $0,00 \mathrm{~B}$ \\
\hline LE-1 & $0,28 \mathrm{~B}$ & $3,25 \mathrm{~A}$ & $0,27 \mathrm{~B}$ & $4,15 \mathrm{~A}$ & $3,69 \mathrm{~A}$ & $0,00 \mathrm{C}$ \\
\hline LE-2 & $0,00 \mathrm{~B}$ & $3,16 \mathrm{~A}$ & $0,00 \mathrm{~B}$ & $3,38 \mathrm{~A}$ & $2,95 \mathrm{~A}$ & $0,00 \mathrm{~B}$ \\
\hline LA-1 & $0,00 \mathrm{~B}$ & $4,93 \mathrm{~A}$ & $0,01 \mathrm{~B}$ & $5,27 \mathrm{~A}$ & $4,42 \mathrm{~A}$ & $0,00 \mathrm{~B}$ \\
\hline PV-1 & $0,19 \mathrm{C}$ & $6,32 \mathrm{~A}$ & $0,37 \mathrm{~B}$ & $6,35 \mathrm{~A}$ & $7,02 \mathrm{~A}$ & $0,00 \mathrm{D}$ \\
\hline LA-2 & $0,00 \mathrm{C}$ & $3,89 \mathrm{~A}$ & $0,25 \mathrm{~B}$ & $4,45 \mathrm{~A}$ & $4,54 \mathrm{~A}$ & $0,00 \mathrm{C}$ \\
\hline LA-3 & $0,98 \mathrm{~B}$ & $5,33 \mathrm{~A}$ & $1,08 \mathrm{~B}$ & $5,63 \mathrm{~A}$ & $5,09 \mathrm{~A}$ & $0,29 \mathrm{C}$ \\
\hline TR-1 & $0,82 \mathrm{~B}$ & $4,45 \mathrm{~A}$ & $0,79 \mathrm{~B}$ & $4,48 \mathrm{~A}$ & $4,36 \mathrm{~A}$ & $0,32 \mathrm{C}$ \\
\hline LA-4 & $0,00 \mathrm{~B}$ & $6,88 \mathrm{~A}$ & $0,00 \mathrm{~B}$ & $5,85 \mathrm{~A}$ & $5,44 \mathrm{~A}$ & $0,00 \mathrm{~B}$ \\
\hline PV-2 & $0,22 \mathrm{~B}$ & $5,93 \mathrm{~A}$ & $0,28 \mathrm{~B}$ & $5,59 \mathrm{~A}$ & $5,64 \mathrm{~A}$ & $0,00 \mathrm{C}$ \\
\hline LA-5 & $1,90 \mathrm{~B}$ & $4,15 \mathrm{~A}$ & $1,72 \mathrm{~B}$ & $4,32 \mathrm{~A}$ & $4,75 \mathrm{~A}$ & $1,25 \mathrm{~B}$ \\
\hline PV-3 & $0,00 \mathrm{C}$ & $0,58 \mathrm{~A}$ & $0,00 \mathrm{C}$ & $0,35 \mathrm{~B}$ & $0,25 \mathrm{~B}$ & $0,00 \mathrm{C}$ \\
\hline LRa & $0,00 \mathrm{~B}$ & $1,76 \mathrm{~A}$ & $0,00 \mathrm{~B}$ & $1,46 \mathrm{~A}$ & $1,25 \mathrm{~A}$ & $0,00 \mathrm{~B}$ \\
\hline LE-3 & $0,00 \mathrm{~B}$ & $1,09 \mathrm{~A}$ & $0,00 \mathrm{~B}$ & $1,11 \mathrm{~A}$ & $0,76 \mathrm{~A}$ & $0,00 \mathrm{~B}$ \\
\hline PE & $0,41 \mathrm{~B}$ & $4,51 \mathrm{~A}$ & $0,49 \mathrm{~B}$ & $4,36 \mathrm{~A}$ & $4,27 \mathrm{~A}$ & $0,00 \mathrm{C}$ \\
\hline PV-4 & $0,00 \mathrm{~B}$ & $4,11 \mathrm{~A}$ & $0,00 \mathrm{~B}$ & $4,67 \mathrm{~A}$ & $3,93 \mathrm{~A}$ & $0,00 \mathrm{~B}$ \\
\hline TR-2 & $0,96 \mathrm{~B}$ & $3,30 \mathrm{~A}$ & $0,88 \mathrm{~B}$ & $3,17 \mathrm{~A}$ & $3,16 \mathrm{~A}$ & $0,80 \mathrm{~B}$ \\
\hline $\mathrm{AQa}$ & $0,00 \mathrm{~B}$ & $3,21 \mathrm{~A}$ & $0,00 \mathrm{~B}$ & $4,45 \mathrm{~A}$ & $3,26 \mathrm{~A}$ & $0,00 \mathrm{~B}$ \\
\hline LV-1 & $0,00 \mathrm{~B}$ & $2,76 \mathrm{~A}$ & $0,00 \mathrm{~B}$ & $2,61 \mathrm{~A}$ & $1,86 \mathrm{~A}$ & $0,00 \mathrm{~B}$ \\
\hline \multirow{3}{*}{$\begin{array}{l}\text { Solos } \\
\text { alcalinos }\end{array}$} & \multicolumn{4}{|c|}{ Composto de resíduo urbano } & \multirow{3}{*}{$\begin{array}{c}\text { Gessagem } \\
\text { e } \\
\text { adubação }\end{array}$} & \multirow{3}{*}{ Testemunha } \\
\hline & \multicolumn{2}{|c|}{ sem gessagem } & \multicolumn{2}{|c|}{ com gessagem } & & \\
\hline & sem adubação & com adubação & sem adubação & com adubação & & \\
\hline & - & - & $\mathrm{mg}$ & $\mathrm{m}^{-3}-\ldots$ & -1-n-nas & - \\
\hline $\mathrm{CL}$ & $0,00 \mathrm{D}$ & $1,48 \mathrm{~B}$ & $0,85 \mathrm{C}$ & $2,35 \mathrm{~A}$ & $1,97 \mathrm{AB}$ & $0,00 \mathrm{D}$ \\
\hline $\mathrm{CV}$ & $0,56 \mathrm{C}$ & $2,53 \mathrm{~A}$ & $1,04 \mathrm{~B}$ & $2,55 \mathrm{~A}$ & $2,32 \mathrm{~A}$ & $0,13 \mathrm{D}$ \\
\hline LA-6 & $0,00 \mathrm{D}$ & $1,96 \mathrm{~B}$ & $0,86 \mathrm{C}$ & $2,66 \mathrm{AB}$ & $3,04 \mathrm{~A}$ & $0,00 \mathrm{D}$ \\
\hline LV -2 & $1,57 \mathrm{C}$ & $3,27 \mathrm{AB}$ & $2,36 \mathrm{~B}$ & $3,99 \mathrm{~A}$ & $3,93 \mathrm{~A}$ & $1,15 \mathrm{C}$ \\
\hline SS & $6,83 \mathrm{~A}$ & $8,87 \mathrm{~A}$ & $8,42 \mathrm{~A}$ & $9,31 \mathrm{~A}$ & $10,40 \mathrm{~A}$ & $7,18 \mathrm{~A}$ \\
\hline
\end{tabular}

‡-Médias seguidas de mesma letra, nas colunas, não diferem entre si pelo teste de Tukey ao nível de $5 \%$. 
Tabela 46. Disponibilidade de titânio em solos adubados com composto de resíduo urbano.

\begin{tabular}{|c|c|c|c|c|c|c|}
\hline \multirow{3}{*}{$\begin{array}{l}\text { Solos } \\
\text { ácidos }\end{array}$} & \multicolumn{4}{|c|}{ Composto de resíduo urbano } & \multirow{3}{*}{$\begin{array}{c}\text { Calagem } \\
\text { e } \\
\text { adubação }\end{array}$} & \multirow{3}{*}{ Testemunha } \\
\hline & \multicolumn{2}{|c|}{ sem calagem } & \multicolumn{2}{|c|}{ com calagem } & & \\
\hline & sem adubação & com adubação & sem adubação & com adubação & & \\
\hline & \multicolumn{6}{|c|}{$\mathrm{mg} \mathrm{dm}^{-3}$} \\
\hline GPH & $0,03 \mathrm{~A}^{\ddagger}$ & $0,02 \mathrm{~A}$ & $0,02 \mathrm{~A}$ & $0,02 \mathrm{~A}$ & $0,03 \mathrm{~A}$ & $0,02 \mathrm{~A}$ \\
\hline AQd & $0,10 \mathrm{~A}$ & $0,09 \mathrm{~A}$ & $0,09 \mathrm{~A}$ & $0,07 \mathrm{~A}$ & $0,05 \mathrm{~A}$ & $0,07 \mathrm{~A}$ \\
\hline LUa & $0,00 \mathrm{~A}$ & $0,01 \mathrm{~A}$ & $0,01 \mathrm{~A}$ & $0,01 \mathrm{~A}$ & $0,01 \mathrm{~A}$ & $0,00 \mathrm{~A}$ \\
\hline LE-1 & $0,01 \mathrm{~A}$ & $0,01 \mathrm{~A}$ & $0,02 \mathrm{~A}$ & $0,01 \mathrm{~A}$ & $0,01 \mathrm{~A}$ & $0,01 \mathrm{~A}$ \\
\hline LE-2 & $0,01 \mathrm{~A}$ & $0,02 \mathrm{~A}$ & $0,02 \mathrm{~A}$ & $0,01 \mathrm{~A}$ & $0,01 \mathrm{~A}$ & $0,00 \mathrm{~A}$ \\
\hline LA-1 & $0,00 \mathrm{~A}$ & $0,00 \mathrm{~A}$ & $0,00 \mathrm{~A}$ & $0,00 \mathrm{~A}$ & $0,00 \mathrm{~A}$ & $0,00 \mathrm{~A}$ \\
\hline PV-1 & $0,04 \mathrm{~A}$ & $0,02 \mathrm{AB}$ & $0,01 \mathrm{~B}$ & $0,03 \mathrm{AB}$ & $0,01 \mathrm{~B}$ & $0,01 \mathrm{~B}$ \\
\hline LA-2 & $0,00 \mathrm{~A}$ & $0,00 \mathrm{~A}$ & $0,00 \mathrm{~A}$ & $0,00 \mathrm{~A}$ & $0,00 \mathrm{~A}$ & $0,00 \mathrm{~A}$ \\
\hline LA-3 & $0,03 \mathrm{~B}$ & $0,03 \mathrm{~B}$ & $0,03 \mathrm{~B}$ & $0,04 \mathrm{AB}$ & $0,03 \mathrm{~B}$ & $0,06 \mathrm{~A}$ \\
\hline TR-1 & $0,04 \mathrm{AB}$ & $0,06 \mathrm{~A}$ & $0,05 \mathrm{AB}$ & 0,02 B & $0,05 \mathrm{AB}$ & $0,07 \mathrm{~A}$ \\
\hline LA-4 & $0,03 \mathrm{AB}$ & $0,04 \mathrm{~A}$ & $0,01 \mathrm{~B}$ & $0,01 \mathrm{~B}$ & $0,01 \mathrm{~B}$ & $0,01 \mathrm{~B}$ \\
\hline PV-2 & $0,01 \mathrm{~A}$ & $0,02 \mathrm{~A}$ & $0,02 \mathrm{~A}$ & $0,02 \mathrm{~A}$ & $0,02 \mathrm{~A}$ & $0,01 \mathrm{~A}$ \\
\hline LA-5 & $0,02 \mathrm{~B}$ & $0,02 \mathrm{~B}$ & $0,03 \mathrm{AB}$ & $0,05 \mathrm{~A}$ & $0,04 \mathrm{AB}$ & $0,04 \mathrm{AB}$ \\
\hline PV-3 & $0,04 \mathrm{~A}$ & $0,01 \mathrm{~B}$ & $0,04 \mathrm{~A}$ & $0,01 \mathrm{~B}$ & $0,00 \mathrm{~B}$ & $0,00 \mathrm{~B}$ \\
\hline LRa & $0,02 \mathrm{~A}$ & $0,03 \mathrm{~A}$ & $0,02 \mathrm{~A}$ & $0,02 \mathrm{~A}$ & $0,03 \mathrm{~A}$ & $0,03 \mathrm{~A}$ \\
\hline LE-3 & $0,01 \mathrm{~A}$ & $0,02 \mathrm{~A}$ & $0,00 \mathrm{~A}$ & $0,00 \mathrm{~A}$ & $0,01 \mathrm{~A}$ & $0,00 \mathrm{~A}$ \\
\hline $\mathrm{PE}$ & $0,02 \mathrm{~A}$ & $0,03 \mathrm{~A}$ & $0,03 \mathrm{~A}$ & $0,04 \mathrm{~A}$ & $0,04 \mathrm{~A}$ & $0,02 \mathrm{~A}$ \\
\hline PV-4 & $0,01 \mathrm{~B}$ & $0,00 \mathrm{~B}$ & $0,00 \mathrm{~B}$ & $0,03 \mathrm{AB}$ & $0,00 \mathrm{~B}$ & $0,05 \mathrm{~A}$ \\
\hline TR-2 & $0,04 \mathrm{~A}$ & $0,05 \mathrm{~A}$ & $0,05 \mathrm{~A}$ & $0,04 \mathrm{~A}$ & $0,05 \mathrm{~A}$ & $0,04 \mathrm{~A}$ \\
\hline $\mathrm{AQa}$ & $0,07 \mathrm{~A}$ & $0,09 \mathrm{~A}$ & $0,09 \mathrm{~A}$ & $0,12 \mathrm{~A}$ & $0,08 \mathrm{~A}$ & $0,09 \mathrm{~A}$ \\
\hline LV-1 & $0,09 \mathrm{~A}$ & $0,17 \mathrm{~A}$ & $0,14 \mathrm{~A}$ & $0,11 \mathrm{~A}$ & $0,17 \mathrm{~A}$ & $0,59 \mathrm{~A}$ \\
\hline \multirow{3}{*}{$\begin{array}{l}\text { Solos } \\
\text { alcalinos }\end{array}$} & \multicolumn{4}{|c|}{ Composto de resíduo urbano } & \multirow{3}{*}{$\begin{array}{c}\text { Gessagem } \\
\text { e } \\
\text { adubação }\end{array}$} & \multirow{3}{*}{ Testemunha } \\
\hline & \multicolumn{2}{|c|}{ sem gessagem } & \multicolumn{2}{|c|}{ com gessagem } & & \\
\hline & sem adubação & com adubação & sem adubação & com adubação & & \\
\hline & - & 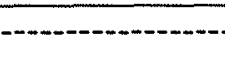 & mg & $\mathrm{m}^{-3} \ldots$ & - & - \\
\hline $\mathrm{CL}$ & $0,02 \mathrm{~A}$ & $0,03 \mathrm{~A}$ & $0,04 \mathrm{~A}$ & $0,04 \mathrm{~A}$ & $0,03 \mathrm{~A}$ & $0,02 \mathrm{~A}$ \\
\hline $\mathrm{CV}$ & $0,05 \mathrm{~A}$ & $0,03 \mathrm{~A}$ & $0,04 \mathrm{~A}$ & $0,06 \mathrm{~A}$ & $0,04 \mathrm{~A}$ & $0,03 \mathrm{~A}$ \\
\hline LA-6 & $0,01 \mathrm{~A}$ & $0,01 \mathrm{~A}$ & $0,02 \mathrm{~A}$ & $0,01 \mathrm{~A}$ & $0,02 \mathrm{~A}$ & $0,01 \mathrm{~A}$ \\
\hline LV-2 & $0,01 \mathrm{~A}$ & $0,01 \mathrm{~A}$ & $0,03 \mathrm{~A}$ & $0,02 \mathrm{~A}$ & $0,03 \mathrm{~A}$ & $0,02 \mathrm{~A}$ \\
\hline SS & $0,02 \mathrm{~A}$ & $0,02 \mathrm{~A}$ & $0,02 \mathrm{~A}$ & $0,02 \mathrm{~A}$ & $0,01 \mathrm{~A}$ & $0,01 \mathrm{~A}$ \\
\hline
\end{tabular}

¥-Médias seguidas de mesma letra, nas colunas, não diferem entre si pelo teste de Tukey ao nível de $5 \%$. 
Tabela 47. Disponibilidade de vanádio em solos adubados com composto de resíduo urbano.

\begin{tabular}{|c|c|c|c|c|c|c|}
\hline \multirow{3}{*}{$\begin{array}{l}\text { Solos } \\
\text { ácidos }\end{array}$} & \multicolumn{4}{|c|}{ Composto de resíduo urbano } & \multirow{3}{*}{$\begin{array}{c}\text { Calagem } \\
\mathrm{e} \\
\text { adubação }\end{array}$} & \multirow{3}{*}{ Testemunha } \\
\hline & \multicolumn{2}{|c|}{ sem calagem } & \multicolumn{2}{|c|}{ com calagem } & & \\
\hline & sem adubação & com adubação & sem adubação & com adubação & & \\
\hline & - & - & $\mathrm{mg} \mathrm{c}$ & $m^{-3} \cdots$ & 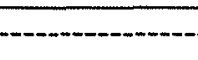 & - \\
\hline GPH & $0,34 \mathrm{CD}^{\ddagger}$ & $0,39 \mathrm{AB}$ & $0,32 \mathrm{D}$ & $0,38 \mathrm{BC}$ & $0,44 \mathrm{~A}$ & $0,42 \mathrm{~A}$ \\
\hline AQd & $0,00 \mathrm{~A}$ & $0,02 \mathrm{~A}$ & $0,00 \mathrm{~A}$ & $0,00 \mathrm{~A}$ & $0,00 \mathrm{~A}$ & $0,00 \mathrm{~A}$ \\
\hline LUa & $0,06 \mathrm{D}$ & $0,10 \mathrm{BC}$ & $0,08 \mathrm{CD}$ & $0,13 \mathrm{AB}$ & $0,14 \mathrm{~A}$ & $0,12 \mathrm{AB}$ \\
\hline LE-1 & $0,08 \mathrm{~B}$ & $0,10 \mathrm{AB}$ & $0,10 \mathrm{AB}$ & $0,13 \mathrm{~A}$ & $0,13 \mathrm{~A}$ & $0,11 \mathrm{AB}$ \\
\hline LE-2 & $0,02 \mathrm{BC}$ & $0,07 \mathrm{~A}$ & $0,04 \mathrm{AB}$ & $0,03 \mathrm{BC}$ & $0,04 \mathrm{AB}$ & $0,00 \mathrm{C}$ \\
\hline LA-1 & $0,06 \mathrm{~B}$ & $0,11 \mathrm{~A}$ & $0,05 \mathrm{~B}$ & $0,09 \mathrm{AB}$ & $0,09 \mathrm{AB}$ & $0,12 \mathrm{~A}$ \\
\hline PV-1 & $0,02 \mathrm{C}$ & $0,07 \mathrm{~B}$ & $0,02 \mathrm{C}$ & $0,08 \mathrm{AB}$ & $0,11 \mathrm{~A}$ & $0,06 \mathrm{~B}$ \\
\hline LA-2 & $0,12 \mathrm{~A}$ & $0,13 \mathrm{~A}$ & $0,06 \mathrm{~B}$ & $0,10 \mathrm{AB}$ & $0,10 \mathrm{~A}$ & $0,09 \mathrm{AB}$ \\
\hline LA-3 & $0,04 \mathrm{BC}$ & $0,07 \mathrm{AB}$ & $0,01 \mathrm{C}$ & $0,06 \mathrm{~B}$ & $0,10 \mathrm{~A}$ & $0,06 \mathrm{~B}$ \\
\hline TR-1 & $0,11 \mathrm{~A}$ & $0,12 \mathrm{~A}$ & $0,09 \mathrm{~A}$ & $0,11 \mathrm{~A}$ & $0,12 \mathrm{~A}$ & $0,10 \mathrm{~A}$ \\
\hline LA-4 & $0,11 \mathrm{~B}$ & $0,18 \mathrm{~A}$ & $0,01 \mathrm{C}$ & $0,08 \mathrm{~B}$ & $0,09 \mathrm{~B}$ & $0,02 \mathrm{C}$ \\
\hline PV-2 & $0,05 \mathrm{CD}$ & $0,11 \mathrm{~B}$ & $0,02 \mathrm{D}$ & $0,08 \mathrm{BC}$ & $0,16 \mathrm{~A}$ & $0,04 \mathrm{D}$ \\
\hline LA-5 & $0,29 \mathrm{BC}$ & $0,33 \mathrm{AB}$ & $0,29 \mathrm{BC}$ & $0,32 \mathrm{AB}$ & $0,34 \mathrm{~A}$ & $0,28 \mathrm{C}$ \\
\hline PV-3 & $0,00 \mathrm{~B}$ & $0,03 \mathrm{~A}$ & $0,03 \mathrm{~A}$ & $0,02 \mathrm{AB}$ & $0,00 \mathrm{~B}$ & $0,00 \mathrm{~B}$ \\
\hline $\mathrm{LRa}$ & $0,00 \mathrm{~A}$ & $0,01 \mathrm{~A}$ & $0,00 \mathrm{~A}$ & $0,01 \mathrm{~A}$ & $0,01 \mathrm{~A}$ & $0,00 \mathrm{~A}$ \\
\hline LE-3 & $0,05 \mathrm{~A}$ & $0,06 \mathrm{~A}$ & $0,06 \mathrm{~A}$ & $0,07 \mathrm{~A}$ & $0,04 \mathrm{~A}$ & $0,05 \mathrm{~A}$ \\
\hline $\mathrm{PE}$ & $0,07 \mathrm{AB}$ & $0,10 \mathrm{~A}$ & $0,06 \mathrm{~B}$ & $0,10 \mathrm{~A}$ & $0,11 \mathrm{~A}$ & $0,10 \mathrm{~A}$ \\
\hline PV -4 & $0,00 \mathrm{~A}$ & $0,00 \mathrm{~A}$ & $0,00 \mathrm{~A}$ & $0,00 \mathrm{~A}$ & $0,00 \mathrm{~A}$ & $0,00 \mathrm{~A}$ \\
\hline TR-2 & $0,28 \mathrm{BC}$ & $0,33 \mathrm{~A}$ & $0,30 \mathrm{AB}$ & $0,25 \mathrm{C}$ & $0,30 \mathrm{AB}$ & $0,28 \mathrm{BC}$ \\
\hline $\mathrm{AQa}$ & $0,00 \mathrm{C}$ & $0,04 \mathrm{AB}$ & $0,00 \mathrm{C}$ & $0,07 \mathrm{~A}$ & $0,02 \mathrm{BC}$ & $0,04 \mathrm{AB}$ \\
\hline LV-1 & $0,03 \mathrm{BC}$ & $0,06 \mathrm{~B}$ & $0,01 \mathrm{C}$ & $0,06 \mathrm{~B}$ & $0,03 \mathrm{C}$ & $0,18 \mathrm{~A}$ \\
\hline \multirow{3}{*}{$\begin{array}{c}\text { Solos } \\
\text { alcalinos }\end{array}$} & \multicolumn{4}{|c|}{ Composto de resíduo urbano } & \multirow{3}{*}{$\begin{array}{c}\text { Gessagem } \\
\mathrm{e} \\
\text { adubação }\end{array}$} & \multirow{3}{*}{ Testemunha } \\
\hline & \multicolumn{2}{|c|}{ sem gessagem } & \multicolumn{2}{|c|}{ com gessagem } & & \\
\hline & sem adubação & com adubação & sem adubação & com adubação & & \\
\hline & -non & (n) & $\mathrm{mg}$ & $\mathrm{Im}^{-3}$ & (-) & -..........- \\
\hline $\mathrm{CL}$ & $0,14 \mathrm{AB}$ & $0,16 \mathrm{AB}$ & $0,18 \mathrm{~A}$ & $0,19 \mathrm{~A}$ & $0,17 \mathrm{~A}$ & $0,12 \mathrm{~B}$ \\
\hline $\mathrm{CV}$ & $0,15 \mathrm{BC}$ & $0,16 \mathrm{~B}$ & $0,16 \mathrm{~B}$ & $0,24 \mathrm{~A}$ & $0,18 \mathrm{~B}$ & $0,11 \mathrm{C}$ \\
\hline LA-6 & $0,08 \mathrm{BC}$ & $0,11 \mathrm{AB}$ & $0,14 \mathrm{~A}$ & $0,14 \mathrm{~A}$ & $0,11 \mathrm{AB}$ & $0,05 \mathrm{C}$ \\
\hline LV-2 & $0,10 \mathrm{BC}$ & $0,13 \mathrm{AB}$ & $0,13 \mathrm{AB}$ & $0,18 \mathrm{~A}$ & $0,14 \mathrm{AB}$ & $0,07 \mathrm{C}$ \\
\hline SS & $0,28 \mathrm{~B}$ & $0,37 \mathrm{~A}$ & $0,29 \mathrm{~B}$ & $0,36 \mathrm{~A}$ & $0,36 \mathrm{~A}$ & $0,23 \mathrm{C}$ \\
\hline
\end{tabular}

‡-Médias seguidas de mesma letra, nas colunas, não diferem entre si pelo teste de Tukey ao nível de $5 \%$. 
aplicação de composto e adubo, com ou sem gesso, e de gesso + adubação em todos os solos alcalinos, excluindo-se o solo SS. O aumento nos teores de $\mathrm{Sr}$ foi devido aos altos teores deste elemento nos superfosfato simples e no gesso natural. A aplicação do composto isoladamente e com calcário não diferiu da testemunha, cujos teores de $\mathrm{Sr}$ no solo foram baixos ou não detectados, exceto nos solos GPH, AQd e LA-5.

Não foram verificados efeitos significativos de tratamentos para os teores de titânio nos solos ácidos e alcalinos. Destaca-se o solo LV-1, cujo o teor na testemunha foi de $0,59 \mathrm{mg} \mathrm{dm}^{-3}$ e tendeu a diminuir nos demais tratamentos. Nos demais solos o teor de Ti foi inferior à $0,10 \mathrm{mg} \mathrm{dm}^{-3}$.

O teor de vanádio disponível (Tabela 47), nos solos ácidos GPH, LUa, LA-1, PV-1, AQd e LV-1, foi diminuído; e no solo LA-4, foi aumentado devido à aplicação de composto isoladamente. Os teores de $\mathrm{V}$ não foram modificados nos solos AQd, LE-1, LA-2, LA-3, TR-1, LRa, LE-3, PE, PV-4 e TR-2. Nos solos alcalinos foi observado um efeito oposto sobre a disponibilidade do $\mathrm{V}$, que teve seus teores aumentados em todos os tratamentos (exceto para o composto isolado nos solos $\mathrm{CL}, \mathrm{CV}$, LA-6 e LV-2), inclusive a gessagem + adubação.

Resultados semelhantes foram reportados por Cravo (1995), que observou que a aplicação de composto de São Paulo aumento os teores de $\mathrm{Pb}, \mathrm{Sr}$ e Ti, em um solo argiloso; e que teores de $\mathrm{Cr}$ só foram detectados em um solo arenoso que, também, apresentou diminuição no teor de $\mathrm{V}$ com o aumento da dose de aplicação do composto. $\mathrm{O}$ autor verificou que o teor de $\mathrm{Pb}$ diminuiu no solo após o segundo cultivo de alface.

Não obstante dos altos teores totais de metais observado no composto empregado no experimento, os teores disponíveis dos metais avaliados não apresentaram aumentos expressivos e que poderiam indicar problemas de toxicidade às plantas e aos animais. E conforme foi discutido por Petruzzelli (1989), a determinação dos teores totais de metais em compostos de resíduo urbano, isoladamente, não se constitui em um bom avaliador do potencial de disponibilidade dos elementos no solo. O mesmo é valido para a análise de totais no solo para caracterização dos níveis de contaminação. 


\subsection{Efeito da adubação com composto de resíduo urbano sobre as plantas de arroz}

\subsubsection{Produção de matéria seca}

As Tabelas 48,49 e 50 contém os resultados de produção de matéria seca da parte aérea, de raízes do primeiro cultivo de arroz (IAC 167) e da parte aérea do segundo cultivo. Verificou-se uma forte interação entre solos e tratamentos sobre a produção de matéria seca da planta.

A aplicação de composto com adubo, na ausência ou presença de calcário, promoveu as maiores produções de matéria seca da parte aérea, nos dois cultivos, e de raízes. Todavia, não houve diferenças significativas com os resultados devido à aplicação de calcário + adubo. Excluindo-se, no solo LE-2 (para a matéria seca no primeiro cultivo), nos solos GPH, LE-2 e PV-3 (para a matéria seca de raiz) e nos solos PV-2 e LA-5 (para a matéria seca da parte aérea no segundo cultivo) onde o composto + adubo foi superior. Os tratamentos com composto não diferiram entre si nos solos GPH, AQd, PV-2, LA-5, LE-3, PE e TR-2 quanto à produção de matéria seca da parte aérea no primeiro cultivo. Os tratamentos com composto e composto + calcário foram inferiores à calagem + adubação e superiores ou semelhantes à testemunha. Nos solos alcalinos, a aplicação de composto + gesso, dentre os tratamentos com composto, causou a maior produção de matéria seca da parte aérea, e não diferiu do tratamento com gesso + adubo. A produção de matéria seca de raiz apresentou a mesma tendência de resposta da parte aérea, todavia não houve efeito de tratamentos nos solos ácidos AQd, PE, TR-2, LV-1 e no solo alcalino SS. Em alguns solos a produção de matéria seca de raízes foi

semelhante ou mesmo superior à da parte aérea, como no caso dos solos LA-4, PV-3, LRa e AQa.

A produção de matéria seca da parte aérea no segundo cultivo foi modificada de modo semelhante ao primeiro. Todavia, em praticamente todos os solos, houve um efeito mais pronunciado do composto + adubo, em relação ao composto + calagem + adubo e calagem + adubo, e a aplicação de composto sem adubo, com ou sem calagem, não diferiu da testemunha. Entretanto, observou-se tendência do tratamento 
Tabela 48. Produção de matéria seca da parte aérea da cultura de arroz em solos adubados composto de resíduo urbano.

\begin{tabular}{|c|c|c|c|c|c|c|}
\hline \multirow{3}{*}{$\begin{array}{l}\text { Solos } \\
\text { ácidos }\end{array}$} & \multicolumn{4}{|c|}{ Composto de resíduo urbano } & \multirow{3}{*}{$\begin{array}{c}\text { Calagem } \\
e \\
\text { adubação }\end{array}$} & \multirow{3}{*}{ Testemunha } \\
\hline & \multicolumn{2}{|c|}{ sem calagem } & \multicolumn{2}{|c|}{ com calagem } & & \\
\hline & sem adubação & com adubação & sem adubaçāo & com adubação & & \\
\hline & 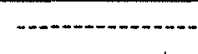 & (n) & $\mathrm{mg} / \mathrm{p}$ & anta -............ & (n).................... & 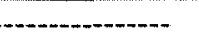 \\
\hline GPH & $835 \mathrm{AB}^{\ddagger}$ & $1425 \mathrm{~A}$ & $977 \mathrm{AB}$ & $1445 \mathrm{~A}$ & $583 \mathrm{~B}$ & $863 \mathrm{AB}$ \\
\hline AQd & $304 \mathrm{~B}$ & $355 \mathrm{~B}$ & $403 \mathrm{AB}$ & $373 \mathrm{~B}$ & $937 \mathrm{~A}$ & $282 \mathrm{~B}$ \\
\hline LUa & $796 \mathrm{~A}$ & $1286 \mathrm{~A}$ & $17 \mathrm{~B}$ & $1443 \mathrm{~A}$ & $1141 \mathrm{~A}$ & $153 \mathrm{~B}$ \\
\hline LE-1 & $533 \mathrm{AB}$ & $649 \mathrm{AB}$ & $310 \mathrm{~B}$ & $890 \mathrm{~A}$ & $951 \mathrm{~A}$ & $187 \mathrm{~B}$ \\
\hline LE-2 & $190 \mathrm{BC}$ & $1200 \mathrm{~A}$ & $28 \mathrm{C}$ & $24 \mathrm{C}$ & $506 \mathrm{~B}$ & $110 \mathrm{BC}$ \\
\hline LA-1 & $296 \mathrm{CD}$ & $655 \mathrm{BC}$ & $42 \mathrm{D}$ & $1394 \mathrm{~A}$ & $1295 \mathrm{AB}$ & $430 \mathrm{CD}$ \\
\hline PV -1 & $1028 \mathrm{~A}$ & $49 \mathrm{~B}$ & $191 \mathrm{~B}$ & $742 \mathrm{~A}$ & $1406 \mathrm{~A}$ & $200 \mathrm{~B}$ \\
\hline LA-2 & $1288 \mathrm{~A}$ & $1472 \mathrm{~A}$ & $529 \mathrm{BC}$ & $1119 \mathrm{AB}$ & $1176 \mathrm{~A}$ & $453 \mathrm{C}$ \\
\hline LA-3 & $827 \mathrm{ABC}$ & $1284 \mathrm{~A}$ & $621 \mathrm{BC}$ & $1213 \mathrm{AB}$ & $1397 \mathrm{~A}$ & $470 \mathrm{C}$ \\
\hline TR-1 & $16 \mathrm{C}$ & $782 \mathrm{~A}$ & $203 \mathrm{BC}$ & $857 \mathrm{~A}$ & $642 \mathrm{AB}$ & $96 \mathrm{C}$ \\
\hline LA-4 & $567 \mathrm{~B}$ & $1233 \mathrm{~A}$ & $441 \mathrm{~B}$ & $19 \mathrm{C}$ & $1366 \mathrm{~A}$ & $23 \mathrm{C}$ \\
\hline PV-2 & $1073 \mathrm{~A}$ & $1264 \mathrm{~A}$ & $783 \mathrm{AB}$ & $1256 \mathrm{~A}$ & $1052 \mathrm{~A}$ & $395 \mathrm{~B}$ \\
\hline LA-5 & $1026 \mathrm{~A}$ & $1341 \mathrm{~A}$ & $1058 \mathrm{~A}$ & $1713 \mathrm{~A}$ & $1192 \mathrm{~A}$ & $361 \mathrm{~B}$ \\
\hline PV-3 & $538 \mathrm{BC}$ & $1282 \mathrm{~A}$ & $476 \mathrm{BC}$ & $1407 \mathrm{~A}$ & $842 \mathrm{AB}$ & $137 \mathrm{C}$ \\
\hline LRa & $410 \mathrm{~B}$ & $1312 \mathrm{~A}$ & 347 B & $1069 \mathrm{~A}$ & $991 \mathrm{~A}$ & $169 \mathrm{~B}$ \\
\hline LE-3 & $819 \mathrm{AB}$ & $1401 \mathrm{~A}$ & $873 \mathrm{AB}$ & $1234 \mathrm{~A}$ & $1269 \mathrm{~A}$ & $453 \mathrm{~B}$ \\
\hline $\mathrm{PE}$ & $245 \mathrm{~A}$ & $599 \mathrm{~A}$ & $359 \mathrm{~A}$ & $594 \mathrm{~A}$ & $636 \mathrm{~A}$ & $199 \mathrm{~A}$ \\
\hline PV -4 & $441 \mathrm{BC}$ & $1399 \mathrm{~A}$ & $201 \mathrm{C}$ & $1339 \mathrm{~A}$ & $863 \mathrm{AB}$ & $244 \mathrm{C}$ \\
\hline TR-2 & $569 \mathrm{AB}$ & $491 \mathrm{AB}$ & $642 \mathrm{AB}$ & $1067 \mathrm{~A}$ & $1087 \mathrm{~A}$ & $288 \mathrm{~B}$ \\
\hline $\mathrm{AQa}$ & $573 \mathrm{BC}$ & $1356 \mathrm{~A}$ & $703 \mathrm{AB}$ & $1124 \mathrm{AB}$ & $1211 \mathrm{AB}$ & $198 \mathrm{C}$ \\
\hline LV-1 & $835 \mathrm{AB}$ & $1483 \mathrm{~A}$ & $561 \mathrm{~B}$ & $1371 \mathrm{~A}$ & $1378 \mathrm{~A}$ & 443 B \\
\hline \multirow{3}{*}{$\begin{array}{c}\text { Solos } \\
\text { alcalinos }\end{array}$} & \multicolumn{4}{|c|}{ Composto de resíduo urbano } & \multirow{3}{*}{$\begin{array}{c}\text { Gessagem } \\
\mathrm{e} \\
\text { adubação }\end{array}$} & \multirow{3}{*}{ Testemunha } \\
\hline & \multicolumn{2}{|c|}{ sem gessagem } & \multicolumn{2}{|c|}{ com gessagem } & & \\
\hline & sem adubação & com adubação & sem adubação & com adubação & & \\
\hline & 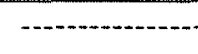 & - & $\mathrm{mg} / \mathrm{I}$ & anta -........... & - & 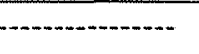 \\
\hline $\mathrm{CL}$ & $16 \mathrm{~B}$ & $939 \mathrm{~A}$ & $701 \mathrm{~A}$ & $1307 \mathrm{~A}$ & $771 \mathrm{~A}$ & $16 \mathrm{~B}$ \\
\hline $\mathrm{CV}$ & $176 \mathrm{BC}$ & $360 \mathrm{AB}$ & $85 \mathrm{CD}$ & $515 \mathrm{AB}$ & $757 \mathrm{~A}$ & $27 \mathrm{D}$ \\
\hline LA- 6 & $510 \mathrm{AB}$ & $1153 \mathrm{~A}$ & $14 \mathrm{C}$ & $364 \mathrm{~B}$ & $682 \mathrm{AB}$ & $392 \mathrm{AB}$ \\
\hline LV-2 & $258 \mathrm{AB}$ & $378 \mathrm{AB}$ & $23 \mathrm{C}$ & $14 \mathrm{C}$ & $677 \mathrm{~A}$ & $113 \mathrm{~B}$ \\
\hline SS & $52 \mathrm{~A}$ & $25 \mathrm{~A}$ & $24 \mathrm{~A}$ & $21 \mathrm{~A}$ & $52 \mathrm{~A}$ & $13 \mathrm{~A}$ \\
\hline
\end{tabular}

\$-Médias seguidas de mesma letra, nas colunas, não diferem entre si pelo teste de Tukey ao nível de $5 \%$. 
Tabela 49. Produção de matéria seca de raiz pela cultura de arroz em solos adubados composto de resíduo urbano.

\begin{tabular}{|c|c|c|c|c|c|c|}
\hline \multirow{3}{*}{$\begin{array}{l}\text { Solos } \\
\text { ácidos }\end{array}$} & \multicolumn{4}{|c|}{ Composto de resíduo urbano } & \multirow{3}{*}{$\begin{array}{c}\text { Calagem } \\
\mathrm{e} \\
\text { adubação }\end{array}$} & \multirow{3}{*}{ Testemunha } \\
\hline & \multicolumn{2}{|c|}{ sem calagem } & \multicolumn{2}{|c|}{ com calagem } & & \\
\hline & sem adubação & com adubação & sem adubação & com adubaçāo & & \\
\hline & \multicolumn{6}{|c|}{ mg/planta - } \\
\hline GPH & $371 \mathrm{~A}^{\ddagger}$ & $505 \mathrm{~A}$ & $333 \mathrm{~A}$ & $524 \mathrm{~A}$ & $55 \mathrm{~B}$ & $333 \mathrm{~A}$ \\
\hline AQd & $242 \mathrm{~A}$ & $203 \mathrm{~A}$ & $305 \mathrm{~A}$ & $203 \mathrm{~A}$ & $521 \mathrm{~A}$ & $229 \mathrm{~A}$ \\
\hline LUa & $583 \mathrm{~A}$ & $668 \mathrm{~A}$ & $1 \mathrm{~B}$ & $447 \mathrm{~A}$ & $563 \mathrm{~A}$ & $82 \mathrm{~B}$ \\
\hline LE-1 & $142 \mathrm{AB}$ & $139 \mathrm{AB}$ & $100 \mathrm{AB}$ & $307 \mathrm{AB}$ & $382 \mathrm{~A}$ & $89 \mathrm{~B}$ \\
\hline LE-2 & $168 \mathrm{BC}$ & $716 \mathrm{~A}$ & $6 \mathrm{C}$ & $3 \mathrm{C}$ & $275 \mathrm{~B}$ & $112 \mathrm{BC}$ \\
\hline LA-1 & $211 \mathrm{BC}$ & $277 \mathrm{~B}$ & $5 \mathrm{C}$ & $905 \mathrm{~A}$ & $1017 \mathrm{~A}$ & $441 \mathrm{~B}$ \\
\hline PV-1 & $674 \mathrm{~A}$ & $6 \mathrm{C}$ & $158 \mathrm{BC}$ & $459 \mathrm{AB}$ & $792 \mathrm{~A}$ & $154 \mathrm{BC}$ \\
\hline LA-2 & $1020 \mathrm{~A}$ & $584 \mathrm{ABC}$ & $242 \mathrm{C}$ & $477 \mathrm{BC}$ & $783 \mathrm{AB}$ & $400 \mathrm{BC}$ \\
\hline LA-3 & $502 \mathrm{AB}$ & $567 \mathrm{AB}$ & $346 \mathrm{~B}$ & $648 \mathrm{AB}$ & $762 \mathrm{~A}$ & $373 \mathrm{AB}$ \\
\hline TR-1 & $2 \mathrm{D}$ & $397 \mathrm{BC}$ & $160 \mathrm{CD}$ & $1081 \mathrm{~A}$ & $696 \mathrm{AB}$ & $137 \mathrm{CD}$ \\
\hline LA-4 & $1040 \mathrm{BC}$ & $1158 \mathrm{~B}$ & $587 \mathrm{C}$ & $13 \mathrm{D}$ & $1964 \mathrm{~A}$ & $11 \mathrm{D}$ \\
\hline PV -2 & $690 \mathrm{~A}$ & $542 \mathrm{~A}$ & $654 \mathrm{~A}$ & $688 \mathrm{~A}$ & $523 \mathrm{~A}$ & $90 \mathrm{~B}$ \\
\hline LA-5 & $552 \mathrm{~A}$ & $392 \mathrm{AB}$ & $526 \mathrm{~A}$ & $678 \mathrm{~A}$ & $542 \mathrm{~A}$ & $104 \mathrm{~B}$ \\
\hline PV -3 & $364 \mathrm{BC}$ & $1269 \mathrm{~A}$ & $572 \mathrm{~B}$ & $1473 \mathrm{~A}$ & $470 \mathrm{~B}$ & $145 \mathrm{C}$ \\
\hline LRa & $306 \mathrm{BC}$ & $874 \mathrm{~A}$ & 296 BC & $794 \mathrm{~A}$ & $640 \mathrm{AB}$ & $200 \mathrm{C}$ \\
\hline LE-3 & $313 \mathrm{AB}$ & $664 \mathrm{~A}$ & $366 \mathrm{AB}$ & $516 \mathrm{AB}$ & $551 \mathrm{~A}$ & $198 \mathrm{~A}$ \\
\hline $\mathrm{PE}$ & $91 \mathrm{~A}$ & $209 \mathrm{~A}$ & $168 \mathrm{~A}$ & $181 \mathrm{~A}$ & $177 \mathrm{~A}$ & $157 \mathrm{~A}$ \\
\hline PV -4 & $256 \mathrm{BC}$ & $835 \mathrm{~A}$ & $84 \mathrm{C}$ & $717 \mathrm{~A}$ & $487 \mathrm{AB}$ & $191 \mathrm{BC}$ \\
\hline TR-2 & $226 \mathrm{~A}$ & $107 \mathrm{~A}$ & $264 \mathrm{~A}$ & $294 \mathrm{~A}$ & $326 \mathrm{~A}$ & $128 \mathrm{~A}$ \\
\hline $\mathrm{AQa}$ & $971 \mathrm{AB}$ & $1008 \mathrm{AB}$ & $1529 \mathrm{~A}$ & $735 \mathrm{BC}$ & $1248 \mathrm{AB}$ & $483 \mathrm{C}$ \\
\hline LV-1 & $744 \mathrm{~A}$ & $703 \mathrm{~A}$ & $452 \mathrm{~A}$ & $732 \mathrm{~A}$ & $733 \mathrm{~A}$ & $453 \mathrm{~A}$ \\
\hline \multirow{3}{*}{$\begin{array}{c}\text { Solos } \\
\text { alcalinos }\end{array}$} & \multicolumn{4}{|c|}{ Composto de resíduo urbano } & \multirow{3}{*}{$\begin{array}{l}\text { Gessagem } \\
\text { e } \\
\text { adubação }\end{array}$} & \multirow{3}{*}{ Testemunha } \\
\hline & \multicolumn{2}{|c|}{ sem gessagem } & \multicolumn{2}{|c|}{ com gessagem } & & \\
\hline & sem adubação & com adubação & sem adubação & com adubação & & \\
\hline & -..n. & - & $\mathrm{mg} / \mathrm{p}$ & anta - - & - & - \\
\hline $\mathrm{CL}$ & $2 \mathrm{~B}$ & $577 \mathrm{~A}$ & $569 \mathrm{~A}$ & $775 \mathrm{~A}$ & $427 \mathrm{~A}$ & $1 \mathrm{~B}$ \\
\hline $\mathrm{CV}$ & $61 \mathrm{AB}$ & $102 \mathrm{~A}$ & $18 \mathrm{BC}$ & $178 \mathrm{~A}$ & $246 \mathrm{~A}$ & $7 \mathrm{C}$ \\
\hline LA-6 & $293 \mathrm{AB}$ & $631 \mathrm{~A}$ & $1 \mathrm{C}$ & $147 \mathrm{~B}$ & $360 \mathrm{AB}$ & $207 \mathrm{AB}$ \\
\hline LV-2 & $95 \mathrm{AB}$ & $97 \mathrm{AB}$ & $3 \mathrm{D}$ & $10 \mathrm{CD}$ & $324 \mathrm{~A}$ & $42 \mathrm{BC}$ \\
\hline SS & $6 \mathrm{~A}$ & $3 \mathrm{~A}$ & $2 \mathrm{~A}$ & $2 \mathrm{~A}$ & $10 \mathrm{~A}$ & $1 \mathrm{~A}$ \\
\hline
\end{tabular}

$\bar{\ddagger}$ - Médias seguidas de mesma letra, nas colunas, não diferem entre si pelo teste de Tukey ao nível de $5 \%$. 
Tabela 50. Produção de matéria seca da parte aérea da cultura de arroz em solos adubados composto de resíduo urbano, no segundo cultivo.

\begin{tabular}{|c|c|c|c|c|c|c|}
\hline \multirow{3}{*}{$\begin{array}{l}\text { Solos } \\
\text { ácidos }\end{array}$} & \multicolumn{4}{|c|}{ Composto de resíduo urbano } & \multirow{3}{*}{$\begin{array}{c}\text { Calagem } \\
\text { e } \\
\text { adubação }\end{array}$} & \multirow{3}{*}{ Testemunha } \\
\hline & \multicolumn{2}{|c|}{ sem calagem } & \multicolumn{2}{|c|}{ com calagem } & & \\
\hline & sem adubação & com adubação & sem adubação & com adubação & & \\
\hline & - & - & $\mathrm{mg} / \mathrm{pl}$ & anta...$--\ldots$ & -1n-...-...- & 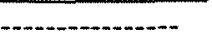 \\
\hline GPH & $197 \mathrm{~B}^{\ddagger}$ & $555 \mathrm{~A}$ & $345 \mathrm{AB}$ & $346 \mathrm{AB}$ & $538 \mathrm{~A}$ & $291 \mathrm{AB}$ \\
\hline AQd & $177 \mathrm{CD}$ & $483 \mathrm{AB}$ & $123 \mathrm{D}$ & $323 \mathrm{BC}$ & $664 \mathrm{~A}$ & $117 \mathrm{D}$ \\
\hline LUa & $470 \mathrm{~B}$ & $1479 \mathrm{~A}$ & $190 \mathrm{C}$ & $1028 \mathrm{~A}$ & $1140 \mathrm{~A}$ & $130 \mathrm{C}$ \\
\hline LE-1 & $327 \mathrm{~B}$ & $1033 \mathrm{~A}$ & $336 \mathrm{~B}$ & $724 \mathrm{~A}$ & $861 \mathrm{~A}$ & $198 \mathrm{~B}$ \\
\hline LE-2 & $140 \mathrm{BC}$ & $955 \mathrm{~A}$ & $120 \mathrm{C}$ & $1004 \mathrm{~A}$ & $966 \mathrm{~A}$ & $334 \mathrm{~B}$ \\
\hline LA-1 & $387 \mathrm{~B}$ & $1071 \mathrm{~A}$ & $271 \mathrm{BC}$ & $1045 \mathrm{~A}$ & $852 \mathrm{~A}$ & $111 \mathrm{C}$ \\
\hline PV -1 & $272 \mathrm{~B}$ & $1137 \mathrm{~A}$ & $170 \mathrm{~B}$ & $890 \mathrm{~A}$ & $841 \mathrm{~A}$ & $128 \mathrm{~B}$ \\
\hline LA-2 & $408 \mathrm{~B}$ & $1009 \mathrm{~A}$ & $266 \mathrm{BC}$ & $724 \mathrm{~A}$ & $767 \mathrm{~A}$ & $130 \mathrm{C}$ \\
\hline LA-3 & $386 \mathrm{~B}$ & $1113 \mathrm{~A}$ & $370 \mathrm{~B}$ & $1194 \mathrm{~A}$ & $935 \mathrm{~A}$ & $168 \mathrm{~B}$ \\
\hline TR-1 & $46 \mathrm{~B}$ & $618 \mathrm{~A}$ & $168 \mathrm{~B}$ & $654 \mathrm{~A}$ & $655 \mathrm{~A}$ & $86 \mathrm{~B}$ \\
\hline LA-4 & $216 \mathrm{~B}$ & $931 \mathrm{~A}$ & $211 \mathrm{~B}$ & $625 \mathrm{~A}$ & $773 \mathrm{~A}$ & $94 \mathrm{~B}$ \\
\hline PV-2 & $274 \mathrm{C}$ & $1010 \mathrm{~A}$ & $253 \mathrm{C}$ & $670 \mathrm{AB}$ & $544 \mathrm{~B}$ & $138 \mathrm{C}$ \\
\hline LA-5 & $512 \mathrm{~B}$ & $1024 \mathrm{~A}$ & $546 \mathrm{~B}$ & $1249 \mathrm{~A}$ & $571 \mathrm{~B}$ & $228 \mathrm{C}$ \\
\hline PV -3 & $334 \mathrm{~B}$ & $1067 \mathrm{~A}$ & $248 \mathrm{~B}$ & $922 \mathrm{~A}$ & $854 \mathrm{~A}$ & $164 \mathrm{~B}$ \\
\hline $\mathrm{LRa}$ & $313 \mathrm{~B}$ & $1061 \mathrm{~A}$ & $211 \mathrm{~B}$ & $919 \mathrm{~A}$ & $1012 \mathrm{~A}$ & $150 \mathrm{~B}$ \\
\hline LE-3 & $357 \mathrm{BC}$ & $850 \mathrm{~A}$ & $397 \mathrm{~B}$ & $903 \mathrm{~A}$ & $794 \mathrm{~A}$ & $160 \mathrm{C}$ \\
\hline $\mathrm{PE}$ & $377 \mathrm{~B}$ & $1203 \mathrm{~A}$ & $421 \mathrm{~B}$ & $1106 \mathrm{~A}$ & $923 \mathrm{~A}$ & $200 \mathrm{~B}$ \\
\hline PV -4 & $365 \mathrm{~B}$ & $1098 \mathrm{~A}$ & $243 \mathrm{BC}$ & $1016 \mathrm{~A}$ & $1063 \mathrm{~A}$ & $105 \mathrm{C}$ \\
\hline TR-2 & $412 \mathrm{~B}$ & $1154 \mathrm{~A}$ & $317 \mathrm{~B}$ & $1146 \mathrm{~A}$ & $1142 \mathrm{~A}$ & $312 \mathrm{~B}$ \\
\hline $\mathrm{AQa}$ & $239 \mathrm{~B}$ & $1123 \mathrm{~A}$ & $235 \mathrm{~B}$ & $771 \mathrm{~A}$ & $1103 \mathrm{~A}$ & $122 \mathrm{~B}$ \\
\hline $\mathrm{LV}-1$ & $238 \mathrm{~B}$ & $939 \mathrm{~A}$ & $232 \mathrm{~B}$ & $778 \mathrm{~A}$ & $836 \mathrm{~A}$ & $148 \mathrm{~B}$ \\
\hline \multirow{3}{*}{$\begin{array}{c}\text { Solos } \\
\text { alcalinos }\end{array}$} & \multicolumn{4}{|c|}{ Composto de resíduo urbano } & \multirow{3}{*}{$\begin{array}{c}\text { Gessagem } \\
\mathrm{e} \\
\text { adubação }\end{array}$} & \multirow{3}{*}{ Testemunha } \\
\hline & \multicolumn{2}{|c|}{ sem gessagem } & \multicolumn{2}{|c|}{ com gessagem } & & \\
\hline & sem adubação & com adubação & sem adubação & com adubação & & \\
\hline & (............... & 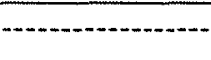 & mg/p & anta -................ & (a) & 4 \\
\hline $\mathrm{CL}$ & $503 \mathrm{AB}$ & $859 \mathrm{~A}$ & $319 \mathrm{~B}$ & $853 \mathrm{~A}$ & $503 \mathrm{AB}$ & $72 \mathrm{C}$ \\
\hline $\mathrm{CV}$ & $165 \mathrm{ABC}$ & $270 \mathrm{AB}$ & $151 \mathrm{BC}$ & $354 \mathrm{~A}$ & $318 \mathrm{AB}$ & $105 \mathrm{C}$ \\
\hline LA-6 & $294 \mathrm{C}$ & $618 \mathrm{AB}$ & $297 \mathrm{BC}$ & $646 \mathrm{~A}$ & $984 \mathrm{~A}$ & $204 \mathrm{C}$ \\
\hline LV-2 & $193 \mathrm{C}$ & $525 \mathrm{AB}$ & $303 \mathrm{BC}$ & $490 \mathrm{AB}$ & $729 \mathrm{~A}$ & $262 \mathrm{BC}$ \\
\hline SS & $128 \mathrm{~B}$ & $160 \mathrm{AB}$ & $186 \mathrm{AB}$ & $177 \mathrm{AB}$ & $316 \mathrm{~A}$ & $97 \mathrm{~B}$ \\
\hline
\end{tabular}

¥-Médias seguidas de mesma letra, nas colunas, não diferem entre si pelo teste de Tukey ao nível de $5 \%$. 
com composto + calcário (nos solos ácido) ou com composto + gesso (nos solos alcalinos) de apresentarem, em alguns solos, uma produção de matéria seca um pouco inferior à testemunha. Tal fato pode ser devido a um desbalanceamento entre os cátions $\mathrm{Ca}, \mathrm{Mg}, \mathrm{K}$ e Na na solução do solo.

No solo SS foi observado as menores produções de matéria seca da parte aérea e de raiz. Este efeito foi devido à alta condutividade elétrica, elevado $\mathrm{pH}$ e da alta salinidade, que em parte foram intensificados pela aplicação do composto. No segundo cultivo, este efeito foi minimizado pela aplicação de gesso e adubo, embora as produções observadas ainda tenham sido as menores.

De modo semelhante, alguns autores têm observado que as plantas respondem melhor à aplicação de composto quando há complementação com adubação mineral (Cravo, 1995; Lopes et al., 1996). Outros autores não observaram diferenças significativas entre a aplicação de composto com ou sem adubo (Zen et al., 1994). Rodrigues (1998) relatou produções de matéria seca da parte aérea e de raízes, em experimento de casa de vegetação com micronutrientes em solos da Amazônia, semelhantes às observadas neste trabalho. Mortvedt \& Giordano (1975) não observaram redução na produção de matéria seca e nem efeitos fitotóxicos em plantas de milho adubadas com composto contendo altas doses de $\mathrm{Zn}$ e de $\mathrm{Cr}$.

Um importante fator controlador de possíveis efeitos negativos ao desenvolvimento das culturas é o período de contato do composto com o solo, ou seja o período de incubação para a estabilização do material orgânico adicionado ao solo. De acordo com Mazur (1997), há a necessidade, independentemente do solo, de um intervalo de tempo entre a aplicação do composto de resíduo urbano e a semeadura, para que os efeitos benéficos do composto possam atuar sobre as plantas, ou então, para que não ocorram efeitos maléficos à nutrição e produção dos vegetais.

Pelos resultados obtidos no presente trabalho, pode-se aventar que os efeitos negativos na produção do arroz foram muito mais devido às condições químicas desfavoráveis ao bom desenvolvimento das plantas (ex. alta condutividade elétrica, elevado $\mathrm{pH}$, etc.) do que por problemas de fitotoxicidade causada por metais oriundos do composto. 


\subsubsection{Absorção de macronutri entes e de sódio}

O efeito da aplicação de composto de resíduo urbano, na presença ou ausência de calcário e adubo sobre a absorção de nitrogênio, fósforo, enxofre, potássio, cálcio, magnésio e sódio são apresentados nas Tabelas $51,52,53,54,55,56$ e 57, respectivamente.

Foi verificado que, para os tratamentos com composto, houve um aumento significativo na absorção de $\mathrm{N}, \mathrm{P}, \mathrm{S}, \mathrm{K}, \mathrm{Ca}$ e $\mathrm{Mg}$ devido à aplicação do composto com adubo, na presença ou ausência de calcário nos solos ácidos, e devido à aplicação de composto com adubo, na presença ou ausência de gesso, nos solos alcalinos. Todavia, a aplicação de calcário com adubo mineral, nos solos ácidos, ou de gesso com adubo, nos solos alcalinos, promoveu resultados semelhantes. Os tratamentos com composto e com composto + calagem, nos solos ácidos, ou com composto e com composto + gesso, nos solos alcalinos, geralmente não diferiram da testemunha.

A absorção de sódio pelas plantas de arroz, de um modo geral, foram superiores devido à aplicação de composto + calcário e composto + calcário + adubo, embora em um grande parte dos solos ácidos, não tenha havido diferenças entre os diferentes modos de aplicação de composto. Embora se esperasse maior absorção de $\mathrm{Na}$ pelas plantas devido à aplicação do composto, cuja a análise revelou conter altos teores de $\mathrm{Na}$, o tratamento com calcário + adubo promoveu resultado praticamente semelhante, indicando que há um certo equilíbrio entre as bases trocáveis presentes no composto.

Cravo (1995) verificou aumentou na absorção de K, diminuição de $\mathrm{Mg}$ e ausência sobre os outros macronutrientes em alface adubada com composto de São Paulo, e Lopes et al. (1996) relataram o aumento da absorção de nitrogênio em plantas de caupi devido à adubação com composto e baixas doses de nitrogênio. 
Tabela 51. Absorção de nitrogênio pela parte aérea da cultura de arroz em solos adubados com composto de resíduo urbano.

\begin{tabular}{|c|c|c|c|c|c|c|}
\hline \multirow{3}{*}{$\begin{array}{l}\text { Solos } \\
\text { ácidos }\end{array}$} & \multicolumn{4}{|c|}{ Composto de resíduo urbano } & \multirow{3}{*}{$\begin{array}{c}\text { Calagem } \\
\mathrm{e} \\
\text { adubação }\end{array}$} & \multirow{3}{*}{ Testemunha } \\
\hline & \multicolumn{2}{|c|}{ sem calagem } & \multicolumn{2}{|c|}{ com calagem } & & \\
\hline & sem adubação & com adubação & sem adubação & com adubação & & \\
\hline & & & $\mathrm{mg} / \mathrm{p}$ & anta --------. & & \\
\hline GPH & $11,44 \mathrm{~B}^{\ddagger}$ & $22,20 \mathrm{~A}$ & $15,11 \mathrm{AB}$ & $18,99 \mathrm{AB}$ & $18,02 \mathrm{AB}$ & $12,58 \mathrm{~B}$ \\
\hline AQd & $4,01 \mathrm{~B}$ & $6,81 \mathrm{AB}$ & $5,01 \mathrm{~B}$ & $7,79 \mathrm{AB}$ & $11,57 \mathrm{~A}$ & $2,74 \mathrm{~B}$ \\
\hline LUa & $15,33 \mathrm{~B}$ & $23,08 \mathrm{AB}$ & $0,67 \mathrm{C}$ & $27,04 \mathrm{~A}$ & $18,21 \mathrm{AB}$ & $4,03 \mathrm{C}$ \\
\hline LE-1 & $10,62 \mathrm{AB}$ & $13,84 \mathrm{AB}$ & $6,96 \mathrm{~B}$ & $16,20 \mathrm{~A}$ & $14,11 \mathrm{~A}$ & $1,82 \mathrm{C}$ \\
\hline LE-2 & $3,42 \mathrm{~B}$ & $16,72 \mathrm{~A}$ & $1,12 \mathrm{~B}$ & $0,82 \mathrm{~B}$ & $10,24 \mathrm{~A}$ & $2,19 \mathrm{~B}$ \\
\hline LA-1 & $6,47 \mathrm{~B}$ & $14,47 \mathrm{~A}$ & $0,93 \mathrm{C}$ & $18,43 \mathrm{~A}$ & $16,92 \mathrm{~A}$ & $11,62 \mathrm{AB}$ \\
\hline PV -1 & $13,66 \mathrm{AB}$ & $1,51 \mathrm{C}$ & $3,59 \mathrm{C}$ & $12,36 \mathrm{~B}$ & $21,46 \mathrm{~A}$ & $5,07 \mathrm{C}$ \\
\hline LA-2 & $16,92 \mathrm{~B}$ & $30,00 \mathrm{~A}$ & $9,60 \mathrm{~B}$ & $15,73 \mathrm{~B}$ & $12,73 \mathrm{~B}$ & $14,70 \mathrm{~B}$ \\
\hline LA-3 & $9,44 \mathrm{BCD}$ & $17,30 \mathrm{~A}$ & $8,25 \mathrm{CD}$ & $14,13 \mathrm{ABC}$ & $16,57 \mathrm{AB}$ & $6,34 \mathrm{D}$ \\
\hline TR-1 & $0,32 \mathrm{C}$ & $9,80 \mathrm{~A}$ & $2,44 \mathrm{BC}$ & $10,74 \mathrm{~A}$ & $6,37 \mathrm{AB}$ & $1,23 \mathrm{C}$ \\
\hline LA-4 & $6,22 \mathrm{~B}$ & $14,75 \mathrm{~A}$ & $5,87 \mathrm{~B}$ & $0,66 \mathrm{C}$ & $17,52 \mathrm{~A}$ & $0,84 \mathrm{C}$ \\
\hline PV -2 & $14,65 \mathrm{AB}$ & $22,12 \mathrm{~A}$ & $9,44 \mathrm{BC}$ & $21,28 \mathrm{~A}$ & $20,55 \mathrm{~A}$ & $6,74 \mathrm{C}$ \\
\hline LA-5 & $15,13 \mathrm{CD}$ & $30,84 \mathrm{AB}$ & $21,06 \mathrm{BC}$ & $33,19 \mathrm{~A}$ & $27,59 \mathrm{AB}$ & $10,36 \mathrm{D}$ \\
\hline PV -3 & $7,52 \mathrm{~B}$ & $18,58 \mathrm{~A}$ & $7,44 \mathrm{BC}$ & $20,27 \mathrm{~A}$ & $16,12 \mathrm{~A}$ & $2,34 \mathrm{C}$ \\
\hline $\mathrm{LRa}$ & $4,48 \mathrm{BC}$ & $13,43 \mathrm{~A}$ & $4,13 \mathrm{BC}$ & $12,81 \mathrm{~A}$ & $9,61 \mathrm{AB}$ & $1,51 \mathrm{C}$ \\
\hline LE-3 & $9,72 \mathrm{BC}$ & $17,51 \mathrm{AB}$ & $9,84 \mathrm{BC}$ & $17,97 \mathrm{~A}$ & $14,57 \mathrm{AB}$ & $6,88 \mathrm{C}$ \\
\hline $\mathrm{PE}$ & $4,12 \mathrm{BC}$ & $10,97 \mathrm{~A}$ & $4,45 \mathrm{BC}$ & $8,29 \mathrm{AB}$ & $14,08 \mathrm{~A}$ & $1,99 \mathrm{C}$ \\
\hline PV-4 & $5,27 \mathrm{BC}$ & $16,94 \mathrm{~A}$ & $2,26 \mathrm{C}$ & $15,54 \mathrm{~A}$ & $10,52 \mathrm{AB}$ & $3,82 \mathrm{C}$ \\
\hline TR-2 & $12,10 \mathrm{BC}$ & $13,81 \mathrm{~B}$ & $12,14 \mathrm{BC}$ & $23,42 \mathrm{~A}$ & $23,78 \mathrm{~A}$ & $6,69 \mathrm{C}$ \\
\hline $\mathrm{AQa}$ & $9,34 \mathrm{~B}$ & $18,41 \mathrm{~A}$ & $8,31 \mathrm{~B}$ & $15,74 \mathrm{AB}$ & $14,46 \mathrm{AB}$ & $2,40 \mathrm{C}$ \\
\hline LV-1 & $10,67 \mathrm{BC}$ & $20,99 \mathrm{~A}$ & $7,12 \mathrm{C}$ & $19,60 \mathrm{~A}$ & $16,89 \mathrm{AB}$ & $5,54 \mathrm{C}$ \\
\hline \multirow{3}{*}{$\begin{array}{l}\text { Solos } \\
\text { alcalinos }\end{array}$} & \multicolumn{4}{|c|}{ Composto de resíduo urbano } & \multirow{3}{*}{$\begin{array}{c}\text { Gessagem } \\
\mathrm{e} \\
\text { adubação }\end{array}$} & \multirow{3}{*}{ Testemunha } \\
\hline & \multicolumn{2}{|c|}{ sem gessagem } & \multicolumn{2}{|c|}{ com gessagem } & & \\
\hline & sem adubação & com adubação & sem adubação & com adubação & & \\
\hline & & & $\mathrm{mg} / \mathrm{p}$ & lanta -........- & - & (n)- \\
\hline $\mathrm{CL}$ & $0,53 \mathrm{~B}$ & $14,31 \mathrm{~A}$ & $6,55 \mathrm{~A}$ & $13,17 \mathrm{~A}$ & $8,72 \mathrm{~A}$ & $0,59 \mathrm{~B}$ \\
\hline $\mathrm{CV}$ & $3,32 \mathrm{BC}$ & $8,94 \mathrm{AB}$ & $2,10 \mathrm{CD}$ & $11,58 \mathrm{~A}$ & $11,97 \mathrm{~A}$ & $0,74 \mathrm{D}$ \\
\hline LA-6 & $7,42 \mathrm{AB}$ & $15,72 \mathrm{~A}$ & $0,22 \mathrm{C}$ & $9,27 \mathrm{AB}$ & $9,35 \mathrm{AB}$ & $5,52 \mathrm{~B}$ \\
\hline $\mathrm{LV}-2$ & $6,43 \mathrm{AB}$ & $10,31 \mathrm{~A}$ & $0,74 \mathrm{C}$ & $0,32 \mathrm{C}$ & $13,67 \mathrm{~A}$ & $3,04 \mathrm{~B}$ \\
\hline SS & $1,29 \mathrm{~A}$ & $0,59 \mathrm{~A}$ & $0,73 \mathrm{~A}$ & $0,61 \mathrm{~A}$ & $1,23 \mathrm{~A}$ & $0,48 \mathrm{~A}$ \\
\hline
\end{tabular}

¥-Médias seguidas de mesma letra, nas colunas, não diferem entre si pelo teste de Tukey ao nível de $5 \%$. 
Tabela 52. Absorção de fósforo pela parte aérea da cultura de arroz em solos adubados com composto de resíduo urbano.

\begin{tabular}{|c|c|c|c|c|c|c|}
\hline \multirow{3}{*}{$\begin{array}{l}\text { Solos } \\
\text { ácidos }\end{array}$} & \multicolumn{4}{|c|}{ Composto de resíduo urbano } & \multirow{3}{*}{$\begin{array}{c}\text { Calagem } \\
\mathrm{e} \\
\text { adubação }\end{array}$} & \multirow{3}{*}{ Testemunha } \\
\hline & \multicolumn{2}{|c|}{ sem calagem } & \multicolumn{2}{|c|}{ com calagem } & & \\
\hline & sem adubação & com adubação & sem adubação & com adubação & & \\
\hline & \multicolumn{6}{|c|}{ mg/planta } \\
\hline GPH & $1,76 \mathrm{~B}^{\ddagger}$ & $4,32 \mathrm{~A}$ & $1,49 \mathrm{~B}$ & $4,00 \mathrm{~A}$ & $1,81 \mathrm{~B}$ & $1,56 \mathrm{~B}$ \\
\hline AQd & $0,64 \mathrm{~B}$ & $1,30 \mathrm{~B}$ & $0,83 \mathrm{~B}$ & $0,99 \mathrm{~B}$ & $9,9 \mathrm{~A}$ & $0,77 \mathrm{~B}$ \\
\hline LUa & $1,09 \mathrm{~B}$ & $2,95 \mathrm{~A}$ & $0,03 \mathrm{C}$ & $2,77 \mathrm{~A}$ & $3,16 \mathrm{~A}$ & $0,08 \mathrm{C}$ \\
\hline LE-1 & $1,33 \mathrm{BC}$ & $1,02 \mathrm{BC}$ & $0,68 \mathrm{CD}$ & $2,25 \mathrm{AB}$ & $3,21 \mathrm{~A}$ & $0,20 \mathrm{D}$ \\
\hline LE-2 & $0,18 \mathrm{~B}$ & $2,10 \mathrm{~A}$ & $0,09 \mathrm{~B}$ & $0,13 \mathrm{~B}$ & $1,12 \mathrm{~A}$ & $0,03 \mathrm{~B}$ \\
\hline LA-1 & $0,46 \mathrm{C}$ & $2,18 \mathrm{~B}$ & $0,10 \mathrm{D}$ & $3,04 \mathrm{AB}$ & $4,90 \mathrm{~A}$ & $0,35 \mathrm{CD}$ \\
\hline PV-1 & $1,06 \mathrm{~B}$ & $0,27 \mathrm{C}$ & $0,25 \mathrm{C}$ & $1,51 \mathrm{~B}$ & $3,70 \mathrm{~A}$ & $0,15 \mathrm{C}$ \\
\hline LA-2 & $1,80 \mathrm{~B}$ & $4,49 \mathrm{~A}$ & $0,55 \mathrm{C}$ & $2,76 \mathrm{AB}$ & $4,69 \mathrm{~A}$ & $0,32 \mathrm{C}$ \\
\hline LA-3 & $1,13 \mathrm{~B}$ & $3,59 \mathrm{~A}$ & $0,96 \mathrm{~B}$ & $3,34 \mathrm{~A}$ & $5,10 \mathrm{~A}$ & $0,27 \mathrm{C}$ \\
\hline TR-1 & $0,08 \mathrm{CD}$ & $1,38 \mathrm{~A}$ & $0,30 \mathrm{BC}$ & $1,32 \mathrm{~A}$ & $0,91 \mathrm{AB}$ & $0,04 \mathrm{D}$ \\
\hline LA-4 & $0,68 \mathrm{~B}$ & $2,98 \mathrm{~A}$ & $0,49 \mathrm{BC}$ & $0,14 \mathrm{CD}$ & $4,71 \mathrm{~A}$ & $0,06 \mathrm{D}$ \\
\hline PV-2 & $1,14 \mathrm{~B}$ & $3,58 \mathrm{~A}$ & $1,07 \mathrm{~B}$ & $3,03 \mathrm{~A}$ & $4,43 \mathrm{~A}$ & $0,32 \mathrm{C}$ \\
\hline LA -5 & $1,40 \mathrm{~B}$ & $3,79 \mathrm{~A}$ & $1,33 \mathrm{~B}$ & $4,91 \mathrm{~A}$ & $3,38 \mathrm{~A}$ & $0,58 \mathrm{~B}$ \\
\hline PV -3 & $0,66 \mathrm{BC}$ & $2,38 \mathrm{~A}$ & $0,52 \mathrm{C}$ & $1,68 \mathrm{AB}$ & $1,69 \mathrm{~A}$ & $0,09 \mathrm{D}$ \\
\hline $\mathrm{LRa}$ & $0,67 \mathrm{~B}$ & $2,70 \mathrm{~A}$ & $0,42 \mathrm{BC}$ & $1,96 \mathrm{~A}$ & $1,72 \mathrm{~A}$ & $0,10 \mathrm{C}$ \\
\hline LE-3 & $2,86 \mathrm{AB}$ & $4,49 \mathrm{~A}$ & $2,13 \mathrm{BC}$ & $3,22 \mathrm{AB}$ & $4,16 \mathrm{AB}$ & $1,21 \mathrm{C}$ \\
\hline $\mathrm{PE}$ & $0,36 \mathrm{BC}$ & $1,43 \mathrm{~A}$ & $0,41 \mathrm{BC}$ & $1,02 \mathrm{AB}$ & $1,95 \mathrm{~A}$ & $0,11 \mathrm{C}$ \\
\hline PV -4 & $0,67 \mathrm{~B}$ & $4,10 \mathrm{~A}$ & $0,20 \mathrm{~B}$ & $3,13 \mathrm{~A}$ & $2,18 \mathrm{~A}$ & $0,28 \mathrm{~B}$ \\
\hline TR-2 & $0,69 \mathrm{CD}$ & $1,22 \mathrm{BC}$ & $0,80 \mathrm{C}$ & $2,81 \mathrm{~A}$ & $2,28 \mathrm{AB}$ & $0,23 \mathrm{D}$ \\
\hline AQa & $0,95 \mathrm{C}$ & $3,32 \mathrm{AB}$ & $0,92 \mathrm{C}$ & $2,49 \mathrm{~B}$ & $5,57 \mathrm{~A}$ & $0,22 \mathrm{D}$ \\
\hline LV-1 & $1,75 \mathrm{AB}$ & $3,29 \mathrm{~A}$ & $0,85 \mathrm{BC}$ & $2,77 \mathrm{~A}$ & $2,82 \mathrm{~A}$ & $0,31 \mathrm{C}$ \\
\hline \multirow{3}{*}{$\begin{array}{c}\text { Solos } \\
\text { alcalinos }\end{array}$} & \multicolumn{4}{|c|}{ Composto de resíduo urbano } & \multirow{3}{*}{$\begin{array}{c}\text { Gessagem } \\
\text { e } \\
\text { adubação }\end{array}$} & \multirow{3}{*}{ Testemunha } \\
\hline & \multicolumn{2}{|c|}{ sem gessagem } & \multicolumn{2}{|c|}{ com gessagem } & & \\
\hline & sem adubação & com adubação & sem adubação & com adubação & & \\
\hline & $\ldots$ & . n.................. & $\mathrm{mg} / \mathrm{p}$ & lanta -........... & - & - \\
\hline $\mathrm{CL}$ & $0,10 \mathrm{~B}$ & $1,45 \mathrm{~A}$ & $0,86 \mathrm{~A}$ & $1,98 \mathrm{~A}$ & $2,07 \mathrm{~A}$ & $0,10 \mathrm{~B}$ \\
\hline $\mathrm{CV}$ & $0,11 \mathrm{~B}$ & $0,61 \mathrm{~A}$ & $0,09 \mathrm{~B}$ & $0,65 \mathrm{~A}$ & $1,08 \mathrm{~A}$ & $0,06 \mathrm{~B}$ \\
\hline LA- 6 & $0,40 \mathrm{~B}$ & $1,61 \mathrm{~A}$ & $0,05 \mathrm{C}$ & $0,69 \mathrm{AB}$ & $1,53 \mathrm{~A}$ & $0,44 \mathrm{~B}$ \\
\hline $\mathrm{LV}-2$ & $0,47 \mathrm{~B}$ & $0,86 \mathrm{AB}$ & $0,05 \mathrm{D}$ & $0,08 \mathrm{D}$ & $1,40 \mathrm{~A}$ & $0,18 \mathrm{C}$ \\
\hline SS & $0,07 \mathrm{AB}$ & $0,09 \mathrm{~A}$ & $0,07 \mathrm{AB}$ & $0,08 \mathrm{~A}$ & $0,11 \mathrm{~A}$ & $0,03 \mathrm{C}$ \\
\hline
\end{tabular}

\$-Médias seguidas de mesma letra, nas colunas, não diferem entre si pelo teste de Tukey ao nível de 5\%. 
Tabela 53. Absorção de enxofre pela parte aérea da cultura de arroz em solos adubados com composto de resíduo urbano.

\begin{tabular}{|c|c|c|c|c|c|c|}
\hline \multirow{3}{*}{$\begin{array}{l}\text { Solos } \\
\text { ácidos }\end{array}$} & \multicolumn{4}{|c|}{ Composto de resíduo urbano } & \multirow{3}{*}{$\begin{array}{c}\text { Calagem } \\
\mathrm{e} \\
\text { adubação }\end{array}$} & \multirow{3}{*}{ Testemunha } \\
\hline & \multicolumn{2}{|c|}{ sem calagem } & \multicolumn{2}{|c|}{ com calagem } & & \\
\hline & sem adubação & com adubação & sem adubação & com adubação & & \\
\hline & \multicolumn{6}{|c|}{ mg/planta -..... - } \\
\hline GPH & $2,12 \mathrm{~B}^{\ddagger}$ & $4,78 \mathrm{~A}$ & $2,38 \mathrm{AB}$ & $4,59 \mathrm{~A}$ & $2,44 \mathrm{AB}$ & $2,02 \mathrm{~B}$ \\
\hline AQd & $0,69 \mathrm{BC}$ & $1,55 \mathrm{ABC}$ & $0,91 \mathrm{BC}$ & $1,73 \mathrm{AB}$ & $2,97 \mathrm{~A}$ & $0,52 \mathrm{C}$ \\
\hline LUa & $2,48 \mathrm{~B}$ & $9,09 \mathrm{~A}$ & $0,10 \mathrm{C}$ & $4,96 \mathrm{~B}$ & $4,29 \mathrm{~B}$ & $0,33 \mathrm{C}$ \\
\hline LE-1 & $2,04 \mathrm{AB}$ & $1,81 \mathrm{AB}$ & $0,87 \mathrm{BC}$ & $3,63 \mathrm{~A}$ & $3,37 \mathrm{~A}$ & $0,20 \mathrm{C}$ \\
\hline LE-2 & $0,60 \mathrm{~B}$ & $3,76 \mathrm{~A}$ & $0,22 \mathrm{~B}$ & $0,20 \mathrm{~B}$ & $1,88 \mathrm{~A}$ & $0,18 \mathrm{~B}$ \\
\hline LA-1 & $0,72 \mathrm{DE}$ & $2,53 \mathrm{BC}$ & $0,21 \mathrm{E}$ & $4,40 \mathrm{AB}$ & $5,39 \mathrm{~A}$ & $1,69 \mathrm{CD}$ \\
\hline PV-1 & $3,06 \mathrm{~A}$ & $0,24 \mathrm{~B}$ & $0,53 \mathrm{~B}$ & $2,83 \mathrm{~A}$ & $5,26 \mathrm{~A}$ & $0,66 \mathrm{~B}$ \\
\hline LA-2 & $3,84 \mathrm{ABC}$ & $5,82 \mathrm{~A}$ & $2,04 \mathrm{C}$ & $4,38 \mathrm{AB}$ & $4,57 \mathrm{~A}$ & $2,14 \mathrm{BC}$ \\
\hline LA-3 & $1,99 \mathrm{BC}$ & $4,31 \mathrm{~A}$ & $1,51 \mathrm{C}$ & $4,12 \mathrm{AB}$ & $4,74 \mathrm{~A}$ & $1,08 \mathrm{C}$ \\
\hline TR-1 & $0,07 \mathrm{C}$ & $2,29 \mathrm{~A}$ & $0,46 \mathrm{BC}$ & $2,24 \cdot \mathrm{A}$ & $1,20 \mathrm{AB}$ & $0,11 \mathrm{C}$ \\
\hline LA-4 & $1,27 \mathrm{~B}$ & $3,69 \mathrm{~A}$ & $1,18 \mathrm{~B}$ & $0,25 \mathrm{C}$ & $4,57 \mathrm{~A}$ & $0,09 \mathrm{C}$ \\
\hline PV-2 & $2,89 \mathrm{BC}$ & $3,96 \mathrm{AB}$ & $2,03 \mathrm{BC}$ & $4,24 \mathrm{AB}$ & $5,75 \mathrm{~A}$ & $1,32 \mathrm{C}$ \\
\hline LA-5 & $2,81 \mathrm{CD}$ & $6,41 \mathrm{~A}$ & $3,18 \mathrm{BC}$ & $6,04 \mathrm{AB}$ & $5,31 \mathrm{ABC}$ & $1,28 \mathrm{D}$ \\
\hline PV-3 & $1,11 \mathrm{CD}$ & $3,88 \mathrm{~A}$ & $1,30 \mathrm{BC}$ & $4,11 \mathrm{~A}$ & $3,06 \mathrm{AB}$ & $0,31 \mathrm{D}$ \\
\hline $\mathrm{LRa}$ & $0,79 \mathrm{~B}$ & $3,85 \mathrm{~A}$ & $0,80 \mathrm{~B}$ & $4,40 \mathrm{~A}$ & $2,43 \mathrm{~A}$ & $0,27 \mathrm{~B}$ \\
\hline LE-3 & $2,51 \mathrm{AB}$ & $3,99 \mathrm{~A}$ & $1,86 \mathrm{AB}$ & $3,64 \mathrm{AB}$ & $3,18 \mathrm{AB}$ & $1,63 \mathrm{~B}$ \\
\hline $\mathrm{PE}$ & $0,67 \mathrm{BC}$ & $2,12 \mathrm{~A}$ & $0,72 \mathrm{BC}$ & $1,59 \mathrm{AB}$ & $2,70 \mathrm{~A}$ & $0,36 \mathrm{C}$ \\
\hline $\mathrm{PV}-4$ & $1,07 \mathrm{BC}$ & $4,29 \mathrm{~A}$ & $0,40 \mathrm{C}$ & $4,27 \mathrm{~A}$ & $2,45 \mathrm{AB}$ & $0,90 \mathrm{C}$ \\
\hline TR-2 & $1,50 \mathrm{CD}$ & $2,39 \mathrm{ABC}$ & $1,96 \mathrm{BCD}$ & $4,85 \mathrm{~A}$ & $3,95 \mathrm{AB}$ & $0,87 \mathrm{D}$ \\
\hline AQa & $1,73 \mathrm{BC}$ & $4,18 \mathrm{~A}$ & $1,62 \mathrm{BC}$ & $3,50 \mathrm{AB}$ & $3,61 \mathrm{AB}$ & $0,60 \mathrm{C}$ \\
\hline LV-1 & $2,34 \mathrm{AB}$ & $4,51 \mathrm{~A}$ & $1,25 \mathrm{~B}$ & $3,86 \mathrm{~A}$ & $3,94 \mathrm{~A}$ & $1,33 \mathrm{~B}$ \\
\hline \multirow{3}{*}{$\begin{array}{c}\text { Solos } \\
\text { alcalinos }\end{array}$} & \multicolumn{4}{|c|}{ Composto de resíduo urbano } & \multirow{3}{*}{$\begin{array}{c}\text { Gessagem } \\
\text { e } \\
\text { adubação }\end{array}$} & \multirow{3}{*}{ Testemunha } \\
\hline & \multicolumn{2}{|c|}{ sem gessagem } & \multicolumn{2}{|c|}{ com gessagem } & & \\
\hline & sem adubação & com adubação & sem adubação & com adubação & & \\
\hline & -.............. & - & $\mathrm{mg} / \mathrm{p}$ & lanta & - n. & - \\
\hline $\mathrm{CL}$ & $0,08 \mathrm{C}$ & $2,39 \mathrm{AB}$ & $1,10 \mathrm{~B}$ & $3,01 \mathrm{~A}$ & $1,92 \mathrm{AB}$ & $0,08 \mathrm{C}$ \\
\hline $\mathrm{CV}$ & $0,41 \mathrm{~B}$ & $1,30 \mathrm{~A}$ & $0,26 \mathrm{BC}$ & $1,38 \mathrm{~A}$ & $2,40 \mathrm{~A}$ & $0,11 \mathrm{C}$ \\
\hline LA-6 & $0,78 \mathrm{BC}$ & $3,00 \mathrm{~A}$ & $0,06 \mathrm{D}$ & $1,88 \mathrm{AB}$ & $3,14 \mathrm{~A}$ & $0,54 \mathrm{C}$ \\
\hline LV-2 & $0,76 \mathrm{BC}$ & $1,73 \mathrm{AB}$ & $0,48 \mathrm{CD}$ & $0,16 \mathrm{D}$ & $3,27 \mathrm{~A}$ & $0,24 \mathrm{D}$ \\
\hline SS & $0,32 \mathrm{AB}$ & $0,42 \mathrm{~A}$ & $0,33 \mathrm{~A}$ & $0,45 \mathrm{~A}$ & $0,76 \mathrm{~A}$ & $0,11 \mathrm{~B}$ \\
\hline
\end{tabular}

$\ddagger$ - Médias seguidas de mesma letra, nas colunas, não diferem entre si pelo teste de Tukey ao nível de $5 \%$. 
Tabela 54. Absorção de potássio pela parte aérea da cultura de arroz em solos adubados com composto de resíduo urbano.

\begin{tabular}{|c|c|c|c|c|c|c|}
\hline \multirow{3}{*}{$\begin{array}{l}\text { Solos } \\
\text { ácidos }\end{array}$} & \multicolumn{4}{|c|}{ Composto de resíduo urbano } & \multirow{3}{*}{$\begin{array}{c}\text { Calagem } \\
e \\
\text { adubação }\end{array}$} & \multirow{3}{*}{ Testemunha } \\
\hline & \multicolumn{2}{|c|}{ sem calagem } & \multicolumn{2}{|c|}{ com calagem } & & \\
\hline & sem adubação & com adubação & sem adubação & com adubação & & \\
\hline & \multicolumn{6}{|c|}{ …- mg/planta - } \\
\hline GPH & $28,00 \mathrm{~B}^{\ddagger}$ & $46,37 \mathrm{~A}$ & $31,53 \mathrm{AB}$ & $46,86 \mathrm{~A}$ & $18,83 \mathrm{~B}$ & $25,26 \mathrm{~B}$ \\
\hline AQd & $9,73 \mathrm{AB}$ & $13,27 \mathrm{AB}$ & $13,87 \mathrm{AB}$ & $10,26 \mathrm{AB}$ & $18,52 \mathrm{~A}$ & $5,42 \mathrm{~B}$ \\
\hline LUa & $24,02 \mathrm{AB}$ & $38,36 \mathrm{~A}$ & $0,03 \mathrm{C}$ & $38,67 \mathrm{~A}$ & $10,30 \mathrm{BC}$ & $2,64 \mathrm{C}$ \\
\hline LE-1 & $21,37 \mathrm{AB}$ & $14,40 \mathrm{BC}$ & $10,18 \mathrm{BC}$ & $32,12 \mathrm{~A}$ & $23,30 \mathrm{AB}$ & $4,61 \mathrm{C}$ \\
\hline LE-2 & 5,72 B & $29,89 \mathrm{~A}$ & $0,76 \mathrm{~B}$ & $0,90 \mathrm{~B}$ & $9,23 \mathrm{~B}$ & $1,86 \mathrm{~B}$ \\
\hline LA-1 & $7,85 \mathrm{CD}$ & $21,50 \mathrm{AB}$ & $1,71 \mathrm{CD}$ & $36,09 \mathrm{~A}$ & $12,49 \mathrm{BC}$ & $0,54 \mathrm{D}$ \\
\hline PV -1 & $24,63 \mathrm{~A}$ & $1,89 \mathrm{C}$ & $7,21 \mathrm{BC}$ & $19,33 \mathrm{AB}$ & $7,86 \mathrm{BC}$ & $2,16 \mathrm{C}$ \\
\hline LA-2 & $25,25 \mathrm{BC}$ & $42,07 \mathrm{~A}$ & $9,85 \mathrm{D}$ & $29,22 \mathrm{AB}$ & $12,22 \mathrm{CD}$ & $2,19 \mathrm{D}$ \\
\hline LA-3 & $24,39 \mathrm{AB}$ & $39,58 \mathrm{~A}$ & $20,06 \mathrm{BC}$ & $30,89 \mathrm{AB}$ & $17,82 \mathrm{BC}$ & $7,26 \mathrm{C}$ \\
\hline TR-1 & $0,62 \mathrm{C}$ & $20,59 \mathrm{AB}$ & $6,26 \mathrm{C}$ & $31,83 \mathrm{~A}$ & $9,99 \mathrm{BC}$ & $1,68 \mathrm{C}$ \\
\hline LA-4 & $19,45 \mathrm{~B}$ & $38,38 \mathrm{~A}$ & $16,26 \mathrm{~B}$ & $0,93 \mathrm{C}$ & $26,08 \mathrm{AB}$ & $0,93 \mathrm{C}$ \\
\hline PV -2 & $29,68 \mathrm{ABC}$ & $40,82 \mathrm{~A}$ & $23,99 \mathrm{BC}$ & $39,60 \mathrm{AB}$ & $21,00 \mathrm{C}$ & $5,98 \mathrm{D}$ \\
\hline LA-5 & $33,03 \mathrm{~B}$ & $39,17 \mathrm{AB}$ & $36,49 \mathrm{AB}$ & $53,14 \mathrm{~A}$ & $36,61 \mathrm{AB}$ & $10,15 \mathrm{C}$ \\
\hline PV -3 & $16,04 \mathrm{BC}$ & $38,04 \mathrm{~A}$ & $15,63 \mathrm{BC}$ & $40,82 \mathrm{~A}$ & $20,26 \mathrm{~B}$ & $4,16 \mathrm{C}$ \\
\hline $\mathrm{LRa}$ & $12,09 \mathrm{~B}$ & $35,01 \mathrm{~A}$ & $11,41 \mathrm{~B}$ & $32,44 \mathrm{~A}$ & 14,42 B & $3,47 \mathrm{~B}$ \\
\hline LE-3 & $25,63 \mathrm{BC}$ & $46,60 \mathrm{~A}$ & $25,63 \mathrm{BC}$ & $36,01 \mathrm{AB}$ & $32,69 \mathrm{AB}$ & $14,74 \mathrm{C}$ \\
\hline $\mathrm{PE}$ & $7,63 \mathrm{AB}$ & $18,11 \mathrm{~A}$ & $9,31 \mathrm{AB}$ & $14,25 \mathrm{AB}$ & $16,85 \mathrm{~A}$ & $2,50 \mathrm{~B}$ \\
\hline $\mathrm{PV}-4$ & $13,59 \mathrm{~B}$ & $37,05 \mathrm{~A}$ & $6,98 \mathrm{~B}$ & $34,92 \mathrm{~A}$ & $10,08 \mathrm{~B}$ & $1,90 \mathrm{~B}$ \\
\hline TR-2 & $18,35 \mathrm{BC}$ & $18,80 \mathrm{BC}$ & 23,98 B & $41,80 \mathrm{~A}$ & $32,23 \mathrm{AB}$ & $9,12 \mathrm{C}$ \\
\hline $\mathrm{AQa}$ & $15,75 \mathrm{~B}$ & $36,81 \mathrm{~A}$ & $21,74 \mathrm{AB}$ & $32,80 \mathrm{~A}$ & $13,60 \mathrm{BC}$ & $2,39 \mathrm{C}$ \\
\hline LV-1 & $24,30 \mathrm{AB}$ & $40,16 \mathrm{~A}$ & $16,96 \mathrm{BC}$ & $34,04 \mathrm{~A}$ & $16,59 \mathrm{BC}$ & $6,37 \mathrm{C}$ \\
\hline \multirow{3}{*}{$\begin{array}{c}\text { Solos } \\
\text { alcalinos }\end{array}$} & \multicolumn{4}{|c|}{ Composto de resíduo urbano } & \multirow{3}{*}{$\begin{array}{c}\text { Gessagem } \\
\mathrm{e} \\
\text { adubação }\end{array}$} & \multirow{3}{*}{ Testemunha } \\
\hline & \multicolumn{2}{|c|}{ sem gessagem } & \multicolumn{2}{|c|}{ com gessagem } & & \\
\hline & sem adubação & com adubação & sem adubação & com adubação & & \\
\hline & & 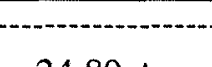 & - 119 & 500 & 1710 & $3 \mathrm{~B}$ \\
\hline $\mathrm{CL}$ & $0,82 \mathrm{~B}$ & $24,89 \mathrm{~A}$ & $13,52 \mathrm{~A}$ & $35,32 \mathrm{~A}$ & $17,19 \mathrm{~A}$ & $0,93 \mathrm{~B}$ \\
\hline $\mathrm{CV}$ & 4,45 BCD & $8,14 \mathrm{ABC}$ & $1,93 \mathrm{CD}$ & $13,11 \mathrm{AB}$ & $21,74 \mathrm{~A}$ & $1,24 \mathrm{D}$ \\
\hline LA-6 & $12,20 \mathrm{~B}$ & $42,82 \mathrm{~A}$ & $0,51 \mathrm{C}$ & $10,22 \mathrm{~B}$ & $16,36 \mathrm{AB}$ & $13,23 \mathrm{AB}$ \\
\hline LV-2 & $10,27 \mathrm{AB}$ & $15,88 \mathrm{~A}$ & $0,05 \mathrm{D}$ & $0,70 \mathrm{C}$ & $24,89 \mathrm{~A}$ & $3,78 \mathrm{~B}$ \\
\hline SS & $0,80 \mathrm{~A}$ & $0,52 \mathrm{~A}$ & $0,55 \mathrm{~A}$ & $0,40 \mathrm{AB}$ & $0,71 \mathrm{~A}$ & $0,06 \mathrm{~B}$ \\
\hline
\end{tabular}

$\ddagger$ - Médias seguidas de mesma letra, nas colunas, não diferem entre si pelo teste de Tukey ao nível de $5 \%$. 
Tabela 55. Absorção de cálcio pela parte aérea da cultura de arroz em solos adubados com composto de resíduo urbano.

\begin{tabular}{|c|c|c|c|c|c|c|}
\hline \multirow{3}{*}{$\begin{array}{l}\text { Solos } \\
\text { ácidos }\end{array}$} & \multicolumn{4}{|c|}{ Composto de resíduo urbano } & \multirow{3}{*}{$\begin{array}{c}\text { Calagem } \\
\text { e } \\
\text { adubação }\end{array}$} & \multirow{3}{*}{ Testemunha } \\
\hline & \multicolumn{2}{|c|}{ sem calagem } & \multicolumn{2}{|c|}{ com calagem } & & \\
\hline & sem adubaçāo & com adubação & sem adubação & com adubação & & \\
\hline & 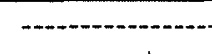 & - & $\mathrm{mg} / \mathrm{p}$ & anta -........... & (1) & - \\
\hline GPH & $3,61 \mathrm{~B}^{\ddagger}$ & $7,04 \mathrm{AB}$ & $4,76 \mathrm{AB}$ & $7,55 \mathrm{~A}$ & $3,96 \mathrm{AB}$ & $4,51 \mathrm{AB}$ \\
\hline AQd & $1,60 \mathrm{~B}$ & $2,51 \mathrm{~B}$ & $2,01 \mathrm{~B}$ & $2,73 \mathrm{~B}$ & $7,21 \mathrm{~A}$ & $1,75 \mathrm{~B}$ \\
\hline LUa & $4,27 \mathrm{~B}$ & $7,46 \mathrm{AB}$ & $0,32 \mathrm{C}$ & $8,51 \mathrm{~A}$ & $9,50 \mathrm{~A}$ & $0,41 \mathrm{C}$ \\
\hline LE-1 & $2,94 \mathrm{AB}$ & $2,22 \mathrm{ABC}$ & $1,39 \mathrm{BC}$ & $4,80 \mathrm{~A}$ & $5,06 \mathrm{~A}$ & $0,64 \mathrm{C}$ \\
\hline LE-2 & $1,06 \mathrm{~B}$ & $6,34 \mathrm{~A}$ & $0,57 \mathrm{~B}$ & $0,52 \mathrm{~B}$ & $3,73 \mathrm{~A}$ & $0,21 \mathrm{~B}$ \\
\hline LA-1 & $1,89 \mathrm{CD}$ & $4,03 \mathrm{BC}$ & $0,31 \mathrm{E}$ & $8,02 \mathrm{AB}$ & $8,96 \mathrm{~A}$ & $1,54 \mathrm{D}$ \\
\hline PV-1 & $5,80 \mathrm{AB}$ & $0,55 \mathrm{C}$ & $0,97 \mathrm{C}$ & $5,64 \mathrm{~B}$ & $10,51 \mathrm{~A}$ & $1,13 \mathrm{C}$ \\
\hline LA-2 & $6,63 \mathrm{~A}$ & $7,51 \mathrm{~A}$ & $2,88 \mathrm{~B}$ & $6,75 \mathrm{~A}$ & $8,08 \mathrm{~A}$ & $1,39 \mathrm{~B}$ \\
\hline LA-3 & $3,74 \mathrm{BC}$ & $6,88 \mathrm{AB}$ & $2,94 \mathrm{C}$ & $7,10 \mathrm{AB}$ & $8,55 \mathrm{~A}$ & $2,10 \mathrm{C}$ \\
\hline TR-1 & $0,12 \mathrm{D}$ & $3,57 \mathrm{~A}$ & $1,06 \mathrm{BC}$ & $3,83 \mathrm{~A}$ & $3,14 \mathrm{AB}$ & $0,27 \mathrm{CD}$ \\
\hline LA-4 & $2,82 \mathrm{~B}$ & $7,32 \mathrm{~A}$ & $2,37 \mathrm{~B}$ & $0,36 \mathrm{C}$ & $8,53 \mathrm{~A}$ & $0,23 \mathrm{C}$ \\
\hline PV-2 & $5,94 \mathrm{~A}$ & $7,36 \mathrm{~A}$ & $4,19 \mathrm{AB}$ & $7,32 \mathrm{~A}$ & $5,98 \mathrm{~A}$ & $1,82 \mathrm{~B}$ \\
\hline LA-5 & $4,48 \mathrm{~B}$ & $7,84 \mathrm{AB}$ & $5,13 \mathrm{AB}$ & $9,18 \mathrm{~A}$ & $6,20 \mathrm{AB}$ & $1,56 \mathrm{C}$ \\
\hline PV -3 & $2,34 \mathrm{~B}$ & $6,85 \mathrm{~A}$ & $2,50 \mathrm{~B}$ & $7,07 \mathrm{~A}$ & $4,80 \mathrm{AB}$ & $0,62 \mathrm{C}$ \\
\hline $\mathrm{LRa}$ & $1,71 \mathrm{~B}$ & $7,66 \mathrm{~A}$ & $1,68 \mathrm{~B}$ & $6,58 \mathrm{~A}$ & $5,59 \mathrm{~A}$ & $0,59 \mathrm{~B}$ \\
\hline LE-3 & $3,76 \mathrm{AB}$ & $6,79 \mathrm{~A}$ & $4,10 \mathrm{AB}$ & $6,54 \mathrm{~A}$ & $6,49 \mathrm{~A}$ & $1,94 \mathrm{~B}$ \\
\hline $\mathrm{PE}$ & $1,44 \mathrm{BC}$ & $4,54 \mathrm{~A}$ & $2,01 \mathrm{ABC}$ & $3,53 \mathrm{AB}$ & $4,61 \mathrm{~A}$ & $1,06 \mathrm{C}$ \\
\hline PV -4 & $2,38 \mathrm{BC}$ & $8,74 \mathrm{~A}$ & $1,09 \mathrm{C}$ & $8,13 \mathrm{~A}$ & $5,05 \mathrm{AB}$ & $1,50 \mathrm{C}$ \\
\hline TR-2 & $2,41 \mathrm{CD}$ & $4,29 \mathrm{ABC}$ & $2,81 \mathrm{BCD}$ & $6,57 \mathrm{~A}$ & $6,00 \mathrm{AB}$ & $1,56 \mathrm{D}$ \\
\hline $\mathrm{AQa}$ & $3,45 \mathrm{~B}$ & $6,65 \mathrm{AB}$ & $3,41 \mathrm{~B}$ & $6,08 \mathrm{AB}$ & $7,19 \mathrm{~A}$ & $0,96 \mathrm{C}$ \\
\hline LV-1 & $4,31 \mathrm{AB}$ & $6,75 \mathrm{~A}$ & $2,42 \mathrm{BC}$ & $6,92 \mathrm{~A}$ & $7,23 \mathrm{~A}$ & $1,65 \mathrm{C}$ \\
\hline \multirow{3}{*}{$\begin{array}{l}\text { Solos } \\
\text { alcalinos }\end{array}$} & \multicolumn{4}{|c|}{ Composto de resíduo urbano } & \multirow{3}{*}{$\begin{array}{c}\text { Gessagem } \\
\mathrm{e} \\
\text { adubação }\end{array}$} & \multirow{3}{*}{ Testemunha } \\
\hline & \multicolumn{2}{|c|}{ sem gessagem } & \multicolumn{2}{|c|}{ com gessagem } & & \\
\hline & sem adubação & com adubação & sem adubação & com adubação & & \\
\hline & -..n-n. & - & $\mathrm{mg} / \mathrm{F}$ & anta & (n) & - \\
\hline $\mathrm{CL}$ & $0,19 \mathrm{~B}$ & $4,63 \mathrm{~A}$ & $2,48 \mathrm{~A}$ & $6,02 \mathrm{~A}$ & $3,35 \mathrm{~A}$ & $0,15 \mathrm{~B}$ \\
\hline $\mathrm{CV}$ & $1,36 \mathrm{BC}$ & $3,12 \mathrm{AB}$ & $0,87 \mathrm{CD}$ & $4,09 \mathrm{~A}$ & $6,39 \mathrm{~A}$ & $0,53 \mathrm{D}$ \\
\hline LA-6 & $1,65 \mathrm{~B}$ & $6,62 \mathrm{~A}$ & $0,27 \mathrm{C}$ & $3,15 \mathrm{AB}$ & $4,31 \mathrm{AB}$ & $1,66 \mathrm{~B}$ \\
\hline LV-2 & $1,64 \mathrm{~B}$ & $2,80 \mathrm{AB}$ & $0,50 \mathrm{C}$ & $0,29 \mathrm{C}$ & $4,96 \mathrm{~A}$ & $0,51 \mathrm{C}$ \\
\hline SS & $0,24 \mathrm{AB}$ & $0,33 \mathrm{~A}$ & $0,23 \mathrm{AB}$ & $0,36 \mathrm{~A}$ & $0,32 \mathrm{~A}$ & $0,13 \mathrm{~B}$ \\
\hline
\end{tabular}

$\$$-Médias seguidas de mesma letra, nas colunas, não diferem entre si pelo teste de Tukey ao nível de $5 \%$. 
Tabela 56. Absorção de magnésio pela parte aérea da cultura de arroz em solos adubados com composto de resíduo urbano.

\begin{tabular}{|c|c|c|c|c|c|c|}
\hline \multirow{3}{*}{$\begin{array}{l}\text { Solos } \\
\text { ácidos }\end{array}$} & \multicolumn{4}{|c|}{ Composto de resíduo urbano } & \multirow{3}{*}{$\begin{array}{c}\text { Calagem } \\
\mathrm{e} \\
\text { adubação }\end{array}$} & \multirow{3}{*}{ Testemunha } \\
\hline & \multicolumn{2}{|c|}{ sem calagem } & \multicolumn{2}{|c|}{ com calagem } & & \\
\hline & sem adubação & com adubação & sem adubação & com adubação & & \\
\hline & \multicolumn{6}{|c|}{ - mplanta - } \\
\hline GPH & $3,18 \mathrm{~A}^{\ddagger}$ & $6,11 \mathrm{~A}$ & $4,19 \mathrm{~A}$ & $6,30 \mathrm{~A}$ & $3,79 \mathrm{~A}$ & $4,08 \mathrm{~A}$ \\
\hline AQd & $1,73 \mathrm{~B}$ & $2,14 \mathrm{~B}$ & $2,22 \mathrm{~B}$ & $2,05 \mathrm{~B}$ & $6,66 \mathrm{~A}$ & $2,09 \mathrm{~B}$ \\
\hline LUa & $3,86 \mathrm{~B}$ & $7,43 \mathrm{AB}$ & $0,07 \mathrm{C}$ & $9,84 \mathrm{~A}$ & $11,88 \mathrm{~A}$ & $0,25 \mathrm{C}$ \\
\hline LE-1 & $3,39 \mathrm{AB}$ & $2,15 \mathrm{ABC}$ & $1,29 \mathrm{BC}$ & $4,16 \mathrm{~A}$ & $5,09 \mathrm{~A}$ & $0,62 \mathrm{C}$ \\
\hline LE-2 & $0,65 \mathrm{~B}$ & $5,29 \mathrm{~A}$ & $0,25 \mathrm{~B}$ & $0,20 \mathrm{~B}$ & $4,29 \mathrm{~A}$ & $0,14 \mathrm{~B}$ \\
\hline LA-1 & $1,32 \mathrm{BC}$ & $3,24 \mathrm{~B}$ & $0,23 \mathrm{C}$ & $7,96 \mathrm{~A}$ & $11,43 \mathrm{~A}$ & $2,20 \mathrm{~B}$ \\
\hline PV-1 & $5,80 \mathrm{AB}$ & $0,28 \mathrm{C}$ & $0,74 \mathrm{C}$ & $4,27 \mathrm{~B}$ & $10,61 \mathrm{~A}$ & $0,86 \mathrm{C}$ \\
\hline LA-2 & $9,07 \mathrm{~A}$ & $10,84 \mathrm{~A}$ & $2,69 \mathrm{~B}$ & $7,23 \mathrm{~A}$ & 10,25 & $2,19 \mathrm{~B}$ \\
\hline LA-3 & $3,80 \mathrm{BC}$ & $6,10 \mathrm{AB}$ & $2,96 \mathrm{BC}$ & $6,13 \mathrm{AB}$ & $8,34 \mathrm{~A}$ & $1,82 \mathrm{C}$ \\
\hline TR-1 & $0,08 \mathrm{~B}$ & $3,26 \mathrm{~A}$ & $0,74 \mathrm{~B}$ & $3,63 \mathrm{~A}$ & $3,08 \mathrm{~A}$ & $0,20 \mathrm{~B}$ \\
\hline $\mathrm{LA}-4$ & $2,20 \mathrm{BC}$ & $5,35 \mathrm{AB}$ & $1,86 \mathrm{C}$ & $0,11 \mathrm{D}$ & $7,18 \mathrm{~A}$ & $0,10 \mathrm{D}$ \\
\hline PV -2 & $5,49 \mathrm{~A}$ & $6,53 \mathrm{~A}$ & $3,90 \mathrm{AB}$ & $6,60 \mathrm{~A}$ & $6,01 \mathrm{~A}$ & $1,43 \mathrm{~B}$ \\
\hline LA -5 & $3,88 \mathrm{BC}$ & $7,92 \mathrm{AB}$ & $4,81 \mathrm{AB}$ & $9,41 \mathrm{~A}$ & $6,44 \mathrm{AB}$ & $1,47 \mathrm{C}$ \\
\hline PV -3 & $2,11 \mathrm{C}$ & $5,59 \mathrm{AB}$ & $2,41 \mathrm{BC}$ & $6,48 \mathrm{~A}$ & $6,03 \mathrm{~A}$ & $0,35 \mathrm{D}$ \\
\hline $\mathrm{LRa}$ & $1,45 \mathrm{~B}$ & $6,08 \mathrm{~A}$ & $1,35 \mathrm{~B}$ & $6,29 \mathrm{~A}$ & $5,19 \mathrm{~A}$ & $0,56 \mathrm{~B}$ \\
\hline LE-3 & $4,72 \mathrm{AB}$ & $6,91 \mathrm{~A}$ & $4,98 \mathrm{AB}$ & $7,59 \mathrm{~A}$ & $7,75 \mathrm{~A}$ & $2,76 \mathrm{~B}$ \\
\hline $\mathrm{PE}$ & $1,02 \mathrm{C}$ & $3,52 \mathrm{AB}$ & $1,37 \mathrm{BC}$ & $2,49 \mathrm{ABC}$ & $5,41 \mathrm{~A}$ & $0,83 \mathrm{C}$ \\
\hline PV -4 & $1,78 \mathrm{BC}$ & $6,87 \mathrm{~A}$ & $0,71 \mathrm{C}$ & $7,37 \mathrm{~A}$ & $4,50 \mathrm{AB}$ & $1,61 \mathrm{C}$ \\
\hline TR-2 & $2,32 \mathrm{C}$ & $3,10 \mathrm{BC}$ & $2,98 \mathrm{BC}$ & $6,09 \mathrm{AB}$ & $7,25 \mathrm{~A}$ & $1,01 \mathrm{C}$ \\
\hline $\mathrm{AQa}$ & $3,15 \mathrm{~B}$ & $6,10 \mathrm{AB}$ & $3,80 \mathrm{AB}$ & $5,49 \mathrm{AB}$ & $7,40 \mathrm{~A}$ & $0,71 \mathrm{C}$ \\
\hline $\mathrm{LV}-1$ & $4,91 \mathrm{AB}$ & $7,42 \mathrm{~A}$ & $2,76 \mathrm{BC}$ & $8,36 \mathrm{~A}$ & $9,20 \mathrm{~A}$ & $1,69 \mathrm{C}$ \\
\hline \multirow{3}{*}{$\begin{array}{l}\text { Solos } \\
\text { alcalinos }\end{array}$} & \multicolumn{4}{|c|}{ Composto de resíduo urbano } & \multirow{3}{*}{$\begin{array}{c}\text { Gessagem } \\
e^{\text {adubação }}\end{array}$} & \multirow{3}{*}{ Testemunha } \\
\hline & \multicolumn{2}{|c|}{ sem gessagem } & \multicolumn{2}{|c|}{ com gessagem } & & \\
\hline & sem adubação & com adubação & sem adubação & com adubação & & \\
\hline & - & - & $\mathrm{mg} / \mathrm{f}$ & anta & .................... & - \\
\hline $\mathrm{CL}$ & $0,12 \mathrm{~B}$ & $2,85 \mathrm{~A}$ & $1,24 \mathrm{~A}$ & $3,39 \mathrm{~A}$ & $2,26 \mathrm{~A}$ & $0,10 \mathrm{~B}$ \\
\hline $\mathrm{CV}$ & $0,44 \mathrm{BC}$ & $1,44 \mathrm{AB}$ & $0,26 \mathrm{CD}$ & $1,60 \mathrm{~A}$ & $3,41 \mathrm{~A}$ & $0,12 \mathrm{D}$ \\
\hline LA-6 & $1,13 \mathrm{~B}$ & $4,14 \mathrm{~A}$ & $0,09 \mathrm{C}$ & $1,51 \mathrm{AB}$ & $2,67 \mathrm{AB}$ & $1,33 \mathrm{AB}$ \\
\hline LV-2 & $1,13 \mathrm{~A}$ & $1,94 \mathrm{~A}$ & $0,18 \mathrm{~B}$ & $0,12 \mathrm{~B}$ & $3,34 \mathrm{~A}$ & $0,34 \mathrm{~B}$ \\
\hline SS & $0,23 \mathrm{~A}$ & $0,29 \mathrm{~A}$ & $0,23 \mathrm{~A}$ & $0,24 \mathrm{~A}$ & $0,29 \mathrm{~A}$ & $0,11 \mathrm{~A}$ \\
\hline
\end{tabular}

†- Médias seguidas de mesma letra, nas colunas, não diferem entre si pelo teste de Tukey ao nível de $5 \%$. 


\subsubsection{Absorção de micronutrie ntes}

Os valores de absorção de boro, cobalto, cobre, ferro, manganês, molibdênio, níquel e zinco pelas plantas de arroz cultivadas em solos adubados com composto de resíduo urbano, na presença ou ausência de calcário e adubo, são apresentados nas Tabelas 58, 59, 60, 61, 62, 63, 64 e 65, respectivamente.

De modo semelhante ao que foi que foi verificado para os macronutrientes, dentre os tratamentos com composto, os tratamentos com composto + adubo, na presença ou ausência de calcário (nos solos ácidos), e os tratamentos com composto + adubo, na presença ou ausência de gesso (nos solos alcalinos) promoveram aumentos na absorção de B, Co, Fe, Mo, Ni e Zn, e não diferiram da calagem + adubação ou da gessagem + adubação, respectivamente. Observou-se que, no solo LA-5, houve uma absorção de Mn bem superior aos níveis considerados tóxicos à cultura do arroz.

A absorção de $M n$ apresentou um padrão distinto dos demais micronutrientes. Assim, diferentemente do que tem sido observado entre os modos de aplicação do composto, verificou-se que os tratamentos com composto e com composto + adubo causaram uma maior absorção de Mn pelas plantas de arroz. Porém, também não diferiram da aplicação de calcário + adubo. O tratamento com composto + calagem levou à diminuição da absorção de Mn nos solos GPH, LUa, LE-1, LA-1, PV-1, PV-2, LA-5, PV-4 e LV-1.

Nos solos alcalinos foi evidenciado um padrão diferente para cada solo. Assim, houve um aumento na absorção de Mn no solo CL devido ao composto + adubo e composto + gesso; no CL houve aumento em todos os tratamentos com composto; no LA-6 houve diminuição devido ao composto + gesso; no LA-2 houve aumento devido ao composto isoladamente; e no SS houve aumento devido ao composto e composto + gesso. Ressalva-se, porém que em todos os solos não houve diferença entre estes tratamentos e a aplicação de gesso + adubo. 
Tabela 57. Absorção de sódio pela parte aérea da cultura de arroz em solos adubados com composto de resíduo urbano.

\begin{tabular}{|c|c|c|c|c|c|c|}
\hline \multirow{3}{*}{$\begin{array}{l}\text { Solos } \\
\text { ácidos }\end{array}$} & \multicolumn{4}{|c|}{ Composto de resíduo urbano } & \multirow{3}{*}{$\begin{array}{l}\text { Calagem } \\
\mathrm{e} \\
\text { adubação }\end{array}$} & \multirow{3}{*}{ Testemunha } \\
\hline & \multicolumn{2}{|c|}{ sem calagem } & \multicolumn{2}{|c|}{ com calagem } & & \\
\hline & sem adubação & com adubação & sem adubação & com adubação & & \\
\hline & \multicolumn{6}{|c|}{ - mg/planta - } \\
\hline GPH & $0,39 \mathrm{~A}^{\ddagger}$ & $0,97 \mathrm{~A}$ & $0,72 \mathrm{~A}$ & $1,01 \mathrm{~A}$ & $0,45 \mathrm{~A}$ & $0,59 \mathrm{~A}$ \\
\hline AQd & $0,61 \mathrm{~A}$ & $0,36 \mathrm{~A}$ & $0,66 \mathrm{~A}$ & $0,65 \mathrm{~A}$ & $0,38 \mathrm{~A}$ & $0,23 \mathrm{~A}$ \\
\hline LUa & $1,57 \mathrm{~A}$ & $2,56 \mathrm{~A}$ & $0,04 \mathrm{~B}$ & $1,86 \mathrm{~A}$ & $0,97 \mathrm{~A}$ & $0,10 \mathrm{~B}$ \\
\hline LE-1 & $0,49 \mathrm{~A}$ & $0,38 \mathrm{AB}$ & $0,39 \mathrm{AB}$ & $0,83 \mathrm{~A}$ & $0,14 \mathrm{BC}$ & $0,08 \mathrm{C}$ \\
\hline LE-2 & $0,60 \mathrm{AB}$ & $1,29 \mathrm{~A}$ & $0,25 \mathrm{BC}$ & $0,21 \mathrm{BC}$ & $0,23 \mathrm{BC}$ & $0,09 \mathrm{C}$ \\
\hline LA-1 & $0,63 \mathrm{AB}$ & $0,93 \mathrm{~A}$ & $0,21 \mathrm{~B}$ & $1,62 \mathrm{~A}$ & $1,03 \mathrm{~A}$ & $1,15 \mathrm{~A}$ \\
\hline PV-1 & $2,44 \mathrm{~A}$ & $0,16 \mathrm{D}$ & $0,24 \mathrm{CD}$ & $0,69 \mathrm{BC}$ & $1,33 \mathrm{AB}$ & $0,19 \mathrm{D}$ \\
\hline LA-2 & $4,43 \mathrm{~A}$ & $1,84 \mathrm{AB}$ & $2,20 \mathrm{AB}$ & $1,23 \mathrm{~B}$ & $1,09 \mathrm{~B}$ & $1,31 \mathrm{~B}$ \\
\hline LA-3 & $0,74 \mathrm{~A}$ & $0,77 \mathrm{~A}$ & $0,83 \mathrm{~A}$ & $0,68 \mathrm{AB}$ & $0,72 \mathrm{AB}$ & $0,24 \mathrm{~B}$ \\
\hline TR-1 & $0,10 \mathrm{BC}$ & $0,38 \mathrm{~A}$ & $0,25 \mathrm{AB}$ & $0,50 \mathrm{~A}$ & $0,31 \mathrm{AB}$ & $0,03 \mathrm{C}$ \\
\hline LA -4 & $0,57 \mathrm{~A}$ & $0,63 \mathrm{~A}$ & $0,42 \mathrm{~A}$ & $0,23 \mathrm{~A}$ & $0,32 \mathrm{~A}$ & $0,05 \mathrm{~B}$ \\
\hline PV -2 & $0,57 \mathrm{AB}$ & $1,21 \mathrm{~A}$ & $0,52 \mathrm{AB}$ & $1,28 \mathrm{~A}$ & $0,59 \mathrm{AB}$ & $0,32 \mathrm{~B}$ \\
\hline LA-5 & $0,53 \mathrm{~A}$ & $0,73 \mathrm{~A}$ & $0,77 \mathrm{~A}$ & $1,21 \mathrm{~A}$ & $0,51 \mathrm{~A}$ & $0,15 \mathrm{~B}$ \\
\hline PV -3 & $0,57 \mathrm{AB}$ & $0,80 \mathrm{~A}$ & $0,42 \mathrm{AB}$ & $0,67 \mathrm{~A}$ & $0,18 \mathrm{~B}$ & $0,05 \mathrm{C}$ \\
\hline $\mathrm{LRa}$ & $0,36 \mathrm{~A}$ & $0,69 \mathrm{~A}$ & $0,44 \mathrm{~A}$ & $0,54 \mathrm{~A}$ & $0,33 \mathrm{~A}$ & $0,08 \mathrm{~B}$ \\
\hline LE-3 & $0,70 \mathrm{~A}$ & $0,82 \mathrm{~A}$ & $0,81 \mathrm{~A}$ & $0,94 \mathrm{~A}$ & $0,22 \mathrm{~B}$ & $0,04 \mathrm{C}$ \\
\hline $\mathrm{PE}$ & $0,50 \mathrm{ABC}$ & $1,27 \mathrm{~A}$ & $0,38 \mathrm{BC}$ & $0,71 \mathrm{AB}$ & $0,21 \mathrm{C}$ & $0,22 \mathrm{C}$ \\
\hline PV-4 & $0,61 \mathrm{AB}$ & $0,96 \mathrm{~A}$ & $0,26 \mathrm{~B}$ & $0,75 \mathrm{AB}$ & $0,37 \mathrm{AB}$ & $0,27 \mathrm{~B}$ \\
\hline TR-2 & $0,46 \mathrm{~A}$ & $1,05 \mathrm{~A}$ & $0,54 \mathrm{~A}$ & $0,82 \mathrm{~A}$ & $0,89 \mathrm{~A}$ & $0,10 \mathrm{~B}$ \\
\hline $\mathrm{AQa}$ & $0,73 \mathrm{~A}$ & $1,55 \mathrm{~A}$ & $0,97 \mathrm{~A}$ & $1,06 \mathrm{~A}$ & $1,48 \mathrm{~A}$ & $1,36 \mathrm{~A}$ \\
\hline LV-1 & $0,93 \mathrm{~A}$ & $1,30 \mathrm{~A}$ & $0,61 \mathrm{~A}$ & $1,10 \mathrm{~A}$ & $1,22 \mathrm{~A}$ & $0,48 \mathrm{~A}$ \\
\hline \multirow{3}{*}{$\begin{array}{l}\text { Solos } \\
\text { alcalinos }\end{array}$} & \multicolumn{4}{|c|}{ Composto de resíduo urbano } & \multirow{3}{*}{$\begin{array}{c}\text { Gessagem } \\
e \\
\text { adubação }\end{array}$} & \multirow{3}{*}{ Testemunha } \\
\hline & \multicolumn{2}{|c|}{ sem gessagem } & \multicolumn{2}{|c|}{ com gessagem } & & \\
\hline & sem adubação & com adubação & sem adubação & com adubação & & \\
\hline & 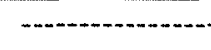 & (n) & mg/p & lanta ................ & - & 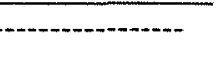 \\
\hline $\mathrm{CL}$ & $0,07 \mathrm{CD}$ & $0,26 \mathrm{AB}$ & $0,16 \mathrm{ABC}$ & $0,38 \mathrm{~A}$ & $0,14 \mathrm{BC}$ & $0,04 \mathrm{D}$ \\
\hline $\mathrm{CV}$ & $0,33 \mathrm{~A}$ & $0,37 \mathrm{~A}$ & $0,16 \mathrm{~A}$ & $0,35 \mathrm{~A}$ & $0,20 \mathrm{~A}$ & $0,04 \mathrm{~B}$ \\
\hline LA-6 & $0,23 \mathrm{BC}$ & $0,63 \mathrm{~A}$ & $0,12 \mathrm{C}$ & $0,43 \mathrm{AB}$ & $0,31 \mathrm{AB}$ & $0,03 \mathrm{D}$ \\
\hline $\mathrm{LV}-2$ & $0,43 \mathrm{AB}$ & $0,54 \mathrm{~A}$ & $0,33 \mathrm{ABC}$ & $0,13 \mathrm{CD}$ & $0,21 \mathrm{BC}$ & $0,05 \mathrm{D}$ \\
\hline SS & $1,63 \mathrm{~A}$ & $1,77 \mathrm{~A}$ & $1,56 \mathrm{~A}$ & $1,32 \mathrm{~A}$ & $1,70 \mathrm{~A}$ & $0,42 \mathrm{~B}$ \\
\hline
\end{tabular}

‡-Médias seguidas de mesma letra, nas colunas, não diferem entre si pelo teste de Tukey ao nível de 5\%. 
Tabela 58. Absorção de boro pela parte aérea da cultura de arroz em solos adubados com composto de resíduo urbano.

\begin{tabular}{|c|c|c|c|c|c|c|}
\hline \multirow{3}{*}{$\begin{array}{l}\text { Solos } \\
\text { ácidos }\end{array}$} & \multicolumn{4}{|c|}{ Composto de resíduo urbano } & \multirow{3}{*}{$\begin{array}{c}\text { Calagem } \\
\mathrm{e} \\
\text { adubação }\end{array}$} & \multirow{3}{*}{ Testemunha } \\
\hline & \multicolumn{2}{|c|}{ sem calagem } & \multicolumn{2}{|c|}{ com calagem } & & \\
\hline & sem adubaçāo & com adubação & sem adubação & com adubação & & \\
\hline & \multicolumn{6}{|c|}{ mg/planta - } \\
\hline GPH & $6,46 \mathrm{~A}^{\ddagger}$ & $10,93 \mathrm{~A}$ & $6,88 \mathrm{~A}$ & $12,81 \mathrm{~A}$ & $6,45 \mathrm{~A}$ & $5,94 \mathrm{~A}$ \\
\hline AQd & $5,07 \mathrm{~B}$ & $7,25 \mathrm{AB}$ & $6,00 \mathrm{~B}$ & $7,06 \mathrm{AB}$ & $14,18 \mathrm{~A}$ & $4,49 \mathrm{~B}$ \\
\hline LUa & $7,27 \mathrm{~B}$ & $13,31 \mathrm{AB}$ & $0,35 \mathrm{D}$ & $13,60 \mathrm{AB}$ & $21,39 \mathrm{~A}$ & $2,15 \mathrm{C}$ \\
\hline LE-1 & $4,82 \mathrm{BC}$ & $4,06 \mathrm{C}$ & $2,39 \mathrm{C}$ & $10,57 \mathrm{AB}$ & $12,88 \mathrm{~A}$ & $1,61 \mathrm{C}$ \\
\hline LE-2 & $2,74 \mathrm{~B}$ & $14,36 \mathrm{~A}$ & $0,59 \mathrm{C}$ & $1,83 \mathrm{BC}$ & $7,82 \mathrm{~A}$ & $0,75 \mathrm{BC}$ \\
\hline LA-1 & $4,77 \mathrm{CD}$ & $11,30 \mathrm{AB}$ & $2,16 \mathrm{D}$ & $14,06 \mathrm{AB}$ & $19,28 \mathrm{~A}$ & $8,06 \mathrm{BC}$ \\
\hline PV-1 & $13,33 \mathrm{~A}$ & $2,28 \mathrm{~B}$ & $3,86 \mathrm{~B}$ & $11,56 \mathrm{~A}$ & $13,77 \mathrm{~A}$ & $2,75 \mathrm{~B}$ \\
\hline LA-2 & $13,31 \mathrm{ABC}$ & $16,02 \mathrm{AB}$ & $6,27 \mathrm{C}$ & $14,08 \mathrm{AB}$ & $17,72 \mathrm{~A}$ & $8,43 \mathrm{BC}$ \\
\hline LA-3 & $5,58 \mathrm{~B}$ & $10,27 \mathrm{AB}$ & $10,56 \mathrm{AB}$ & $16,51 \mathrm{~A}$ & $16,15 \mathrm{~A}$ & $5,29 \mathrm{~B}$ \\
\hline TR-1 & $1,59 \mathrm{C}$ & $7,76 \mathrm{~A}$ & $2,89 \mathrm{BC}$ & $10,43 \mathrm{~A}$ & $5,68 \mathrm{AB}$ & $1,26 \mathrm{C}$ \\
\hline $\mathrm{LA}-4$ & $6,07 \mathrm{BC}$ & $11,80 \mathrm{AB}$ & $4,36 \mathrm{CD}$ & $1,82 \mathrm{DE}$ & $13,65 \mathrm{~A}$ & $0,55 \mathrm{E}$ \\
\hline PV-2 & $8,26 \mathrm{BC}$ & $14,61 \mathrm{AB}$ & $4,02 \mathrm{C}$ & $8,93 \mathrm{BC}$ & $18,05 \mathrm{~A}$ & $6,82 \mathrm{C}$ \\
\hline LA-5 & $9,95 \mathrm{AB}$ & $18,82 \mathrm{~A}$ & $5,48 \mathrm{~B}$ & $17,28 \mathrm{~A}$ & $13,89 \mathrm{~A}$ & $6,44 \mathrm{~B}$ \\
\hline PV-3 & $4,23 \mathrm{BC}$ & $11,27 \mathrm{~A}$ & $6,62 \mathrm{AB}$ & $13,20 \mathrm{~A}$ & $9,26 \mathrm{AB}$ & $1,73 \mathrm{C}$ \\
\hline LRa & $4,02 \mathrm{BC}$ & $12,45 \mathrm{~A}$ & $4,49 \mathrm{BC}$ & $7,89 \mathrm{AB}$ & $8,63 \mathrm{AB}$ & $2,32 \mathrm{C}$ \\
\hline LE-3 & $6,75 \mathrm{C}$ & $11,42 \mathrm{ABC}$ & $9,47 \mathrm{BC}$ & $15,74 \mathrm{AB}$ & $21,24 \mathrm{~A}$ & $6,05 \mathrm{C}$ \\
\hline $\mathrm{PE}$ & $2,63 \mathrm{C}$ & $7,80 \mathrm{AB}$ & $3,17 \mathrm{BC}$ & $4,93 \mathrm{ABC}$ & $8,06 \mathrm{~A}$ & $1,85 \mathrm{C}$ \\
\hline PV -4 & $7,37 \mathrm{BC}$ & $20,48 \mathrm{~A}$ & $1,98 \mathrm{D}$ & $13,72 \mathrm{AB}$ & $9,68 \mathrm{BC}$ & $4,13 \mathrm{CD}$ \\
\hline TR-2 & $4,42 \mathrm{~B}$ & $8,40 \mathrm{AB}$ & $4,66 \mathrm{AB}$ & $9,13 \mathrm{AB}$ & $10,33 \mathrm{~A}$ & $4,31 \mathrm{~B}$ \\
\hline $\mathrm{AQa}$ & $5,55 \mathrm{BC}$ & $11,95 \mathrm{AB}$ & $5,22 \mathrm{C}$ & $13,21 \mathrm{~A}$ & $9,11 \mathrm{ABC}$ & $4,18 \mathrm{C}$ \\
\hline LV-1 & $9,50 \mathrm{ABC}$ & $13,34 \mathrm{AB}$ & $6,21 \mathrm{BC}$ & $15,73 \mathrm{~A}$ & $16,88 \mathrm{~A}$ & $4,95 \mathrm{C}$ \\
\hline \multirow{3}{*}{$\begin{array}{l}\text { Solos } \\
\text { alcalinos }\end{array}$} & \multicolumn{4}{|c|}{ Composto de resíduo urbano } & \multirow{3}{*}{$\begin{array}{c}\text { Gessagem } \\
\text { e } \\
\text { adubação }\end{array}$} & \multirow{3}{*}{ Testemunha } \\
\hline & \multicolumn{2}{|c|}{ sem gessagem } & \multicolumn{2}{|c|}{ com gessagem } & & \\
\hline & sem adubação & com adubação & sem adubação & com adubação & & \\
\hline & & & $\mathrm{mg} / \mathrm{p}$ & anta -........-. & (n) & 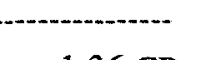 \\
\hline $\mathrm{CL}$ & $0,96 \mathrm{D}$ & $5,66 \mathrm{AB}$ & $2,55 \mathrm{BC}$ & $6,82 \mathrm{~A}$ & $3,84 \mathrm{AB}$ & $1,36 \mathrm{CD}$ \\
\hline $\mathrm{CV}$ & $1,87 \mathrm{BC}$ & $6,48 \mathrm{~A}$ & $1,36 \mathrm{C}$ & $3,95 \mathrm{AB}$ & $6,51 \mathrm{~A}$ & $1,37 \mathrm{C}$ \\
\hline LA-6 & $2,50 \mathrm{BC}$ & $10,49 \mathrm{~A}$ & $1,29 \mathrm{C}$ & $4,87 \mathrm{AB}$ & $4,76 \mathrm{AB}$ & $2,41 \mathrm{BC}$ \\
\hline LV-2 & $4,22 \mathrm{~A}$ & $4,50 \mathrm{~A}$ & $0,94 \mathrm{~B}$ & $1,21 \mathrm{~B}$ & $7,00 \mathrm{~A}$ & $1,46 \mathrm{~B}$ \\
\hline SS & $1,41 \mathrm{~A}$ & $1,39 \mathrm{~A}$ & $1,04 \mathrm{~A}$ & $1,34 \mathrm{~A}$ & $1,35 \mathrm{~A}$ & $0,5 \mathrm{~A}$ \\
\hline
\end{tabular}

₹-Médias seguidas de mesma letra, nas colunas, não diferem entre si pelo teste de Tukey ao nível de $5 \%$. 
Tabela 59. Absorção de cobalto pela parte aérea da cultura de arroz em solos adubados com composto de resíduo urbano

\begin{tabular}{|c|c|c|c|c|c|c|}
\hline \multirow{3}{*}{$\begin{array}{l}\text { Solos } \\
\text { ácidos }\end{array}$} & \multicolumn{4}{|c|}{ Composto de resíduo urbano } & \multirow{3}{*}{$\begin{array}{l}\text { Calagem } \\
\mathrm{e} \\
\text { adubação }\end{array}$} & \multirow{3}{*}{ Testemunha } \\
\hline & \multicolumn{2}{|c|}{ sem calagem } & \multicolumn{2}{|c|}{ com calagem } & & \\
\hline & sem adubação & com adubação & sem adubação & com adubação & & \\
\hline & \multicolumn{6}{|c|}{ mg/planta - } \\
\hline GPH & $0,11 A^{\ddagger}$ & $0,14 \mathrm{~A}$ & $0,08 \mathrm{~A}$ & $0,15 \mathrm{~A}$ & $0,17 \mathrm{~A}$ & $0,07 \mathrm{~A}$ \\
\hline AQd & $0,03 \mathrm{~B}$ & $0,07 \mathrm{AB}$ & $0,10 \mathrm{~A}$ & $0,05 \mathrm{AB}$ & $0,10 \mathrm{~A}$ & $0,04 \mathrm{AB}$ \\
\hline LUa & $0,11 \mathrm{BC}$ & $0,12 \mathrm{BC}$ & $0,01 \mathrm{D}$ & $0,25 \mathrm{AB}$ & $0,37 \mathrm{~A}$ & $0,05 \mathrm{C}$ \\
\hline LE-1 & $0,07 \mathrm{~B}$ & $0,07 \mathrm{~B}$ & $0,07 \mathrm{~B}$ & $0,26 \mathrm{~A}$ & $0,30 \mathrm{~A}$ & $0,02 \mathrm{C}$ \\
\hline LE-2 & $0,02 \mathrm{BC}$ & $0,11 \mathrm{~A}$ & $0,01 \mathrm{CD}$ & $0,01 \mathrm{CD}$ & $0,07 \mathrm{AB}$ & $0,00 \mathrm{D}$ \\
\hline LA-1 & $0,07 \mathrm{BC}$ & $0,20 \mathrm{~A}$ & $0,00 \mathrm{D}$ & $0,16 \mathrm{AB}$ & $0,16 \mathrm{AB}$ & $0,02 \mathrm{C}$ \\
\hline PV-1 & $0,26 \mathrm{~A}$ & $0,02 \mathrm{~B}$ & $0,03 \mathrm{~B}$ & $0,16 \mathrm{~A}$ & $0,13 \mathrm{~A}$ & $0,03 \mathrm{~B}$ \\
\hline LA-2 & $0,07 \mathrm{~B}$ & $0,18 \mathrm{AB}$ & $0,10 \mathrm{~B}$ & $0,29 \mathrm{~A}$ & $0,36 \mathrm{~A}$ & $0,11 \mathrm{~B}$ \\
\hline LA-3 & $0,09 \mathrm{BC}$ & $0,15 \mathrm{AB}$ & $0,09 \mathrm{BC}$ & $0,35 \mathrm{~A}$ & $0,22 \mathrm{AB}$ & $0,05 \mathrm{C}$ \\
\hline TR-1 & $0,01 \mathrm{C}$ & $0,18 \mathrm{~A}$ & $0,07 \mathrm{~B}$ & $0,25 \mathrm{~A}$ & $0,19 \mathrm{~A}$ & $0,01 \mathrm{C}$ \\
\hline LA-4 & $0,06 \mathrm{~A}$ & $0,08 \mathrm{~A}$ & $0,05 \mathrm{~A}$ & $0,01 \mathrm{~B}$ & $0,08 \mathrm{~A}$ & $0,01 \mathrm{~B}$ \\
\hline PV-2 & $0,10 \mathrm{C}$ & $0,26 \mathrm{AB}$ & $0,13 \mathrm{ABC}$ & $0,12 \mathrm{BC}$ & $0,28 \mathrm{~A}$ & $0,08 \mathrm{C}$ \\
\hline LA-5 & $0,31 \mathrm{~A}$ & $0,27 \mathrm{~A}$ & $0,11 \mathrm{BC}$ & $0,17 \mathrm{AB}$ & $0,20 \mathrm{AB}$ & $0,04 \mathrm{C}$ \\
\hline PV -3 & $0,03 \mathrm{C}$ & $0,08 \mathrm{BC}$ & $0,03 \mathrm{C}$ & $0,22 \mathrm{~A}$ & $0,10 \mathrm{AB}$ & $0,03 \mathrm{C}$ \\
\hline $\mathrm{LRa}$ & $0,06 \mathrm{~B}$ & $0,18 \mathrm{~A}$ & $0,07 \mathrm{AB}$ & $0,11 \mathrm{AB}$ & $0,13 \mathrm{AB}$ & $0,01 \mathrm{C}$ \\
\hline LE-3 & $0,10 \mathrm{AB}$ & $0,08 \mathrm{AB}$ & $0,07 \mathrm{~B}$ & $0,13 \mathrm{AB}$ & $0,18 \mathrm{~A}$ & $0,07 \mathrm{~B}$ \\
\hline $\mathrm{PE}$ & $0,04 \mathrm{~B}$ & $0,13 \mathrm{~A}$ & $0,04 \mathrm{~B}$ & $0,05 \mathrm{~B}$ & $0,07 \mathrm{AB}$ & $0,02 \mathrm{~B}$ \\
\hline PV -4 & $0,10 \mathrm{~B}$ & $0,42 \mathrm{~A}$ & $0,02 \mathrm{C}$ & $0,05 \mathrm{BC}$ & $0,06 \mathrm{~B}$ & $0,04 \mathrm{BC}$ \\
\hline TR-2 & $0,07 \mathrm{AB}$ & $0,12 \mathrm{~A}$ & $0,08 \mathrm{AB}$ & $0,09 \mathrm{AB}$ & $0,13 \mathrm{~A}$ & $0,04 \mathrm{~B}$ \\
\hline $\mathrm{AQa}$ & $0,02 \mathrm{~B}$ & $0,12 \mathrm{~A}$ & $0,07 \mathrm{AB}$ & $0,12 \mathrm{~A}$ & $0,10 \mathrm{~A}$ & $0,03 \mathrm{~B}$ \\
\hline LV-1 & $0,01 \mathrm{C}$ & $0,06 \mathrm{AB}$ & $0,04 \mathrm{ABC}$ & $0,02 \mathrm{BC}$ & $0,08 \mathrm{~A}$ & $0,04 \mathrm{ABC}$ \\
\hline \multirow{3}{*}{$\begin{array}{l}\text { Solos } \\
\text { alcalinos }\end{array}$} & \multicolumn{4}{|c|}{ Composto de resíduo urbano } & \multirow{3}{*}{$\begin{array}{c}\text { Gessagem } \\
\mathrm{e} \\
\text { adubação }\end{array}$} & \multirow{3}{*}{ Testemunha } \\
\hline & \multicolumn{2}{|c|}{ sem gessagem } & \multicolumn{2}{|c|}{ com gessagem } & & \\
\hline & sem adubação & com adubação & sem adubação & com adubação & & \\
\hline & & & $\mathrm{mg} / \mathrm{p}$ & anta -............ & - & 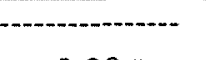 \\
\hline$C L$ & $0,00 \mathrm{~B}$ & $0,06 \mathrm{~A}$ & $0,05 \mathrm{~A}$ & $0,10 \mathrm{~A}$ & $0,11 \mathrm{~A}$ & $0,00 \mathrm{~B}$ \\
\hline $\mathrm{CV}$ & $0,05 \mathrm{BC}$ & $0,11 \mathrm{AB}$ & $0,03 \mathrm{CD}$ & $0,15 \mathrm{~A}$ & $0,21 \mathrm{~A}$ & $0,01 \mathrm{D}$ \\
\hline LA-6 & $0,08 \mathrm{~A}$ & $0,17 \mathrm{~A}$ & $0,01 \mathrm{~B}$ & $0,09 \mathrm{~A}$ & $0,14 \mathrm{~A}$ & $0,07 \mathrm{~A}$ \\
\hline LV-2 & $0,06 \mathrm{~B}$ & $0,07 \mathrm{AB}$ & $0,01 \mathrm{C}$ & $0,01 \mathrm{C}$ & $0,16 \mathrm{~A}$ & $0,02 \mathrm{C}$ \\
\hline SS & $0,01 \mathrm{AB}$ & $0,02 \mathrm{~A}$ & $0,01 \mathrm{~A}$ & $0,03 \mathrm{~A}$ & $0,02 \mathrm{~A}$ & $0,01 \mathrm{~B}$ \\
\hline
\end{tabular}


Tabela 60. Absorção de cobre pela parte aérea da cultura de arroz em solos adubados com composto de resíduo urbano.

\begin{tabular}{|c|c|c|c|c|c|c|}
\hline \multirow{3}{*}{$\begin{array}{l}\text { Solos } \\
\text { ácidos }\end{array}$} & \multicolumn{4}{|c|}{ Composto de resíduo urbano } & \multirow{3}{*}{$\begin{array}{c}\text { Calagem } \\
\mathrm{e} \\
\text { adubação }\end{array}$} & \multirow{3}{*}{ Testemunha } \\
\hline & \multicolumn{2}{|c|}{ sem calagem } & \multicolumn{2}{|c|}{ com calagem } & & \\
\hline & sem adubação & com adubação & sem adubação & com adubação & & \\
\hline & & 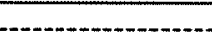 & $\mathrm{mg} / \mathrm{pl}$ & anta -.............. & & 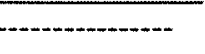 \\
\hline GPH & $14,72 \mathrm{~A}^{\ddagger}$ & $18,50 \mathrm{~A}$ & $14,27 \mathrm{~A}$ & $18,20 \mathrm{~A}$ & $12,32 \mathrm{~A}$ & $15,72 \mathrm{~A}$ \\
\hline AQd & $4,43 \mathrm{AB}$ & $5,03 \mathrm{AB}$ & $5,87 \mathrm{AB}$ & $5,45 \mathrm{AB}$ & $6,44 \mathrm{~A}$ & $1,84 \mathrm{~B}$ \\
\hline LUa & $13,07 \mathrm{~A}$ & $16,63 \mathrm{~A}$ & $0,27 \mathrm{~B}$ & $22,44 \mathrm{~A}$ & $13,31 \mathrm{~A}$ & $1,61 \mathrm{~B}$ \\
\hline LE-1 & $11,53 \mathrm{AB}$ & $10,25 \mathrm{AB}$ & $6,06 \mathrm{BC}$ & $18,22 \mathrm{~A}$ & $15,81 \mathrm{~A}$ & $2,37 \mathrm{C}$ \\
\hline LE-2 & $2,77 \mathrm{~B}$ & $12,53 \mathrm{~A}$ & $0,98 \mathrm{BC}$ & $0,79 \mathrm{BC}$ & $3,90 \mathrm{~B}$ & $0,25 \mathrm{C}$ \\
\hline LA-1 & $5,21 \mathrm{~B}$ & $11,07 \mathrm{AB}$ & $0,97 \mathrm{C}$ & $17,35 \mathrm{~A}$ & $13,20 \mathrm{~A}$ & $5,33 \mathrm{~B}$ \\
\hline PV -1 & $16,23 \mathrm{~A}$ & $1,27 \mathrm{C}$ & $3,95 \mathrm{BC}$ & $10,38 \mathrm{AB}$ & $11,53 \mathrm{~A}$ & $2,21 \mathrm{C}$ \\
\hline LA-2 & $18,63 \mathrm{AB}$ & $27,42 \mathrm{~A}$ & $9,04 \mathrm{BCD}$ & $15,86 \mathrm{ABC}$ & $8,59 \mathrm{CD}$ & $3,40 \mathrm{D}$ \\
\hline LA-3 & $9,81 \mathrm{~A}$ & $10,08 \mathrm{~A}$ & $9,76 \mathrm{~A}$ & $11,95 \mathrm{~A}$ & $6,90 \mathrm{AB}$ & $3,22 \mathrm{~B}$ \\
\hline TR-1 & $0,51 \mathrm{D}$ & $11,81 \mathrm{~A}$ & $3,53 \mathrm{BC}$ & $12,33 \mathrm{~A}$ & $7,59 \mathrm{AB}$ & $1,53 \mathrm{CD}$ \\
\hline $\mathrm{LA}-4$ & $6,59 \mathrm{~A}$ & $12,43 \mathrm{~A}$ & $7,58 \mathrm{~A}$ & $0,59 \mathrm{~B}$ & $10,36 \mathrm{~A}$ & $0,35 \mathrm{~B}$ \\
\hline PV-2 & $14,46 \mathrm{~A}$ & $22,49 \mathrm{~A}$ & $12,64 \mathrm{AB}$ & $18,72 \mathrm{~A}$ & $13,59 \mathrm{~A}$ & $5,43 \mathrm{~B}$ \\
\hline LA-5 & $14,07 \mathrm{~A}$ & $21,66 \mathrm{~A}$ & $15,59 \mathrm{~A}$ & $21,02 \mathrm{~A}$ & $15,02 \mathrm{~A}$ & $4,66 \mathrm{~B}$ \\
\hline PV-3 & $5,06 \mathrm{~A}$ & $10,54 \mathrm{~A}$ & $6,66 \mathrm{~A}$ & $11,39 \mathrm{~A}$ & $5,58 \mathrm{~A}$ & 0,92 в \\
\hline LRa & $7,48 \mathrm{~B}$ & $18,44 \mathrm{~A}$ & $7,41 \mathrm{~B}$ & $18,96 \mathrm{~A}$ & $9,81 \mathrm{AB}$ & $2,12 \mathrm{C}$ \\
\hline LE-3 & $8,96 \mathrm{AB}$ & $12,71 \mathrm{~A}$ & $8,07 \mathrm{AB}$ & $12,45 \mathrm{~A}$ & $9,39 \mathrm{AB}$ & $4,08 \mathrm{~B}$ \\
\hline $\mathrm{PE}$ & $4,34 \mathrm{AB}$ & $9,77 \mathrm{~A}$ & $5,51 \mathrm{AB}$ & $6,50 \mathrm{AB}$ & $7,80 \mathrm{~A}$ & $2,13 \mathrm{~B}$ \\
\hline $\mathrm{PV}-4$ & $6,67 \mathrm{BC}$ & $16,07 \mathrm{~A}$ & $2,55 \mathrm{C}$ & $12,45 \mathrm{AB}$ & $4,41 \mathrm{C}$ & $3,12 \mathrm{C}$ \\
\hline TR-2 & $9,91 \mathrm{AB}$ & $10,87 \mathrm{AB}$ & $11,06 \mathrm{AB}$ & $20,15 \mathrm{~A}$ & $14,91 \mathrm{~A}$ & $5,27 \mathrm{~B}$ \\
\hline AQa & $8,81 \mathrm{~A}$ & $13,69 \mathrm{~A}$ & $10,79 \mathrm{~A}$ & $10,88 \mathrm{~A}$ & $5,83 \mathrm{~A}$ & $1,43 \mathrm{~B}$ \\
\hline LV-1 & $10,52 \mathrm{AB}$ & $15,11 \mathrm{~A}$ & $6,73 \mathrm{ABC}$ & $13,52 \mathrm{AB}$ & $6,28 \mathrm{BC}$ & $3,09 \mathrm{C}$ \\
\hline \multirow{3}{*}{$\begin{array}{l}\text { Solos } \\
\text { alcalinos }\end{array}$} & \multicolumn{4}{|c|}{ Composto de resíduo urbano } & \multirow{3}{*}{$\begin{array}{c}\text { Gessagem } \\
\text { e } \\
\text { adubação }\end{array}$} & \multirow{3}{*}{ Testemunha } \\
\hline & \multicolumn{2}{|c|}{ sem gessagem } & \multicolumn{2}{|c|}{ com gessagem } & & \\
\hline & sem adubação & com adubação & sem adubação & com adubação & & \\
\hline & (n) & $\cdots$ & $\mathrm{mg} / \mathrm{p}$ & anta -............- & - & 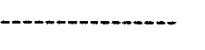 \\
\hline $\mathrm{CL}$ & $0,45 \mathrm{~B}$ & $7,17 \mathrm{~A}$ & $3,60 \mathrm{~A}$ & $8,05 \mathrm{~A}$ & $6,07 \mathrm{~A}$ & $0,44 \mathrm{~B}$ \\
\hline $\mathrm{CV}$ & $1,83 \mathrm{BC}$ & $3,98 \mathrm{AB}$ & $0,97 \mathrm{CD}$ & $4,54 \mathrm{~A}$ & $4,89 \mathrm{~A}$ & $0,39 \mathrm{D}$ \\
\hline LA-6 & $4,97 \mathrm{AB}$ & $10,98 \mathrm{~A}$ & $0,41 \mathrm{C}$ & $5,50 \mathrm{AB}$ & $6,93 \mathrm{~A}$ & $3,41 \mathrm{~B}$ \\
\hline $\mathrm{LV}-2$ & $5,02 \mathrm{~A}$ & $5,07 \mathrm{~A}$ & $0,41 \mathrm{C}$ & $0,44 \mathrm{C}$ & $7,86 \mathrm{~A}$ & $1,25 \mathrm{~B}$ \\
\hline SS & $0,85 \mathrm{~A}$ & $0,74 \mathrm{~A}$ & $0,66 \mathrm{~A}$ & $0,62 \mathrm{~A}$ & $0,72 \mathrm{~A}$ & $0,21 \mathrm{~B}$ \\
\hline
\end{tabular}

$\$$ - Médias seguidas de mesma letra, nas colunas, não diferem entre si pelo teste de Tukey ao nível de $5 \%$. 
Tabela 61. Absorção de ferro pela parte aérea da cultura de arroz em solos adubados com composto de resíduo urbano.

\begin{tabular}{|c|c|c|c|c|c|c|}
\hline \multirow{3}{*}{$\begin{array}{c}\text { Solos } \\
\text { ácidos }\end{array}$} & \multicolumn{4}{|c|}{ Composto de resíduo urbano } & \multirow{3}{*}{$\begin{array}{c}\text { Calagem } \\
\mathrm{e} \\
\text { adubação }\end{array}$} & \multirow{3}{*}{ Testemunha } \\
\hline & \multicolumn{2}{|c|}{ sem calagem } & \multicolumn{2}{|c|}{ com calagem } & & \\
\hline & sem adubação & com adubação & sem adubaçāo & com adubação & & \\
\hline & \multicolumn{6}{|c|}{ mg/planta - } \\
\hline GPH & $66,9 \mathrm{~B}^{\ddagger}$ & $176,6 \mathrm{~A}$ & $94,7 \mathrm{AB}$ & $139,4 \mathrm{AB}$ & $62,7 \mathrm{~B}$ & $75,5 \mathrm{AB}$ \\
\hline AQd & $30,8 \mathrm{~A}$ & $29,0 \mathrm{~A}$ & $54,7 \mathrm{~A}$ & $30,0 \mathrm{~A}$ & $88,5 \mathrm{~A}$ & $36,6 \mathrm{~A}$ \\
\hline LUa & $103,1 \mathrm{~A}$ & $195,2 \mathrm{~A}$ & $8,5 \mathrm{~B}$ & $183,8 \mathrm{~A}$ & $136,6 \mathrm{~A}$ & $18,2 \mathrm{~B}$ \\
\hline LE-1 & $77,8 \mathrm{ABC}$ & 29,4 BC & $34,9 \mathrm{BC}$ & $89,7 \mathrm{AB}$ & $106,8 \mathrm{~A}$ & $27,2 \mathrm{C}$ \\
\hline LE-2 & $32,2 \mathrm{BC}$ & $134,2 \mathrm{~A}$ & $9,0 \mathrm{C}$ & $10,3 \mathrm{C}$ & $77,2 \mathrm{AB}$ & $16,4 \mathrm{C}$ \\
\hline LA-1 & $45,8 \mathrm{CD}$ & $76,2 \mathrm{BC}$ & $11,9 \mathrm{D}$ & $153,3 \mathrm{AB}$ & $257,3 \mathrm{~A}$ & $143,2 \mathrm{AB}$ \\
\hline PV-1 & $177,5 \mathrm{~A}$ & $10,2 \mathrm{C}$ & $33,8 \mathrm{C}$ & $109,7 \mathrm{AB}$ & $176,3 \mathrm{~A}$ & $42,1 \mathrm{BC}$ \\
\hline LA-2 & $204,9 \mathrm{~A}$ & $203,4 \mathrm{~A}$ & $83,8 \mathrm{~B}$ & $132,9 \mathrm{AB}$ & $156,0 \mathrm{AB}$ & $107,3 \mathrm{AB}$ \\
\hline LA-3 & $83,1 \mathrm{~A}$ & $118,7 \mathrm{~A}$ & $78,3 \mathrm{~A}$ & $125,3 \mathrm{~A}$ & $138,9 \mathrm{~A}$ & $69,8 \mathrm{~A}$ \\
\hline TR-1 & $17,4 \mathrm{~B}$ & $124,6 \mathrm{~A}$ & $22,8 \mathrm{~B}$ & $103,0 \mathrm{~A}$ & $97,4 \mathrm{~A}$ & $13,5 \mathrm{~B}$ \\
\hline LA-4 & $61,4 \mathrm{~B}$ & $118,8 \mathrm{AB}$ & $62,4 \mathrm{~B}$ & $5,6 \mathrm{C}$ & $172,8 \mathrm{~A}$ & $4,7 \mathrm{C}$ \\
\hline PV-2 & $89,2 \mathrm{~A}$ & $116,3 \mathrm{~A}$ & $63,2 \mathrm{~A}$ & $96,6 \mathrm{~A}$ & $102,8 \mathrm{~A}$ & $60,1 \mathrm{~A}$ \\
\hline LA-5 & $96,0 \mathrm{AB}$ & $157,8 \mathrm{~A}$ & $82,4 \mathrm{AB}$ & $162,5 \mathrm{~A}$ & $128,1 \mathrm{~A}$ & $41,8 \mathrm{~B}$ \\
\hline PV -3 & $62,0 \mathrm{~B}$ & $126,1 \mathrm{AB}$ & $65,2 \mathrm{~B}$ & $186,9 \mathrm{~A}$ & $95,4 \mathrm{AB}$ & $16,6 \mathrm{C}$ \\
\hline LRa & $60,8 \mathrm{ABC}$ & $145,2 \mathrm{~A}$ & $54,8 \mathrm{BC}$ & $111,9 \mathrm{AB}$ & $151,1 \mathrm{~A}$ & $21,2 \mathrm{C}$ \\
\hline LE-3 & $98,7 \mathrm{BC}$ & $159,9 \mathrm{AB}$ & $221,3 \mathrm{AB}$ & $244,5 \mathrm{~A}$ & $190,4 \mathrm{AB}$ & $54,2 \mathrm{C}$ \\
\hline $\mathrm{PE}$ & $30,9 \mathrm{~A}$ & $73,2 \mathrm{~A}$ & $43,8 \mathrm{~A}$ & $36,4 \mathrm{~A}$ & $72,6 \mathrm{~A}$ & $30,5 \mathrm{~A}$ \\
\hline PV -4 & $68,9 \mathrm{BC}$ & $133,9 \mathrm{AB}$ & $29,3 \mathrm{C}$ & $235,9 \mathrm{~A}$ & $68,0 \mathrm{BC}$ & $30,6 \mathrm{C}$ \\
\hline TR-2 & $60,8 \mathrm{AB}$ & $64,7 \mathrm{AB}$ & $82,6 \mathrm{AB}$ & $130,4 \mathrm{~A}$ & $108,0 \mathrm{~A}$ & $35,8 \mathrm{~B}$ \\
\hline $\mathrm{AQa}$ & $89,0 \mathrm{AB}$ & $157,3 \mathrm{~A}$ & $84,0 \mathrm{AB}$ & $106,9 \mathrm{~A}$ & $126,6 \mathrm{~A}$ & $33,3 \mathrm{~B}$ \\
\hline LV-1 & $104,3 \mathrm{AB}$ & $159,3 \mathrm{~A}$ & $69,0 \mathrm{AB}$ & $140,6 \mathrm{~A}$ & $145,8 \mathrm{~A}$ & $47,4 \mathrm{~B}$ \\
\hline \multirow{3}{*}{$\begin{array}{c}\text { Solos } \\
\text { alcalinos }\end{array}$} & \multicolumn{4}{|c|}{ Composto de resíduo urbano } & \multirow{3}{*}{$\begin{array}{c}\text { Gessagem } \\
\mathrm{e} \\
\text { adubação }\end{array}$} & \multirow{3}{*}{ Testemunha } \\
\hline & \multicolumn{2}{|c|}{ sem gessagem } & \multicolumn{2}{|c|}{ com gessagem } & & \\
\hline & sem adubação & com adubação & sem adubação & com adubação & & \\
\hline & & & $\mathrm{mg} / \mathrm{l}$ & anta -................ & . & - \\
\hline $\mathrm{CL}$ & $6,6 \mathrm{~B}$ & $45,6 \mathrm{~A}$ & $27,8 \mathrm{~A}$ & $67,3 \mathrm{~A}$ & $50,4 \mathrm{~A}$ & $5,6 \mathrm{~B}$ \\
\hline $\mathrm{CV}$ & $11,1 \mathrm{~B}$ & $40,8 \mathrm{~A}$ & $7,3 \mathrm{~B}$ & $29,6 \mathrm{~A}$ & $54,3 \mathrm{~A}$ & $5,9 \mathrm{~B}$ \\
\hline LA- 6 & $19,0 \mathrm{~B}$ & $81,8 \mathrm{~A}$ & $5,3 \mathrm{C}$ & $40,8 \mathrm{AB}$ & $67,2 \mathrm{~A}$ & $19,5 \mathrm{~B}$ \\
\hline LV-2 & $22,1 \mathrm{~A}$ & $26,8 \mathrm{~A}$ & $3,5 \mathrm{~B}$ & $5,5 \mathrm{~B}$ & $32,7 \mathrm{~A}$ & $6,7 \mathrm{~B}$ \\
\hline SS & $8,7 \mathrm{~A}$ & $14,7 \mathrm{~A}$ & $13,1 \mathrm{~A}$ & $6,5 \mathrm{~A}$ & $13,5 \mathrm{~A}$ & $7,7 \mathrm{~A}$ \\
\hline
\end{tabular}

†-Médias seguidas de mesma letra, nas colunas, não diferem entre si pelo teste de Tukey ao nível de $5 \%$. 
Tabela 62. Absorção de manganês pela parte aérea da cultura de arroz em solos adubados com composto de resíduo urbano.

\begin{tabular}{|c|c|c|c|c|c|c|}
\hline \multirow{3}{*}{$\begin{array}{l}\text { Solos } \\
\text { ácidos }\end{array}$} & \multicolumn{4}{|c|}{ Composto de resíduo urbano } & \multirow{3}{*}{$\begin{array}{c}\text { Calagem } \\
\mathrm{e} \\
\text { adubação }\end{array}$} & \multirow{3}{*}{ Testemunha } \\
\hline & \multicolumn{2}{|c|}{ sem calagem } & \multicolumn{2}{|c|}{ com calagem } & & \\
\hline & sem adubação & com adubação & sem adubação & com adubação & & \\
\hline & \multicolumn{6}{|c|}{ mg/planta - } \\
\hline GPH & $342,8 \mathrm{C}^{\ddagger}$ & $954,2 \mathrm{~B}$ & $218,8 \mathrm{C}$ & $1117,1 \mathrm{~B}$ & $2837,6 \mathrm{~A}$ & $1328,9 \mathrm{AB}$ \\
\hline AQd & $130,6 \mathrm{AB}$ & $39,4 \mathrm{~B}$ & $170,7 \mathrm{AB}$ & $44,9 \mathrm{~B}$ & $389,3 \mathrm{~A}$ & $159,0 \mathrm{AB}$ \\
\hline LUa & $466,9 \mathrm{AB}$ & $1082,7 \mathrm{~A}$ & $2,3 \mathrm{C}$ & $354,3 \mathrm{~B}$ & $407,4 \mathrm{~B}$ & $488,4 \mathrm{AB}$ \\
\hline LE-1 & $62,8 \mathrm{BC}$ & $52,1 \mathrm{C}$ & $45,8 \mathrm{C}$ & $153,1 \mathrm{BC}$ & $1532,1 \mathrm{~A}$ & $225,3 \mathrm{~B}$ \\
\hline LE-2 & $222,4 \mathrm{AB}$ & $586,0 \mathrm{~A}$ & $55,5 \mathrm{BC}$ & $35,2 \mathrm{C}$ & $354,1 \mathrm{~A}$ & $78, \mathrm{BC}$ \\
\hline LA-1 & $423,9 \mathrm{~A}$ & $748,0 \mathrm{~A}$ & $9,4 \mathrm{~B}$ & $435,9 \mathrm{~A}$ & $851,7 \mathrm{~A}$ & $620,0 \mathrm{~A}$ \\
\hline PV-1 & $869,3 \mathrm{~A}$ & $118,1 \mathrm{BC}$ & $41,4 \mathrm{C}$ & $204,9 \mathrm{~B}$ & $1292,7 \mathrm{~A}$ & $819,9 \mathrm{~A}$ \\
\hline LA-2 & $763,3 \mathrm{AB}$ & $1200,8 \mathrm{~A}$ & $187,5 \mathrm{C}$ & $374,6 \mathrm{BC}$ & $1008,5 \mathrm{AB}$ & $395,2 \mathrm{BC}$ \\
\hline LA-3 & $408,8 \mathrm{ABC}$ & $172,0 \mathrm{C}$ & $302,7 \mathrm{BC}$ & $188,5 \mathrm{C}$ & $865,2 \mathrm{~A}$ & $788,8 \mathrm{AB}$ \\
\hline TR-1 & $7,9 \mathrm{D}$ & $419,5 \mathrm{AB}$ & $186,7 \mathrm{BC}$ & $594,1 \mathrm{~A}$ & $777,6 \mathrm{~A}$ & $114,7 \mathrm{C}$ \\
\hline LA-4 & $358,7 \mathrm{~B}$ & 330,3 B & $184,1 \mathrm{BC}$ & $6,0 \mathrm{D}$ & $2568,0 \mathrm{~A}$ & $49,4 \mathrm{C}$ \\
\hline PV-2 & $694,7 \mathrm{CD}$ & $1282,4 \mathrm{BC}$ & $451,6 \mathrm{D}$ & $357,6 \mathrm{D}$ & $5774,1 \mathrm{~A}$ & $2514,0 \mathrm{~B}$ \\
\hline LA-5 & $2277,4 \mathrm{C}$ & $8174,4 \mathrm{~A}$ & $717,3 \mathrm{D}$ & $4290,9 \mathrm{BC}$ & $7287,3 \mathrm{AB}$ & $2833,2 \mathrm{C}$ \\
\hline PV-3 & $703,4 \mathrm{~A}$ & $718,4 \mathrm{~A}$ & $453,5 \mathrm{~A}$ & $477,4 \mathrm{~A}$ & $311,8 \mathrm{~A}$ & $307,4 \mathrm{~A}$ \\
\hline $\mathrm{LRa}$ & $873,6 \mathrm{~A}$ & $602,6 \mathrm{~A}$ & $499,8 \mathrm{AB}$ & 175,4 B & $662,6 \mathrm{~A}$ & $427,7 \mathrm{AB}$ \\
\hline LE-3 & $1071,1 \mathrm{~A}$ & $573,2 \mathrm{AB}$ & $934,9 \mathrm{~A}$ & $245,1 \mathrm{~B}$ & $1109,2 \mathrm{~A}$ & $1015,8 \mathrm{~A}$ \\
\hline $\mathrm{PE}$ & $221,5 \mathrm{~A}$ & $284,7 \mathrm{~A}$ & $283,2 \mathrm{~A}$ & $176,7 \mathrm{~A}$ & $298,8 \mathrm{~A}$ & $323,2 \mathrm{~A}$ \\
\hline PV -4 & $613,2 \mathrm{AB}$ & $364,3 \mathrm{AB}$ & $84,6 \mathrm{C}$ & $239,7 \mathrm{BC}$ & $658,1 \mathrm{AB}$ & $920,8 \mathrm{~A}$ \\
\hline TR-2 & $130,2 \mathrm{BC}$ & $90,3 \mathrm{C}$ & $130,2 \mathrm{BC}$ & $166,5 \mathrm{BC}$ & $917,3 \mathrm{~A}$ & $416,0 \mathrm{AB}$ \\
\hline $\mathrm{AQa}$ & $203,3 \mathrm{AB}$ & $390,0 \mathrm{~A}$ & $171,4 \mathrm{AB}$ & $107,1 \mathrm{~B}$ & $350,0 \mathrm{AB}$ & $123,8 \mathrm{AB}$ \\
\hline LV-1 & $830,7 \mathrm{~A}$ & $777,2 \mathrm{~A}$ & $248,1 \mathrm{~B}$ & 179,2 в & $1176,0 \mathrm{~A}$ & $1153,2 \mathrm{~A}$ \\
\hline \multirow{3}{*}{$\begin{array}{l}\text { Solos } \\
\text { alcalinos }\end{array}$} & \multicolumn{4}{|c|}{ Composto de resíduo urbano } & \multirow{3}{*}{$\begin{array}{c}\text { Gessagem } \\
\mathrm{e} \\
\text { adubação }\end{array}$} & \multirow{3}{*}{ Testemunha } \\
\hline & \multicolumn{2}{|c|}{ sem gessagem } & \multicolumn{2}{|c|}{ com gessagem } & & \\
\hline & sem adubação & com adubação & sem adubação & com adubação & & \\
\hline & - & - & $\mathrm{mg} / \mathrm{f}$ & lanta -............ & - & 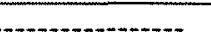 \\
\hline $\mathrm{CL}$ & $1,3 \mathrm{~B}$ & $54,2 \mathrm{~A}$ & $126,5 \mathrm{~A}$ & $106,2 \mathrm{~A}$ & $157,5 \mathrm{~A}$ & $1,4 \mathrm{~B}$ \\
\hline $\mathrm{CV}$ & $24,2 \mathrm{AB}$ & $31,4 \mathrm{AB}$ & $13,7 \mathrm{~B}$ & $45,9 \mathrm{AB}$ & $57,4 \mathrm{~A}$ & $3,7 \mathrm{C}$ \\
\hline LA- 6 & $74,9 \mathrm{~A}$ & $129,8 \mathrm{~A}$ & $2,3 \mathrm{~B}$ & $32,8 \mathrm{~A}$ & $77,9 \mathrm{~A}$ & $40,1 \mathrm{~A}$ \\
\hline $\mathrm{LV}-2$ & $76,8 \mathrm{~A}$ & $26,3 \mathrm{AB}$ & $3,7 \mathrm{CD}$ & $1,6 \mathrm{D}$ & $49,8 \mathrm{~A}$ & $7,3 \mathrm{BC}$ \\
\hline SS & $6,0 \mathrm{~A}$ & $2,3 \mathrm{AB}$ & $4,0 \mathrm{~A}$ & $2,2 \mathrm{AB}$ & $2,9 \mathrm{AB}$ & $1,3 \mathrm{~B}$ \\
\hline
\end{tabular}

$\mp$ - Médias seguidas de mesma letra, nas colunas, não diferem entre si pelo teste de Tukey ao nível de $5 \%$. 


\subsubsection{Absorção de metais}

A absorção de bário pelas plantas de arroz foi bastante variável com o solo (Tabela 66). Nos solos ácidos, não houve efeito de tratamentos nos solos LE-1, LE3, PE e LV-1. A aplicação de calcário + adubo promoveu a maior absorção deste elemento em todos os solos, excluindo-se o solo GPH, onde a absorção neste tratamento foi inferior a todos os outros. Os diferentes tratamentos com composto tenderam a não diferirem entre si. Nos solos alcalinos, a aplicação de composto com adubo não diferiu do gesso + adubo e, geralmente conduziram a uma maior absorção de Ba pelas plantas.

Os dos tratamentos, praticamente não diferiram entre si, quantos a absorção de cádmio, cromo, chumbo e estrôncio (Tabelas 67, 68, 69 e 70), que foram maiores nos tratamentos com composto + adubo, composto + calcário e calcário + adubo, nos solos ácidos e; nos tratamentos composto + adubo composto + gesso + adubo e gesso + adubo, solos ácidos (exceto no solo LV-2, onde o composto + gesso + adubo diminuiu a absorção dos respectivos metais).

A absorção de titânio pelas plantas de arroz (Tabela 71), praticamente não diferiu dos outros elementos, mas mostrou que os tratamentos 'com composto e composto + gesso apresentaram pequenas diferenças com os tratamentos composto + adubo e composto + gesso + adubo. Nos solos alcalinos foram observados efeitos semelhantes aos do $\mathrm{Cd}, \mathrm{Cr}, \mathrm{Pb}$ e $\mathrm{Sr}$.

Resultados semelhantes foram relatados por Gigliotti et al. (1996). Estes autores observaram que plantas de milho crescidas um em solos tratados com composto de resíduo urbano durante seis anos, apresentaram uma maior absorção de $\mathrm{Cu}, \mathrm{Zn}, \mathrm{Pb}$, $\mathrm{Cr}$ e de $\mathrm{Ni}$, do que as testemunhas. Porém, devido ao maior desenvolvimento das plantas tratadas com o composto, as concentrações destes elementos nas plantas tratadas e não tratadas praticamente não diferiram entre si.

Com relação à distribuição dos metais nas partes da planta, tem-se que o B, Mn, Zn, e Ni distribuem-se de maneira relativamente uniforme nas raízes e na parte aérea; o $\mathrm{Co}, \mathrm{Cu}$, $\mathrm{Mo}$ e $\mathrm{Cd}$ geralmente se acumulam nas raízes, mas podem ser encontradas em (altạ concentrações elevadas na parte aérea; e o $\mathrm{Cr}, \mathrm{Pb}, \mathrm{Ag}, \mathrm{Sn}, \mathrm{Ti}$ e V 
Tabela 66. Absorção de bário pela parte aérea da cultura de arroz em solos adubados com composto de resíduo urbano.

\begin{tabular}{|c|c|c|c|c|c|c|}
\hline \multirow{3}{*}{$\begin{array}{l}\text { Solos } \\
\text { ácidos }\end{array}$} & \multicolumn{4}{|c|}{ Composto de resíduo urbano } & \multirow{3}{*}{$\begin{array}{c}\text { Calagem } \\
\mathrm{e} \\
\text { adubação }\end{array}$} & \multirow{3}{*}{ Testemunha } \\
\hline & \multicolumn{2}{|c|}{ sem calagem } & \multicolumn{2}{|c|}{ com calagem } & & \\
\hline & sem adubação & com adubação & sem adubação & com adubação & & \\
\hline & \multicolumn{6}{|c|}{ mg/planta - - m } \\
\hline GPH & $38,5 \mathrm{~A}^{\ddagger}$ & $37,8 \mathrm{~A}$ & $42,7 \mathrm{~A}$ & $40,3 \mathrm{~A}$ & $8,2 \mathrm{~B}$ & $39,0 \mathrm{~A}$ \\
\hline AQd & $7,6 \mathrm{AB}$ & $4,2 \mathrm{~B}$ & $10,9 \mathrm{AB}$ & $2,8 \mathrm{~B}$ & $19,2 \mathrm{~A}$ & $10,4 \mathrm{AB}$ \\
\hline LUa & $14,2 \mathrm{AB}$ & $18,9 \mathrm{~A}$ & $0,2 \mathrm{C}$ & $15,8 \mathrm{~A}$ & $21,5 \mathrm{~A}$ & $3,8 \mathrm{~B}$ \\
\hline LE-1 & $16,9 \mathrm{~A}$ & $7,6 \mathrm{~A}$ & $10,1 \mathrm{~A}$ & $10,2 \mathrm{~A}$ & $19,4 \mathrm{~A}$ & $6,9 \mathrm{~A}$ \\
\hline LE-2 & $3,2 \mathrm{BC}$ & $22,5 \mathrm{~A}$ & $0,5 \mathrm{C}$ & $0,6 \mathrm{C}$ & $12,3 \mathrm{AB}$ & $2,0 \mathrm{C}$ \\
\hline LA-1 & $1,6 \mathrm{CD}$ & $3,0 \mathrm{BCD}$ & $0,3 \mathrm{D}$ & $10,2 \mathrm{AB}$ & $22,2 \mathrm{~A}$ & $5,4 \mathrm{BC}$ \\
\hline PV-1 & $16,4 \mathrm{AB}$ & $0,7 \mathrm{D}$ & $1,7 \mathrm{CD}$ & $5,1 \mathrm{BCD}$ & $26,5 \mathrm{~A}$ & $8,4 \mathrm{BC}$ \\
\hline LA-2 & $24,4 \mathrm{AB}$ & $12,8 \mathrm{ABC}$ & $3,6 \mathrm{C}$ & $14,5 \mathrm{ABC}$ & $25,8 \mathrm{~A}$ & $7,8 \mathrm{BC}$ \\
\hline LA-3 & $7,7 \mathrm{AB}$ & $8,4 \mathrm{AB}$ & $4,8 \mathrm{AB}$ & $10,9 \mathrm{AB}$ & 13,9 A & $2,8 \mathrm{~B}$ \\
\hline TR-1 & $0,7 \mathrm{C}$ & $12,7 \mathrm{AB}$ & $7,8 \mathrm{AB}$ & $13,8 \mathrm{AB}$ & $19,2 \mathrm{~A}$ & $4,9 \mathrm{BC}$ \\
\hline LA-4 & $10,1 \mathrm{AB}$ & $14,2 \mathrm{AB}$ & $5,5 \mathrm{~B}$ & $0,3 \mathrm{C}$ & $26,0 \mathrm{~A}$ & $0,7 \mathrm{C}$ \\
\hline PV-2 & $25,0 \mathrm{AB}$ & $14,6 \mathrm{AB}$ & $12,1 \mathrm{~B}$ & $12,6 \mathrm{AB}$ & $28,8 \mathrm{AB}$ & $35,0 \mathrm{~A}$ \\
\hline LA-5 & $54,9 \mathrm{AB}$ & $26,5 \mathrm{~B}$ & $62,2 \mathrm{~A}$ & $44,3 \mathrm{AB}$ & $34,3 \mathrm{AB}$ & $39,4 \mathrm{AB}$ \\
\hline PV-3 & $8,3 \mathrm{AB}$ & $19,4 \mathrm{~A}$ & $5,9 \mathrm{AB}$ & $16,2 \mathrm{~A}$ & $20,1 \mathrm{~A}$ & $2,5 \mathrm{~B}$ \\
\hline LRa & $8,1 \mathrm{BC}$ & $32,7 \mathrm{~A}$ & $4,7 \mathrm{C}$ & $23,8 \mathrm{AB}$ & $27,4 \mathrm{~A}$ & $12,5 \mathrm{ABC}$ \\
\hline LE-3 & $20,5 \mathrm{~A}$ & $34,3 \mathrm{~A}$ & $19,6 \mathrm{~A}$ & $33,2 \mathrm{~A}$ & $30,3 \mathrm{~A}$ & $16,2 \mathrm{~A}$ \\
\hline $\mathrm{PE}$ & $14,0 \mathrm{~A}$ & $10,7 \mathrm{~A}$ & $17,5 \mathrm{~A}$ & $8,9 \mathrm{~A}$ & $17,8 \mathrm{~A}$ & $17,7 \mathrm{~A}$ \\
\hline PV-4 & 7,9 AB & $20,9 \mathrm{~A}$ & $1,7 \mathrm{~B}$ & $19,2 \mathrm{~A}$ & $13,7 \mathrm{~A}$ & $10,4 \mathrm{~A}$ \\
\hline TR-2 & $16,4 \mathrm{AB}$ & $6,4 \mathrm{~B}$ & $17,7 \mathrm{AB}$ & $18,1 \mathrm{AB}$ & $22,9 \mathrm{~A}$ & $28,3 \mathrm{~A}$ \\
\hline $\mathrm{AQa}$ & $5,4 \mathrm{AB}$ & $9,3 \mathrm{AB}$ & $6,3 \mathrm{AB}$ & $10,0 \mathrm{AB}$ & $12,9 \mathrm{~A}$ & $2,4 \mathrm{~B}$ \\
\hline LV-1 & $13,0 \mathrm{~A}$ & $15,6 \mathrm{~A}$ & $9,8 \mathrm{~A}$ & $17,3 \mathrm{~A}$ & $23,1 \mathrm{~A}$ & $23,1 \mathrm{~A}$ \\
\hline \multirow{3}{*}{$\begin{array}{l}\text { Solos } \\
\text { alcalinos }\end{array}$} & \multicolumn{4}{|c|}{ Composto de resíduo urbano } & \multirow{3}{*}{$\begin{array}{c}\text { Gessagem } \\
\mathrm{e} \\
\text { adubação }\end{array}$} & \multirow{3}{*}{ Testemunha } \\
\hline & \multicolumn{2}{|c|}{ sem gessagem } & \multicolumn{2}{|c|}{ com gessagem } & & \\
\hline & sem adubação & com adubação & sem adubação & com adubação & & \\
\hline & & & $\mathrm{mg} / \mathrm{p}$ & anta & (n) & 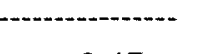 \\
\hline$C L$ & $0,33 \mathrm{~B}$ & $17,04 \mathrm{~A}$ & $13,62 \mathrm{~A}$ & $13,32 \mathrm{~A}$ & $4,12 \mathrm{~A}$ & $0,47 \mathrm{~B}$ \\
\hline CV & $2,90 \mathrm{AB}$ & $7,16 \mathrm{~A}$ & $0,90 \mathrm{~B}$ & $5,36 \mathrm{~A}$ & $12,32 \mathrm{~A}$ & $0,92 \mathrm{~B}$ \\
\hline LA-6 & $5,00 \mathrm{~A}$ & $13,53 \mathrm{~A}$ & $0,32 \mathrm{~B}$ & $3,73 \mathrm{~A}$ & $9,11 \mathrm{~A}$ & $5,73 \mathrm{~A}$ \\
\hline LV-2 & $4,38 \mathrm{AB}$ & $6,90 \mathrm{~A}$ & $0,37 \mathrm{CD}$ & $0,25 \mathrm{D}$ & $12,34 \mathrm{~A}$ & $1,46 \mathrm{BC}$ \\
\hline SS & $1,00 \mathrm{~A}$ & $0,33 \mathrm{AB}$ & $0,18 \mathrm{~B}$ & $0,25 \mathrm{AB}$ & $0,21 \mathrm{~B}$ & $0,19 \mathrm{~B}$ \\
\hline
\end{tabular}

† - Médias seguidas de mesma letra, nas colunas, não diferem entre si pelo teste de Tukey ao nível de $5 \%$. 
Tabela 67. Absorção de cádmio pela parte aérea da cultura de arroz em solos adubados com composto de resíduo urbano.

\begin{tabular}{|c|c|c|c|c|c|c|}
\hline \multirow{3}{*}{$\begin{array}{l}\text { Solos } \\
\text { ácidos }\end{array}$} & \multicolumn{4}{|c|}{ Composto de resíduo urbano } & \multirow{3}{*}{$\begin{array}{c}\text { Calagem } \\
\mathrm{e} \\
\text { adubação }\end{array}$} & \multirow{3}{*}{ Testemunha } \\
\hline & \multicolumn{2}{|c|}{ sem calagem } & \multicolumn{2}{|c|}{ com calagem } & & \\
\hline & sem adubação & com adubação & sem adubação & com adubação & & \\
\hline & \multicolumn{6}{|c|}{ 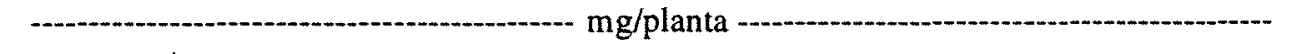 } \\
\hline GPH & $0,40 \mathrm{BC}^{\ddagger}$ & $0,85 \mathrm{~A}$ & $0,22 \mathrm{CD}$ & $0,63 \mathrm{AB}$ & $0,94 \mathrm{~A}$ & $0,17 \mathrm{D}$ \\
\hline AQd & $0,02 \mathrm{~B}$ & $0,04 \mathrm{AB}$ & $0,05 \mathrm{AB}$ & $0,02 \mathrm{~B}$ & $0,10 \mathrm{~A}$ & $0,03 \mathrm{~B}$ \\
\hline LUa & $0,13 \mathrm{~B}$ & $0,29 \mathrm{~A}$ & $0,00 \mathrm{D}$ & $0,22 \mathrm{AB}$ & $0,20 \mathrm{AB}$ & $0,04 \mathrm{C}$ \\
\hline LE-1 & $0,04 \mathrm{CD}$ & $0,08 \mathrm{BC}$ & $0,06 \mathrm{CD}$ & $0,18 \mathrm{AB}$ & $0,25 \mathrm{~A}$ & $0,02 \mathrm{D}$ \\
\hline LE-2 & $0,03 \mathrm{BC}$ & $0,22 \mathrm{~A}$ & $0,01 \mathrm{CD}$ & $0,00 \mathrm{D}$ & $0,05 \mathrm{~B}$ & $0,01 \mathrm{CD}$ \\
\hline LA-1 & $0,09 \mathrm{BC}$ & $0,23 \mathrm{~A}$ & $0,00 \mathrm{D}$ & $0,16 \mathrm{AB}$ & $0,16 \mathrm{AB}$ & $0,05 \mathrm{C}$ \\
\hline PV-1 & $0,14 \mathrm{~A}$ & $0,02 \mathrm{~B}$ & $0,01 \mathrm{~B}$ & $0,05 \mathrm{AB}$ & $0,11 \mathrm{~A}$ & $0,02 \mathrm{~B}$ \\
\hline LA-2 & $0,20 \mathrm{AB}$ & $0,40 \mathrm{~A}$ & $0,07 \mathrm{C}$ & $0,26 \mathrm{~A}$ & $0,31 \mathrm{~A}$ & $0,10 \mathrm{BC}$ \\
\hline LA-3 & $0,05 \mathrm{BC}$ & $0,15 \mathrm{AB}$ & $0,06 \mathrm{BC}$ & $0,28 \mathrm{~A}$ & $0,18 \mathrm{~A}$ & $0,04 \mathrm{C}$ \\
\hline TR-1 & $0,00 \mathrm{C}$ & $0,16 \mathrm{~A}$ & $0,03 \mathrm{~B}$ & $0,15 \mathrm{~A}$ & $0,12 \mathrm{~A}$ & $0,01 \mathrm{BC}$ \\
\hline LA-4 & $0,02 \mathrm{BC}$ & $0,06 \mathrm{~B}$ & $0,03 \mathrm{~B}$ & $0,00 \mathrm{D}$ & $0,22 \mathrm{~A}$ & $0,00 \mathrm{CD}$ \\
\hline PV-2 & $0,14 \mathrm{ABC}$ & $0,26 \mathrm{AB}$ & $0,12 \mathrm{BC}$ & $0,18 \mathrm{ABC}$ & $0,27 \mathrm{~A}$ & $0,09 \mathrm{C}$ \\
\hline LA-5 & $0,37 \mathrm{~A}$ & $0,40 \mathrm{~A}$ & $0,25 \mathrm{AB}$ & $0,35 \mathrm{~A}$ & $0,36 \mathrm{~A}$ & $0,15 \mathrm{~B}$ \\
\hline PV-3 & $0,07 \mathrm{AB}$ & $0,12 \mathrm{~A}$ & $0,04 \mathrm{~B}$ & $0,15 \mathrm{~A}$ & $0,12 \mathrm{~A}$ & $0,02 \mathrm{~B}$ \\
\hline LRa & $0,03 \mathrm{~B}$ & $0,17 \mathrm{~A}$ & $0,03 \mathrm{~B}$ & $0,16 \mathrm{~A}$ & $0,10 \mathrm{~A}$ & $0,03 \mathrm{~B}$ \\
\hline LE-3 & $0,08 \mathrm{~A}$ & $0,12 \mathrm{~A}$ & $0,07 \mathrm{~A}$ & $0,12 \mathrm{~A}$ & $0,17 \mathrm{~A}$ & $0,09 \mathrm{~A}$ \\
\hline PE & $0,03 \mathrm{~B}$ & $0,12 \mathrm{~A}$ & $0,04 \mathrm{AB}$ & $0,05 \mathrm{AB}$ & $0,12 \mathrm{~A}$ & $0,03 \mathrm{~B}$ \\
\hline PV-4 & $0,09 \mathrm{~B}$ & $0,41 \mathrm{~A}$ & $0,01 \mathrm{C}$ & $0,13 \mathrm{~B}$ & $0,09 \mathrm{~B}$ & $0,05 \mathrm{~B}$ \\
\hline TR-2 & $0,10 \mathrm{BC}$ & $0,12 \mathrm{BC}$ & $0,08 \mathrm{BC}$ & $0,18 \mathrm{AB}$ & $0,36 \mathrm{~A}$ & $0,07 \mathrm{C}$ \\
\hline $\mathrm{AQa}$ & $0,11 \mathrm{~A}$ & $0,12 \mathrm{~A}$ & $0,03 \mathrm{~B}$ & $0,05 \mathrm{AB}$ & $0,07 \mathrm{AB}$ & $0,04 \mathrm{AB}$ \\
\hline LV-1 & $0,11 \mathrm{~A}$ & $0,13 \mathrm{~A}$ & $0,03 \mathrm{~B}$ & $0,07 \mathrm{AB}$ & $0,07 \mathrm{AB}$ & $0,02 \mathrm{~B}$ \\
\hline \multirow{3}{*}{$\begin{array}{c}\text { Solos } \\
\text { alcalinos }\end{array}$} & \multicolumn{4}{|c|}{ Composto de resíduo urbano } & \multirow{3}{*}{$\begin{array}{c}\text { Gessagem } \\
e^{-} \\
\text {adubação }\end{array}$} & \multirow{3}{*}{ Testemunha } \\
\hline & \multicolumn{2}{|c|}{ sem gessagem } & \multicolumn{2}{|c|}{ com gessagem } & & \\
\hline & sem adubação & com adubação & sem adubação & com adubação & & \\
\hline & & - & $m g / p$ & anta -................. & -1 & - \\
\hline $\mathrm{CL}$ & $0,00 \mathrm{~B}$ & $0,13 \mathrm{~A}$ & $0,08 \mathrm{~A}$ & $0,16 \mathrm{~A}$ & $0,10 \mathrm{~A}$ & $0,00 \mathrm{~B}$ \\
\hline $\mathrm{CV}$ & $0,03 \mathrm{BC}$ & $0,05 \mathrm{AB}$ & $0,01 \mathrm{C}$ & $0,10 \mathrm{AB}$ & $0,12 \mathrm{~A}$ & $0,00 \mathrm{D}$ \\
\hline LA-6 & $0,07 \mathrm{~A}$ & $0,14 \mathrm{~A}$ & $0,00 \mathrm{~B}$ & $0,04 \mathrm{~A}$ & $0,09 \mathrm{~A}$ & $0,06 \mathrm{~A}$ \\
\hline LV-2 & $0,05 \mathrm{~A}$ & $0,04 \mathrm{AB}$ & $0,00 \mathrm{C}$ & $0,00 \mathrm{C}$ & $0,11 \mathrm{~A}$ & $0,01 \mathrm{~B}$ \\
\hline SS & $0,00 \mathrm{~A}$ & $0,01 \mathrm{~A}$ & $0,00 \mathrm{~A}$ & $0,01 \mathrm{~A}$ & $0,00 \mathrm{~A}$ & $0,00 \mathrm{~A}$ \\
\hline
\end{tabular}

$\ddagger$ - Médias seguidas de mesma letra, nas colunas, não diferem entre si pelo teste de Tukey ao nível de 5\%. 
Tabela 68. Absorção de cromo pela parte aérea da cultura de arroz em solos adubados com composto de resíduo urbano.

\begin{tabular}{|c|c|c|c|c|c|c|}
\hline \multirow{3}{*}{$\begin{array}{l}\text { Solos } \\
\text { ácidos }\end{array}$} & \multicolumn{4}{|c|}{ Composto de resíduo urbano } & \multirow{3}{*}{$\begin{array}{c}\text { Calagem } \\
\mathrm{e} \\
\text { adubação }\end{array}$} & \multirow{3}{*}{ Testemunha } \\
\hline & \multicolumn{2}{|c|}{ sem calagem } & \multicolumn{2}{|c|}{ com calagem } & & \\
\hline & sem adubação & com adubação & sem adubação & com adubação & & \\
\hline & \multicolumn{6}{|c|}{ - mg/planta - } \\
\hline GPH & $0,41 \mathrm{AB}^{\ddagger}$ & $0,65 \mathrm{AB}$ & $0,44 \mathrm{AB}$ & $0,86 \mathrm{~A}$ & $0,33 \mathrm{~B}$ & $0,38 \mathrm{AB}$ \\
\hline AQd & $0,19 \mathrm{~B}$ & $0,29 \mathrm{AB}$ & $0,35 \mathrm{AB}$ & $0,20 \mathrm{~B}$ & $0,69 \mathrm{~A}$ & $0,21 \mathrm{~B}$ \\
\hline LUa & $0,48 \mathrm{~B}$ & $0,98 \mathrm{AB}$ & $0,02 \mathrm{C}$ & $1,20 \mathrm{~A}$ & $1,37 \mathrm{~A}$ & $0,08 \mathrm{C}$ \\
\hline LE-1 & $0,31 \mathrm{BC}$ & $0,15 \mathrm{CD}$ & $0,19 \mathrm{C}$ & $0,73 \mathrm{AB}$ & $0,81 \mathrm{~A}$ & $0,04 \mathrm{D}$ \\
\hline LE-2 & $0,05 \mathrm{~B}$ & $0,50 \mathrm{~A}$ & $0,03 \mathrm{~B}$ & $0,03 \mathrm{~B}$ & $0,41 \mathrm{~A}$ & $0,02 \mathrm{~B}$ \\
\hline LA-1 & $0,26 \mathrm{~B}$ & $0,62 \mathrm{AB}$ & $0,03 \mathrm{C}$ & $0,84 \mathrm{~A}$ & $1,10 \mathrm{~A}$ & $0,28 \mathrm{~B}$ \\
\hline PV-1 & $0,84 \mathrm{AB}$ & $0,06 \mathrm{D}$ & $0,15 \mathrm{CD}$ & $0,42 \mathrm{BC}$ & $1,01 \mathrm{~A}$ & $0,16 \mathrm{CD}$ \\
\hline $\mathrm{LA}-2$ & $0,91 \mathrm{~A}$ & $1,17 \mathrm{~A}$ & $0,34 \mathrm{~B}$ & $0,95 \mathrm{~A}$ & $1,35 \mathrm{~A}$ & $0,38 \mathrm{~B}$ \\
\hline LA-3 & $0,45 \mathrm{ABC}$ & $0,67 \mathrm{AB}$ & $0,32 \mathrm{BC}$ & $0,79 \mathrm{~A}$ & $0,88 \mathrm{~A}$ & $0,24 \mathrm{C}$ \\
\hline TR-1 & $0,01 \mathrm{C}$ & $0,35 \mathrm{AB}$ & $0,11 \mathrm{~B}$ & $0,46 \mathrm{~A}$ & $0,45 \mathrm{~A}$ & $0,02 \mathrm{C}$ \\
\hline LA-4 & $0,17 \mathrm{~B}$ & $0,37 \mathrm{~B}$ & $0,19 \mathrm{~B}$ & $0,02 \mathrm{C}$ & $0,94 \mathrm{~A}$ & $0,01 \mathrm{C}$ \\
\hline PV -2 & $0,60 \mathrm{~B}$ & $0,98 \mathrm{~B}$ & $0,55 \mathrm{AB}$ & $0,85 \mathrm{~B}$ & $2,82 \mathrm{~A}$ & $0,61 \mathrm{~B}$ \\
\hline LA-5 & $0,28 \mathrm{C}$ & $1,99 \mathrm{~A}$ & $0,34 \mathrm{C}$ & $0,96 \mathrm{~B}$ & $2,00 \mathrm{~A}$ & $0,59 \mathrm{BC}$ \\
\hline PV -3 & $0,18 \mathrm{CD}$ & $0,34 \mathrm{BC}$ & $0,29 \mathrm{BC}$ & $1,03 \mathrm{~A}$ & $0,67 \mathrm{AB}$ & $0,07 \mathrm{D}$ \\
\hline LRa & $0,22 \mathrm{~B}$ & $0,70 \mathrm{~A}$ & $0,24 \mathrm{~B}$ & $0,56 \mathrm{AB}$ & $0,50 \mathrm{AB}$ & $0,05 \mathrm{C}$ \\
\hline LE-3 & $0,48 \mathrm{AB}$ & $0,63 \mathrm{AB}$ & $0,53 \mathrm{AB}$ & $0,69 \mathrm{AB}$ & $0,91 \mathrm{~A}$ & $0,30 \mathrm{~B}$ \\
\hline $\mathrm{PE}$ & $0,10 \mathrm{C}$ & $0,35 \mathrm{AB}$ & $0,15 \mathrm{BC}$ & $0,24 \mathrm{ABC}$ & $0,52 \mathrm{~A}$ & $0,09 \mathrm{C}$ \\
\hline PV -4 & $0,35 \mathrm{BC}$ & $1,26 \mathrm{~A}$ & $0,07 \mathrm{D}$ & $0,61 \mathrm{AB}$ & $0,32 \mathrm{BC}$ & $0,21 \mathrm{D}$ \\
\hline TR-2 & $0,30 \mathrm{BC}$ & $0,26 \mathrm{BC}$ & $0,32 \mathrm{ABC}$ & $0,58 \mathrm{AB}$ & $0,77 \mathrm{~A}$ & $0,15 \mathrm{C}$ \\
\hline $\mathrm{AQa}$ & $0,21 \mathrm{~A}$ & $0,16 \mathrm{~A}$ & $0,18 \mathrm{~A}$ & $0,28 \mathrm{~A}$ & $0,24 \mathrm{~A}$ & $0,10 \mathrm{~A}$ \\
\hline LV-1 & $0,35 \mathrm{AB}$ & $0,48 \mathrm{AB}$ & $0,24 \mathrm{~B}$ & $0,79 \mathrm{~A}$ & $0,82 \mathrm{~A}$ & $0,18 \mathrm{~B}$ \\
\hline \multirow{3}{*}{$\begin{array}{l}\text { Solos } \\
\text { alcalinos }\end{array}$} & \multicolumn{4}{|c|}{ Composto de resíduo urbano } & \multirow{3}{*}{$\begin{array}{c}\text { Gessagem } \\
e \\
\text { adubação }\end{array}$} & \multirow{3}{*}{ Testemunha } \\
\hline & \multicolumn{2}{|c|}{ sem gessagem } & \multicolumn{2}{|c|}{ com gessagem } & & \\
\hline & sem adubação & com adubaçāo & sem adubação & com adubação & & \\
\hline & - & - & $\mathrm{mg} / \mathrm{p}$ & anta -........... & - & 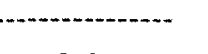 \\
\hline $\mathrm{CL}$ & $0,01 \mathrm{C}$ & $0,25 \mathrm{AB}$ & $0,09 \mathrm{~B}$ & $0,34 \mathrm{~A}$ & $0,36 \mathrm{~A}$ & $0,01 \mathrm{C}$ \\
\hline $\mathrm{CV}$ & $0,09 \mathrm{BC}$ & $0,25 \mathrm{AB}$ & $0,05 \mathrm{C}$ & $0,33 \mathrm{~A}$ & $0,60 \mathrm{~A}$ & $0,03 \mathrm{C}$ \\
\hline LA-6 & $0,16 \mathrm{~B}$ & $0,72 \mathrm{~A}$ & $0,02 \mathrm{C}$ & $0,23 \mathrm{AB}$ & $0,38 \mathrm{AB}$ & $0,20 \mathrm{~B}$ \\
\hline LV-2 & $0,15 \mathrm{~A}$ & $0,24 \mathrm{~A}$ & $0,03 \mathrm{~B}$ & $0,02 \mathrm{~B}$ & $0,49 \mathrm{~A}$ & $0,05 \mathrm{~B}$ \\
\hline SS & $0,04 \mathrm{~A}$ & $0,04 \mathrm{~A}$ & $0,04 \mathrm{~A}$ & $0,04 \mathrm{~A}$ & $0,04 \mathrm{~A}$ & $0,01 \mathrm{~B}$ \\
\hline
\end{tabular}

‡-Médias seguidas de mesma letra, nas colunas, não diferem entre si pelo teste de Tukey ao nível de $5 \%$. 
Tabela 63. Absorção de molibdênio pela parte aérea da cultura de arroz em solos adubados com composto de resíduo urbano.

\begin{tabular}{|c|c|c|c|c|c|c|}
\hline \multirow{3}{*}{$\begin{array}{l}\text { Solos } \\
\text { ácidos }\end{array}$} & \multicolumn{4}{|c|}{ Composto de resíduo urbano } & \multirow{3}{*}{$\begin{array}{c}\text { Calagem } \\
\mathrm{e} \\
\text { adubação }\end{array}$} & \multirow{3}{*}{ Testemunha } \\
\hline & \multicolumn{2}{|c|}{ sem calagem } & \multicolumn{2}{|c|}{ com calagem } & & \\
\hline & sem adubação & com adubação & sem adubação & com adubação & & \\
\hline & & ............... & $\mathrm{mg} / \mathrm{p}$ & anta --.---..- & -n-n-n & 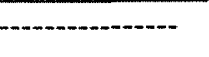 \\
\hline GPH & $0,58 \mathrm{~A}^{\ddagger}$ & $0,65 \mathrm{~A}$ & $0,48 \mathrm{~A}$ & $0,73 \mathrm{~A}$ & $0,73 \mathrm{~A}$ & $0,37 \mathrm{~A}$ \\
\hline AQd & $0,25 \mathrm{AB}$ & $0,35 \mathrm{AB}$ & $0,48 \mathrm{AB}$ & $0,30 \mathrm{AB}$ & $0,54 \mathrm{~A}$ & $0,17 \mathrm{~B}$ \\
\hline LUa & $0,46 \mathrm{~B}$ & $0,54 \mathrm{AB}$ & $0,03 \mathrm{C}$ & $1,19 \mathrm{~A}$ & $1,20 \mathrm{~A}$ & $0,22 \mathrm{~B}$ \\
\hline LE-1 & $0,26 \mathrm{CD}$ & $0,38 \mathrm{BC}$ & $0,23 \mathrm{CD}$ & $0,81 \mathrm{AB}$ & $1,14 \mathrm{~A}$ & $0,07 \mathrm{D}$ \\
\hline LE-2 & $0,07 \mathrm{BC}$ & $0,44 \mathrm{~A}$ & $0,03 \mathrm{C}$ & $0,02 \mathrm{C}$ & $0,23 \mathrm{AB}$ & $0,01 \mathrm{C}$ \\
\hline LA-1 & $0,33 \mathrm{~B}$ & $0,88 \mathrm{~A}$ & $0,03 \mathrm{C}$ & $1,06 \mathrm{~A}$ & $0,91 \mathrm{~A}$ & $0,31 \mathrm{~B}$ \\
\hline PV-1 & $1,04 \mathrm{~A}$ & $0,07 \mathrm{C}$ & $0,16 \mathrm{BC}$ & $0,46 \mathrm{AB}$ & $0,69 \mathrm{~A}$ & $0,17 \mathrm{BC}$ \\
\hline LA-2 & $0,92 \mathrm{AB}$ & $1,12 \mathrm{~A}$ & $0,4 \mathrm{~B}$ & $1,22 \mathrm{~A}$ & $1,39 \mathrm{~A}$ & $0,46 \mathrm{~B}$ \\
\hline LA-3 & $0,62 \mathrm{ABC}$ & $0,83 \mathrm{ABC}$ & $0,39 \mathrm{BC}$ & $1,05 \mathrm{~A}$ & $0,90 \mathrm{AB}$ & $0,33 \mathrm{C}$ \\
\hline TR-1 & $0,02 \mathrm{C}$ & $0,54 \mathrm{~A}$ & $0,18 \mathrm{~B}$ & $0,79 \mathrm{~A}$ & $0,73 \mathrm{~A}$ & $0,04 \mathrm{BC}$ \\
\hline LA-4 & $0,20 \mathrm{~B}$ & $0,40 \mathrm{~B}$ & $0,33 \mathrm{~B}$ & $0,03 \mathrm{C}$ & $1,05 \mathrm{~A}$ & $0,03 \mathrm{C}$ \\
\hline PV-2 & $0,63 \mathrm{~A}$ & $1,21 \mathrm{AB}$ & $0,68 \mathrm{~B}$ & $0,80 \mathrm{~B}$ & $2,08 \mathrm{~A}$ & $0,64 \mathrm{~B}$ \\
\hline LA-5 & $1,11 \mathrm{AB}$ & $1,37 \mathrm{~A}$ & $0,58 \mathrm{BC}$ & $1,51 \mathrm{~A}$ & $1,35 \mathrm{~A}$ & $0,37 \mathrm{C}$ \\
\hline PV -3 & $0,16 \mathrm{C}$ & $0,80 \mathrm{~A}$ & $0,28 \mathrm{BC}$ & $1,13 \mathrm{~A}$ & $0,56 \mathrm{AB}$ & $0,15 \mathrm{C}$ \\
\hline $\mathrm{LRa}$ & $0,32 \mathrm{AB}$ & $0,59 \mathrm{~A}$ & $0,31 \mathrm{AB}$ & $0,44 \mathrm{~A}$ & $0,35 \mathrm{~A}$ & $0,09 \mathrm{~B}$ \\
\hline LE-3 & $0,64 \mathrm{~A}$ & $0,49 \mathrm{~A}$ & $0,53 \mathrm{~A}$ & $0,74 \mathrm{~A}$ & $0,82 \mathrm{~A}$ & $0,45 \mathrm{~A}$ \\
\hline $\mathrm{PE}$ & $0,13 \mathrm{~A}$ & $0,32 \mathrm{~A}$ & $0,17 \mathrm{~A}$ & $0,11 \mathrm{~A}$ & $0,33 \mathrm{~A}$ & $0,12 \mathrm{~A}$ \\
\hline PV -4 & $0,54 \mathrm{~B}$ & $1,82 \mathrm{~A}$ & $0,10 \mathrm{C}$ & $0,67 \mathrm{~B}$ & $0,36 \mathrm{BC}$ & $0,26 \mathrm{BC}$ \\
\hline TR-2 & $0,37 \mathrm{AB}$ & $0,23 \mathrm{AB}$ & $0,38 \mathrm{AB}$ & $0,45 \mathrm{AB}$ & $0,62 \mathrm{~A}$ & $0,20 \mathrm{~B}$ \\
\hline $\mathrm{AQa}$ & $0,33 \mathrm{ABC}$ & $0,47 \mathrm{~A}$ & $0,14 \mathrm{BC}$ & $0,16 \mathrm{ABC}$ & $0,40 \mathrm{AB}$ & $0,11 \mathrm{C}$ \\
\hline LV-1 & $0,33 \mathrm{~A}$ & $0,57 \mathrm{~A}$ & $0,25 \mathrm{~A}$ & $0,60 \mathrm{~A}$ & $0,61 \mathrm{~A}$ & $0,35 \mathrm{~A}$ \\
\hline \multirow{3}{*}{$\begin{array}{l}\text { Solos } \\
\text { alcalinos }\end{array}$} & \multicolumn{4}{|c|}{ Composto de resíduo urbano } & \multirow{3}{*}{$\begin{array}{c}\text { Gessagem } \\
\text { e } \\
\text { adubação }\end{array}$} & \multirow{3}{*}{ Testemunha } \\
\hline & \multicolumn{2}{|c|}{ sem gessagem } & \multicolumn{2}{|c|}{ com gessagem } & & \\
\hline & sem adubaçāo & com adubação & sem adubaçāo & com adubação & & \\
\hline & - & (n) & $\mathrm{mg} / \mathrm{p}$ & anta -.............. & (1) & -nann \\
\hline CL & $0,01 \mathrm{~B}$ & $0,31 \mathrm{~A}$ & $0,13 \mathrm{~A}$ & $0,45 \mathrm{~A}$ & $0,29 \mathrm{~A}$ & $0,01 \mathrm{~B}$ \\
\hline $\mathrm{CV}$ & $0,09 \mathrm{AB}$ & $0,19 \mathrm{AB}$ & $0,05 \mathrm{BC}$ & $0,33 \mathrm{~A}$ & $0,32 \mathrm{~A}$ & $0,02 \mathrm{C}$ \\
\hline LA-6 & $0,29 \mathrm{AB}$ & $0,72 \mathrm{~A}$ & $0,01 \mathrm{C}$ & $0,10 \mathrm{~B}$ & $0,19 \mathrm{AB}$ & $0,25 \mathrm{AB}$ \\
\hline LV-2 & $0,17 \mathrm{AB}$ & $0,14 \mathrm{AB}$ & $0,02 \mathrm{C}$ & $0,02 \mathrm{BC}$ & $0,45 \mathrm{~A}$ & $0,07 \mathrm{BC}$ \\
\hline SS & $0,04 \mathrm{~A}$ & $0,04 \mathrm{~A}$ & $0,04 \mathrm{~A}$ & $0,04 \mathrm{~A}$ & $0,05 \mathrm{~A}$ & $0,02 \mathrm{~A}$ \\
\hline
\end{tabular}


Tabela 64. Absorção de níquel pela parte aérea da cultura de arroz em solos adubados com composto de resíduo urbano.

\begin{tabular}{|c|c|c|c|c|c|c|}
\hline \multirow{3}{*}{$\begin{array}{l}\text { Solos } \\
\text { ácidos }\end{array}$} & \multicolumn{4}{|c|}{ Composto de resíduo urbano } & \multirow{3}{*}{$\begin{array}{l}\text { Calagem } \\
\mathrm{e} \\
\text { adubação }\end{array}$} & \multirow{3}{*}{ Testemunha } \\
\hline & \multicolumn{2}{|c|}{ sem calagem } & \multicolumn{2}{|c|}{ com calagem } & & \\
\hline & sem adubação & com adubação & sem adubação & com adubação & & \\
\hline & & . & $\mathrm{mg} / \mathrm{p}$ & anta -................ & -................... & (n) \\
\hline GPH & $1,21 \mathrm{~A}^{\ddagger}$ & $1,28 \mathrm{~A}$ & $0,76 \mathrm{AB}$ & $1,39 \mathrm{~A}$ & $1,30 \mathrm{~A}$ & $0,25 \mathrm{~B}$ \\
\hline AQd & $0,19 \mathrm{~B}$ & $0,57 \mathrm{AB}$ & $0,93 \mathrm{~A}$ & $0,38 \mathrm{AB}$ & $1,08 \mathrm{~A}$ & $0,37 \mathrm{AB}$ \\
\hline LUa & $0,94 \mathrm{AB}$ & $0,54 \mathrm{~B}$ & $0,05 \mathrm{C}$ & $2,35 \mathrm{~A}$ & $2,43 \mathrm{~A}$ & 0,43 B \\
\hline LE-1 & 0,74 B & $0,85 \mathrm{~B}$ & $0,75 \mathrm{~B}$ & $2,71 \mathrm{~A}$ & $3,37 \mathrm{~A}$ & $0,11 \mathrm{C}$ \\
\hline LE-2 & $0,08 \mathrm{BC}$ & $1,05 \mathrm{~A}$ & $0,04 \mathrm{C}$ & $0,02 \mathrm{C}$ & $0,23 \mathrm{~B}$ & $0,02 \mathrm{C}$ \\
\hline LA-1 & $0,61 \mathrm{BC}$ & $1,83 \mathrm{~A}$ & $0,04 \mathrm{D}$ & $1,85 \mathrm{~A}$ & $0,88 \mathrm{AB}$ & $0,17 \mathrm{CD}$ \\
\hline PV-1 & $2,07 \mathrm{~A}$ & $0,13 \mathrm{C}$ & $0,27 \mathrm{BC}$ & $0,72 \mathrm{~B}$ & $0,55 \mathrm{~B}$ & $0,09 \mathrm{C}$ \\
\hline LA-2 & $0,48 \mathrm{C}$ & $1,79 \mathrm{AB}$ & $0,67 \mathrm{BC}$ & $2,98 \mathrm{~A}$ & $3,05 \mathrm{~A}$ & $1,23 \mathrm{ABC}$ \\
\hline LA-3 & $1,05 \mathrm{AB}$ & $1,72 \mathrm{AB}$ & $0,68 \mathrm{BC}$ & $2,48 \mathrm{~A}$ & $1,46 \mathrm{AB}$ & $0,31 \mathrm{C}$ \\
\hline TR-1 & $0,08 \mathrm{C}$ & $1,87 \mathrm{~A}$ & $0,66 \mathrm{~B}$ & $2,68 \mathrm{~A}$ & $2,04 \mathrm{~A}$ & $0,07 \mathrm{C}$ \\
\hline LA-4 & $0,40 \mathrm{~A}$ & $0,61 \mathrm{~A}$ & $0,43 \mathrm{~A}$ & $0,06 \mathrm{~B}$ & $0,57 \mathrm{~A}$ & $0,04 \mathrm{~B}$ \\
\hline PV-2 & $1,05 \mathrm{AB}$ & $2,16 \mathrm{~A}$ & $0,99 \mathrm{AB}$ & $1,27 \mathrm{AB}$ & $1,57 \mathrm{AB}$ & $0,70 \mathrm{~B}$ \\
\hline LA-5 & $2,05 \mathrm{~A}$ & $0,59 \mathrm{BC}$ & $1,38 \mathrm{AB}$ & $0,88 \mathrm{AB}$ & $1,68 \mathrm{AB}$ & $0,19 \mathrm{~B}$ \\
\hline PV -3 & $0,26 \mathrm{~B}$ & $1,42 \mathrm{~A}$ & $0,21 \mathrm{~B}$ & $2,48 \mathrm{~A}$ & $0,98 \mathrm{~A}$ & $0,22 \mathrm{~B}$ \\
\hline $\mathrm{LRa}$ & $0,46 \mathrm{~B}$ & $1,82 \mathrm{~A}$ & $0,58 \mathrm{~B}$ & $1,00 \mathrm{AB}$ & $1,06 \mathrm{AB}$ & $0,07 \mathrm{C}$ \\
\hline LE-3 & $0,62 \mathrm{~A}$ & $0,81 \mathrm{~A}$ & $0,45 \mathrm{~A}$ & $0,95 \mathrm{~A}$ & $1,30 \mathrm{~A}$ & $0,44 \mathrm{~A}$ \\
\hline PE & $0,19 \mathrm{~B}$ & $0,80 \mathrm{~A}$ & $0,36 \mathrm{AB}$ & $0,26 \mathrm{AB}$ & $0,50 \mathrm{AB}$ & $0,13 \mathrm{~B}$ \\
\hline PV -4 & $0,76 \mathrm{~B}$ & $4,45 \mathrm{~A}$ & $0,06 \mathrm{D}$ & $0,57 \mathrm{BC}$ & $0,23 \mathrm{BCD}$ & $0,20 \mathrm{CD}$ \\
\hline TR-2 & $0,70 \mathrm{AB}$ & $0,37 \mathrm{AB}$ & $0,98 \mathrm{~A}$ & $0,35 \mathrm{AB}$ & $0,83 \mathrm{AB}$ & $0,25 \mathrm{~B}$ \\
\hline $\mathrm{AQa}$ & $0,38 \mathrm{AB}$ & $1,08 \mathrm{~A}$ & $0,44 \mathrm{AB}$ & $0,91 \mathrm{AB}$ & $0,81 \mathrm{AB}$ & $0,28 \mathrm{~B}$ \\
\hline LV-1 & $0,19 \mathrm{~A}$ & $0,58 \mathrm{~A}$ & $0,43 \mathrm{~A}$ & $0,42 \mathrm{~A}$ & $0,45 \mathrm{~A}$ & $0,28 \mathrm{~A}$ \\
\hline \multirow{3}{*}{$\begin{array}{c}\text { Solos } \\
\text { alcalinos }\end{array}$} & \multicolumn{4}{|c|}{ Composto de resíduo urbano } & \multirow{3}{*}{$\begin{array}{l}\text { Gessagem } \\
\text { e } \\
\text { adubação }\end{array}$} & \multirow{3}{*}{ Testemunha } \\
\hline & \multicolumn{2}{|c|}{ sem gessagem } & \multicolumn{2}{|c|}{ com gessagem } & & \\
\hline & sem adubação & com adubaçāo & sem adubação & com adubação & & \\
\hline & (n) & - & $\ldots \mathrm{mg} / \mathrm{t}$ & anta -............ & - & .................. \\
\hline $\mathrm{CL}$ & $0,03 \mathrm{C}$ & $0,33 \mathrm{~B}$ & $0,42 \mathrm{~B}$ & $1,41 \mathrm{~A}$ & $0,97 \mathrm{AB}$ & $0,03 \mathrm{C}$ \\
\hline $\mathrm{CV}$ & $0,36 \mathrm{BC}$ & $0,65 \mathrm{ABC}$ & $0,22 \mathrm{C}$ & $1,26 \mathrm{~A}$ & $0,69 \mathrm{AB}$ & $0,03 \mathrm{D}$ \\
\hline LA-6 & $0,63 \mathrm{AB}$ & $1,79 \mathrm{~A}$ & $0,03 \mathrm{D}$ & $0,20 \mathrm{C}$ & $0,54 \mathrm{BC}$ & $0,85 \mathrm{AB}$ \\
\hline LV-2 & $0,45 \mathrm{AB}$ & $0,45 \mathrm{AB}$ & $0,05 \mathrm{D}$ & $0,08 \mathrm{CD}$ & $1,36 \mathrm{~A}$ & $0,23 \mathrm{BC}$ \\
\hline SS & $0,08 \mathrm{~A}$ & $0,12 \mathrm{~A}$ & $0,15 \mathrm{~A}$ & $0,14 \mathrm{~A}$ & $0,18 \mathrm{~A}$ & $0,07 \mathrm{~A}$ \\
\hline
\end{tabular}

\$-Médias seguidas de mesma letra, nas colunas, não diferem entre si pelo teste de Tukey ao nível de $5 \%$. 
Tabela 65. Absorção de zinco pela parte aérea da cultura de arroz em solos adubados com composto de resíduo urbano.

\begin{tabular}{|c|c|c|c|c|c|c|}
\hline \multirow{3}{*}{$\begin{array}{l}\text { Solos } \\
\text { ácidos }\end{array}$} & \multicolumn{4}{|c|}{ Composto de resíduo urbano } & \multirow{3}{*}{$\begin{array}{c}\text { Calagem } \\
\mathrm{e} \\
\text { adubação }\end{array}$} & \multirow{3}{*}{ Testemunha } \\
\hline & \multicolumn{2}{|c|}{ sem calagem } & \multicolumn{2}{|c|}{ com calagem } & & \\
\hline & sem adubação & com adubação & sem adubação & com adubação & & \\
\hline & \multicolumn{6}{|c|}{ - mg/planta - } \\
\hline GPH & $200,1 \mathrm{ABC}^{\ddagger}$ & $328,6 \mathrm{~A}$ & $149,4 \mathrm{BC}$ & $223,0 \mathrm{AB}$ & $94,2 \mathrm{C}$ & $97,7 \mathrm{C}$ \\
\hline $\mathrm{AQd}$ & $35,8 \mathrm{~B}$ & $56,2 \mathrm{~B}$ & $42,8 \mathrm{~B}$ & $63,8 \mathrm{~B}$ & $195,5 \mathrm{~A}$ & $32,9 \mathrm{~B}$ \\
\hline LUa & $193,3 \mathrm{~B}$ & $382,0 \mathrm{~A}$ & $2,6 \mathrm{C}$ & $143,7 \mathrm{~B}$ & $95,9 \mathrm{~B}$ & $10,2 \mathrm{C}$ \\
\hline LE-1 & $56,7 \mathrm{BC}$ & $60,0 \mathrm{BC}$ & $28,0 \mathrm{C}$ & $104,6 \mathrm{AB}$ & $153,4 \mathrm{~A}$ & $17,9 \mathrm{C}$ \\
\hline LE-2 & $19,7 \mathrm{BC}$ & $153,9 \mathrm{~A}$ & $4,3 \mathrm{BC}$ & $3,1 \mathrm{C}$ & $30,1 \mathrm{~B}$ & $3,6 \mathrm{BC}$ \\
\hline LA-1 & $57,5 \mathrm{C}$ & $161,8 \mathrm{AB}$ & $3,6 \mathrm{D}$ & $146,3 \mathrm{ABC}$ & $191.1 \mathrm{~A}$ & $81,6 \mathrm{BC}$ \\
\hline PV -1 & $195,5 \mathrm{~A}$ & $9,1 \mathrm{C}$ & $16,5 \mathrm{BC}$ & $64,6 \mathrm{~B}$ & $174,0 \mathrm{~A}$ & $24,6 \mathrm{BC}$ \\
\hline LA-2 & $484,2 \mathrm{~A}$ & $530,1 \mathrm{~A}$ & $50,6 \mathrm{C}$ & $112,7 \mathrm{BC}$ & $158,5 \mathrm{~B}$ & $62,1 \mathrm{C}$ \\
\hline LA-3 & $86,0 \mathrm{ABC}$ & $160,1 \mathrm{~A}$ & $64,6 \mathrm{BC}$ & $123,4 \mathrm{AB}$ & $189,0 \mathrm{~A}$ & $41,0 \mathrm{C}$ \\
\hline TR-1 & $1,3 \mathrm{C}$ & $102,2 \mathrm{~A}$ & $15,1 \mathrm{BC}$ & $73,7 \mathrm{~A}$ & $53,8 \mathrm{AB}$ & $6,1 \mathrm{C}$ \\
\hline LA -4 & $62,9 \mathrm{AB}$ & $142,1 \mathrm{~A}$ & $44,9 \mathrm{~B}$ & $2,7 \mathrm{C}$ & $145,2 \mathrm{~A}$ & $1,9 \mathrm{C}$ \\
\hline PV-2 & $172,1 \mathrm{~A}$ & 206,6 A & $119,9 \mathrm{AB}$ & $155,0 \mathrm{~A}$ & $145,4 \mathrm{~A}$ & $54,0 \mathrm{~B}$ \\
\hline LA-5 & $304,0 \mathrm{~A}$ & $230,7 \mathrm{AB}$ & $171,8 \mathrm{AB}$ & $258,2 \mathrm{AB}$ & $142,7 \mathrm{~B}$ & $27,6 \mathrm{C}$ \\
\hline PV-3 & $69,6 \mathrm{BC}$ & $226,1 \mathrm{~A}$ & $43,8 \mathrm{CD}$ & $126,2 \mathrm{AB}$ & $62,1 \mathrm{BC}$ & $9,6 \mathrm{D}$ \\
\hline $\mathrm{LRa}$ & $31,2 \mathrm{BC}$ & $130,5 \mathrm{~A}$ & $26,8 \mathrm{BC}$ & $100,2 \mathrm{~A}$ & $73,6 \mathrm{AB}$ & $10,4 \mathrm{C}$ \\
\hline LE-3 & $125,9 \mathrm{ABC}$ & $254,9 \mathrm{~A}$ & $75,3 \mathrm{BC}$ & $131,0 \mathrm{ABC}$ & $158,9 \mathrm{AB}$ & $55,9 \mathrm{C}$ \\
\hline $\mathrm{PE}$ & $27,8 \mathrm{~B}$ & $83,5 \mathrm{AB}$ & $30,3 \mathrm{~B}$ & $47,9 \mathrm{AB}$ & $109,4 \mathrm{~A}$ & $25,2 \mathrm{~B}$ \\
\hline PV -4 & $42,8 \mathrm{CD}$ & $220,2 \mathrm{~A}$ & $17,4 \mathrm{D}$ & $133,5 \mathrm{AB}$ & $96,4 \mathrm{BC}$ & $38,5 \mathrm{CD}$ \\
\hline TR-2 & $57,0 \mathrm{C}$ & $75,0 \mathrm{BC}$ & $69,5 \mathrm{BC}$ & $159,2 \mathrm{AB}$ & $178,5 \mathrm{~A}$ & $34,4 \mathrm{C}$ \\
\hline $\mathrm{AQa}$ & $105,5 \mathrm{AB}$ & 186,9 A & $72,2 \mathrm{BC}$ & $89,6 \mathrm{ABC}$ & $116,1 \mathrm{AB}$ & $34,6 \mathrm{C}$ \\
\hline LV-1 & $178,3 \mathrm{AB}$ & $302,9 \mathrm{~A}$ & $53,0 \mathrm{C}$ & $130,4 \mathrm{BC}$ & $170,5 \mathrm{AB}$ & $82,0 \mathrm{BC}$ \\
\hline \multirow{3}{*}{$\begin{array}{l}\text { Solos } \\
\text { alcalinos }\end{array}$} & \multicolumn{4}{|c|}{ Composto de resíduo urbano } & \multirow{3}{*}{$\begin{array}{c}\text { Gessagem } \\
\mathrm{e} \\
\text { adubação }\end{array}$} & \multirow{3}{*}{ Testemunha } \\
\hline & \multicolumn{2}{|c|}{ sem gessagem } & \multicolumn{2}{|c|}{ com gessagem } & & \\
\hline & sem adubação & com adubação & sem adubação & com adubação & & \\
\hline & 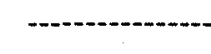 & (1) & $\mathrm{mg} / \mathrm{f}$ & anta -............. & (a) & - \\
\hline $\mathrm{CL}$ & $3,8 \mathrm{~B}$ & $56,9 \mathrm{~A}$ & $42,4 \mathrm{~A}$ & $81,6 \mathrm{~A}$ & $51,7 \mathrm{~A}$ & $1,3 \mathrm{C}$ \\
\hline $\mathrm{CV}$ & $7,1 \mathrm{AB}$ & $15,8 \mathrm{~A}$ & $3,0 \mathrm{BC}$ & $20,3 \mathrm{~A}$ & $20,7 \mathrm{~A}$ & $1,2 \mathrm{C}$ \\
\hline LA-6 & $26,7 \mathrm{AB}$ & $84,8 \mathrm{~A}$ & $1,3 \mathrm{C}$ & $25,8 \mathrm{AB}$ & $29,9 \mathrm{AB}$ & $10,2 \mathrm{~B}$ \\
\hline LV-2 & $24,7 \mathrm{~A}$ & $32,1 \mathrm{~A}$ & $2,2 \mathrm{~B}$ & $1,8 \mathrm{~B}$ & $45,1 \mathrm{~A}$ & $3,0 \mathrm{~B}$ \\
\hline SS & $3,1 \mathrm{~A}$ & $3,0 \mathrm{~A}$ & $2,0 \mathrm{~A}$ & $3,3 \mathrm{~A}$ & $2,5 \mathrm{~A}$ & $0,6 \mathrm{~B}$ \\
\hline
\end{tabular}

†- Médias seguidas de mesma letra, nas colunas, não diferem entre si pelo teste de Tukey ao nível de 5\%. 
Tabela 69. Absorção de chumbo pela parte aérea da cultura de arroz em solos adubados com composto de resíduo urbano.

\begin{tabular}{|c|c|c|c|c|c|c|}
\hline \multirow{3}{*}{$\begin{array}{l}\text { Solos } \\
\text { ácidos }\end{array}$} & \multicolumn{4}{|c|}{ Composto de resíduo urbano } & \multirow{3}{*}{$\begin{array}{c}\text { Calagem } \\
\mathrm{e} \\
\text { adubação }\end{array}$} & \multirow{3}{*}{ Testemunha } \\
\hline & \multicolumn{2}{|c|}{ sem calagem } & \multicolumn{2}{|c|}{ com calagem } & & \\
\hline & sem adubação & com adubação & sem adubaçāo & com adubação & & \\
\hline & \multicolumn{6}{|c|}{ - } \\
\hline GPH & $0,56 \mathrm{AB}^{\ddagger}$ & $1,09 \mathrm{~A}$ & $0,43 \mathrm{AB}$ & $0,60 \mathrm{AB}$ & $0,65 \mathrm{AB}$ & $0,28 \mathrm{~B}$ \\
\hline AQd & $0,14 \mathrm{~B}$ & $0,32 \mathrm{AB}$ & $0,48 \mathrm{AB}$ & $0,19 \mathrm{~B}$ & $0,66 \mathrm{~A}$ & $0,23 \mathrm{AB}$ \\
\hline LUa & $0,69 \mathrm{AB}$ & $0,45 \mathrm{~B}$ & $0,04 \mathrm{C}$ & $1,32 \mathrm{~A}$ & $1,53 \mathrm{~A}$ & $0,33 \mathrm{~B}$ \\
\hline LE-1 & $0,43 \mathrm{C}$ & $0,95 \mathrm{ABC}$ & $0,54 \mathrm{BC}$ & $1,31 \mathrm{AB}$ & $1,71 \mathrm{~A}$ & $0,09 \mathrm{D}$ \\
\hline LE-2 & $0,04 \mathrm{~B}$ & $0,69 \mathrm{~A}$ & $0,03 \mathrm{~B}$ & $0,02 \mathrm{~B}$ & $0,12 \mathrm{~B}$ & $0,02 \mathrm{~B}$ \\
\hline LA-1 & $0,41 \mathrm{BC}$ & $1,34 \mathrm{~A}$ & $0,03 \mathrm{D}$ & $1,30 \mathrm{~A}$ & $0,91 \mathrm{AB}$ & $0,26 \mathrm{C}$ \\
\hline PV-1 & $1,26 \mathrm{~A}$ & $0,08 \mathrm{C}$ & $0,19 \mathrm{BC}$ & $0,42 \mathrm{~B}$ & 0,42 B & $0,10 \mathrm{C}$ \\
\hline LA-2 & $0,81 \mathrm{~B}$ & $1,24 \mathrm{AB}$ & $0,56 \mathrm{~B}$ & $2,00 \mathrm{~A}$ & $2,17 \mathrm{~A}$ & $0,82 \mathrm{~B}$ \\
\hline LA-3 & $0,57 \mathrm{BC}$ & $0,62 \mathrm{ABC}$ & $0,39 \mathrm{BC}$ & $1,40 \mathrm{~A}$ & $0,79 \mathrm{AB}$ & $0,25 \mathrm{C}$ \\
\hline TR-1 & $0,04 \mathrm{C}$ & $0,97 \mathrm{~A}$ & $0,30 \mathrm{~B}$ & $1,26 \mathrm{~A}$ & $0,97 \mathrm{~A}$ & $0,04 \mathrm{C}$ \\
\hline LA-4 & $0,32 \mathrm{C}$ & $1,43 \mathrm{~A}$ & $0,35 \mathrm{BC}$ & $0,04 \mathrm{D}$ & $0,98 \mathrm{AB}$ & $0,03 \mathrm{D}$ \\
\hline PV -2 & $0,84 \mathrm{AB}$ & $1,41 \mathrm{AB}$ & $0,74 \mathrm{C}$ & $0,86 \mathrm{AB}$ & $1,8 \mathrm{~A}$ & $0,61 \mathrm{C}$ \\
\hline LA-5 & $1,33 \mathrm{~A}$ & $0,59 \mathrm{AB}$ & $0,70 \mathrm{~A}$ & $0,83 \mathrm{~A}$ & $0,95 \mathrm{~A}$ & $0,20 \mathrm{~B}$ \\
\hline PV -3 & $0,20 \mathrm{~B}$ & $1,40 \mathrm{~A}$ & $0,22 \mathrm{~B}$ & $1,73 \mathrm{~A}$ & $0,75 \mathrm{~A}$ & $0,18 \mathrm{~B}$ \\
\hline $\mathrm{LRa}$ & $0,32 \mathrm{~B}$ & $1,09 \mathrm{~A}$ & $0,36 \mathrm{~B}$ & $0,70 \mathrm{AB}$ & $0,65 \mathrm{AB}$ & $0,06 \mathrm{C}$ \\
\hline LE-3 & $0,46 \mathrm{AB}$ & $0,47 \mathrm{AB}$ & $0,39 \mathrm{AB}$ & $0,71 \mathrm{AB}$ & $1,00 \mathrm{~A}$ & $0,36 \mathrm{~B}$ \\
\hline $\mathrm{PE}$ & $0,15 \mathrm{ABC}$ & $0,51 \mathrm{~A}$ & $0,25 \mathrm{ABC}$ & $0,07 \mathrm{C}$ & $0,37 \mathrm{AB}$ & $0,13 \mathrm{BC}$ \\
\hline PV -4 & $0,64 \mathrm{~B}$ & $2,90 \mathrm{~A}$ & $0,08 \mathrm{C}$ & $0,09 \mathrm{C}$ & $0,22 \mathrm{BC}$ & $0,20 \mathrm{BC}$ \\
\hline TR-2 & $0,59 \mathrm{~A}$ & $0,19 \mathrm{AB}$ & $0,49 \mathrm{AB}$ & $0,15 \mathrm{~B}$ & $0,41 \mathrm{AB}$ & $0,17 \mathrm{~B}$ \\
\hline $\mathrm{AQa}$ & $0,14 \mathrm{~A}$ & $0,38 \mathrm{~A}$ & $0,21 \mathrm{~A}$ & $0,21 \mathrm{~A}$ & $0,35 \mathrm{~A}$ & $0,19 \mathrm{~A}$ \\
\hline $\mathrm{LV}-1$ & $0,07 \mathrm{C}$ & $0,40 \mathrm{~A}$ & $0,27 \mathrm{AB}$ & $0,32 \mathrm{AB}$ & $0,36 \mathrm{~A}$ & $0,24 \mathrm{AB}$ \\
\hline \multirow{3}{*}{$\begin{array}{l}\text { Solos } \\
\text { alcalinos }\end{array}$} & \multicolumn{4}{|c|}{ Composto de resíduo urbano } & \multirow{3}{*}{$\begin{array}{c}\text { Gessagem } \\
\text { e } \\
\text { adubação }\end{array}$} & \multirow{3}{*}{ Testemunha } \\
\hline & \multicolumn{2}{|c|}{ sem gessagem } & \multicolumn{2}{|c|}{ com gessagem } & & \\
\hline & sem adubação & com adubação & sem adubação & com adubação & & \\
\hline & -n-n-n & (n) & $\mathrm{mg} / \mathrm{p}$ & anta -............... & - & - \\
\hline $\mathrm{CL}$ & $0,02 \mathrm{~B}$ & $0,27 \mathrm{~A}$ & $0,25 \mathrm{~A}$ & $0,68 \mathrm{~A}$ & $0,37 \mathrm{~A}$ & $0,01 \mathrm{~B}$ \\
\hline $\mathrm{CV}$ & $0,16 \mathrm{BC}$ & $0,32 \mathrm{ABC}$ & $0,10 \mathrm{C}$ & $0,74 \mathrm{~A}$ & $0,44 \mathrm{AB}$ & $0,03 \mathrm{D}$ \\
\hline LA-6 & $0,34 \mathrm{AB}$ & $0,83 \mathrm{~A}$ & $0,02 \mathrm{C}$ & $0,12 \mathrm{~B}$ & $0,24 \mathrm{AB}$ & $0,35 \mathrm{AB}$ \\
\hline $\mathrm{LV}-2$ & $0,23 \mathrm{AB}$ & $0,16 \mathrm{~B}$ & $0,03 \mathrm{D}$ & $0,04 \mathrm{CD}$ & $0,67 \mathrm{~A}$ & $0,09 \mathrm{BC}$ \\
\hline SS & $0,04 \mathrm{~A}$ & $0,05 \mathrm{~A}$ & $0,07 \mathrm{~A}$ & $0,06 \mathrm{~A}$ & $0,07 \mathrm{~A}$ & $0,03 \mathrm{~A}$ \\
\hline
\end{tabular}

$\ddagger$ - Médias seguidas de mesma letra, nas colunas, não diferem entre si pelo teste de Tukey ao nível de $5 \%$. 
Tabela 70. Absorção de estrôncio pela parte aérea da cultura de arroz em solos adubados com composto de resíduo urbano.

\begin{tabular}{|c|c|c|c|c|c|c|}
\hline \multirow{3}{*}{$\begin{array}{l}\text { Solos } \\
\text { ácidos }\end{array}$} & \multicolumn{4}{|c|}{ Composto de resíduo urbano } & \multirow{3}{*}{$\begin{array}{c}\text { Calagem } \\
\mathrm{e} \\
\text { adubação }\end{array}$} & \multirow{3}{*}{ Testemunha } \\
\hline & \multicolumn{2}{|c|}{ sem calagem } & \multicolumn{2}{|c|}{ com calagem } & & \\
\hline & sem adubação & com adubação & sem adubação & com adubação & & \\
\hline & - & - & $\mathrm{mg} / \mathrm{pl}$ & anta --.............. & - & n \\
\hline GPH & $12,4 \mathrm{~A}^{\ddagger}$ & $33,0 \mathrm{AB}$ & $16,3 \mathrm{BC}$ & $37,8 \mathrm{~A}$ & $24,0 \mathrm{ABC}$ & $12,5 \mathrm{~A}$ \\
\hline AQd & $6,6 \mathrm{~B}$ & $13,4 \mathrm{~B}$ & $8,2 \mathrm{~B}$ & $13,8 \mathrm{~B}$ & $68,6 \mathrm{~A}$ & $11,9 \mathrm{~B}$ \\
\hline LUa & $9,4 \mathrm{~B}$ & $42,7 \mathrm{~A}$ & $0,9 \mathrm{C}$ & $38,7 \mathrm{~A}$ & $50,5 \mathrm{~A}$ & $1,3 \mathrm{C}$ \\
\hline LE-1 & $7,9 \mathrm{BCD}$ & $11,4 \mathrm{BC}$ & $4,2 \mathrm{CD}$ & $20,1 \mathrm{AB}$ & $29,6 \mathrm{~A}$ & $2,5 \mathrm{D}$ \\
\hline LE-2 & $2,3 \mathrm{~B}$ & $37,4 \mathrm{~A}$ & $1,0 \mathrm{~B}$ & $4,0 \mathrm{~B}$ & $25,5 \mathrm{~A}$ & $0,8 \mathrm{~B}$ \\
\hline LA-1 & $4,3 \mathrm{D}$ & $18,5 \mathrm{C}$ & $0,7 \mathrm{E}$ & $39,3 \mathrm{~B}$ & $72,9 \mathrm{~A}$ & $9,1 \mathrm{CD}$ \\
\hline PV-1 & $20,4 \mathrm{~B}$ & $4,0 \mathrm{C}$ & $2,6 \mathrm{C}$ & $39,7 \mathrm{~B}$ & $94,8 \mathrm{~A}$ & $7,8 \mathrm{C}$ \\
\hline LA-2 & $30,4 \mathrm{~B}$ & $47,4 \mathrm{AB}$ & $9,3 \mathrm{C}$ & $36,0 \mathrm{AB}$ & $59,6 \mathrm{~A}$ & $9,7 \mathrm{C}$ \\
\hline LA-3 & $19,8 \mathrm{D}$ & $44,9 \mathrm{BC}$ & $16,0 \mathrm{D}$ & $58,8 \mathrm{AB}$ & $93,9 \mathrm{~A}$ & $25,7 \mathrm{CD}$ \\
\hline TR-1 & $0,6 \mathrm{~B}$ & $16,4 \mathrm{~A}$ & $2,9 \mathrm{~B}$ & $14,3 \mathrm{~A}$ & $15,4 \mathrm{~A}$ & $0,9 \mathrm{~B}$ \\
\hline LA-4 & $6,0 \mathrm{C}$ & $35,9 \mathrm{~B}$ & $4,8 \mathrm{C}$ & $2,5 \mathrm{CD}$ & $68,6 \mathrm{~A}$ & $0,5 \mathrm{D}$ \\
\hline PV-2 & $18,5 \mathrm{BC}$ & $36,0 \mathrm{AB}$ & $11,8 \mathrm{C}$ & $35,5 \mathrm{AB}$ & $54,9 \mathrm{~A}$ & $11,5 \mathrm{C}$ \\
\hline LA-5 & $15,9 \mathrm{BC}$ & $31,1 \mathrm{AB}$ & $12,8 \mathrm{C}$ & $41,4 \mathrm{~A}$ & $31,5 \mathrm{AB}$ & $5,8 \mathrm{C}$ \\
\hline PV-3 & $4,0 \mathrm{~B}$ & $31,4 \mathrm{~A}$ & $3,6 \mathrm{~B}$ & $21,3 \mathrm{~A}$ & $25,0 \mathrm{~A}$ & $1,7 \mathrm{~B}$ \\
\hline LRa & $3,6 \mathrm{~B}$ & $38,7 \mathrm{~A}$ & $3,2 \mathrm{~B}$ & $29,0 \mathrm{~A}$ & $36,1 \mathrm{~A}$ & $2,4 \mathrm{~B}$ \\
\hline LE-3 & $8,6 \mathrm{BC}$ & $23,9 \mathrm{~A}$ & $9,1 \mathrm{BC}$ & $21,2 \mathrm{AB}$ & $28,3 \mathrm{~A}$ & $6,6 \mathrm{C}$ \\
\hline $\mathrm{PE}$ & $4,6 \mathrm{~B}$ & $27,9 \mathrm{~A}$ & $6,3 \mathrm{~B}$ & $19,4 \mathrm{~A}$ & $28,6 \mathrm{~A}$ & $5,3 \mathrm{~B}$ \\
\hline PV -4 & $5,9 \mathrm{~B}$ & $43,1 \mathrm{~A}$ & $2,7 \mathrm{~B}$ & $41,6 \mathrm{~A}$ & $39,1 \mathrm{~A}$ & $7,1 \mathrm{~B}$ \\
\hline TR-2 & $7,2 \mathrm{~B}$ & $24,2 \mathrm{~A}$ & $7,3 \mathrm{~B}$ & $29,3 \mathrm{~A}$ & $31,8 \mathrm{~A}$ & $6,5 \mathrm{~B}$ \\
\hline $\mathrm{AQa}$ & $7,0 \mathrm{C}$ & $41,5 \mathrm{AB}$ & $7,5 \mathrm{C}$ & $31,5 \mathrm{~B}$ & $74,2 \mathrm{~A}$ & $2,9 \mathrm{C}$ \\
\hline $\mathrm{LV}-1$ & $12,4 \mathrm{~B}$ & $35,7 \mathrm{~A}$ & $4,2 \mathrm{~B}$ & $30,1 \mathrm{~A}$ & $51,9 \mathrm{~A}$ & $8,7 \mathrm{~B}$ \\
\hline \multirow{3}{*}{$\begin{array}{c}\text { Solos } \\
\text { alcalinos }\end{array}$} & \multicolumn{4}{|c|}{ Composto de resíduo urbano } & \multirow{3}{*}{$\begin{array}{c}\text { Gessagem } \\
\mathrm{e} \\
\text { adubação }\end{array}$} & \multirow{3}{*}{ Testemunha } \\
\hline & \multicolumn{2}{|c|}{ sem gessagem } & \multicolumn{2}{|c|}{ com gessagem } & & \\
\hline & sem adubação & com adubação & sem adubação & com adubação & & \\
\hline & -................ & (-n & $\mathrm{mg} / \mathrm{p}$ & anta -.............. & (n) & 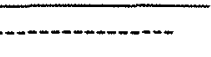 \\
\hline $\mathrm{CL}$ & $0,3 \mathrm{C}$ & $9,3 \mathrm{AB}$ & $4,8 \mathrm{~B}$ & $13,1 \mathrm{~A}$ & $9,6 \mathrm{AB}$ & $0,2 \mathrm{C}$ \\
\hline $\mathrm{CV}$ & $1,5 \mathrm{~B}$ & $6,9 \mathrm{~A}$ & $1,1 \mathrm{~B}$ & $7,3 \mathrm{~A}$ & $10,5 \mathrm{~A}$ & $0,6 \mathrm{~B}$ \\
\hline LA-6 & $3,3 \mathrm{~B}$ & $16,4 \mathrm{~A}$ & $0,5 \mathrm{C}$ & $10,0 \mathrm{~A}$ & $11,4 \mathrm{~A}$ & $2,7 \mathrm{~B}$ \\
\hline LV-2 & $4,6 \mathrm{~B}$ & $10,7 \mathrm{~A}$ & $1,8 \mathrm{C}$ & $1,2 \mathrm{C}$ & $16,2 \mathrm{~A}$ & $1,6 \mathrm{C}$ \\
\hline SS & $2,0 \mathrm{~A}$ & $2,8 \mathrm{~A}$ & $1,4 \mathrm{AB}$ & $2,6 \mathrm{~A}$ & $2,2 \mathrm{~A}$ & $0,8 \mathrm{~B}$ \\
\hline
\end{tabular}

$\ddagger$ - Médias seguidas de mesma letra, nas colunas, não diferem entre si pelo teste de Tukey ao nível de $5 \%$. 
Tabela 71. Absorção de titânio pela parte aérea da cultura de arroz em solos adubados com composto de resíduo urbano.

\begin{tabular}{|c|c|c|c|c|c|c|}
\hline \multirow{3}{*}{$\begin{array}{l}\text { Solos } \\
\text { ácidos }\end{array}$} & \multicolumn{4}{|c|}{ Composto de resíduo urbano } & \multirow{3}{*}{$\begin{array}{c}\text { Calagem } \\
e \\
\text { adubação }\end{array}$} & \multirow{3}{*}{ Testemunha } \\
\hline & \multicolumn{2}{|c|}{ sem calagem } & \multicolumn{2}{|c|}{ com calagem } & & \\
\hline & sem adubação & com adubação & sem adubação & com adubação & & \\
\hline & \multicolumn{6}{|c|}{ - } \\
\hline GPH & $1,41 \mathrm{C}^{\ddagger}$ & $6,52 \mathrm{~A}$ & $3,18 \mathrm{ABC}$ & $4,85 \mathrm{AB}$ & $1,93 \mathrm{BC}$ & $1,63 \mathrm{C}$ \\
\hline AQd & $0,69 \mathrm{~B}$ & $1,38 \mathrm{~B}$ & $1,72 \mathrm{AB}$ & $1,36 \mathrm{~B}$ & $4,72 \mathrm{~A}$ & $1,58 \mathrm{~B}$ \\
\hline LUa & $3,23 \mathrm{~A}$ & $3,18 \mathrm{~A}$ & $0,55 \mathrm{~B}$ & $3,99 \mathrm{~A}$ & $4,80 \mathrm{~A}$ & $0,49 \mathrm{~B}$ \\
\hline LE-1 & $3,85 \mathrm{AB}$ & $2,64 \mathrm{ABC}$ & $2,28 \mathrm{BC}$ & $4,86 \mathrm{AB}$ & $6,47 \mathrm{~A}$ & $1,27 \mathrm{C}$ \\
\hline LE-2 & $1,28 \mathrm{BC}$ & $4,96 \mathrm{~A}$ & $0,52 \mathrm{CD}$ & $0,40 \mathrm{CD}$ & $3,13 \mathrm{AB}$ & $0,29 \mathrm{D}$ \\
\hline LA-1 & $2,63 \mathrm{CD}$ & $4,18 \mathrm{BCD}$ & $1,58 \mathrm{D}$ & $9,89 \mathrm{AB}$ & $15,72 \mathrm{~A}$ & $5,32 \mathrm{BC}$ \\
\hline PV-1 & $5,82 \mathrm{AB}$ & $0,52 \mathrm{C}$ & $3,58 \mathrm{AB}$ & $7,59 \mathrm{~A}$ & $7,39 \mathrm{~A}$ & $2,06 \mathrm{~B}$ \\
\hline LA-2 & $9,46 \mathrm{~A}$ & $10,98 \mathrm{~A}$ & $4,17 \mathrm{~A}$ & $6,56 \mathrm{~A}$ & $7,88 \mathrm{~A}$ & $4,93 \mathrm{~A}$ \\
\hline LA-3 & $2,19 \mathrm{AB}$ & $4,72 \mathrm{AB}$ & $2,29 \mathrm{AB}$ & $5,47 \mathrm{~A}$ & $4,55 \mathrm{AB}$ & $1,63 \mathrm{~B}$ \\
\hline TR-1 & $1,09 \mathrm{~B}$ & $6,60 \mathrm{~A}$ & $0,91 \mathrm{~B}$ & $6,21 \mathrm{~A}$ & $4,37 \mathrm{~A}$ & $0,54 \mathrm{~B}$ \\
\hline LA-4 & $0,87 \mathrm{CD}$ & $5,50 \mathrm{~A}$ & $1,66 \mathrm{BC}$ & $0,28 \mathrm{DE}$ & $4,37 \mathrm{AB}$ & $0,21 \mathrm{E}$ \\
\hline PV -2 & $3,60 \mathrm{~A}$ & $4,54 \mathrm{~A}$ & $2,25 \mathrm{~A}$ & $3,74 \mathrm{~A}$ & $2,31 \mathrm{~A}$ & $1,66 \mathrm{~A}$ \\
\hline LA-5 & $3,02 \mathrm{~A}$ & $2,97 \mathrm{~A}$ & $2,45 \mathrm{~A}$ & $4,15 \mathrm{~A}$ & $2,98 \mathrm{~A}$ & $0,64 \mathrm{~B}$ \\
\hline PV-3 & $1,31 \mathrm{BC}$ & $4,40 \mathrm{~A}$ & $2,63 \mathrm{AB}$ & $7,32 \mathrm{~A}$ & $3,54 \mathrm{AB}$ & $0,59 \mathrm{C}$ \\
\hline $\mathrm{LRa}$ & $2,16 \mathrm{BC}$ & $7,85 \mathrm{~A}$ & $2,56 \mathrm{~B}$ & $7,62 \mathrm{~A}$ & $8,41 \mathrm{~A}$ & $0,72 \mathrm{C}$ \\
\hline LE-3 & $2,96 \mathrm{~B}$ & $7,72 \mathrm{AB}$ & $9,61 \mathrm{~A}$ & $16,81 \mathrm{~A}$ & $10,14 \mathrm{~A}$ & $2,89 \mathrm{~B}$ \\
\hline $\mathrm{PE}$ & $0,96 \mathrm{AB}$ & $2,51 \mathrm{~A}$ & $1,47 \mathrm{AB}$ & $1,26 \mathrm{AB}$ & $2,32 \mathrm{AB}$ & $0,78 \mathrm{~B}$ \\
\hline PV -4 & $4,08 \mathrm{AB}$ & $7,70 \mathrm{~A}$ & $1,81 \mathrm{~B}$ & $8,04 \mathrm{~A}$ & $3,04 \mathrm{AB}$ & $1,44 \mathrm{~B}$ \\
\hline TR-2 & $2,09 \mathrm{AB}$ & $2,42 \mathrm{AB}$ & $3,30 \mathrm{AB}$ & $5,47 \mathrm{~A}$ & $4,0 \mathrm{~A}$ & $1,20 \mathrm{~B}$ \\
\hline $\mathrm{AQa}$ & $2,46 \mathrm{~A}$ & $2,25 \mathrm{AB}$ & $1,45 \mathrm{AB}$ & $2,07 \mathrm{AB}$ & $2,23 \mathrm{AB}$ & $0,74 \mathrm{~B}$ \\
\hline LV-1 & $2,97 \mathrm{AB}$ & $5,21 \mathrm{~A}$ & $2,42 \mathrm{AB}$ & $5,61 \mathrm{~A}$ & $4,90 \mathrm{~A}$ & $1,32 \mathrm{~B}$ \\
\hline \multirow{3}{*}{$\begin{array}{c}\text { Solos } \\
\text { alcalinos }\end{array}$} & \multicolumn{4}{|c|}{ Composto de resíduo urbano } & \multirow{3}{*}{$\begin{array}{c}\text { Gessagem } \\
\text { e } \\
\text { adubação }\end{array}$} & \multirow{3}{*}{ Testemunha } \\
\hline & \multicolumn{2}{|c|}{ sem gessagem } & \multicolumn{2}{|c|}{ com gessagem } & & \\
\hline & sem adubação & com adubação & sem adubação & com adubação & & \\
\hline & - & - & $\mathrm{mg} / \mathrm{p}$ & anta -................ & (n) & - \\
\hline $\mathrm{CL}$ & $0,19 \mathrm{C}$ & $1,26 \mathrm{AB}$ & $0,91 \mathrm{~B}$ & $1,65 \mathrm{AB}$ & $2,56 \mathrm{~A}$ & $0,19 \mathrm{C}$ \\
\hline $\mathrm{CV}$ & $0,39 \mathrm{~B}$ & $1,72 \mathrm{~A}$ & $0,41 \mathrm{~B}$ & $1,87 \mathrm{~A}$ & $2,01 \mathrm{~A}$ & $0,20 \mathrm{~B}$ \\
\hline LA-6 & $0,84 \mathrm{~B}$ & $3,55 \mathrm{~A}$ & $0,22 \mathrm{C}$ & $2,05 \mathrm{AB}$ & $2,15 \mathrm{AB}$ & $1,06 \mathrm{~B}$ \\
\hline LV-2 & $0,61 \mathrm{AB}$ & $0,92 \mathrm{AB}$ & $0,18 \mathrm{C}$ & $0,20 \mathrm{C}$ & $1,24 \mathrm{~A}$ & $0,38 \mathrm{BC}$ \\
\hline SS & $0,63 \mathrm{~A}$ & $0,56 \mathrm{~A}$ & $0,35 \mathrm{~A}$ & $0,42 \mathrm{~A}$ & $0,76 \mathrm{~A}$ & $0,34 \mathrm{~A}$ \\
\hline
\end{tabular}

$\$$ - Médias seguidas de mesma letra, nas colunas, não diferem entre si pelo teste de Tukey ao nível de $5 \%$. 
que ocorrem em baixas concentrações na parte aérea e se acumulam principalmente nas raizes (Melo et al., 1997).

\subsection{Efeito do enriqueciment o do composto de resíduo urbano com $\mathrm{Cd}, \mathrm{Cu}, \mathrm{Mn}, \mathrm{Pb}$ e Zn sobre a extração de metais no solo}

Os resultados das análises das amostras de terra do experimento II, para os teores de cádmio, cobre, manganês, chumbo e zinco nos diferentes solos, pelo extrator DTPA, são apresentados nas Figuras 7A, 7B, 7C, 8A e 8B, respectivamente.

Verificou-se que as extrações de $\mathrm{Cd}, \mathrm{Cu}, \mathrm{Mn}, \mathrm{Pb}$ e $\mathrm{Zn}$ com DTPA apresentaram regressões lineares altamente significativas $\left(R^{2}>0,90\right)$ para todos os metais. Dos metais aplicados pelo composto enriquecido, o cádmio e o manganês foram os que apresentaram maiores valores. Os teores elevados de Mn são em parte devido ao teor natural somado a fração mais solúvel derivada do composto enriquecido. No caso do $\mathrm{Cd}$, todo o conteúdo foi derivado do composto enriquecido. Este fato demonstra que o Cd está presente em uma fração mais solúvel, podendo causar efeitos tóxicos às plantas e animais.

Foi, Também observado que os teores de $\mathrm{K}, \mathrm{Ca}, \mathrm{Mg}, \mathrm{P}, \mathrm{B}, \mathrm{Fe}, \mathrm{Co}, \mathrm{Cr}, \mathrm{Ni}$, $\mathrm{Ti}, \mathrm{Ba}, \mathrm{Sr}$ e V, nos solos do experimento II, não foram modificados pelas doses de enriquecimento do composto de resíduo urbano com os metais $\mathrm{Cd}, \mathrm{Cu}, \mathrm{Mn}, \mathrm{Pb}$ e $\mathrm{Zn}$ (dados não apresentados, semelhantes aos obtidos no experimento $I$ e já foram discutidos).

\subsection{Efeito do enriqueciment o do composto de resíduo urbano com $\mathrm{Cu}, \mathrm{Cd}, \mathrm{Mn}, \mathrm{Pb}$} e Zn sobre a Produção de matéria seca de plantas de arroz

O efeito do enriquecimento do composto de lixo sobres a produção de matéria seca da parte aérea e das raízes das plantas de arroz é apresentado pela Figura 9. Observou-se que não houve redução no desenvolvimento das plantas até o nível de 30 $\mathrm{mg} \mathrm{dm}{ }^{-3}$. Nos solos LA-5 e SS, houve tendência de aumento de produção entre os níveis 
0 a 15 e 0 a $30 \mathrm{mg} \mathrm{dm}^{-3}$. O solo PV-3 apresentou maior capacidade de reagir aos altos níveis de metais aplicados, o que pode estar relacionado ao fato deste solo apresentar alto teor de matéria orgânica nativa (40.83 $\mathrm{g} \mathrm{dm}^{-3}$ de M.O.). De um modo geral foi observado o mesmo comportamento com a produção de matéria seca das raízes.

Foi observado por Bingham et al. (1975) que, dentre quatorze espécies vegetais, o arroz foi a única que apresentou tolerância à doses elevadas de Cd. Eles observaram que a aplicação ao solo de 0 a $640 \mathrm{mg} \mathrm{kg}^{-1}$ de $\mathrm{Cd}$, na forma de lodo de esgoto enriquecido com $\mathrm{CdSO}_{4}$, causou o aumento da produção relativa de arroz. Espécies susceptíveis, como o espinafre, alface, milho, cenoura e soja, tiveram redução de $25 \%$ na produção relativa com a aplicação de 4 a $20 \mathrm{mg} \mathrm{kg}^{-1}$ de Cd. Espécies com tolerância média, tais como tomate, repolho e abobrinha, tiveram redução de $25 \%$ na produção relativa com a aplicação de 160 a $170 \mathrm{mg} \mathrm{kg}^{-1} \mathrm{de} \mathrm{Cd}$.

\subsection{Efeito do enriquecimento do composto de resíduo urbano com $\mathrm{Cu}, \mathrm{Cd}, \mathrm{Mn}, \mathrm{Pb}$ e Zn sobre a absorção de metais em plantas de arroz}

Os efeitos da aplicação ao solo do composto enriquecido com cádmio, cobre, manganês e chumbo e zinco sobre a absorção destes metais em plantas de arroz $\mathrm{Cd}, \mathrm{Cu}, \mathrm{Mn}, \mathrm{Pb}$ e $\mathrm{Zn}$ são apresentados nas Figuras $10,11,12,13$ e 14, respectivamente.

Pela Figura 10, pode-se observar que houve aumento, tanto na absorção quanto na concentração de $\mathrm{Cd}$ devido às doses de enriquecimento com metais. Para os demais metais, foi observado tendência de diminuição da absorção com aumento na concentração.

Foi observado, também, que há uma forte tendência de diminuição na concentração de $\mathrm{K}$, quando há um aumento nas concentrações de $\mathrm{Ca}, \mathrm{Mg}$ e $\mathrm{Na}$, principalmente do $\mathrm{Ca}$ (dados não apresentados). Relações de Ca:Mg próxima de 1 estão relacionadas com uma maior produção de matéria seca. Quando essa relação aumenta $(>1,5)$ a produção de matéria seca é baixa. Esse efeito deve estar relacionado com os altos teores de Ca presente no solo devido à aplicação do composto e com o aumento do pH e condutividade do solo, alterando o crescimento, nutrição e físiologia das plantas. 

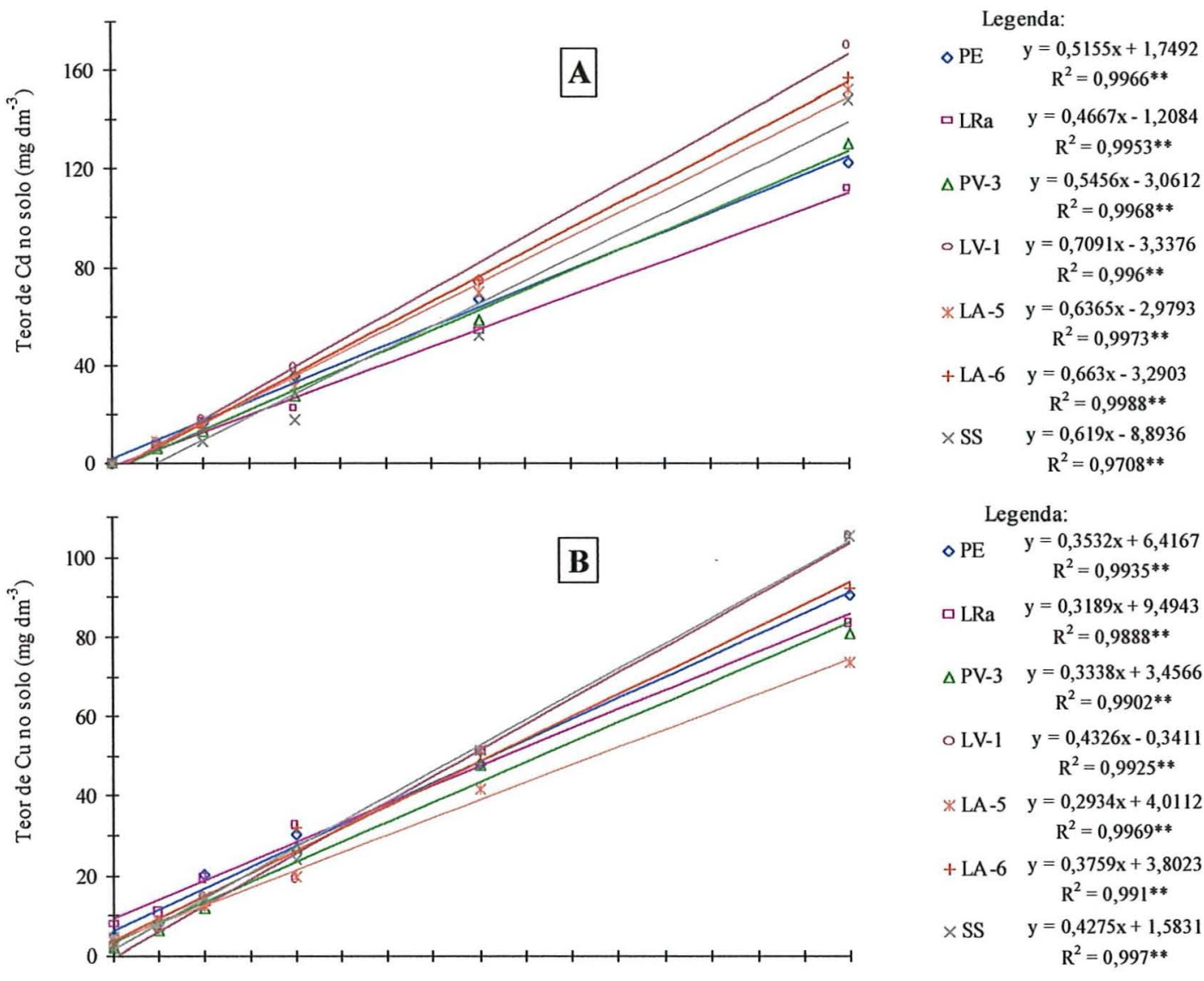

Legenda:

$$
\begin{aligned}
& \diamond P E \quad y=0,3532 x+6,4167 \\
& \mathrm{R}^{2}=0,9935^{* *} \\
& \text { 口 LRa } y=0,3189 x+9,4943 \\
& \mathrm{R}^{2}=0,9888^{* *} \\
& \triangle \mathrm{PV}-3 \quad \mathrm{y}=0,3338 \mathrm{x}+3,4566 \\
& \mathrm{R}^{2}=0,9902^{* *} \\
& \text { o LV-1 } \quad \mathrm{y}=0,4326 \mathrm{x}-0,3411 \\
& \mathrm{R}^{2}=0,9925^{* *} \\
& \text { * LA }-5 \quad \mathrm{y}=0,2934 \mathrm{x}+4,0112 \\
& \mathrm{R}^{2}=0,9969^{* *} \\
& \text { + LA -6 } \quad \mathrm{y}=0,3759 \mathrm{x}+3,8023 \\
& \mathrm{R}^{2}=0,991^{* *} \\
& \begin{aligned}
& \mathrm{SS} \quad \mathrm{y}= 0,4275 \mathrm{x}+1,5831 \\
& \mathrm{R}^{2}=0,997^{* *}
\end{aligned}
\end{aligned}
$$

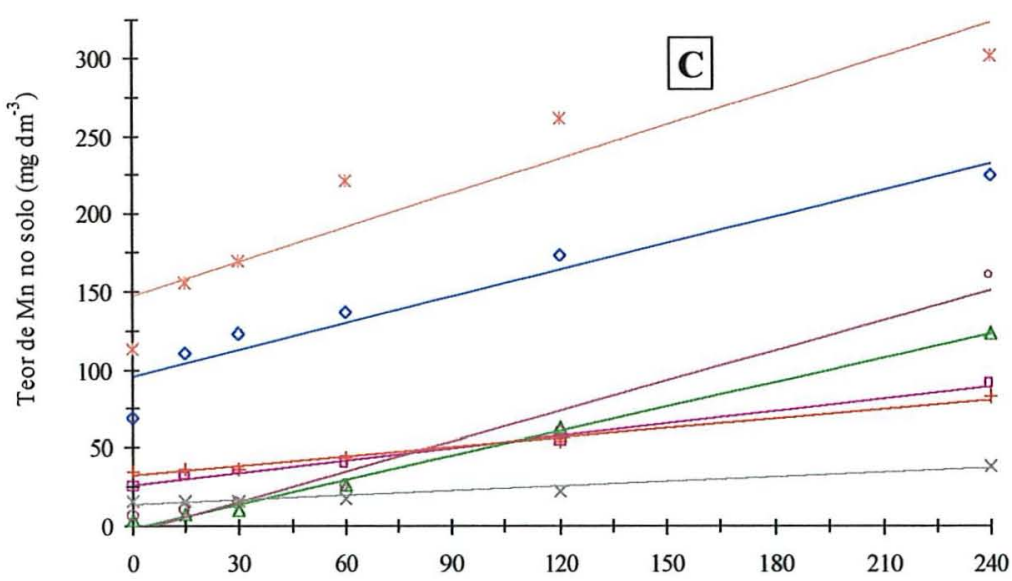

$$
\begin{aligned}
& \text { Legenda: } \\
& \diamond P E \quad y=0,5766 x+95,243 \\
& \mathbf{R}^{2}=0,9289^{* *} \\
& \text { 口 LRa } y=0,2636 x+26,026 \\
& \mathrm{R}^{2}=0,9931^{* *} \\
& \triangle \mathrm{PV}-3 \quad \mathrm{y}=0,5177 \mathrm{x}-1,3768 \\
& \mathrm{R}^{2}=0,9947^{* *}
\end{aligned}
$$

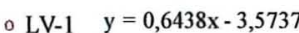

$$
\begin{aligned}
& \mathrm{R}^{2}=0,9755^{* *} \\
& \text { * LA }-5 \quad \mathrm{y}=0,733 \mathrm{x}+147,46 \\
& \mathrm{R}^{2}=0,8696^{* *} \\
& \text { + LA-6 } \quad y=0,203 x+32,468 \\
& \mathrm{R}^{2}=0,9863^{* *} \\
& \times \text { SS } \quad y=0,0983 x+13,733 \\
& \mathrm{R}^{2}=0,9543^{* *}
\end{aligned}
$$

Doses de $\mathrm{Cd}, \mathrm{Cu}, \mathrm{Mn}, \mathrm{Pb}$ e $\mathrm{Zn}$ ( $\mathrm{mg} \mathrm{dm}^{-3}$ ) aplicado ao solo pelo composto enriquecido

Figura 7. Efeito da aplicação de composto de resíduo urbano enriquecido com cádmio, cobre, chumbo, manganês e zinco sobre os teores de cadmio (A), cobre (B) e manganês (C) no solo. 

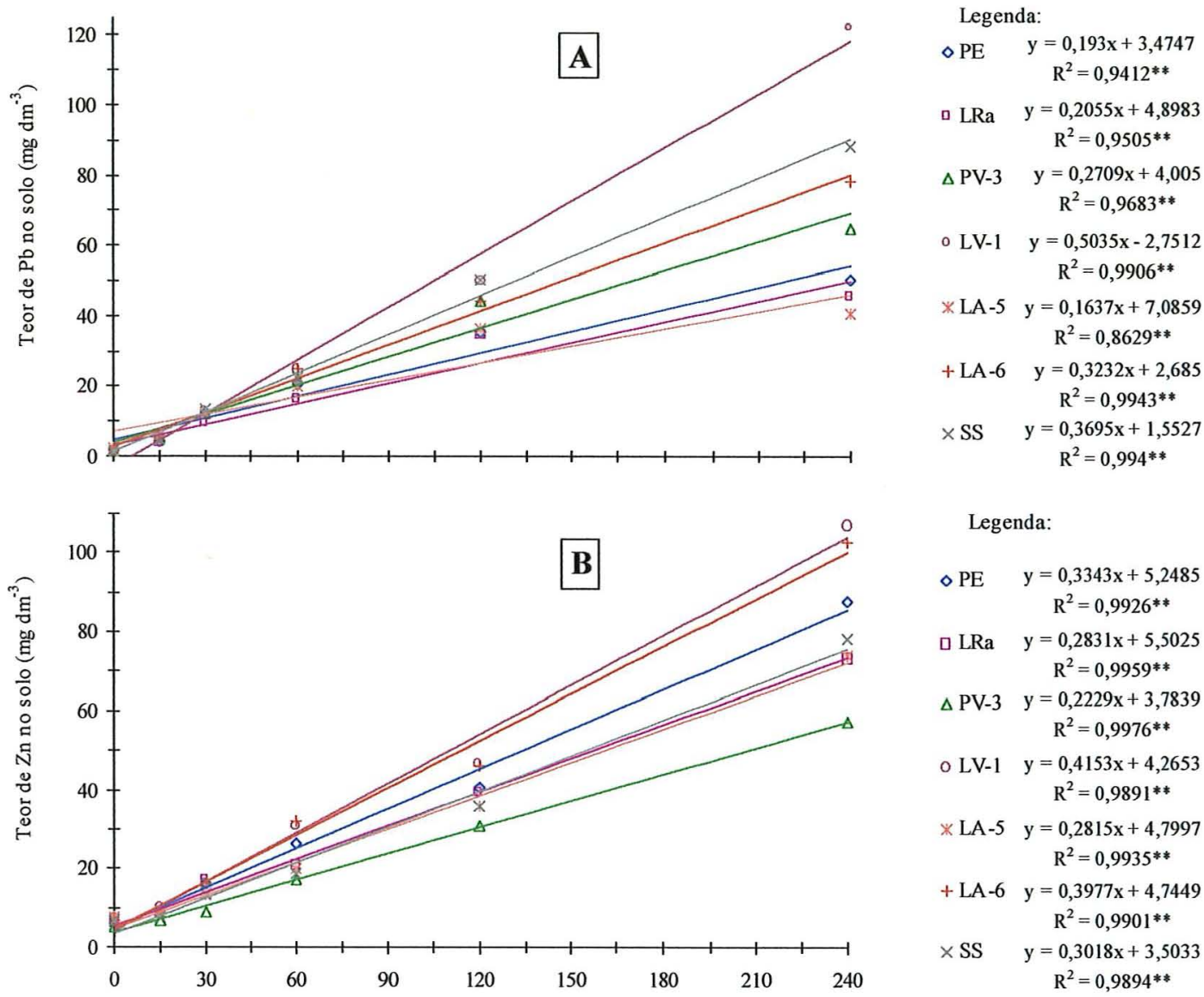

Legenda:

$\diamond \mathrm{PE} \quad \mathrm{y}=0,3343 \mathrm{x}+5,2485$ $\mathrm{R}^{2}=0,9926^{* *}$

$\square$ LRa $y=0,2831 x+5,5025$ $\mathrm{R}^{2}=0,9959^{* *}$

$\triangle \mathrm{PV}-3 \quad \mathrm{y}=0,2229 \mathrm{x}+3,7839$ $\mathrm{R}^{2}=0,9976^{* *}$

○ LV-1 $y=0,4153 x+4,2653$ $\mathrm{R}^{2}=0,9891^{* *}$

* LA-5 y $=0,2815 x+4,7997$ $\mathrm{R}^{2}=0,9935^{* *}$

+ LA-6 $y=0,3977 x+4,7449$ $\mathrm{R}^{2}=0,9901^{* *}$

$\times$ SS $\quad y=0,3018 x+3,5033$ $\mathrm{R}^{2}=0,9894^{* *}$

Doses de $\mathrm{Cd}, \mathrm{Cu}, \mathrm{Mn}, \mathrm{Pb}$ e $\mathrm{Zn}\left(\mathrm{mg} \mathrm{dm}^{-3}\right.$ ) aplicado ao solo pelo composto enriquecido

Figura 8. Efeito da aplicação de composto de resíduo urbano enriquecido com cádmio, cobre, chumbo, manganês e zinco sobre os teores de chumbo (A) e zinco (B) no solo. 


\subsection{Avaliação da eficiência a gronômica dos extratores}

As Tabelas 72 e 73 apresentam os coeficientes de correção entre a extração de nutrientes e metais pelos diferentes extratores e absorção de nutrientes e metais pela parte aérea do arroz, no $1^{\circ}$ cultivo do experimento I. Foram feitas regressões considerando três conjuntos de dados: um com as médias de todos os solos, outro só com as médias dos solos ácidos e outro com os solos calcários e salino-sódico. No conjunto de todos os solos, detectou-se que praticamente todos os extratores foram significativos para o $\mathrm{K}, \mathrm{P}, \mathrm{Cu}, \mathrm{Fe}, \mathrm{Mn}, \mathrm{Zn}, \mathrm{Ba}, \mathrm{Cd}$ e Sr. O DTPA apresentou superioridade para o B e Mo. Considerando-se somente os solos ácidos, praticamente todos os extratores foram significativos com a extração de $\mathrm{K}, \mathrm{P}, \mathrm{Mg}, \mathrm{P}, \mathrm{B}, \mathrm{Cu}, \mathrm{Fe}, \mathrm{Mn}$, $\mathrm{Zn}, \mathrm{Ba}, \mathrm{Cd}, \mathrm{Cr}, \mathrm{Na}$ e Sr. Mas os extratores Mehlich-1 e Mehlich-3 se destacaram pelos maiores coeficientes de correlação. Para os solos alcalinos, os extratores praticamente não apresentaram correlação, embora o Mehlich-3 tenha sido um pouco superior.

Observou-se que os teores obtidos pelo extrator Mehlich-3, para os diversos elementos avaliados, geralmente foram maiores que os resultados dos demais extratores. Todavia, os maiores teores de $\mathrm{P}$ foram promovidos pelo método da resina, método este que é tido como o melhor avaliador da disponibilidade de $\mathrm{P}$ em solos ácidos (Raij et. al., 1987). O extrator AA-EDTA. $\mathrm{Na}_{2}$ tendeu a apresentar teores superiores aos do Mehlich-1 e Wolf-Morgan, enquanto que a solução $\mathrm{CaCl}_{2} \quad 0,01 \mathrm{~mol} \mathrm{~L}^{-1}$ extraiu baixas concentrações dos elementos. A metodologia empregada permitiu, ao menos, a utilização do extrato em $\mathrm{CaCl}_{2} \quad 0,01 \mathrm{~mol} \mathrm{~L}^{-1}$ para se avaliar o $\mathrm{pH}$, a acidez potencial (através do $\mathrm{pH}$ SMP) e teor de $\mathrm{S}_{-} \mathrm{SO}_{4}{ }^{2-}$ paralelamente com a análise dos elementos via ICP-AES. 

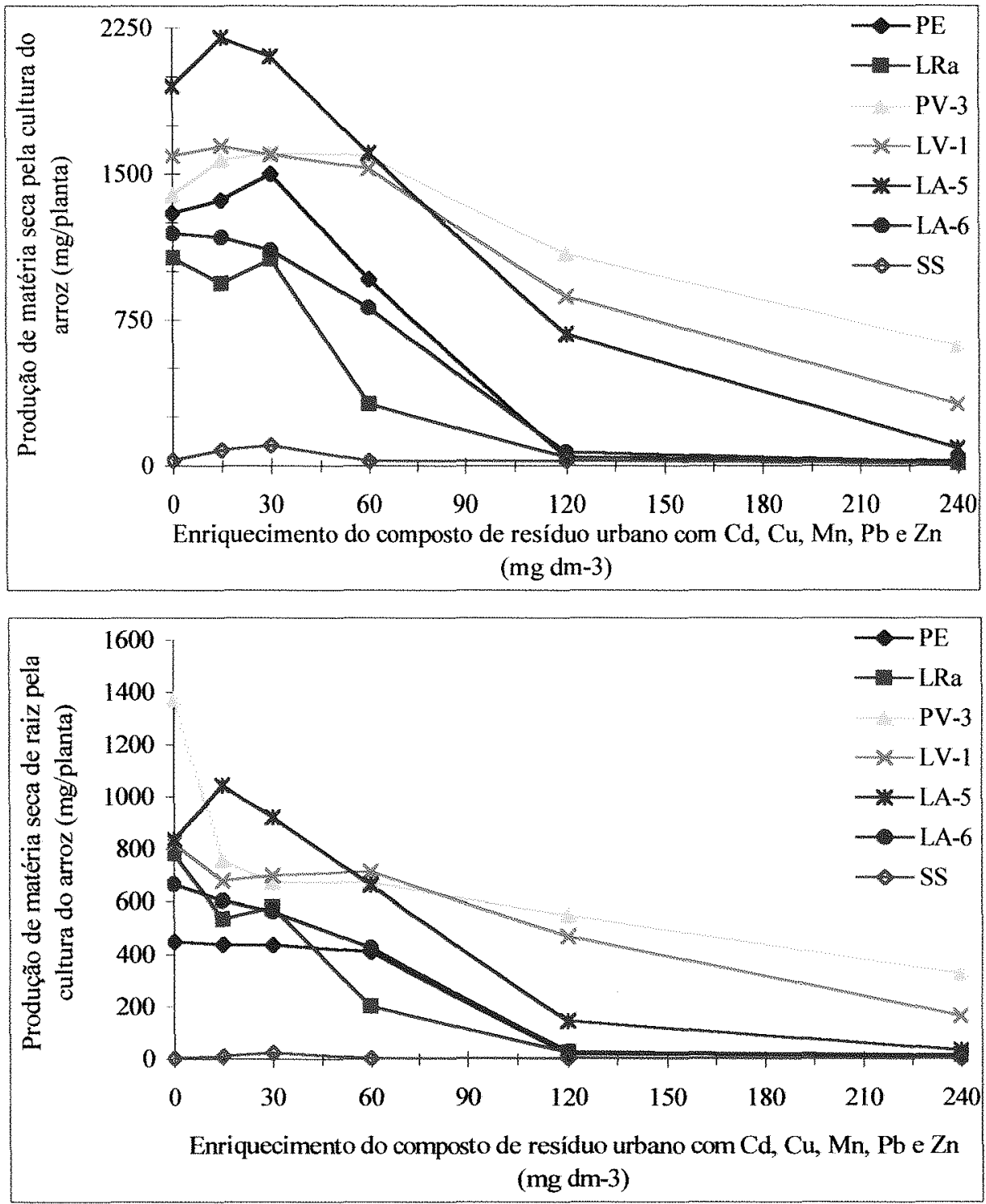

Figura 9. Efeito da aplicação de composto de resíduo urbano enriquecido com $\mathrm{Cd}, \mathrm{Cu}, \mathrm{Mn}, \mathrm{Pb}$ e Zn sobre a produção de matéria seca da parte aérea e raiz da cultura de arroz. 
A Tabela 74 apresenta as correlações entre os teores obtido pelos diferentes extratores e os valores de absorção, concentração, matéria seca da parte aérea e da raízes obtidas na cultura do arroz no experimento II. De um modo geral, todos os extratores apresentaram correlações significativas. Uma parcela significativa destas correlações, é devido aos elevados teores de metais no solo proporcionados pelo composto na dose de $240 \mathrm{mg} \mathrm{dm}^{-3}$ de cada um dos metais. 


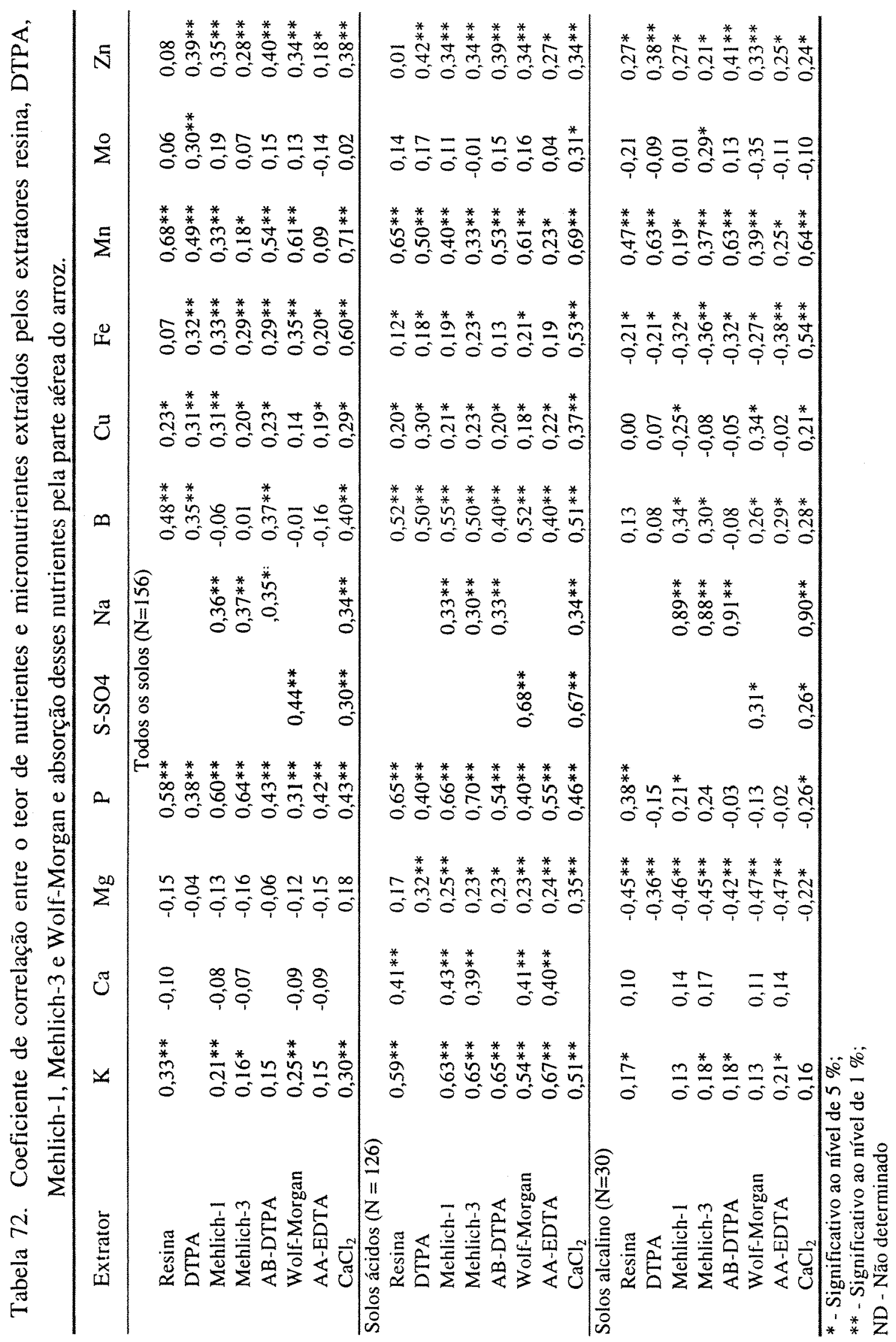




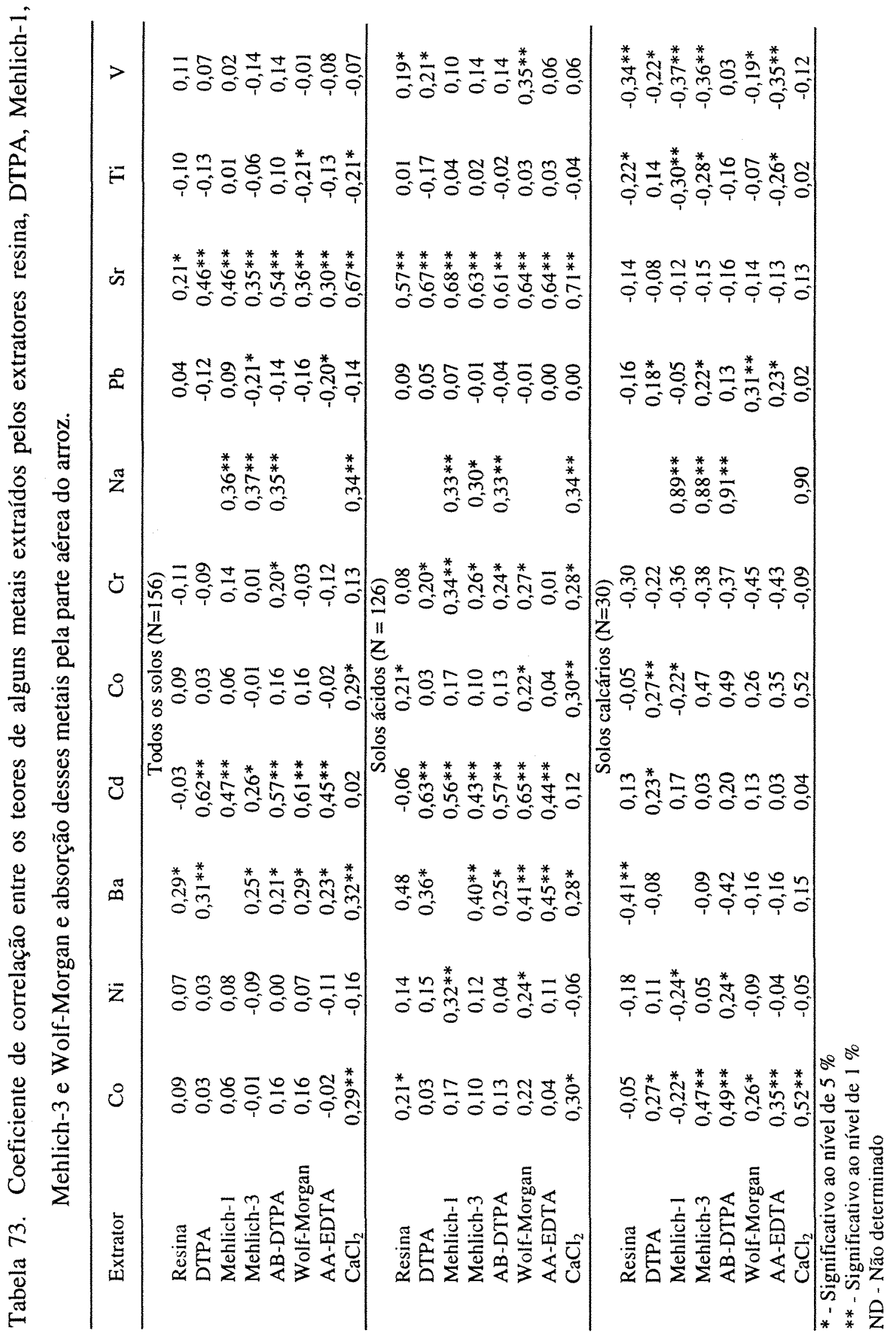




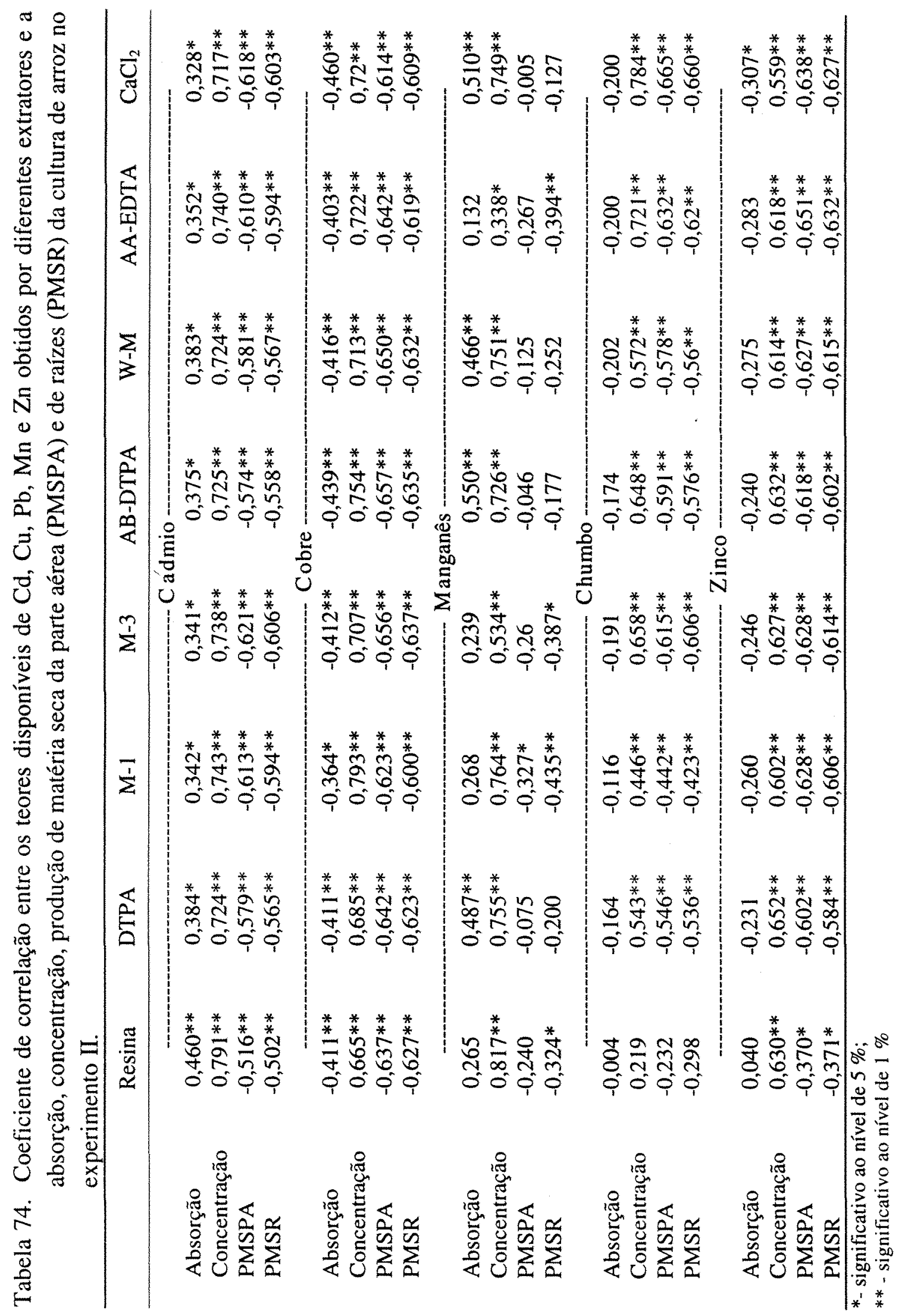




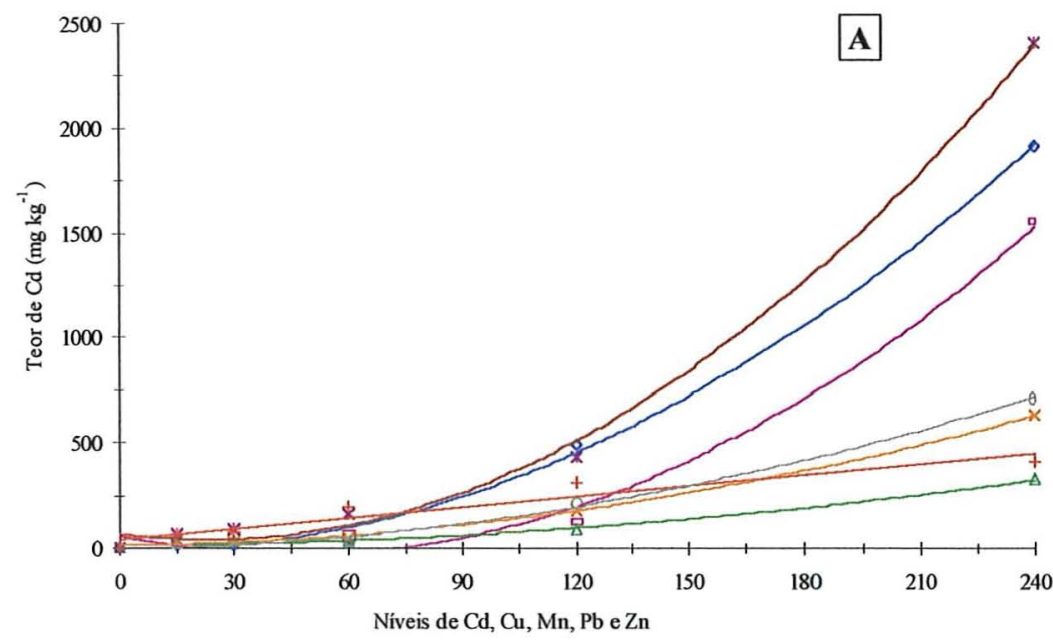

Legenda:
○E $\quad y=0,0352 x^{2}-0,4098 x-3,8495$

$\quad \mathrm{R}^{2}=0,9977^{* *}$

- LRa $\quad \mathrm{y}=0,0417 \mathrm{x}^{2}-3,8716 \mathrm{x}+59,885$ $\mathrm{R}^{2}=0,9908^{* *}$

$\triangle P V-3 \quad y=0,0052 x^{2}+0,055 x+14,02$ $\mathrm{R}^{2}=0,9942^{* *}$

$x$ LV-1 $\quad y=0,01 x^{2}+0,1789 x+13,419$ $\mathrm{R}^{2}=0,9983^{* *}$

$x$ LA-5 $y=0,0504 x^{2}-2,3831 x+69,282$ $\mathrm{R}^{2}=0,9964 * *$

0 LA-6 $y=0,0112 x^{2}+0,3516 x-6,7944$ $\mathrm{R}^{2}=0,9969^{* *}$

$y=1,6947 x+45,01$ $\mathrm{R}^{2}=0,9085^{* *}$

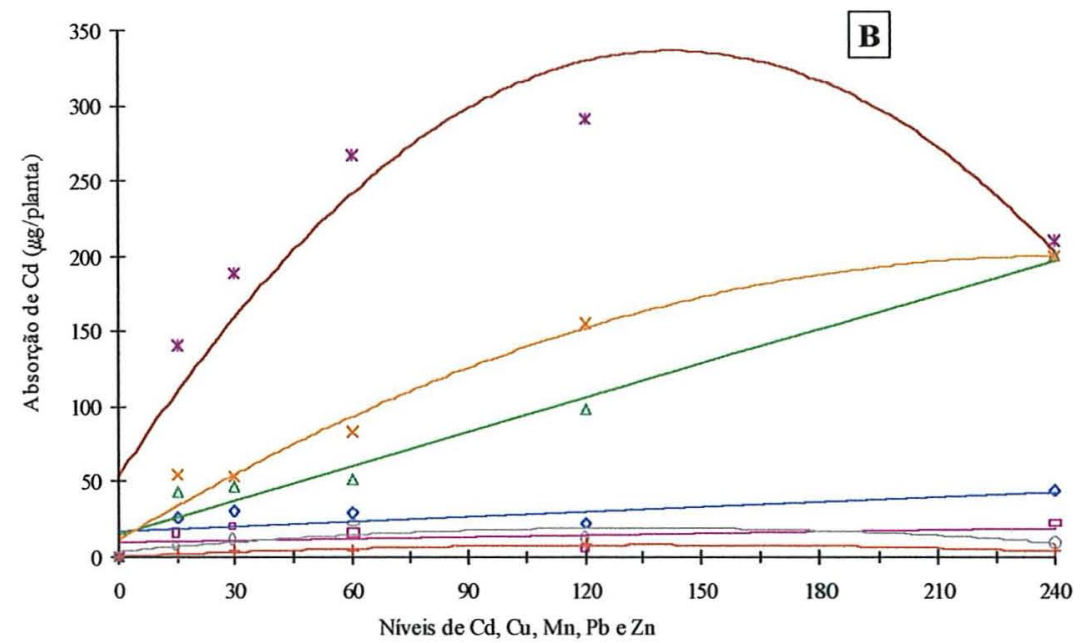

Legenda:

$\diamond P E \quad y=0,1107 x+17,092$ $\mathrm{R}^{2}=0,4747^{*}$

ㅁ LRa $y=0,0387 x+10,43$ $\mathrm{R}^{2}=0,1655^{\mathrm{NS}}$

$\triangle \mathrm{PV}-3 \quad \mathrm{y}=0,7598 \mathrm{x}+14,716$ $\mathrm{R}^{2}=0,97^{* *}$

$x$ LV-1 $\quad y=-0,0032 x^{2}+1,5608 x+11,749$ $\mathrm{R}^{2}=0,9751^{* *}$

* LA-5 $y=-0,014 x^{2}+3,9744 x+53,888$ $\mathrm{R}^{2}=0,8761^{* *}$

0 LA-6 $y=-0,0009 x^{2}+0,2302 x+4,2032$ $\mathrm{R}^{2}=0,5943^{*}$

+ SS $\quad y=-0,0004 x^{2}+0,1179 x+0,5435$ $\mathrm{R}^{2}=0,9156^{*}$

Figura 10. Efeito da aplicação de composto de resíduo urbano enriquecido com cádmio, cobre, manganês, chumbo e zinco sobre os teores de cádmio (A) e absorção de cádmio (B) na parte aérea da cultura de arroz. 

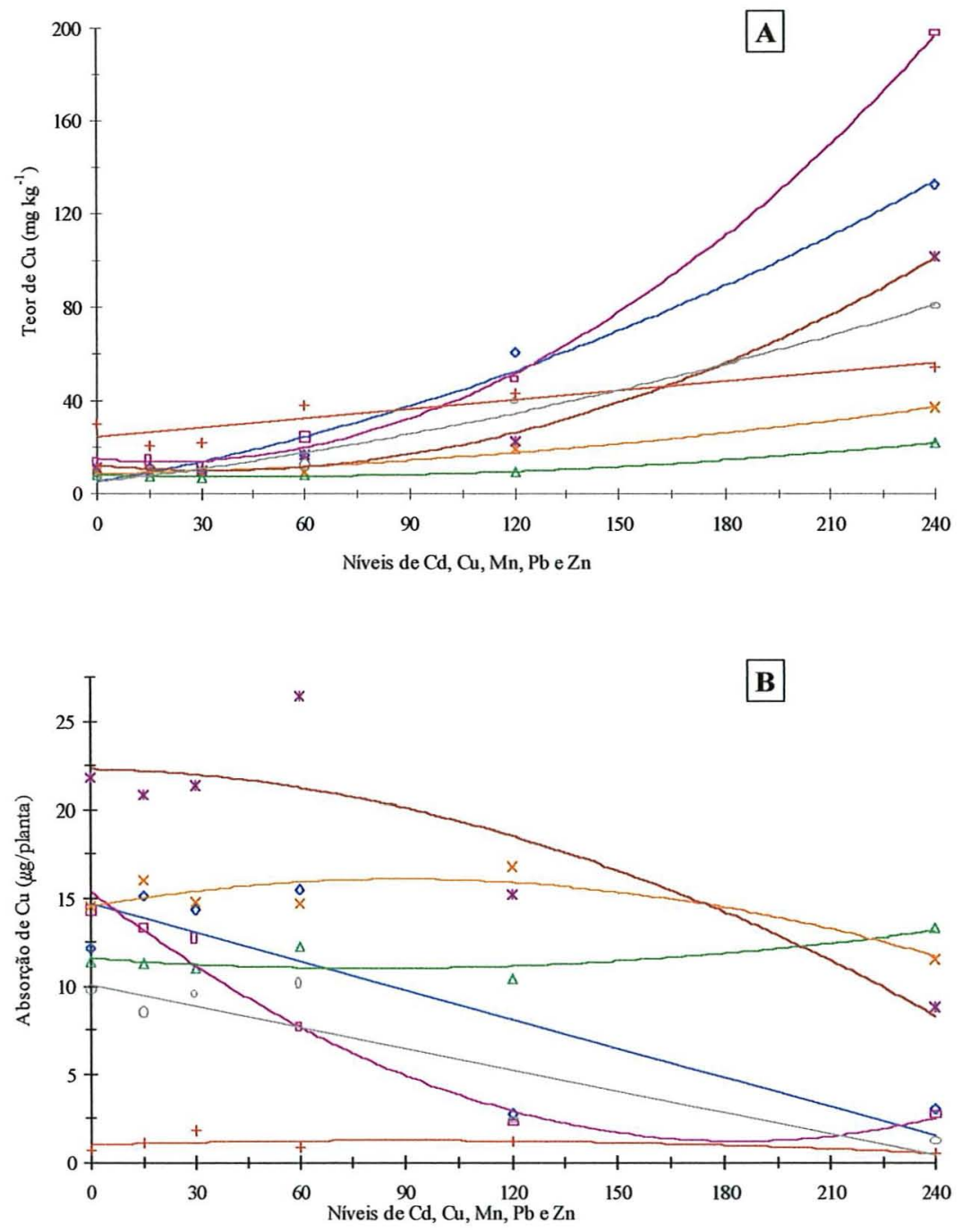

Legenda:

- PE $\quad y=0,0012 x^{2}+0,2526 x+5,1756$ $\mathrm{R}^{2}=0,9864^{* *}$

- LRa $\quad \mathrm{y}=0,0038 \mathrm{x}^{2}-0,1463 \mathrm{x}+15,064$ $\mathrm{R}^{2}=0,9986^{* *}$

$\triangle \mathrm{PV}-3 \quad \mathrm{y}=0,0004 \mathrm{x}^{2}-0,0301 \mathrm{x}+7,8414$ $\mathrm{R}^{2}=0,9966^{* *}$

$\times$ LV-1 $\quad y=0,0004 x^{2}+0,0308 x+8,5488$ $\mathrm{R}^{2}=0,9852^{* *}$

* LA-5 $y=0,0021 x^{2}-0,14 x+12,335$ $\mathrm{R}^{2}=0,9942^{* *}$

(0) LA-6 $y=0,0006 x^{2}+0,1784 x+4,929$ $\mathrm{R}^{2}=0,9856^{* *}$

$\mathrm{y}=0,1334 \mathrm{x}+24,372$ $\mathrm{R}^{2}=0,8278^{* *}$

Legenda:

$\circ \mathrm{PE} \quad \mathrm{y}=-0,0547 x+14,741$
$\mathrm{R}^{2}=0,6799^{* *}$

a LRa $y=0,0004 x^{2}-0,1541 x+15,437$

$$
\mathrm{R}^{2}=0,9699^{* *}
$$

$\triangle P V-3 \quad y=8 E-05 x^{2}-0,0135 x+11,581$

$$
\mathrm{R}^{2}=0,5963^{\mathrm{NS}}
$$

$x$ LV-1 $y=-0,0002 x^{2}+0,0342 x+14,564$

$$
\mathrm{R}^{2}=0,7747^{*}
$$

* LA-5 $y=-0,0002 x^{2}-0,0039 x+22,301$ $\mathrm{R}^{2}=0,7839^{* *}$

- LA-6 $y=-0,0401 x+10,062$ $\mathrm{R}^{2}=0,7957^{* *}$

$\mathrm{y}=-3 \mathrm{E}-05 \mathrm{x}^{2}+0,0057 \mathrm{x}+1,0302$ $\mathrm{R}^{2}=0,3727^{\mathrm{NS}}$

Figura 11. Efeito da aplicação de composto de resíduo urbano enriquecido com cádmio, cobre, manganês, chumbo e zinco sobre os teores de cobre (A) e absorção de cobre (B) na parte aérea da cultura de arroz. 


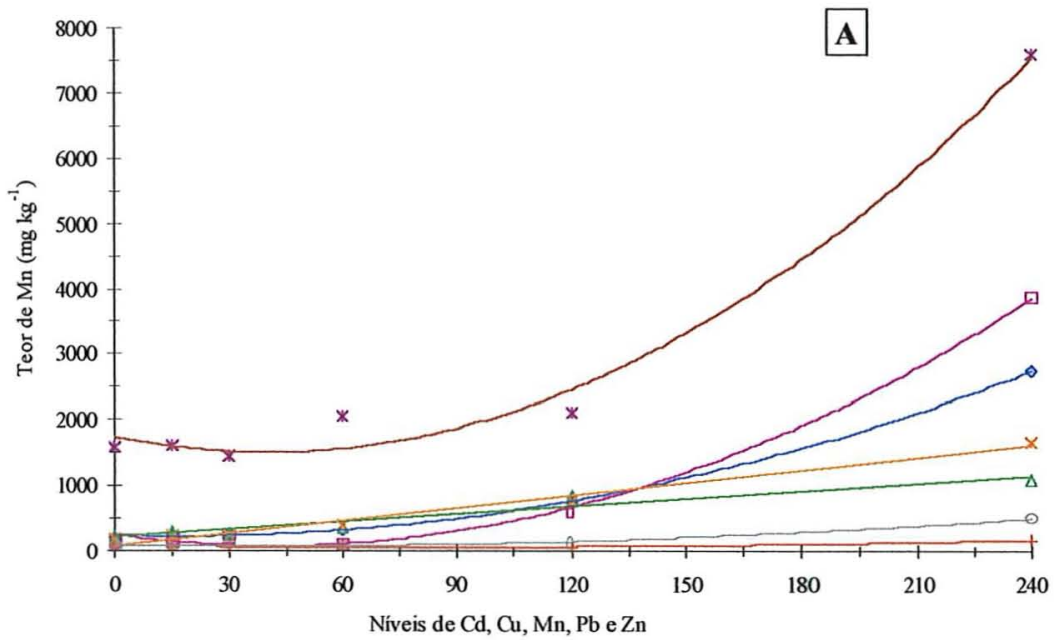

Legenda:

○P $\quad y=0,0506 x^{2}-1,6743 x+234,2$ $\mathrm{R}^{2}=0,999 * *$

- LRa $y=0,0962 x^{2}-8,0637 x+248,88$ $\mathrm{R}^{2}=0,9974^{* *}$

$\triangle \mathrm{PV}-3 \quad \mathrm{y}=3,9098 \mathrm{x}+199,95$ $\mathrm{R}^{2}=0,9273^{* *}$

$\times$ LV-1 $\quad y=6,3315 x+85,766$ $\mathrm{R}^{2}=0,9841^{* *}$

* LA-5 $y=0,1516 x^{2}-12,226 x+1744,6$ $\mathrm{R}^{2}=0,9856^{* *}$

- LA-6 $y=0,0102 x^{2}-0,8018 x+93,955$ $\mathrm{R}^{2}=0,9774^{* *}$

+ SS $\quad y=0,0041 x^{2}-0,605 x+79,785$ $\mathrm{R}^{2}=0,9534^{*}$

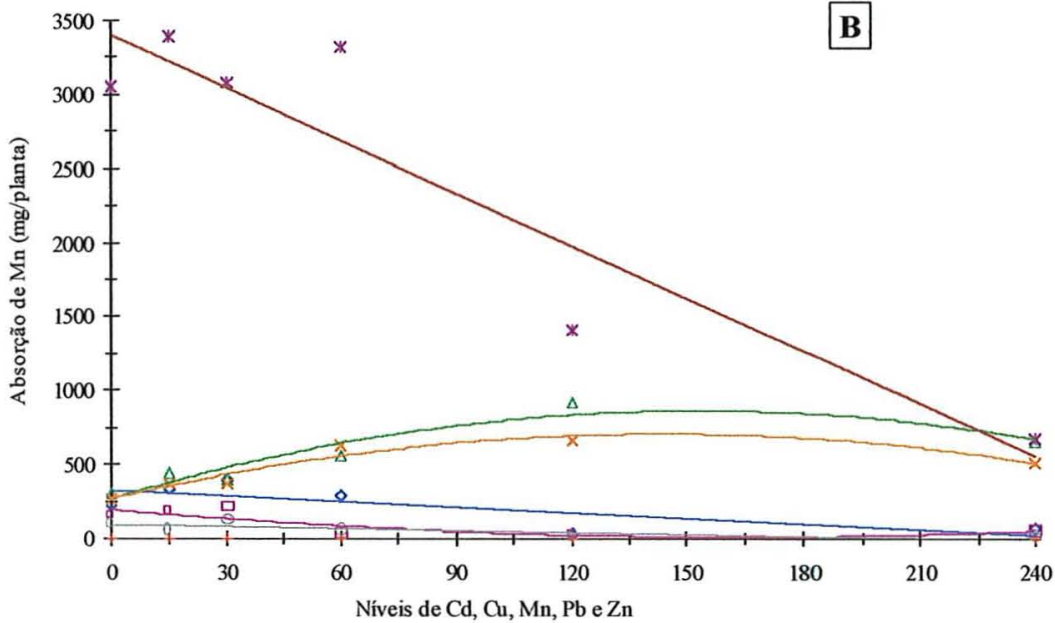

○P $\quad y=-1,262 x+325,34$

$\mathrm{R}^{2}=0,5976^{*}$

- LRa $y=0,0069 x^{2}-2,2491 x+195,76$ $\mathrm{R}^{2}=0,6538^{\mathrm{NS}}$

$\triangle \mathrm{PV}-3 \quad \mathrm{y}=-0,0253 \mathrm{x}^{2}+7,7437 \mathrm{x}+271,07$ $\mathrm{R}^{2}=0,887 * *$

$x$ LV-1 $y=-0,0211 x^{2}+6,0813 x+271,05$ $\mathrm{R}^{2}=0,9293^{* *}$

$*$ LA $-5 \quad y=-11,859 x+3409,6$ $\mathrm{R}^{2}=0,8665^{* *}$

- LA- $6 \quad y=-0,4371 x+98,573$ $\mathrm{R}^{2}=0,6599^{*}$

$y=-0,0094 x+3,5415$ $\mathrm{R}^{2}=0,2917^{\mathrm{NS}}$

Figura 12. Efeito da aplicação de composto de resíduo urbano enriquecido com cádmio, cobre, manganês, chumbo e zinco sobre os teores de manganês (A) e absorção de manganês (B) na parte aérea da cultura de arroz. 


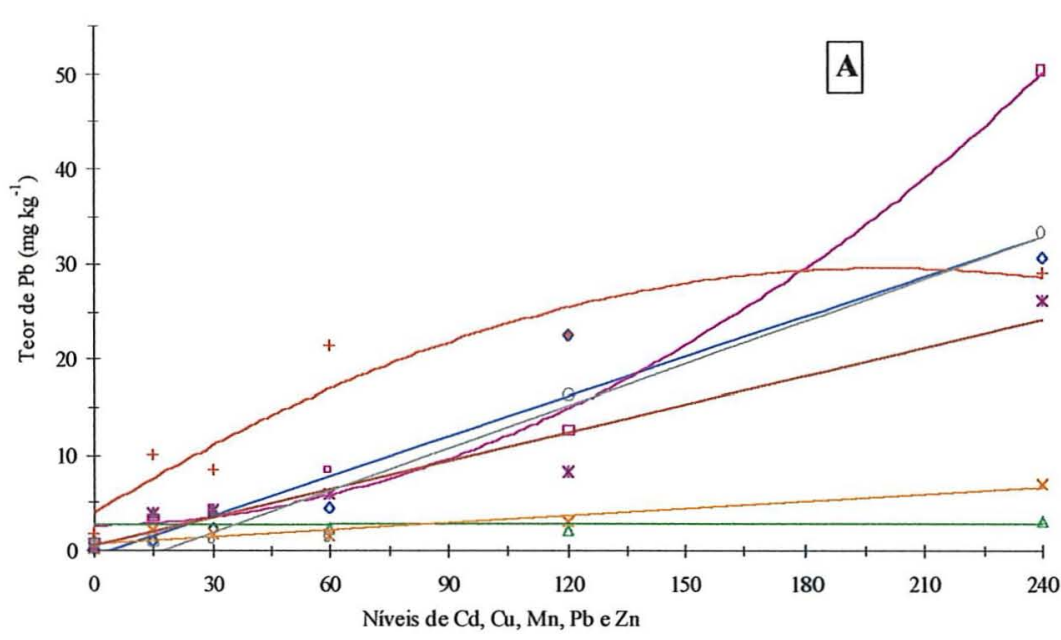

Legenda:

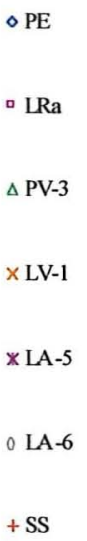

$$
\begin{gathered}
y=0,14 x-0,579 \\
R^{2}=0,9296^{* *} \\
y=0,0008 x^{2}+0,0073 x+2,59 \\
R^{2}=0,9912^{* *} \\
y=0,0005 x+2,7668 \\
R^{2}=0,0012^{N S} \\
y=0,0251 x+0,7297 \\
R^{2}=0,9155^{* *} \\
y=0,0987 x+0,5691 \\
R^{2}=0,9399^{* *} \\
y=0,1477 x-2,5275 \\
R^{2}=0,9617^{* *} \\
y=-0,0006 x^{2}+0,2573 x+3,90 \\
R^{2}=0,9135 * *
\end{gathered}
$$

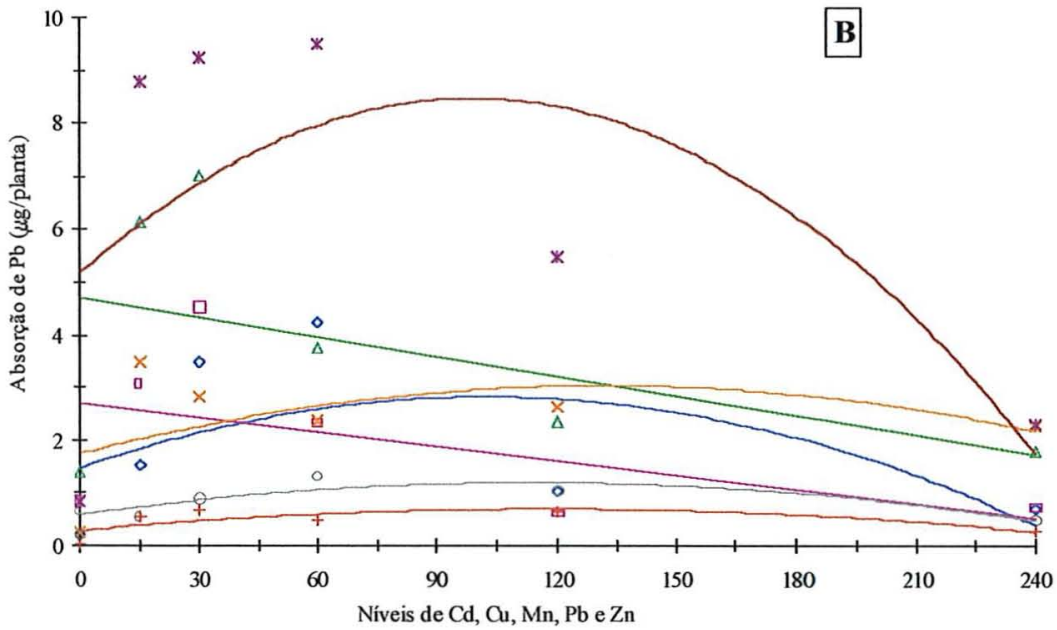

Legenda:

$\triangle \mathrm{PE} \quad \mathrm{y}=-0,0001 \mathrm{x}^{2}+0,0264 \mathrm{x}+1,48$ $\mathrm{R}^{2}=0,292^{* *}$

0 LRa $\quad y=-0,0092 x+2,7271$ $\mathrm{R}^{2}=0,2688^{* *}$

$\triangle P V-3 \quad y=-0,0123 x+4,7071$ $\mathrm{R}^{2}=0,2236^{* *}$

$x$ LV-1 $\quad y=-7 \mathrm{E}-05 x^{2}+0,0195 x+1,76$ $\mathrm{R}^{2}=0,1752^{\mathrm{NS}}$

$\times$ LA $-5 \quad y=-0,0003 x^{2}+0,0667 x+5,18$ $\mathrm{R}^{2}=0,4043^{* *}$

0 LA-6 $y=-5 E-05 x^{2}+0,0106 x+0,60$ $\mathrm{R}^{2}=0,7725^{\mathrm{NS}}$

$y=-3 E-05 x^{2}+0,007 x+0,298$ $\mathrm{R}^{2}=0,4877^{\mathrm{NS}}$

Figura 13. Efeito da aplicação de composto de resíduo urbano enriquecido com cádmio, cobre, manganês, chumbo e zinco sobre os teores de chumbo (A) e absorção de chumbo (B) na parte aérea da cultura de arroz. 

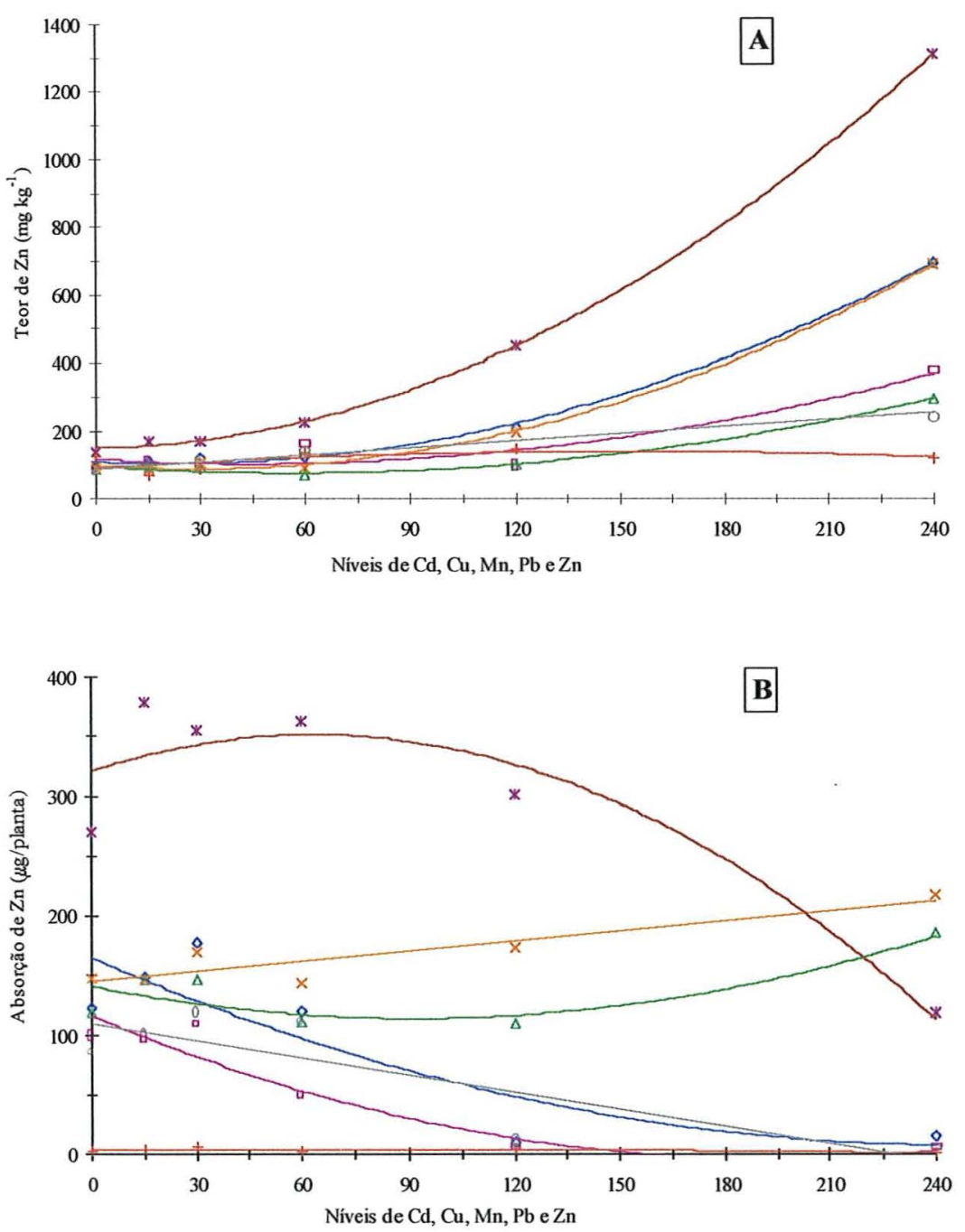

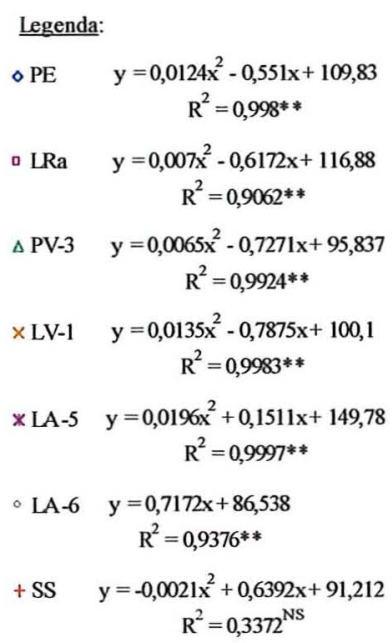

Legenda:

○P $\quad y=0,0026 x^{2}-1,287 x+165,27$ $\mathrm{R}^{2}=0,7427^{* *}$

口. LRa $y=0,0032 x^{2}-1,2444 x+116,58$ $\mathrm{R}^{2}=0,9096^{* *}$

$\triangle P V-3 \quad y=0,0032 x^{2}-0,5833 x+141$ $\mathrm{R}^{2}=0,7302^{* *}$

$x$ LV-1 $y=0,2866 x+144,68$ $\mathrm{R}^{2}=0,8334^{* *}$

x LA-5 $y=-0,0077 x^{2}+0,9707 x+321,06$ $\mathrm{R}^{2}=0,8834 * *$

0 LA-6 $y=-0,4795 x+109,9$ $\mathrm{R}^{2}=0,7159^{* *}$

$y=-0,0001 x^{2}+0,0134 x+4,1465$ $\mathrm{R}^{2}=0,4576^{\mathrm{NS}}$

Figura 14. Efeito da aplicação de composto de resíduo urbano enriquecido com cádmio, cobre, manganês, chumbo e zinco sobre os teores de zinco (A) e absorção de zinco (B) na parte aérea da cultura de arroz. 


\section{CONCLUSÕES}

A partir dosresultados do experimento I, concluiu-se que:

a) A aplicação do composto aumentou o $\mathrm{pH}$ e os teores de $\mathrm{Ca}$ e $\mathrm{Mg}$ e reduziu a acidez potencial do solo, este efeito é mais acentuado quando se aplica composto + calcário;

b) A condutividade elétrica aumentou em cerca de 10 vezes devido à aplicação do composto. O efeito é mais intenso quando se utiliza composto + adubo;

c) A aplicação do composto aumentou os teores de $\mathrm{N}$ total e de $\mathrm{C}$ orgânico;

d) O tratamento com composto + adubação aumentou o teor de K;

e) O composto, independentemente do modo de aplicação, aumentou o teor de Na. Este aumento foi proporcional ao das demais bases trocáveis;

f) Houve aumento na disponibilidade dos demais metais no solo e da absorção pelas plantas, mas estes não diferiram daquele devido à aplicação de calcário com adubo, nos solos ácidos, e com gesso + adubo nos solos;

g) A aplicação do composto com adubo, na presença ou ausência de calagem, promoveu maior produção de arroz, seja da parte aérea ou da raiz;

h) No segundo cultivo de arroz foi evidente a superioridade da aplicação do composto + adubo, sobre os demais tratamentos.

Com relação às observações do experimento II, conclui-se que:

a) Não houve diferenças significativas entre as propriedades químicas dos solos devido à aplicação do composto enriquecido com diferentes doses de metais;

b) No primeiro cultivo de arroz, as plantas de arroz toleram até dose de $30 \mathrm{mg} \mathrm{dm}^{-3}$. Em solos com alto teor de matéria orgânica, as plantas toleram doses de metais de até 60 $\mathrm{mg} \mathrm{dm}{ }^{-3}$, e o peso de matéria seca da raiz, praticamente, não foi afetado com o enriquecimento do composto até a dose de $60 \mathrm{mg} \mathrm{dm}^{-3}$;

c) No segundo cultivo, a dose de $15 \mathrm{mg} \mathrm{dm}^{-3}$ de enriquecimento do composto reduziu a ña produção de matéria seca em cerca de 25 a $40 \%$. Essa diferença foi atribuída a diferença de $\mathrm{pH}$ no solo do primeiro para o segundo cultivo;

d) O cádmio e o manganês foram os metais que apresentaram maior disponibilidade em relação às doses aplicadas. 


\section{REFERÊNCIAS BIBLIOGRÁFICAS}

ABREU, C.A.; RAIJ, B.V. Efeito da reação do solo no zinco extraído pelas soluções de DTPA e Mehlich-1. (Compact disc). In: CONGRESSO LATINO AMERICANO DE CIÊNCIA DO SOLO, 8; REUNIÃO BRASILEIRA DE BIOLOGIA DO SOLO, 1; SIMPÓSIO BRASILEIRO SOBRE MICROBIOLOGLA DO SOLO, 4; REUNIÃO BRASILEIRA SOBRE MICORRIZAS, 6; REUNIÃO BRASILEIRA DE MANEJO E CONSERVAÇÃO DO SOlO E DA ÁGUA, 11. Águas de Lindóia, 1996. Solos Suelos 96. Campinas: SBCS/SLCS, 1996.

ABREU, C.A.; ABREU, M.F.; RAIJ, B.V.; SANTOS, W.R. Comparação de métodos de análise para avaliar a disponibilidade de metais pesados em solos. Revista Brasileira de Ciência do Solo, v.19, n.3, p. 463-468, 1995.

ABREU, M.F.; RAIJ, B.V.; ABREU, M.F; SANTOS, W.R.; ANDRADE, J.C. Efficiency of multinutrient extractants for the determination of available copper in soils. Communications in Soil Science and Plant Analysis, v.27, n.3-4, p.763$771,1996$.

ADRIANO, D.C. Trace elements in terrestrial environment. New York: Springler-Verlag, 1986. 533p.

ALLOWAY, B.J. Heavy Metals in Soils. John Wiley \& Sons: New York, 1993. 339p. 
AMARAL SOBRINHO, N.M.B.; COSTA, L.M.; OLIVEIRA, C.; VELLOSO, A.C.X. Metais pesados em alguns fertilizantes e corretivos. Revista Brasileira de Ciência do Solo, v.16, p.271-276, 1992.

AMARAL SOBRINHO, N.M.B.; COSTA, L.M.; DIAS, L.E.; BARROS, N.F. Aplicação de resíduo siderúrgico em um latossolo vermelho-amarelo: efeito na correção do solo e na disponibilidade de nutrientes e metais pesados. Revista Brasileira de Ciência do Solo, v.17, n.2, p.299-304, 1993.

BATAGLIA, O.C.; RAIJ, B.V. Eficiência de extratores de micronutrientes na análise de solo. Revista Brasileira de Ciência do Solo, v.13, n.2, p.205-212, 1989.

BERTON, R.S.; VALADARES, J.M.A.S. Potencial agrícola de compostos de lixo urbano no Estado de São Paulo. O Agronômico, v.43, n.2/3, p.87-93, 1991.

BINGHAM, F.T.; PAGE, A.L.; MAHLER, R.J.; GANJE, T.J. Growth and cadmium accumulation of plants grown on a soil a soil treated with a cadmium-enriched sewage sludge. Journal of Environmental Quality, v.4, n.2, p.207-211, 1975.

BOAVENTURA, G.R.; SANTOS, A.R.; PINELLI, M.P.; DIAS, R.P. Metodologia analítica para a determinação dos metais pesados em compostos de lixo urbano usando espectrometria de emissão atômica com plasma e espectrometria de absorção atômica. In: CONGRESSO BRASILEIRO DE CIÊNCIA DO SOLO, 25., Viçosa, 1995. Resumos expandidos. Viçosa: SBCS, UFV, 1995. p.23062308 . 
CANTARELLA, H.; RAIJ, B.V.; QUAGGIO, J.A. Situação da análise de solo e planta no Brasil. In: REUNIÃO BRASILEIRA DE FERTLIDADE DO SOLO E NUTRIÇÃO DE PLANTAS, 21., Petrolina, 1994. Fertilizantes: insumo básico para agricultura e combate à fome; anais. Petrolina: EMBRAPA/CPATSA, SBCS, 1995. p.9-33.

CARDOSO, E.J.B.N.; JAHNEL, M.C.; MELONI, R. Avaliação do composto de lixo urbano. In: CONGRESSO BRASILEIRO DE CIÊNCIA DO SOLO, 25., Viçosa, 1995. Resumos expandidos. Viçosa: SBCS, UFV, 1995. p.2297.

CERRI, C.C.; EDUARDO B. de P.; PICCOLO, M. de C. Método de análises em matéria orgânica do solo. Piracicaba: CENA/USP, 1990. 78p. (Disciplina de Matéria Orgânica do Solo, mimeografado).

CONTE, R.A. Determinação de impurezas substitucionais por espectrometria de emissão atômica com plasma acoplado indutivamente (ICP/AES), no processamento de tântalo metálico. São Carlos, 1995. 190p. Tese (Doutorado) Centro de Ciências Exatas e de Tecnologia, Universidade Federal de São Carlos.

COSTA, M.B.B. Adubação orgânica - nova síntese e novo caminho para a agricultura. São Paulo: Ícone Editora, 1983. 104p.

CRAVO, M.S. Composto de lixo urbano como fonte de nutrientes e metais pesados para alface. Piracicaba, 1995. 148p. Tese (Doutorado) - Centro de Energia Nuclear na Agricultura, Universidade de São Paulo.

CRAVO, M.S.; MURAOKA, T.; GINÉ, M.F. Caracterização química de compostos de lixo urbano de algumas usinas brasileiras. Revista Brasileira de Ciência do Solo, v.22, n.3, p.547-553, 1998. 
FERRO NETO, A. Produção racional de composto de lixo urbano. In: SEMINÁRIO SOBRE USO DE RESÍDUOS INDUSTRIAIS E URBANOS EM FLORESTAS, 1., Botucatu, 1994. Trabalhos apresentados. Botucatu: FCA/UNESP, 1994. p.1-14.

GIGLIOTTI, G.; BUSINELLI, D.; GIUSQUINI, P.L. Trace metal uptake and distribution in corn plants grown on a 6-year urban waste compost amended soil. Agriculture, Ecosystems and Environment, v.58, n.2-3, p.199-206, 1996.

GIORDANO, P.M.; MORTVEDT, J.J.; MAYS, D.A. Effect of Municipal Wastes on crop yields and uptake of heavy metals. Journal of Environmental Quality, v.4, n.3, p.394-399, 1975.

GINÉ, M.F. Espectrometria de emissão atômica com plasma acoplado indutivamente. Piracicaba: CENA, 1998, 148p. (Série Didática, 3).

GLÓRIA, N.A. Uso agronômico de resíduos. In: DECHEN, A.R.; BOARETTO, A.E.; VERDADE, F.C. (Coord), REUNIÃO BRASILEIRA DE FERTILIDADE DO SOlO E NUTRIÇÃo DE PLANTA, 20., Piracicaba, 1992. Anais. Campinas: Fundação Cargill, 1992. p.195-212.

GROSSI, M.G.L. Avaliação da qualidade dos produtos obtidos de usina de compostagem brasileiras de lixo doméstico através da determinação de metais pesados e substâncias orgânicas tóxicas. São Paulo, 1993. 22p. Tese (Doutorado) - Instituto de Química, Universidade de São Paulo.

HANLON, E.A.; JOHNSON, G.B. Bray/Kurtz, Mehlich III, AB-DTPA and ammonium acetate extractions for $\mathrm{P}, \mathrm{K}$, and $\mathrm{Mg}$ in four Oklahoma soils. 
Communications in Soil Science and Plant Analysis, v.15, n.3, p.277-294, 1984.

HANLON, E.A.; SCHAFFER, B.; OZORES-HAMPTON, M.; BRYAN, H.H. Ammonium bicarbonate-DTPA extraction of elements from waste-amended calcareous soil. Communications in Soil Science and Plant Analysis, v.27, n.9-10, p.2321-2335, 1996.

HORTENSTINE, C.C.; ROTHWELL, D.F. Use of municipal compost in reclamation of phosphate - mining sand tailings. Journal of Environment Quality, v.1, n.4, p.415-418, 1972.

HOUBA, V.J.G.; NOVOZAMSKY, I.; VAN DER LEE, J.J. Soil testing and plant analysis in Western Europe. Communications in Soil Science and Plant Analysis, v.23, n.17-20, p.2029-2051, 1992.

HOUBA, V.J.G.; NOVOZAMSKY, I.; HUYBREGTS, A.W.M.; VAN DER LEE, J.J. Comparison of soil extraction by $0.01 \mathrm{M} \mathrm{CaCl}_{2}$, by EUF and by some conventional extraction procedures. Plant and Soil, v.96, n.3, p.433-437, 1986.

HOUBA, V.J.G.; NOVOZAMSKY, I.; LEXMOND, Th. M.; VAN DER LEE, J.J. Applicability of $0,01 \mathrm{M} \mathrm{CaCl}_{2}$ as a single extraction solution for the assessment of the nutrient status of soils and other diagnostic purposes. Communications in Soil Science and Plant Analysis, v.21, n.19-20, p.2281-2290, 1990.

IGUE, K.; PAVAN, M.A. Uso eficiente de adubos orgânicos. In: Simpósio sobre fertilizantes orgânicos na agricultura brasileira. Brasília, 1984. p. 383-418. 
JONES JUNIOR, J.B. Universal soil extractants: their composition and use. Communications in Soil Science and Plant Analysis, v.21, n.13-16, p.1091$1101,1990$.

JORDÃO, C.P.; KIYOHARA, R.S.; DAMASCENO, R.N.; BRUNE, W.; PEREIRA, J.L. Speciation of cadmium, copper, lead and zinc in compost from Brazilian urban solid waste treatment plant. Ciência e Cultura Journal of the Brazilian Association for the Advancement of Science, v.48, n.4, p284-287, 1996.

KABATA-PENDIAS, A.; PENDIAS, $\mathrm{H}$. Trace elements in soils and plants. Boca Raton: CRC Press, 1985. 315p.

KIEHL, E.J. Fertilizantes orgânicos. Piracicaba: Editora Agronômica "CERES", 1985. 492p.

KIEHL, E.J.; KIEHL, J.C. Uso de resíduos orgânicos na agricultura brasileira. In: ALVAREZ, V.H.; FONTES, L.E.F.; FONTES, M.P.F. (Ed.). O solo nos grandes domínios morfoclimáticos do Brasil e o desenvolvimento sustentado. Viçosa: SBCS, UFV, DPS, 1996. p.915-930.

LANGENBACH, T.; SARPA, M. Teor de cádmio nos fertilizantes fosfatados brasileiros. Revista Brasileira de Ciência do Solo, v.9, p.181-1197, 1985.

LEE, D.Y.; ZHENG, H.C. Simultaneous extraction of soil phytoavailability cadmium, copper, and lead by chelating resin membrane. Plant and Soil, v.164, n.1, p.19-23, 1994. 
LINDSAY, W.L.; NORVELL, W.A. Development of a DTPA soil test for zinc, iron, manganese, and copper. Soil Science Society of America Journal, v.42, n.3, p.421-428, 1978.

LOPES, A.J.R.; STAMFORD, N.P.; FIGUEIREDO, M.U.B.; BURITY, H.A; FERRAZ, E.B. Respostas da aplicação de composto de lixo urbano, nitrogênio mineral e produtos mineralizantes na fixação do $\mathrm{N}_{2}$ e no rendimento de caupi. Revista Brasileira de Ciência do Solo, v.20, n.1, p.55-62, 1996.

MACLEAN, A.J.; DEKKER, A.J. Lime requirement and availability of nutrients and toxic metals to plants grown in acid mine tailings. Canadian Journal of Soil Science, v.56, n.1, p.27-36, 1976.

MAMO, T.; RICHTER, C.; HEILIGTAG, B. Comparison of extractants for the determination of available phosphorus, potassium, calcium, magnesium and sodium in some Ethiopian and German soils. Communications in Soil Science and Plant Analysis, v.27, n.9-10, p.2197-2212, 1996.

MALAVOLTA, E. Fertilizantes e seu impacto ambiental: micronutrientes e metais pesados, mitos, mistificação e fatos. São Paulo: ProduQuímica, 1994. $153 \mathrm{p}$.

MALAVOLTA, E.; VITTI, G.C.; OLIVEIRA, S.A. de Avaliação do estado nutricional das plantas. Piracicaba: Associação Brasileira para Pesquisa da Potassa e do Fosfato, 1997. 319p.

MARSCHNER, H. Mineral nutrition of higher plants. London: Academic Press, 1995. 889p. 
MATTIAZZO-PREZOTTO, M.E. Química ambiental e agronomia. In: DECHEN, A.R.; BOARETTO, A.E.; VERDADE, F.C. (Coord). REUNIÃO BRASILEIRA DE FERTILIDADE DO SOLO E NUTRIÇÃO DE PLANTAS, 20. Piracicaba, 1992. Anais. Campinas: Fundação Cargill, 1992. p.157-178.

MAZUR, N. Níquel, chumbo, zinco e cobre em solos que receberam composto de resíduos sólidos urbanos. Viçosa, 1997. 129p. Tese (Doutorado) - Universidade Federal de Viçosa.

MAZUR, N.; SANTOS, G.A.; VELLOSO, A.C.X. Efeito do composto de resíduo urbano na disponibilidade de fósforo em solos ácidos. Revista Brasileira de Ciência do Solo, v.7, p.153-156, 1983a.

MAZUR, N.; VELLOSO, A.C.X ; SANTOS, G.A. Efeito do composto de resíduo urbano no $\mathrm{pH}$ e alumínio trocável em solos ácidos. Revista Brasileira de Ciência do Solo, v.7, n.2, p.157-159, 1983b.

MELO,W.J.; MARQUES, M.O.; SILVA, F.C.; BOARETTO,A.E. Uso de resíduos sólidos urbanos na agricultura e impactos ambientais (compact disc). In: CONGRESSO BRASILEIRO DE CIÊNCIA DO SOLO, 26., Rio de Janeiro, 1997. Anais: trabalhos. Rio de Janeiro: SBCS, 1997.

MEHLICH, A. Mehlich 3 soil extractant: a modification of Mehlich 2 extractant. Communications in Soil Science and Plant Analysis, v.15, n. 12, p. 1409-1416, 1984.

MORTVEDT, J.J.; GIORDANO, P.M. Response of corn to zinc and chromium in municipal wastes applied to soil. Journal of Environmental Quality, v.4, n.2, p.170-174, 1975. 
MURAOKA, T.; NEPTUNE, M.L.; NASCIMENTO FILHO, V. Avaliação da disponibilidade de zinco e de manganês do solo para o feijoeiro. I. Zinco. Revista Brasileira de Ciência do Solo, v.7, n.2, p.167-175, 1983a.

MURAOKA, T.; NEPTUNE, M.L.; NASCIMENTO FILHO, V. Avaliação da disponibilidade de zinco e de manganês do solo para o feijoeiro. II. Manganês. Revista Brasileira de Ciência do Solo, v.7, n.2, p.177-182, 1983 b.

OLIVEIRA, T.S. Metais pesados como indicadores de materiais de origem de solos. Viçosa, 1996. 128p. Tese (Doutorado) - Universidade Federal de Viçosa.

PETRUZZELLI, G. Recycling wastes in agriculture. Heavy metal bioavailability. Agriculture, Ecosystems \& Environment, v.27, p.493-503, 1989.

PETRUZZELLI, G.; LUBRANO, L.; GUIDI, G. Heavy metal extractability. BioCycle, v.26, n.8, p.46-48, 1985.

PETRUZZELLI, G.; LUBRANO, L.; GUIDI, G. Uptake and chemical extractability of heavy metals from a four years compost-treated soil. Plant and Soil, v.116, p.23-27, 1989.

PEZZAROZA, B.; MALORGIO, F.; LUBRANO, L.; TOGNONI, F.; PETRUZZELLI, G. Phosphate fertilizer as a source of heavy metals in protected cultivation. Communications in Soil Science and Plant Analysis, v.21, p.737$751,1990$.

RAIJ, B.van. Fertilidade do solo e adubação, Piracicaba: Ceres. 1991. 343p. 
RAIJ, B.van. New diagnostic techniques, universal soil extractants. Communications in Soil Science and Plant Analysis, v.25, n.7-8, p.799-816, 1994.

RAIJ, B.van.; QUAGGIO, J.A.; CANTARELLA, H.; FERREIRA, M.E.; LOPES, A.S.; BATAGLIA, O.C. Análise química do solo para fins de fertilidade. Campinas: Fundação Cargill, 1987. 170p.

ROSS, S.M. Toxic metals in soil-plant systems. Chichester: Wiley, 1994. 469p.

RODRIGUES, M. do R.L. Disponibilidade de micronutrientes em solos da Amazônia. Piracicaba, 1998. 156p. Tese (Doutorado) - Escola Superior de Agricultura "Luiz de Queiroz", Universidade de São Paulo.

SANTOS, O.S. Molibdênio. In: FERREIRA, M.E.; CRUZ, M.C.P. (Ed.) Micronutrientes na Agricultura. Piracicaba: POTAFOS/CNPq, 1991. p.191217.

SAS INSTITUTE INC. SAS-Statistical analysis system (software). Cary: SAS Institute Inc., 1998.

SIKORA, L.J.; YAKOVCHENKO, V. Soil organic matter mineralization after compost amendment. Soil Science Society of America Journal., v.60, p.14011404, 1996.

SILVEIRA, D.J.; SOMMERS, L.E. Extractability of copper, zinc, cadmium, and lead in soils incubated with sewage sludge. Journal of Environmental Quality, v.6, n.1, p.47-52, 1977. 
SIMS, J.T. Comparison of Mehlich 1 and Mehlich 3 extractants for $\mathrm{P}, \mathrm{K}, \mathrm{Ca}, \mathrm{Mg}$, $\mathrm{Mn}, \mathrm{Cu}$ and $\mathrm{Zn}$ in Atlantic Coastal Plain Soils. . Communications in Soil Science and Plant Analysis, v.20, n.17-18, p.1708-1726, 1989.

SINGH, R.R., PRASAD, B.; SINHA, H. Selection of suitable extractant for predicting the response of barley (Hodeum vulgere L.) to copper application in calcareous soils. Plant and Soil, v.93, n.2, p.211-222, 1986.

SIPPOLA, J. Acid ammonium acetate-EDTA universal extractant in soil testing and environmental monitoring. Communications in Soil Science and Plant Analysis, v.25, n.9-10, p.1755-1761, 1994.

SOLTANPOUR, P.N. Use of ammonium bicarbonate-DTPA soil test to evaluate elemental availability and toxicity. Communications in Soil Science and Plant Analysis, v.16, n.3, p.323-338, 1985.

SOLTANPOUR, P.N.; SCHWAB, A.P. A new soil test for simultaneous extraction of macro- and micro-nutrients in alkaline soils. Communications in Soil Science and Plant Analysis, v.8, n.3, p.195-207, 1977.

SOLTANPOUR, P.N.; JONES JUNIOR, J.B.; WORKMAN, S.M. Optical emission spectrometry. In: PAGE, A.L.; MLLER, R.H.; KEENEY, D.R. (Ed.). Methods of soil analysis. Madison: ASA, SSSA, 1982. Part 2, p.29-83.

SOLTANPOUR, P.N.; WORKMAN, S.M. Modification of the NH4HCO3-DTPA soil test to omit carbon blank. Communications in Soil Science and Plant Analysis, v.10, p.1411-1420, 1979. 
SOLTANPOUR, P.N.; WORKMAN, S.M.; SCHWAB, A.P. Use of inductively coupled plasma spectrometry for the simultaneous determination of macro and micronutrients in ammonium bicarbonate-DTPA extracts of soils. Soil Science Society of America Journal, v.43, n.1, p.75-78, 1979.

SOMMERS, L.E.; LINDSAY, W.L. Effect of $\mathrm{pH}$ and redox on predicted heavy metal chelate equilibria in soils. Soil Science Society of America Journal, v.43, n. 1, p.39-47, 1979 .

STREET, J.J.; LINDSAY, W.L.; SABEY, B.R. Solubility and plant uptake of cadmium in soils amended with cadmium and sewage sludge. Journal of Environmental Quality, v.6, n.1, p.72-77, 1977.

TRINDADE, A.V.; VILDOSO, C.I.A.; MUCHOVEJ, R.M.C.; COSTA, L.M. Interação de composto de lixo urbano e fungos micorrízicos na nutrição e crescimento do milho. Revista Brasileira de Ciência do Solo, v.20, n.2, p.199$208,1996$.

VITTI, G.C. Avaliação e interpretação do enxofre no solo e na planta. Jaboticabal: FUNEP, 1988. 37p.

WOLF, B. An improved universal extracting solution and its use for diagnosing soil fertility. Communications in Soil Science and Plant Analysis, v.13, n.12, p.1005-1033, 1982.

XIN, T.H.; TRAINA, S.J.; LOGAN, T.J. Chemical properties of municipal solid waste compost. Journal of Environmental Quality, v.21, p.318-329, 1992. 
ZEN, S.; BELLOTE, A.F.J.; SILVA, H.D; FERREIRA, C.A. Resíduos urbanos como fonte de nutrientes em povoamentos de eucaliptos. In: SEMINÁRIO SOBRE USO DE RESÍDUOS INDUSTRIAIS E URBANOS EM FLORESTAS, 1., Botucatu, 1994. Trabalhos apresentados. Botucatu: FCA/UNESP, 1994. p.25-39.

ZONTA, E.P.; MACHADO, A.A.; SILVEIRA JUNIOR, P. Sistemas de análise estatística para microcomputadores: manual de utilização. Pelotas, 1987. 145 p. 